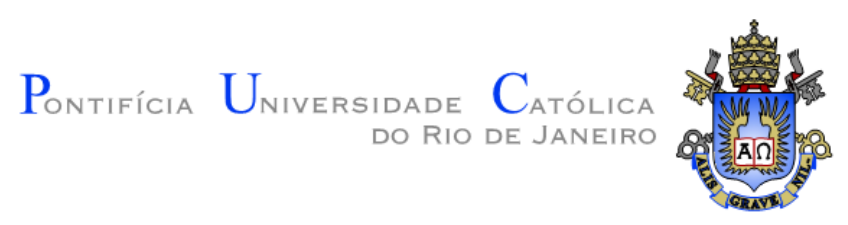

Phillype de Lima Massari

\title{
Avaliação Experimental da Dispersão de Gás em Escoamento Cruzado Oscilatório de Líquido
}

Dissertação de Mestrado

Dissertação apresentada como requisito parcial para obtenção do grau de Mestre pelo Programa de Pós-Graduação em Engenharia Mecânica da PUCRio.

Orientador: Prof. Igor Braga de Paula Co-orientadora: Dra. Maria Helena Farias 
Phillype de Lima Massari

\section{Avaliação Experimental da Dispersão de Gás em Escoamento Cruzado Oscilatório de Líquido}

Dissertação apresentada como requisito parcial para obtenção do grau de Mestre pelo Programa de PósGraduação em Engenharia Mecânica da PUC-Rio. Aprovada pela Comissão Examinadora abaixo assinada.

Prof. Igor Braga de Paula

Orientador

Departamento de Engenharia Mecânica - PUC-Rio

Maria Helena Farias

Co-orientadora

Inmetro

Prof. Luis Fernando Alzuguir Azevedo

Departamento de Engenharia Mecânica - PUC-Rio

Prof. Marcos Sebastião de Paula Gomes

Departamento de Engenharia Mecânica - PUC-Rio

Renan de Souza Teixeira

Inmetro

Prof. Márcio da Silveira Carvalho

Coordenador Setorial do Centro Técnico Científico - PUC-Rio

Rio de Janeiro, 05 de maio de 2017 
Todos os direitos reservados. É proibida a reprodução total ou parcial do trabalho sem autorização da universidade, da autora e do orientador.

\section{Phillype de Lima Massari}

Graduou-se em Engenharia Mecânica na UCP (Universidade Católica de Petrópolis) em 2014. Possui experiência na área de pesquisa, como colaborador do Inmetro (Instituto Nacional de Metrologia, Qualidade e Tecnologia). Participou de diversos congressos internacionais de engenharia mecânica.

Ficha Catalográfica

Massari, Phillype de Lima

Avaliação experimental da dispersão de gás em escoamento cruzado oscilatório de líquido / Phillype de Lima Massari ; orientador: Igor Braga de Paula ; coorientadora: Maria Helena Farias. - 2017.

152 f. : il. color. ; $30 \mathrm{~cm}$

Dissertação (mestrado)-Pontifícia Universidade Católica do Rio de Janeiro, Departamento de Engenharia Mecânica, 2017.

Inclui bibliografia

1. Engenharia Mecânica - Teses. 2. Pluma de bolhas. 3. Ondas superficiais. 4. Escoamento cruzado instável. 5. PIV. I. Paula, Igor Braga de. II. Farias, Maria Helena. III. Pontifícia Universidade Católica do Rio de Janeiro. Departamento de Engenharia Mecânica. IV. Título. 


\section{Agradecimentos}

Primeiramente, gostaria de agradecer a Deus por esta oportunidade que foi colocada em meu caminho. Também, a toda minha família, pois sem o apoio deles não seria possível chegar nesta etapa da minha vida.

Gostaria de agradecer ao CNPq, à PUC-Rio e ao Inmetro, pelos auxílios concedidos.

A realização deste trabalho só foi possível graças à colaboração de diversas pessoas que contribuíram de alguma forma à sua realização. Gostaria de expressar meus agradecimentos aos meus orientadores, o Prof. Igor Braga de Paula e a Maria Helena Farias que aceitaram a responsabilidade da orientação e sempre estiveram dispostos a compartilhar seus conhecimentos para o desenvolvimento deste trabalho.

Agradeço imensamente ao Fábio Ouverney, que sempre esteve presente no laboratório e não mediu esforços para me ajudar no que fosse preciso.

Agradeço à Alessandra Maciel, Lucas Marchesini, Douglas, Yoná e à minha irmã Pollyana, que também estiverem envolvidos de forma direta ou indireta, aos quais a todos, também sou imensamente grato. 


\section{Resumo}

Massari, Phillype de Lima; Paula, Igor Braga de. Avaliação Experimental da Dispersão de Gás em Escoamento Cruzado Oscilatório de Líquido. Rio de Janeiro, 2017. 152p. Dissertação de Mestrado - Departamento de Engenharia Mecânica, Pontifícia Universidade Católica do Rio de Janeiro.

Este trabalho apresenta uma investigação experimental do escoamento induzido pela interação entre uma pluma de bolhas e um escoamento cruzado oscilatório. Condições de escoamento similares podem ser encontrados em processos de aeração artificial utilizados na mitigação da poluição nos rios e na representação de vazamento de gás natural no fundo dos oceanos. No presente trabalho, ondas superficiais controladas foram inseridas em um canal de água para gerar oscilações na corrente do escoamento cruzado. As ondas foram geradas a partir de uma placa móvel na superfície da água e determinadas condições de escoamento instável foram selecionadas para a investigação. $\mathrm{O}$ ar foi injetado pelo fundo do canal para formar a pluma de bolhas. A técnica Particle Image Velocimetry (PIV) foi empregada para medir a velocidade do escoamento. Antes da estimativa da velocidade, as imagens foram pré-processadas aplicando-se rotinas desenvolvidas no Matlab a fim de distinguir as partículas traçadoras das bolhas de ar e criar máscaras dinâmicas para as imagens do sistema PIV. Assim, o campo vetorial de velocidade foi estimado utilizando algoritmos padrão do PIV. Além disso, as propriedades das bolhas, como tamanho e velocidade, também foram estimadas a partir das imagens adquiridas. Finalmente, foi analisada a interação entre a pluma de bolhas com o escoamento cruzado instável.

\section{Palavras-chave}

Pluma de bolhas; Ondas superficiais; Escoamento Cruzado Instável; PIV 


\section{Abstract}

Massari, Phillype de Lima; Paula, Igor Braga de (Advisor). Experimental Evaluation of Gas Dispersion in Oscillatory Cross Flow of Liquid. Rio de Janeiro, 2017. 152p. Dissertação de Mestrado - Departamento de Engenharia Mecânica, Pontifícia Universidade Católica do Rio de Janeiro.

This work presents an experimental investigation of the flow field induced by the interaction between a bubble plume and an oscillating cross flow. Similar flow conditions can be found in artificial aeration processes used for mitigation of pollution contamination in rivers and submarine outfalls in coastal areas. The mixing zone is highly dependent of the flow field near the plume hence the efficiency of aeration processes. In the present work, controlled surface waves were introduced to generate oscillations in streamwise and wall normal components of the cross flow. The waves were excited with a moving paddle and unsteady flow conditions were selected for the investigation. Air was injected in the bottom wall of the water channel to form the bubble plume. Particle Image Velocimetry (PIV) techniques were employed to measure the velocity flow field. Prior to velocity estimation, images were pre-processed using Matlab routines in order to distinguish tracer particles from air bubbles and to create a dynamic mask for the PIV images. Thus, the velocity vector field was estimated using standard PIV algorithms. In addition, properties of the bubbles, such as size and velocity, were also estimated from the acquired images. Finally, the interaction between the bubble plume with the unsteady cross flow was analyzed.

\section{Keywords}

Bubble plume; Surface Waves; Unsteady Cross Flow; PIV 


\section{Sumário}

1 Introdução

2 Revisão Bibliográfica

2.1. Jatos em escoamento cruzado constante

2.2. Jatos em escoamento cruzado oscilatório

2.3. Plumas de bolhas

3 Metodologia e Aparato Experimental

3.1. Canal de circulação de água do Inmetro

3.2. Técnicas e equipamentos de medição

3.2.1. Velocimetria por Imagem de Partícula

3.2.1.1. Partículas traçadoras

3.2.1.2. Fonte de luz (Laser)

3.2.1.3. Câmeras de alta resolução

3.2.1.4. Cálculo dos campos vetoriais de velocidade

3.2.2. Técnica de detecção de sombras

3.3. Montagem do sistema PIV no canal de água 40

3.3.1. Adequação do Led no canal de água 43

3.3.2. Sincronização Led-Laser 44

3.4. Injeção de ar $\quad 46$

3.5. Sistema de injeção de partículas traçadoras 48

3.5.1. Partículas fluorescentes em escoamento bifásico 51

4 Projeto e construção de um gerador de ondas 53

4.1. Conceitos Básicos de Ondas 53

4.1.1. Movimento Orbital 54

4.1.2. Ondas de Águas Profundas $\quad 55$

4.1.3. Ondas de Águas Rasas 56

4.1.4. Ondas de Águas Intermediárias 56

4.2. Gerador de Ondas $\quad 57$ 
4.2.1. Projeto do gerador de ondas 60

4.2.2. Estrutura do gerador de ondas 62

4.2.3. Sensoriamento de fase das ondas 66

5 Metodologia de processamento e análise das imagens 68

5.1. Pré-processamento das imagens 68

5.2. Detecção das bolhas 70

5.2.1. Cálculo do diâmetro das bolhas 72

5.2.2. Cálculo da velocidade das bolhas 73

5.3. Separação de partículas e bolhas $\quad 74$

5.4. Detecção da interface 76

5.5. Processamento dos campos de velocidade 78

6 Avaliação do comportamento do escoamento cruzado 80

6.1. Matriz de ensaios e parâmetros de medição 80

6.2. Caracterização do escoamento sem ondas e sem pluma 82

6.3. Caracterização do escoamento com ondas 86

6.3.1. Ondas de amplitude $=0,5 \mathrm{~cm} \quad 87$

6.3.2. Ondas de amplitude $=2,0 \mathrm{~cm} \quad 90$

6.3.3. Efeito das ondas na interface 93

6.3.4. Análise das flutuações de velocidade 97

6.3.5. Caracterização das ondas 101

6.3.6. Comparação entre os casos sem ondas e com ondas 104

6.4. Caracterização do escoamento com pluma de bolhas e sem ondas

6.4.1. Comparação entre o escoamento cruzado sem ondas e o escoamento sem ondas e sem pluma 114

6.5. Estudo do escoamento com pluma e com ondas 117

6.5.1. Comparação entre o escoamento cruzado sem ondas e com ondas

7 Influência do escoamento cruzado nas características

e propriedades das bolhas

7.1. Características e propriedades das bolhas 
8 Conclusões e sugestões para trabalhos futuros

9 Referências bibliográficas 


\section{Introdução}

Jatos e plumas são classes de escoamentos produzidos por fontes em que o movimento do fluido emitido depende, principalmente, da quantidade de movimento e do empuxo (Lee e Chu, 2003). A emissão de jatos e plumas em ambientes estagnados ou em movimento (escoamento cruzado) podem modelar as descargas de resíduos industriais flutuantes ou não-flutuantes em rios, lagos e oceanos, bem como a dispersão de poluentes na atmosfera. Estudos relacionados com plumas de bolhas ou jatos tem atraído significativa atenção devido à similaridade da sua dinâmica com os eventos de vazamentos que ocorrem na indústria do petróleo e gás, conforme ilustrado na Figura 1. De acordo com Yapa et al. (2011) e Dasanayaka et al. (2009), tanto o gás como o líquido comportam-se como plumas e jatos em escoamento cruzado, respectivamente, quando liberados no fundo do mar devido às correntes marítimas.

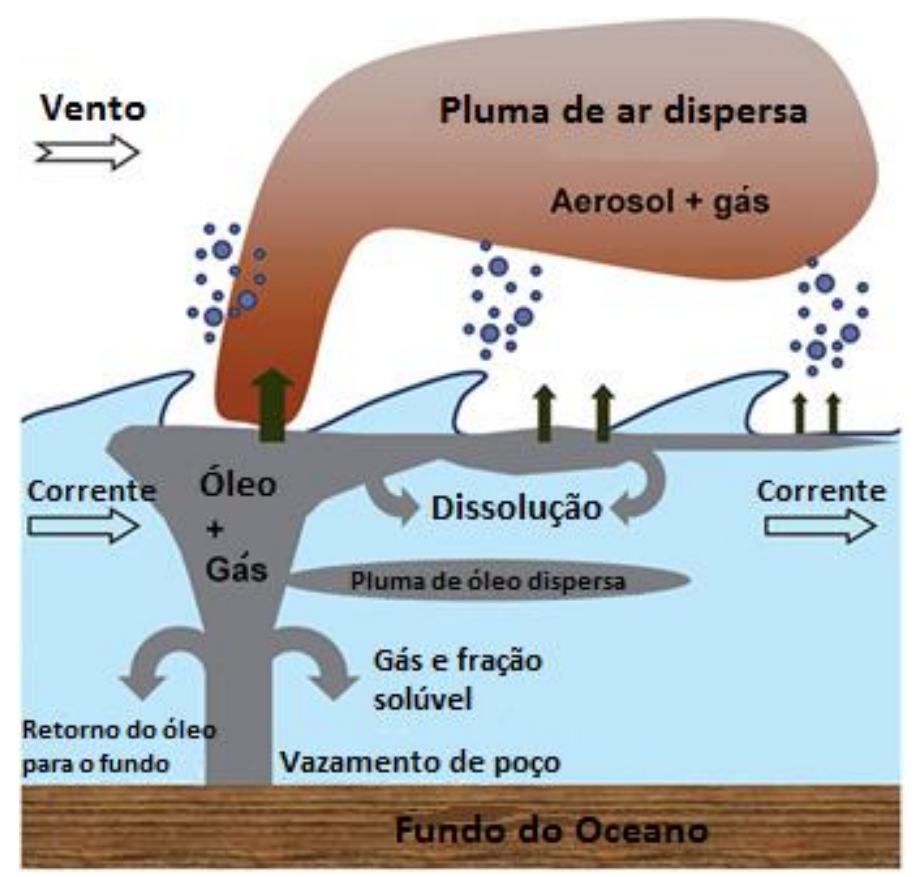

Figura 1 - Ilustração de uma situação de vazamento de óleo e gás no oceano (Ehrenhauser, 2014) 
Na produção de óleo e gás, os efeitos da liberação de hidrocarbonetos no leito marinho dependem de vários fatores, incluindo se o vazamento for de líquido ou gás (Brewer et al., 1997; Szczepanski et al., 1998). No caso de vazamento de líquido, as forças de empuxo tendem a espalhar o material vazado na superfície formando uma mancha poluente. Para um vazamento de gás, embora o empuxo seja maior, forças de arrasto significativas e instabilidade de jato tendem a desintegrar a pluma e fazer com que o gás chegue à superfície como uma série de bolhas. Na superfície, a ignição da pluma de gás pode resultar em um incêndio de superfície do mar. Alternativamente, a pluma pode se dispersar e na superfície a concentração pode ficar abaixo do limite inferior de inflamabilidade antes de haver qualquer possibilidade de encontrar uma fonte de ignição (Sridher, 2012). As ocorrências de um caso ou de outro ainda não estão bem estabelecidas. Um efeito adicional de uma pluma de bolhas de gás é a redução da estabilidade de embarcações, quer devido à perda de flutuação, quer devido ao movimento da água em direção da pluma.

Além da representação de vazamento de gás natural, as plumas de bolhas de gás têm sido usadas para controlar a qualidade da água em lagos, reservatórios e rios. A estratificação da água, tipicamente, consiste na formação de camadas horizontais de água estáveis e com diferentes densidades, ordenadas de forma que as camadas menos densas flutuam sobre as mais densas. Nessa condição, o grau de mistura das camadas é baixo. Devido à estratificação, o transporte vertical de oxigênio de camadas superiores para as camadas inferiores é reduzido, afetando a qualidade da água.

O uso das plumas de bolhas para melhoria da qualidade da água busca promover uma mistura entre as camadas ou simplesmente a dissolução de oxigênio na água. A mistura artificial ou desestratificação consiste na injeção de ar próximo ao fundo de um reservatório usando um difusor de bolhas para que grandes bolhas sejam criadas e possam alcançar a superfície da água. De acordo com Fernando (2013), as bolhas maiores são mais eficientes para estimular a mistura do meio em que são injetadas. Isso porque, quanto maior a área da bolha, maior será o entranhamento do fluido, gerando uma maior mistura. A Figura 2 mostra a diferença dos processos de oxigenação (aeração) e mistura artificial (desestratificação). 


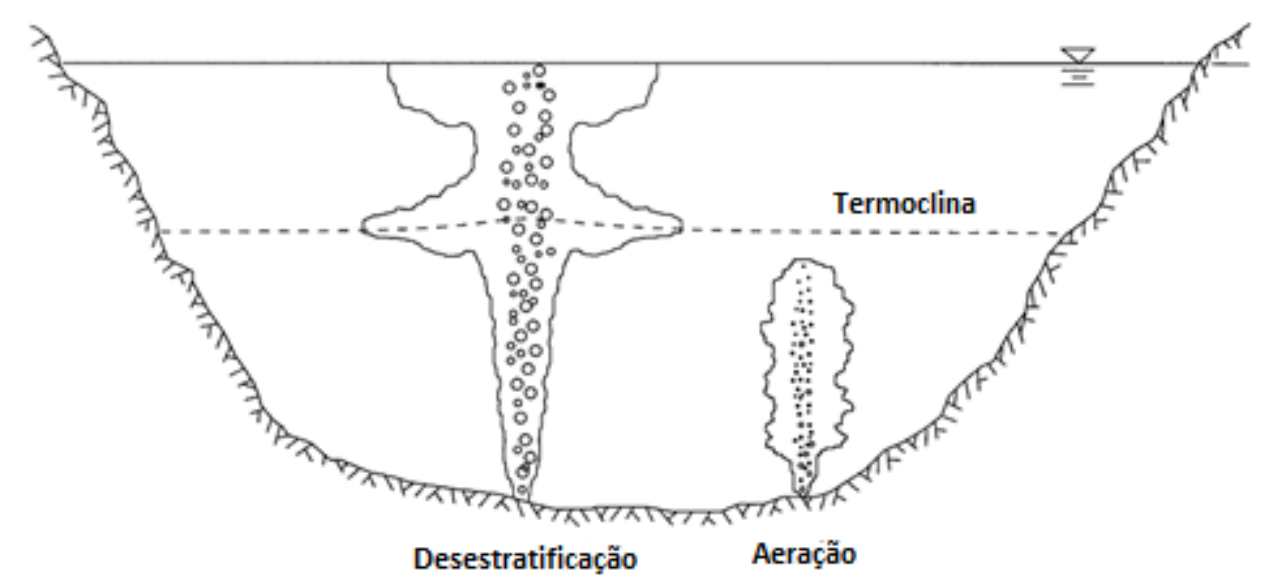

Figura 2 - Esquema representativo de plumas de bolhas usadas para desestratificação e aeração em um reservatório (Fernando, 2013).

O projeto de um sistema de oxigenação envolve diferentes considerações. Enquanto a mistura artificial se utiliza de bolhas grandes, a oxigenação ou aeração demanda bolhas suficientemente pequenas para que o oxigênio possa se dissolver na água. A presença de oxigênio dissolvido em rios e lagos é importante para a vida desses locais. Portanto, o processo de aeração é adequado para mitigar problemas relacionados à poluição.

Visto que em diversas aplicações práticas os conceitos e definições relacionadas às plumas de bolhas são utilizados, julga-se importante a caracterização da dinâmica das bolhas e a sua interação com o escoamento. Isto é relevante para definir as zonas de mistura, nos casos de aeração ou desestratificação. Projetos de sistemas de aeração artificial podem ter um efeito pouco produtivo na melhora da qualidade da água observada próximo à zona de injeção de bolhas, caso a interação entre a pluma e o fluido ambiente seja mal estimada. Nos casos de vazamentos de gás nos oceanos, provenientes da indústria do petróleo, é importante a previsão de alguns parâmetros, tais como a velocidade, o tamanho das bolhas de gás e a interação com as correntes marinhas, pois estas características podem ser determinantes no tempo de espalhamento do óleo até a superfície e até as regiões costeiras. Desta forma, os impactos causados pelo óleo e gás podem ser minimizados se este tempo for considerado no planejamento para contenção dos vazamentos.

Tipicamente, as investigações realizadas acerca deste tipo de escoamento são baseadas na premissa de que a superfície do corpo receptivo se encontra num estado 
estável ou quase estável (Lam e Xia, 2001). Como resultado, os modelos existentes que descrevem a dispersão de uma pluma de bolhas não consideram se a pluma é emitida em um ambiente com flutuações de velocidade. Logo, não é possível garantir que os modelos representam bem a dispersão das plumas em condições próximas a superfície da água, onde a presença de ondas geradas por ventos é constante.

Diante dos fatos aqui apresentados, o presente trabalho tem como objetivo investigar, experimentalmente, o escoamento de uma pluma de bolhas em um ambiente oscilatório, bem como a interação entre as bolhas e as ondas. Além disso, faz parte do escopo realizar a caracterização das bolhas a fim de se obter uma estimativa dos diâmetros e velocidades dessas bolhas sob diferentes condições. A ideia é analisar mudanças na dinâmica das plumas devido à presença de escoamento oscilatório. Assim, pretende-se avaliar se os modelos físicos existentes para ambientes estagnados ou com velocidade constante podem ser utilizados também para os casos com escoamento oscilatório.

O presente trabalho encontra-se dividido em nove capítulos, incluindo a introdução e as referências bibliográficas. O segundo capítulo trata de uma revisão da literatura em que diversos trabalhos relacionados com o assunto desta pesquisa em questão foram abordados e serviram como base para o desenvolvimento da dissertação. O aparato experimental utilizado, as técnicas de medições, procedimentos experimentais e os equipamentos empregados na realização dos experimentos são descritos no capítulo 3 . No capítulo 4 , o projeto e construção de um gerador de ondas é apresentado. A metodologia de processamento e análise das imagens utilizadas nas medições é apresentada no capítulo 5. Nesse capítulo são mostradas as rotinas de processamento de imagens e dos campos vetoriais de velocidade. Já no capítulo 6, são apresentados os resultados referentes ao comportamento do escoamento cruzado e no capítulo 7, são apresentados os resultados das características das bolhas no escoamento cruzado. Os dados obtidos experimentalmente são analisados à luz da teoria e da literatura. Finalmente, as conclusões finais fundamentadas no texto e decorrentes da pesquisa são apresentadas no capítulo 8. Nesse último capítulo são propostas abordagens para trabalhos futuros que darão continuidade a este assunto. 


\section{2 \\ Revisão Bibliográfica}

Este capítulo encontra-se dividido em três tópicos. O primeiro tópico aborda os estudos relacionados aos jatos emitidos na presença de escoamento cruzado estável, em que as principais características deste tipo de escoamento foram investigadas. Conceitos importantes, como a razão de velocidade entre jato e escoamento cruzado são apresentados, mostrando como estas diferentes características podem influenciar nas dispersões dos jatos. O segundo tópico apresenta uma revisão dos estudos de jatos, porém agora, em ambientes não estacionários. Os parâmetros que envolvem a dispersão de jatos em ambientes estáveis são relacionados com as condições das ondas empregadas nestes estudos, revelando como a oscilação da superfície podem afetar o escoamento do jato. Por fim, o último tópico deste capítulo apresenta os principais conceitos das plumas de bolhas, mostrando as características da dispersão das plumas em ambientes estagnados e na presença de escoamento cruzado.

\section{1. Jatos em escoamento cruzado constante}

O comportamento de um jato em escoamento cruzado é afetado por uma série de parâmetros como a geometria da fonte de emissão, a temperatura do ambiente, a velocidade do escoamento cruzado, a razão de densidades, turbulência, além de outras características do escoamento principal. A interação do jato com o escoamento cruzado resulta, tipicamente, em estruturas de vórtices como, por exemplo, vórtices contra rotativos (Counter Rotating Vortex Pair (CVP)), vórtices do tipo ferradura (Horseshoe Vortex) e região de esteira. Essas estruturas são ilustradas na Figura 3. 


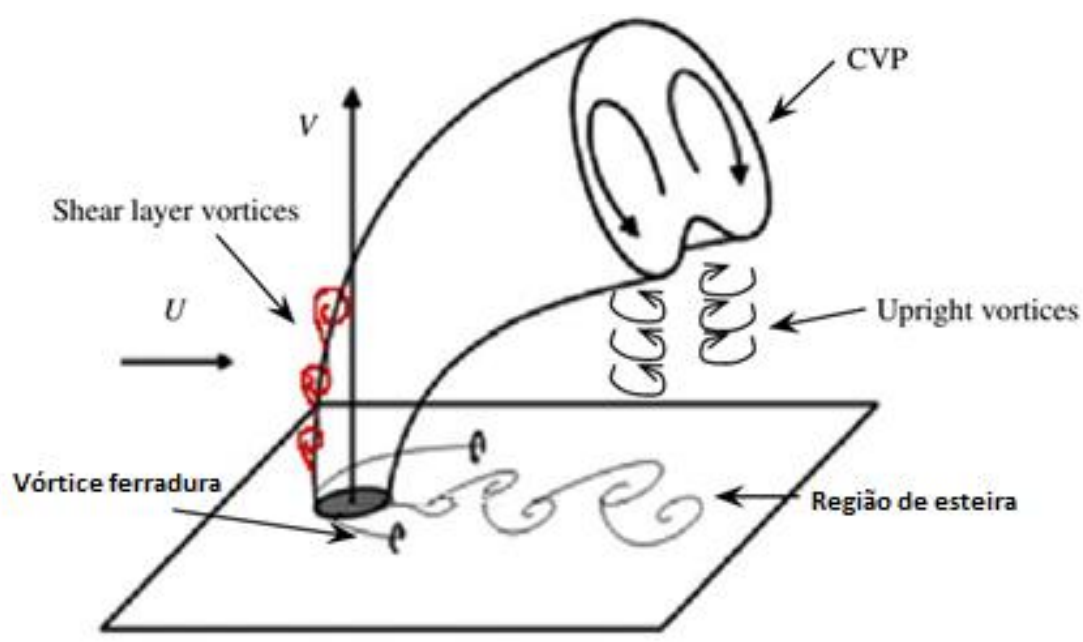

Figura 3 - Principais estruturas de vórtices encontradas no escoamento cruzado (Peplinski, et al. 2015)

Apesar da complexidade do escoamento, é cada vez mais necessário investigar o comportamento da injeção de um fluido e seus efeitos devido à importância deste tipo de escoamento na dispersão de poluentes no ambiente. Um dos estudos recentes acerca deste tópico é o trabalho de Milanovic et al. (2012). Neste estudo foram investigados vórtices instáveis, como estruturas que conectam os vórtices do tipo CVP com a região de esteira (Upright vortices). Os estudos foram realizados em um túnel de vento e fez-se o uso de fumaça para a visualização do escoamento. A fim de investigar a origem e a organização dos diferentes tipos de vórtices no escoamento cruzado, foi necessário usar diferentes tipos de mecanismos intrusivos próximos ao centro de injeção. Observou-se a evolução da esteira de vórtices em diferentes razões de velocidade. Apesar das perturbações mecânicas não influenciarem significativamente a organização periódica das estruturas de vórtices, o autor pôde visualizar características de vórtices similares às encontradas na literatura e apresentadas na Figura 3.

No trabalho de Vincenti et al. (2003) foi utilizada a técnica PIV (Particle Image Velocimetry) - técnica óptica para obter o campo de velocidades do escoamento - para investigar como os vórtices do tipo CVP interagem com os vórtices da camada cisalhante (Shear-layer vortices (SLV)). O autor enfatiza a importância de se entender os mecanismos de instabilidade que levam o SLV a um estado turbulento para o desenvolvimento de técnicas para o controle do escoamento (ex. antecipar a transição para escoamento turbulento e aumentar o 
processo de mistura). Naquele trabalho, os estudos foram realizados em um túnel de água vertical e, para o sistema de injeção, um jato com perfil retangular foi utilizado, como ilustrado na Figura 4.

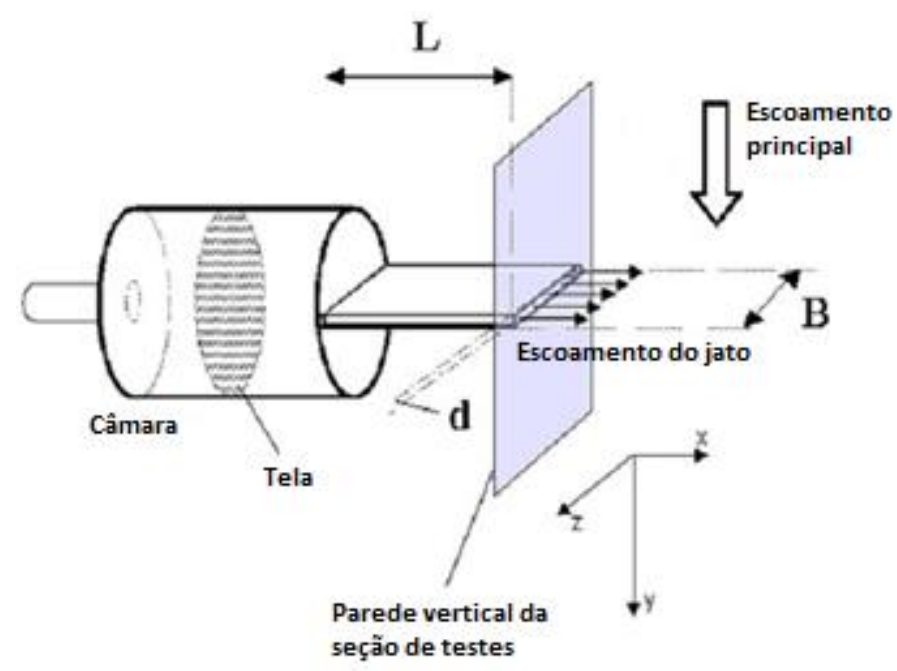

Figura 4 - Esboço do sistema de injeção do trabalho de Vincenti et al, 2003

Vincenti et al. (2003) observaram que a variação da razão de velocidade $R_{V}$ afeta significantemente a evolução de estruturas de vórtices. A razão de velocidades $R_{V}$, é definida como:

$$
R_{V}=\frac{V}{U}
$$

Onde $V$ é a velocidade de saída do jato e $U$ é a velocidade do escoamento principal. Este parâmetro é importante nos estudos de jatos. No trabalho de Vincenti et al. (2003), foi observado que para valores de $R_{V}$ menores que 3 , o escoamento do jato permanece próximo à parede sem qualquer indício de instabilidade. Em $R_{V}=$ 3, o escoamento do jato aparenta estruturas de instabilidade na camada cisalhante (Shear-layer) com o aparecimento regular de vórtices. Para $3<R_{V}<6$, a instabilidade da camada cisalhante do jato já é influenciada pela corrente do escoamento cruzado. E para $R_{V}>6$ os mecanismos de instabilidade de KelvinHelmholtz influenciam significativamente a dinâmica do jato.

New et al. (2003) utilizaram a técnica LIF e empregaram a visualização por corante, em um túnel d'água, para estudar as estruturas de vórtices de um jato com 
bocal elíptico em escoamento cruzado. O perfil elíptico do jato foi estudado para diferentes razões de aspecto $(H / L)$, conforme mostrado na Figura 5 e razões de velocidade de 1 a 5.

$\begin{array}{ccccc}\text { Configuração } & \begin{array}{c}\text { Formato da } \\ \text { saída do jato }\end{array} & \begin{array}{c}H \\ (\mathrm{~mm})\end{array} & \begin{array}{c}L \\ (\mathrm{~mm})\end{array} & \begin{array}{c}\text { Razão de aspecto } \\ (H / L)\end{array} \\ 1 & \Rightarrow \int_{-1}^{\frac{1}{+}} & 18.5 & 55.5 & 0.3 \\ 2 & \Rightarrow \bigcirc & 22.5 & 45 & 0.5 \\ 3 & \Rightarrow \bigcirc & 31.6 & 31.6 & 1.0 \\ 4 & \Rightarrow 0 & 45 & 22.5 & 2.0 \\ 5 & \Rightarrow 0 & 55.5 & 18.5 & 3.0\end{array}$

Figura 5 - Razão de aspecto para diferentes formas (a seta indica a direção do cross flow) (New et al. 2003)

New et al. (2003), observaram que a razão de aspecto tem efeito somente no escoamento próximo ao jato e a influência da razão de aspecto desaparece à medida que se afasta do ponto de injeção. Para baixas razões de aspecto nos jatos elípticos, o escoamento próximo é dominado pelo vórtice do tipo CVP. Já para razões de aspecto altas, além de CVP, há também grande influência da camada cisalhante na formação de outros tipos de vórtices. Isto impõe condições para o aumento ou redução da intensidade de interação dos vórtices.

Radhouane et al. (2009) analisaram, numericamente e experimentalmente em um túnel de vento, utilizando a técnica PIV, a evolução de dois jatos com variação de inclinação, imersos em um escoamento cruzado. Notou-se que, diferentes inclinações do jato influenciam o processo de mistura.

Gutmark et al. (2011) investigaram experimentalmente em um túnel de vento, utilizando a técnica PIV-2D, as dinâmicas de um jato único e dois jatos posicionados em sequência em um escoamento cruzado. A trajetória, penetração e propagação do jato foram as principais características de escoamento estudadas, comparando-se os dois tipos de posicionamento. Os jatos foram fixados em uma placa plana, como mostrado na Figura 6 e a razão de velocidade de trabalho foi fixada em 3. 


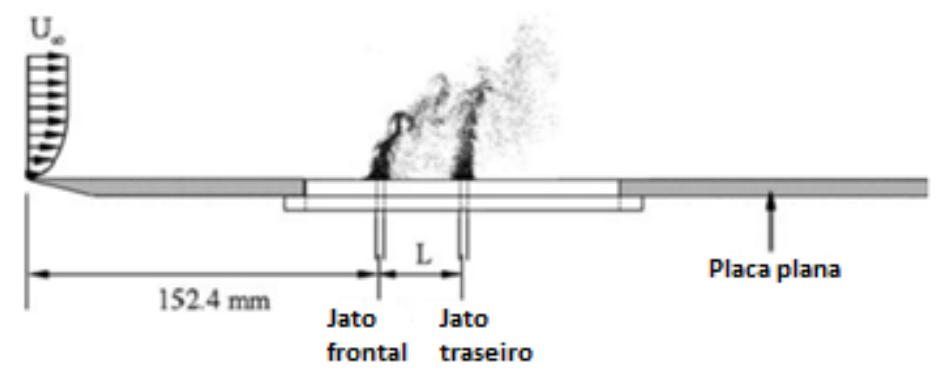

Figura 6 - Posicionamento dos dois jatos (Gutmark \& Ibrahim)

Gutmark e Ibrahim (2011) observaram que, quando os jatos estão posicionados em sequência, o jato traseiro cria um bloqueio, gerando um gradiente de pressão adverso que por sua vez induz separação no jato de frente e aumenta a circulação. Outra característica interessante observada foi que o jato traseiro atinge alturas mais elevadas devido à esteira do jato dianteiro.

\section{2. \\ Jatos em escoamento cruzado oscilatório}

Os estudos apresentados nesta seção correspondem a pesquisas relacionadas com escoamentos monofásicos oscilatórios. Para escoamentos bifásicos com presença de ambiente oscilatório, ainda não foram encontrados estudos na literatura.

As mudanças nas condições do escoamento cruzado podem afetar a dispersão e as características do escoamento dos jatos. No trabalho de Koole e Swan (1994), dois estudos experimentais são apresentados. Neste trabalho, foi analisado um caso com o jato alinhado com a direção do escoamento e um outro com o jato perpendicular ao fluxo. Em ambos os casos os jatos são descarregados na presença de ondas regulares e progressivas. As características principais do escoamento são comparadas com um descarregamento em ambiente estagnado. As comparações confirmam que a oscilação das ondas tem um efeito significantivo sobre a mistura e a diluição. Em particular, os dados experimentais sugerem que uma região de intensa mistura do fluido surge imediatamente à jusante do orifício de descarga. As medições sugerem, também, que o movimento das ondas produz um significante aumento na taxa de entranhamento do fluido ambiente para dentro da região do jato. 
Lam e Xia (2001) descreveram alguns resultados representativos de uma série de experimentos laboratoriais em que o comportamento de um jato emitido na presença de escoamento cruzado oscilatório é investigado por visualizações auxiliadas por computador. A amplitude e a frequência da oscilação do escoamento cruzado foram variadas de maneira sistemática a fim de estudar seus efeitos no comportamento do jato. Uma técnica experimental de oscilação do jato foi empregada para simular uma condição equivalente a um escoamento cruzado instável com velocidade diferente de zero. Esta técnica foi, posteriormente, comparada com a técnica de geração de um ambiente instável a partir de uma placa geradora de ondas. Todos os experimentos foram realizados com a razão de velocidade $(V / U)$ fixa. O autor utiliza um parâmetro de instabilidade, o qual representa o grau de instabilidade do escoamento cruzado. Este parâmetro é definido como:

$$
P_{\text {inst }}=\frac{u_{p}}{U}
$$

Em que $u_{p}=2 \pi f A$ (onde $f$ e $A$ são a frequência e a amplitude das ondas, respectivamente) e $U$ é a velocidade do escoamento principal. Os valores do parâmetro de instabilidade foram variados de 0,25 a 1,5. Outro adimensional empregado foi o número de Strouhal, definido como:

$$
S t=\frac{f D}{U}
$$

Em que $D$ é o diâmetro do injetor, $f$ é a frequência de oscilação das ondas e $U$ é a velocidade do escoamento principal. O número de Strouhal foi variado de 0,0375 a 0,12 . Os dois parâmetros adimensionais foram variados de forma a manter as condições de ondas de águas rasas. As características de dispersão utilizando ambas as técnicas se mostraram similares em diferentes amplitudes e frequências.

Mori e Chang (2003) investigaram o movimento de um jato horizontal sujeito a várias condições de ondas. Neste estudo, a técnica Laser-Induced Fluorescence (LIF) foi empregada para visualizar qualitativamente o campo de escoamento e para medir a linha de posição central do jato. As condições experimentais foram 
estabelecidas de forma que a frequência de oscilação das ondas permanecesse fixa e variações na velocidade de saída do jato $(V)$ e na amplitude das ondas $(A)$ fossem impostas. Consequentemente, a razão de momento onda-jato, também foi variada. A razão de momento é definida como:

$$
R_{M}=\frac{g A^{2}}{2 D V^{2}}
$$

Onde $D$ é o diâmetro do injetor. Os resultados experimentais mostraram que a oscilação do jato tem um atraso de fase em relação as ondas e que este atraso aumenta à medida que se aumenta a distância do orifício ao ponto de medição. Além disso, foi identificado, através de medições, que o jato não interfere na amplitude das ondas.

Mais recentemente, Chang et al. (2013) estudaram os efeitos de flutuação de um jato circular em meio estagnado e com ondas regulares, utilizando a técnica PIV (Figura 7). Foram empregados diferentes tipos de fluido de injeção (água, álcool e solução salina) para gerar diferença de densidade entre o fluido do meio e do jato. Foi observado que os efeitos de empuxo têm uma influência consideravelmente menor do que o efeito de dispersão da onda na difusão do jato. A largura do jato ao longo da sua linha de centro permaneceu constante, independentemente de o jato estar ou não sob efeito das ondas. Porém, a intensidade turbulenta e a tensão de Reynolds do jato aumentaram consideravelmente quando estava sendo emitido na presença de ondas, comparado com a emissão em ambiente estagnado.
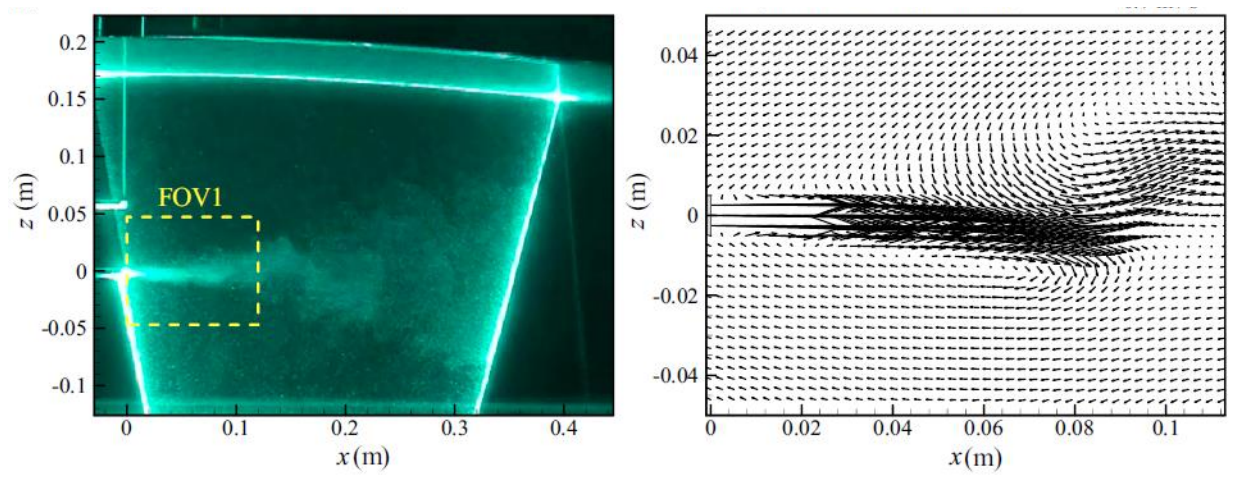

Figura 7 - Comparação entre a imagem capturada e o campo médio de velocidade (Chang, et al, 2013). 
$\mathrm{Xu}$ et al. (2014) fizeram um estudo experimental no qual compararam os perfis de velocidade média de um jato na presença de ondas regulares e aleatórias. Nos experimentos, o nível de água do reservatório foi mantido constante. Um total de 10 casos experimentais foram conduzidos com diferentes amplitude e período de onda e velocidade inicial do jato, além de avaliações de casos no ambiente estagnado, com ondas regulares e ondas aleatórias. Foi visto que a largura de dispersão do jato na presença das ondas é maior do que no ambiente estagnado, indicando que há uma maior mistura na presença de ondas. A movimentação do jato é pouco afetada pela força das ondas devido à baixa razão de momento ondajato $\left(R_{M}\right)$. Com o aumento da distância vertical do orifício do jato, a largura do jato se torna maior e a velocidade ao longo da linha de centro decai mais rápido na presença de ondas do que no ambiente estagnado.

\section{3. \\ Plumas de bolhas}

As plumas são escoamentos conduzidos pela diferença de densidade (empuxo). Em particular, as plumas de bolhas podem se formar quando uma fase imiscível é descarregada localmente em um fluido receptor contínuo, como corpos d'água ou atmosfera. Por causa do empuxo, a fase dispersa se move para longe da fonte de descarga. Da mesma forma, a fase contínua do fluido se move em reação à força de arrasto de cada bolha. A turbulência resultante do escoamento aumenta o entranhamento do fluido ambiente na mistura, resultando em um escoamento de duas fases (Fernando, 2013).

De acordo com a Figura 8, em um local de descarga estagnado, a pluma é simétrica em relação ao eixo z. O perfil de velocidade média da fase contínua na direção vertical, $u(z)$, apresenta, tipicamente, uma distribuição Gaussiana com velocidade máxima $U_{m}(z)$ e largura $b(z)$. Já o perfil da fração em vazio $\alpha(z)$ da fase dispersa se expande mais lentamente. De acordo com Seol e Socolofsky (2008), o perfil de fração de vazio tem largura $b(z)$ e máxima magnitude $\alpha_{m}(z)$, apresentando uma distribuição conhecida como top-hat. 


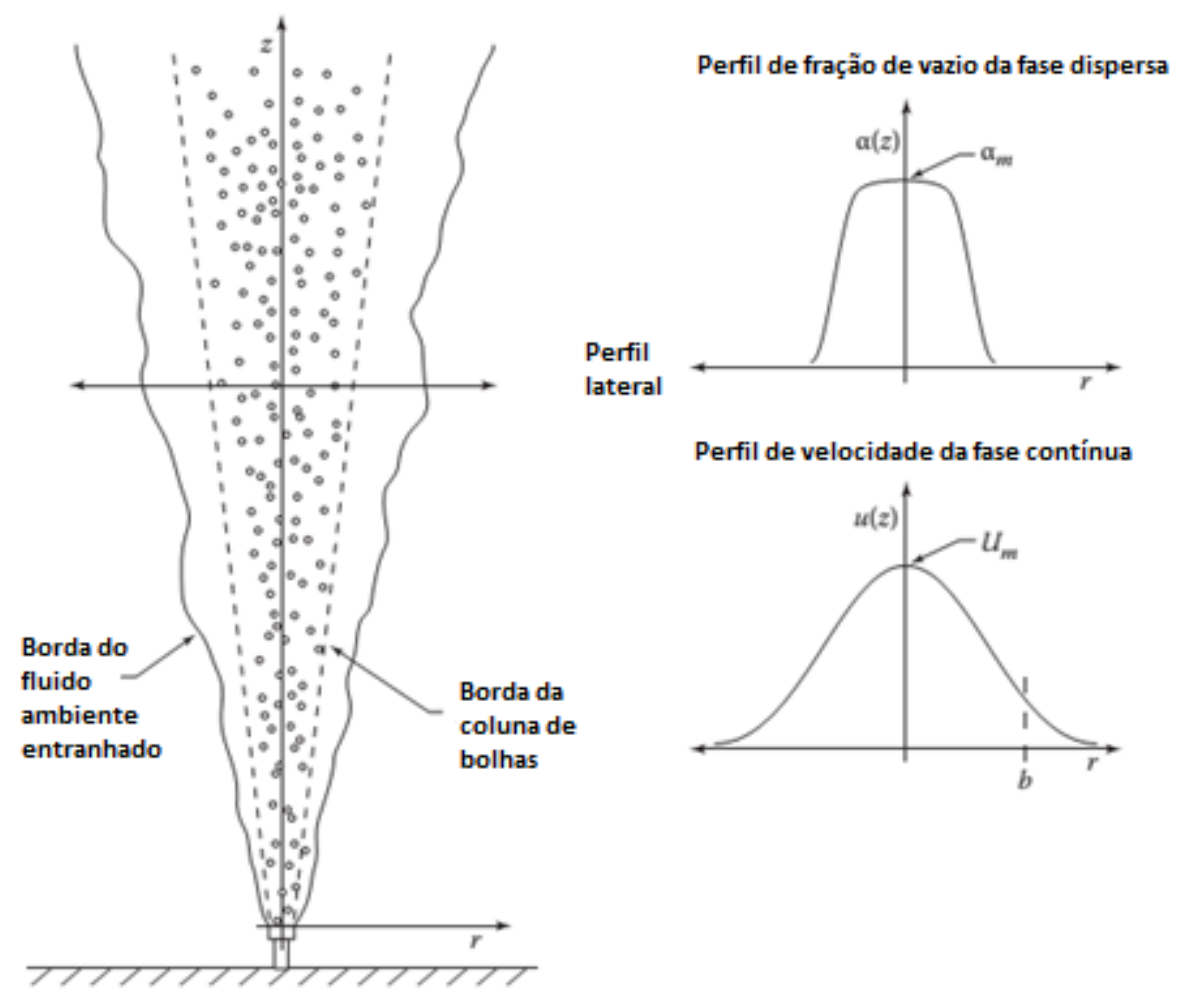

Figura 8 - Esquema de uma simples pluma de bolhas em um fluido estagnado (Fernando, 2013)

Somente a partir da década de 70 é que estudos de plumas começaram a ser realizados de forma substancial, pois até então, poucos trabalhos eram conhecidos (Kobus, 1968, Ditmars e Cederwall, 1974, Crapper, 1977). A partir desses trabalhos pioneiros, e com avanço das técnicas de medição de escoamentos bifásicos, é que foi possível uma melhor caracterização dos perfis de velocidade, fluxo de quantidade de movimento, fluxo de massa, frações de cada fase e configuração das plumas (Crapper, 1977, Duarte, et al., 2007, Farias, et al., 2011 e Weiland e Vlachos, 2013).

Segundo Junior (1997), ao deixar um orifício, um fluxo contínuo de gás se rompe, devido a instabilidades de Kelvin-Helmholtz, formando bolhas discretas espalhadas no líquido, gerando a região da pluma. O gás ascendente arrasta consigo considerável quantidade de líquido (entranhamento) e, por conseguinte, forma-se uma zona de recirculação na região monofásica adjacente à trajetória da pluma. Quando a fonte de gás é puntiforme em meio estagnado, o escoamento é axissimétrico e pode ser dividido em três regiões distintas, como mostra a Figura 9: a Região de Escoamento em Desenvolvimento (Zone of Flow Establishment - 
ZOFE), a Região de Escoamento Desenvolvido (Zone of Established Flow-ZOEF) e a Região de Superfície Livre (Zone of Surface Flow - ZOSF). Em vazamentos submarinos de gás, a massa específica da fase gasosa varia com a pressão e a temperatura locais, fazendo com que as bolhas se expandam à medida que se deslocam para a superfície. Na região de escoamento desenvolvido, a força motriz do escoamento é o empuxo. Na região próxima ao orifício, as forças de inércia e empuxo possuem a mesma ordem de grandeza, ou seja, na região de escoamento em desenvolvimento a pluma de bolhas ainda conserva as características de jato. Já próximo à superfície, as forças devido à tensão superficial estão presentes e devem ser consideradas nas análises do escoamento nesta região.

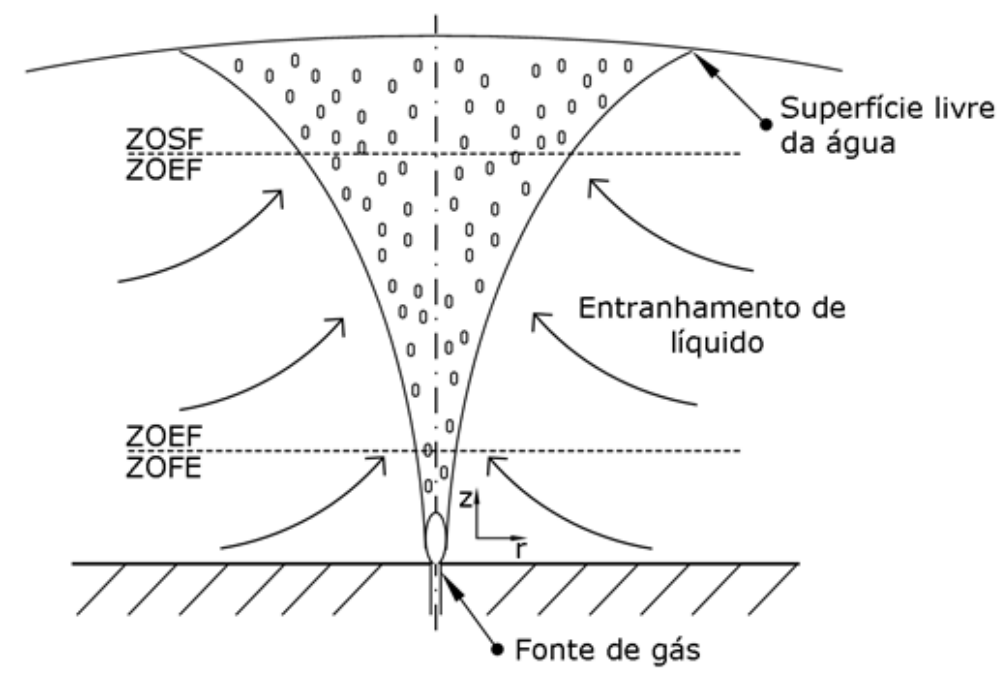

Figura 9 - Zonas de escoamento de uma pluma de bolhas (Junior, 1997)

Em relação ao ambiente em que é emitida a pluma, é importante descrever a densidade do meio, estratificação e aspectos de corrente. Quando a pluma é emitida em um ambiente com escoamento cruzado (Figura 10), a velocidade do fluido local inclina a pluma e todo o fluido entranhado e as bolhas seguem uma única trajetória se movendo junto para longe da fonte de emissão. A corrente passa através da pluma, puxando consigo o fluido entranhado para dentro das esteiras da coluna de bolhas. 


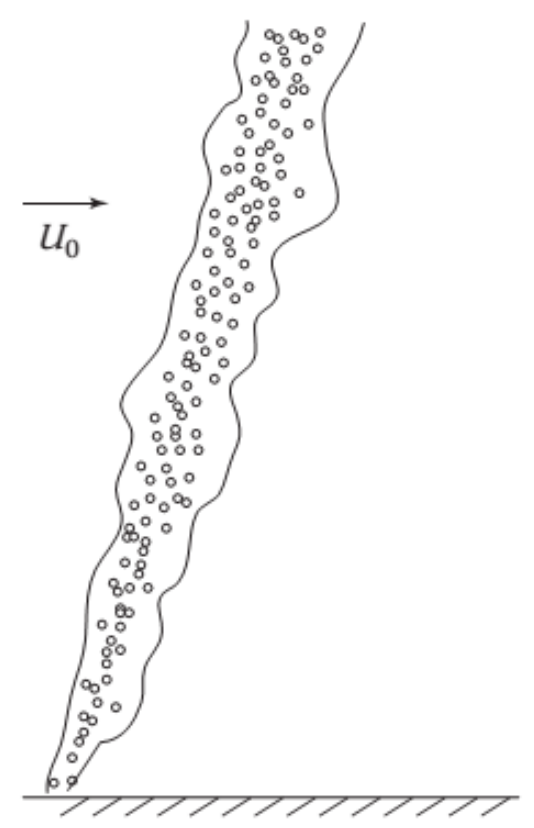

Figura 10 - Pluma de bolhas em presença de escoamento cruzado (Fernando, 2013)

Plumas de bolhas encontradas na indústria do petróleo são, em geral, mais complexas do que a ilustrada na Figura 8. Além da estratificação do meio (o oceano), podem ocorrer também correntes cruzadas e formação de hidratos, o que dificultam a modelagem do problema. Nesse caso, a reprodução das condições do escoamento em laboratório é mais limitada e dispendiosa devido a elevado número de fatores que influenciam no comportamento da pluma (Junior, 1997).

De acordo com Bandara e Yapa (2011), o gás ou o óleo quando liberado em um vazamento forma bolhas por causa da instabilidade criada pela alta turbulência no ponto de vazamento. Além da hidrodinâmica da pluma, a velocidade individual de ascensão das bolhas desempenha um papel importante na determinação do tempo de subida do óleo e do gás até a superfície. A velocidade de ascensão das bolhas dependerá do seu tamanho e da distribuição destas. As bolhas que permanecerem na água por mais tempo serão afetadas pelas correntes marinhas, ocorrendo o transporte vertical e lateral destas. Além disso, as bolhas em escoamentos turbulentos se rompem devido à interação com vórtices turbulentos, altas taxas de cisalhamento ou instabilidade criadas por circulações internas. Por outro lado, as bolhas tendem a coalescer devido à colisão gerada pela turbulência, alto cisalhamento, empuxo ou efeitos de esteira. 
Yapa et al. (2012) estudaram alguns efeitos devido a um vazamento de petróleo e gás em águas profundas: a possível existência de plumas de petróleo submarinas; a existência de gás e seu papel no transporte de pluma de óleo; diferentes fases da pluma de petróleo; e papéis de tamanhos das bolhas durante as diferentes fases. Pelo fato do gás possuir menor massa específica do que petróleo e água, o gás se desloca mais rapidamente na direção da superfície da água do que os outros componentes. Em situações onde as correntes marinhas são mais intensas, o gás se move mais rapidamente que o petróleo, havendo assim a separação das plumas (Socolofsky e Adams, 2002; Chen e Yapa, 2003), impactando na dinâmica e a flutuação da pluma. O gás se dispersa em bolhas de vários tamanhos quando é lançado. Em lançamentos em águas muito profundas, grande parte das bolhas de gás se dissolvem na água antes mesmo de chegar a superfície (Zheng e Yapa, 2012).

As plumas de bolhas perturbam o escoamento ao redor originando diferentes estruturas, que não são observadas em escoamentos de uma única fase, devido à complexidade do movimento translacional e a variação volumétrica das bolhas. $\mathrm{O}$ comportamento do fluido local, assim como as interações mútuas entre as bolhas e vórtices, influencia as características do escoamento (Ruzicka, 2000). Por exemplo, ambas as gerações e as deformações de vórtices na fase líquida devido ao efeito de empuxo causado pela distribuição local das bolhas, a acumulação das bolhas nos núcleos de vórtices e a turbulência gerada pela migração de bolhas, aumenta a instabilidade do escoamento e modifica a turbulência. Os detalhes das estruturas do escoamento causado pelas plumas de bolhas envolvem várias interações entre as bolhas e o líquido ambiente quando as bolhas sobem do fundo até a superfície livre.

Neto (2010) estudou a turbulência gerada por jatos bifásicos do tipo gáslíquido em um tanque estagnado com água. Foram utilizados 4 injetores de bocal circular, que promoviam a injeção de ar. A técnica de Velocimetria por Imagem de Partículas foi empregada na visualização e caracterização do escoamento gerado pelos jatos bifásicos. Concluiu-se, de acordo com os resultados obtidos experimentalmente, que a fração volumétrica de ar influencia consideravelmente nas propriedades turbulentas da fase líquida, tais como energia cinética turbulenta, taxa de dissipação de energia e escalas de comprimento dissipativa, que foram estimadas assumindo a condição de turbulência isotrópica, embasada nas medições de tensões de Reynolds. 
Liu et al. (2005), utilizaram partículas fluorescentes para medir o campo de velocidade instantâneo de líquido, as estruturas do escoamento e a turbulência causada por bolhas de ar em ambiente estagnado. Com a técnica de fluorescência eles realizaram medições em líquidos de diferentes viscosidades. Foi observado que o líquido acima das bolhas é empurrado enquanto o líquido abaixo das bolhas é arrastado pela esteira das bolhas. A trajetória das bolhas foi afetada pela variação da viscosidade do líquido. À medida que a viscosidade do líquido reduz, as bolhas seguem uma trajetória em zig-zag devido à formação de par de vórtices no líquido ao redor. Reduzindo ainda mais a viscosidade observou-se que a trajetória das bolhas se torna espiral, induzindo a formação de grandes estruturas circulares e irregulares.

Em uma pluma, as bolhas apresentam uma velocidade de deslizamento, $U_{S}$, relativa ao fluido ambiente. Em um ambiente estagnado, a velocidade de deslizamento depende de fatores como o tamanho e a forma das bolhas, empuxo e viscosidade. A forma das bolhas muda com o aumento do diâmetro, progredindo desde formatos esféricos para elípticos ou ainda calotas esféricas. Diversos fatores ambientais também podem afetar a velocidade de deslizamento.

Baseando-se em estudos anteriores, os quais mostraram que a mistura de arágua na injeção é mais eficiente para a areação artificial comparado a injeção pura de água, Zhang e Zhu (2013) se propuseram a realizar um estudo para caracterizar as propriedades das bolhas de ar em escoamento cruzado. Dentre as características avaliadas estão: fração de gás, frequência das bolhas, velocidade das bolhas, diâmetro das bolhas e área interfacial. As medições foram feitas com um sensor a fibra óptica em diferentes seções ao longo da linha central da trajetória das bolhas de ar (Figura 11) e os resultados foram comparados com outros estudos realizados em ambiente estagnado. 


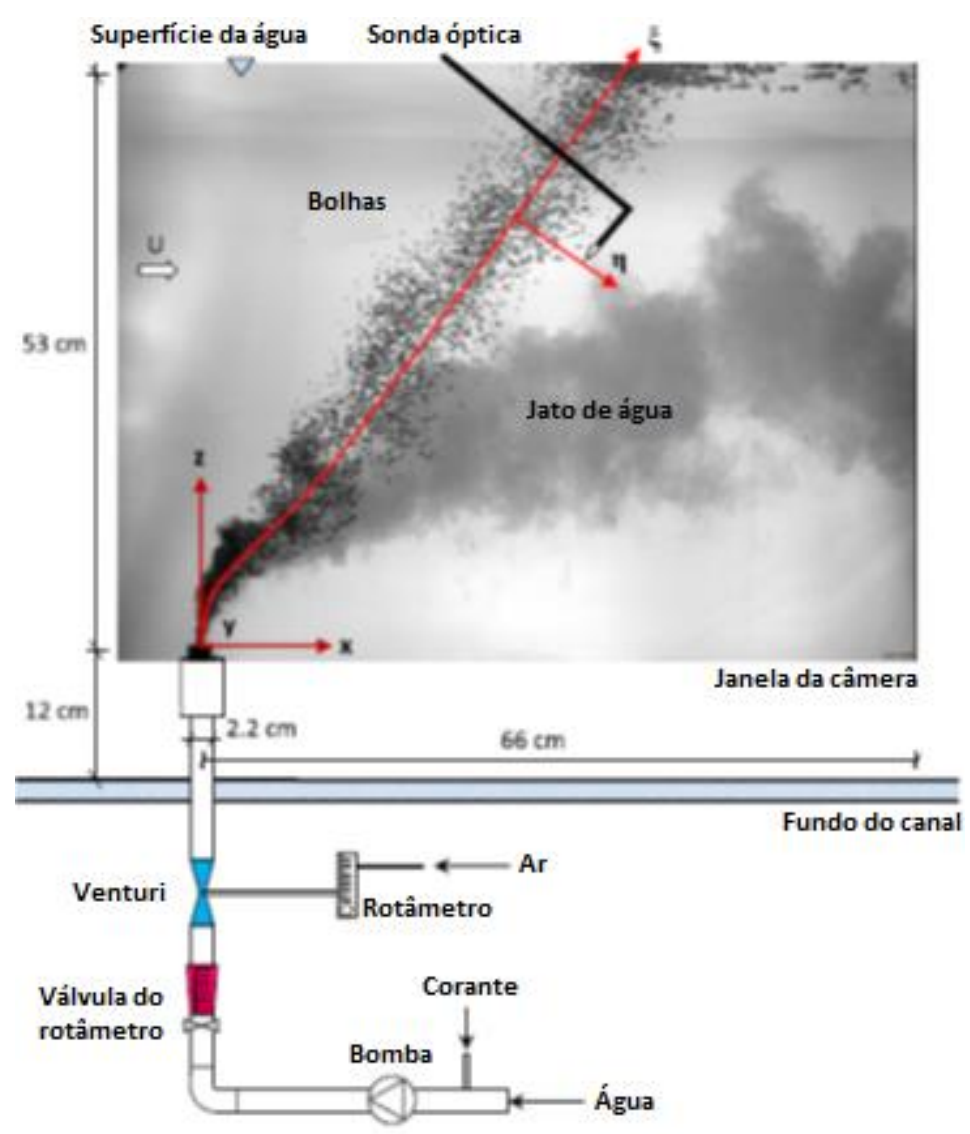

Figura 11 - Aparato experimental (Zhang e Zhu, 2013)

No trabalho de Zhang e Zhu (2013), foi identificado que a distribuição de velocidade das bolhas não segue um perfil Gaussiano, diferentemente da distribuição de velocidade das bolhas no ambiente estagnado. Também pôde ser visto que a velocidade das bolhas a jusante do escoamento é, geralmente, maior do que a velocidade das bolhas a montante. Os autores relataram que este fenômeno está relacionado com a distribuição do tamanho das bolhas, do efeito de esteira das bolhas e da separação das bolhas do jato de água. Outra importante característica analisada foi a velocidade de deslizamento da bolha:

$$
U_{S}=V_{B}-\left(U_{C}+U_{b w}\right)
$$

Em que $V_{B}$ é a velocidade da bolha, $U_{b w}$ é a velocidade da água induzida pela bolha e $U_{C}$ é a velocidade do escoamento cruzado. A velocidade da água induzida pelas bolhas foi avaliada a partir da injeção de corante na região a montante do 
escoamento principal, a linha de corante foi elevada consideravelmente na passagem de bolhas grandes, enquanto que fracamente no caso de bolhas pequenas. Isto confirma que a velocidade da água induzida pelas bolhas só é importante no caso de bolhas grandes. O resultado da velocidade de deslizamento das bolhas se mostraram próximos aos resultados encontrados na literatura dos casos de bolhas solitárias em ambiente estagnado e divergente de outros estudos de pluma de bolhas em ambiente estagnado.

Wang e Socolofsky (2015), realizaram experimentos laboratoriais e um modelo para prever a velocidade de subida das bolhas, considerando os efeitos de esteira e escoamento cruzado. As bolhas foram injetadas no centro de um tanque em diferentes vazões para criar sucessivas correntes de bolhas com espaçamento diferente entre duas consecutivas bolhas. Um sistema de imagens foi usado para coletar as imagens das sombras das bolhas e medir algumas de suas características tais como, tamanho e velocidade de subida. Todas as imagens foram analisadas utilizando um código gerado no ambiente Matlab. As bolhas foram distinguidas do fundo das imagens utilizando uma detecção de contorno através de limiar de intensidade. Como resultado, as imagens cruas foram convertidas em imagens binárias em que as bolhas ocuparam pixels marcados com 1 e os pixels do fundo marcados como 0, de acordo com a ilustração da Figura 12.

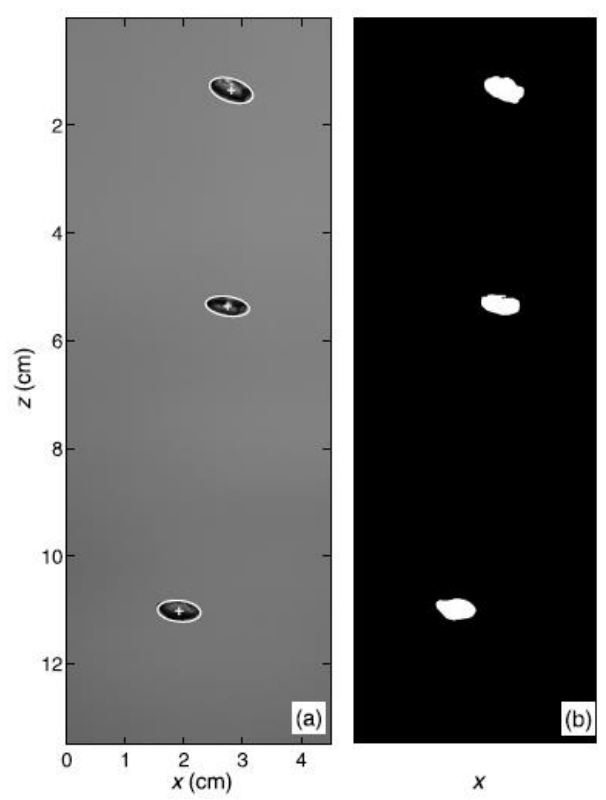

Figura 12 - Amostra da imagem processada com o resultado da detecção das bolhas (Wang e Socolofsky, 2015) 
A velocidade instantânea de subida foi calculada rastreando o deslocamento vertical do centro da bolha detectada durante o tempo entre dois frames consecutivos. Para medir o tamanho das bolhas, a área circular equivalente ao diâmetro das bolhas foi computada para corresponder à área projetada de cada bolha nas imagens binarizadas. Os autores propuseram um modelo empírico para prever a velocidade de subida das bolhas na presença do escoamento cruzado. Foi verificado que, para baixas velocidades do escoamento cruzado, existe uma interação forte entre as várias bolhas subindo. Enquanto que, para velocidades mais altas, essa interação entre as bolhas se torna fraca.

Em vista da grande abrangência das aplicações relacionadas ao escoamento de jatos e plumas, pode-se admitir que, embora muitos estudos tenham sido realizados, ainda existem lacunas que não foram investigadas. A literatura acerca das emissões de plumas de bolhas em ambientes estagnados é ampla, porém, quando se considera a presença de escoamento cruzado, a literatura é recente e ainda restrita. Além disso, não foram encontrados estudos onde a emissão de plumas foi realizada em escoamento cruzado oscilatório. Os trabalhos encontrados envolvem o escoamento de plumas de bolhas e consideram que a superfície livre da fase contínua se encontra em um estado estável, sem perturbação. Porém, sabe-se que, na prática, a grande maioria dos corpos d'água apresentam a superfície em constante movimento, devido a diversos fatores como, por exemplo, a ação dos ventos. Considerando os fatos aqui observados, julga-se importante investigar as características do escoamento cruzado oscilatório e relacioná-las ao contexto de dispersão das plumas de bolhas. 


\section{3 Metodologia e Aparato Experimental}

O presente trabalho é abordado considerando a dispersão de uma pluma de bolhas de ar na presença de um escoamento cruzado oscilatório. Neste estudo, a injeção de ar é feita a partir do fundo de um canal de circulação de água disponível no Inmetro (Alho, et al. 2010). Para a geração do ambiente instável, são realizados o projeto e a construção de um gerador de ondas para o canal de circulação de água. O problema abordado tem aplicação na aeração de rios e lagos, e pode representar de maneira simplificada, eventos de vazamento de gás e descarga de poluentes em regiões costeiras.

O estudo utiliza a técnica de Velocimetria por Imagem de Partículas (do inglês, Particle Image Velocimetry - PIV) para medição dos campos de velocidade do escoamento. Devido à existência de duas fases (líquida e gasosa) na dispersão da pluma de bolhas de ar na água, é necessária a combinação da técnica PIV com a técnica de detecção de sombras. Com esta combinação, é possível distinguir as bolhas de ar das partículas traçadoras através de pré-processamentos das imagens, permitindo assim que o escoamento de cada fase seja investigado. Os campos vetoriais de velocidade resultantes do sistema PIV são usados para encontrar relações entre a dispersão da pluma de bolhas e os casos que envolvem as condições com e sem a presença das ondas. Ainda, com as imagens obtidas, é feita uma caracterização da fase dispersa, estimando-se os diâmetros e as velocidades das bolhas. O desenho esquemático da Figura 13 mostra as principais características do aparato experimental utilizado nos testes. 


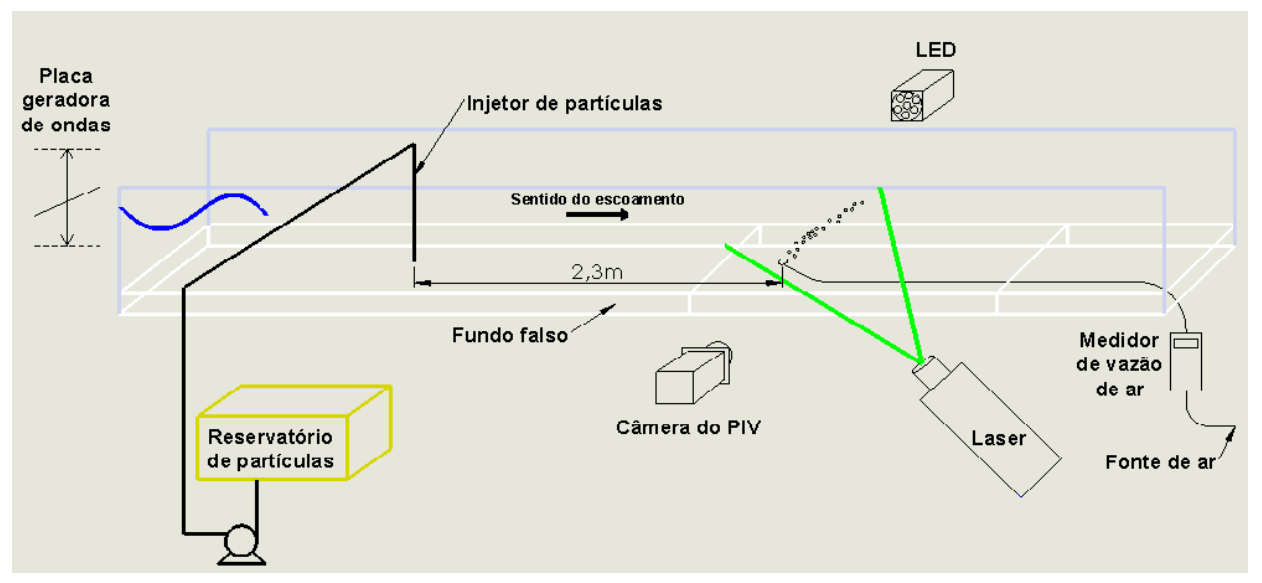

Figura 13 - Esquema do aparato experimental

No primeiro tópico deste capítulo, é feita uma descrição do canal de circulação de água utilizado nos experimentos. Em seguida, são apresentadas as técnicas de medição empregadas, bem como as principais características das mesmas. Os procedimentos de montagem e adaptação dos equipamentos estão apresentados no terceiro item. Na sequência do capítulo, são descritos os sistemas de injeção de ar e de partículas traçadoras. Por fim, descreve-se brevemente o uso de fluorescência para obtenção das imagens.

\section{1. \\ Canal de circulação de água do Inmetro}

O canal de circulação de água (Figura 14 e Figura 15), presente na Divisão de Metrologia em Dinâmica de Fluidos (Dinam), do Instituto Nacional de Metrologia, Qualidade e Tecnologia - Inmetro, proporciona um ambiente de escoamento controlado no qual uma grande variedade de experimentos pode ser conduzida. A instalação foi projetada e construída fora do contexto deste trabalho, com o objetivo de viabilizar a realização de pesquisas relacionadas à gestão ambiental e controle de poluição, medições de turbulência e velocidade, calibração de medidores de vazão, dentre outros. 


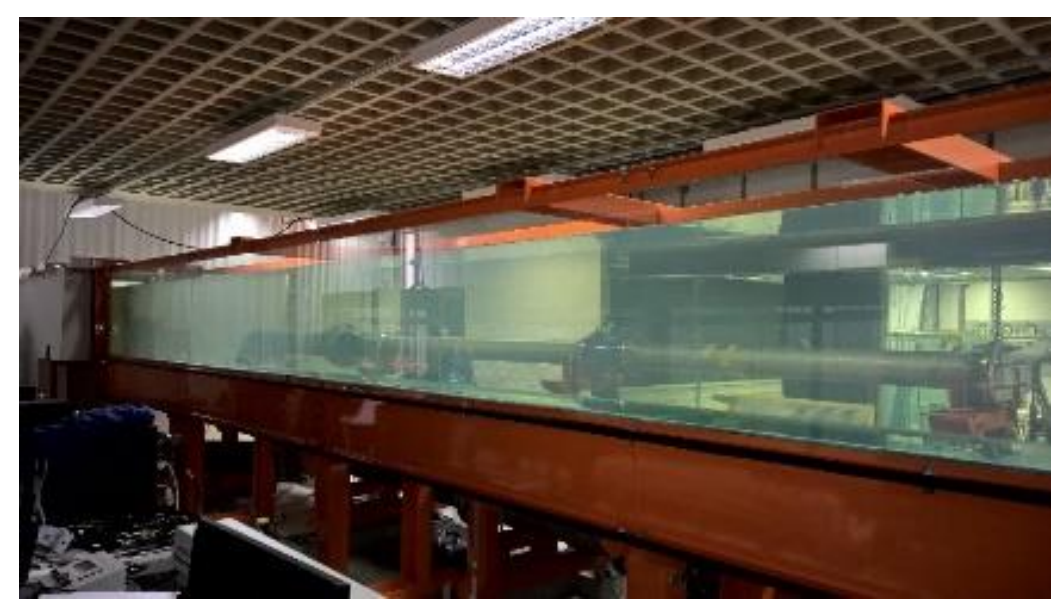

Figura 14 - Vista lateral do canal de água

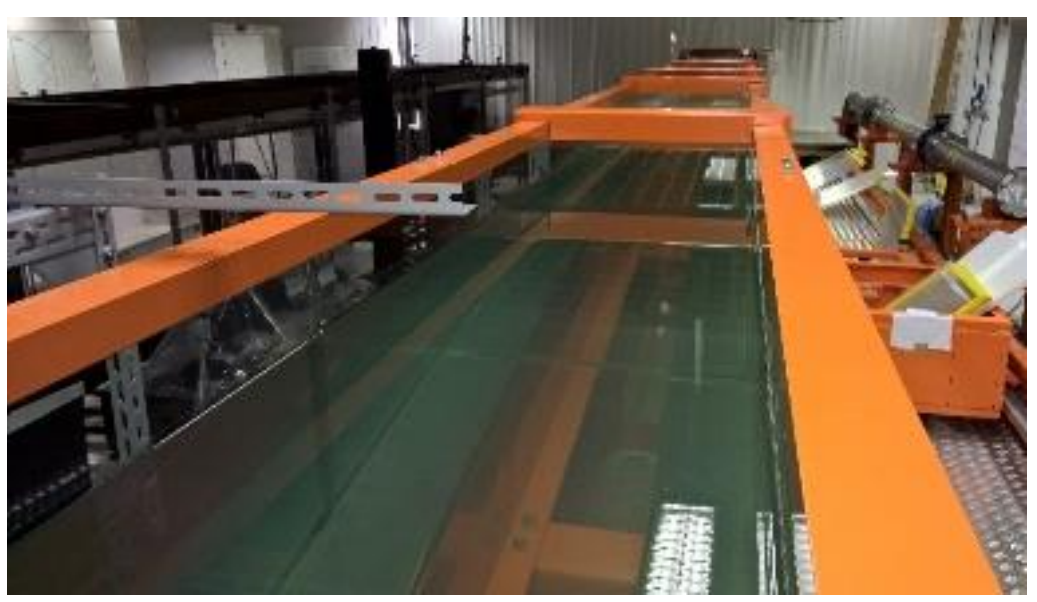

Figura 15 - Vista superior do canal de água

O canal de água possui uma seção de testes com $12 \mathrm{~m}$ de comprimento, com uma área transversal de 0,6 x 0,7 m de largura e altura, respectivamente, composta por placas de vidro de $19 \mathrm{~mm}$ de espessura, todas unidas com silicone de alta resistência. $\mathrm{O}$ fundo do canal também é composto por placas de vidro, o propósito das placas de vidro é permitir a utilização de técnicas ópticas de medição em qualquer seção do canal.

Em um dos lados do canal existe uma plataforma destinada à movimentação de um dispositivo que suporta uma mesa antivibratória para acomodação da instrumentação a ser utilizada no canal. Uma bomba centrífuga, apresentada na Figura 16, de $30 \mathrm{~kW}$ de potência impõe o movimento da água no canal. A vazão máxima é de $648 \mathrm{~m}^{3} / \mathrm{h}$, monitorada por um medidor eletromagnético (calibrado na faixa de vazão de 57 a $1.761 \mathrm{~m}^{3} / \mathrm{h}$ ), possibilitando trabalhar em regimes de 
velocidade de até $0,5 \mathrm{~m} / \mathrm{s}$. Na seção de entrada do canal, direcionadores e retificadores de escoamento foram instalados (Figura 16), além de duas telas de aço inoxidável, destinadas para a homogeneização do escoamento.
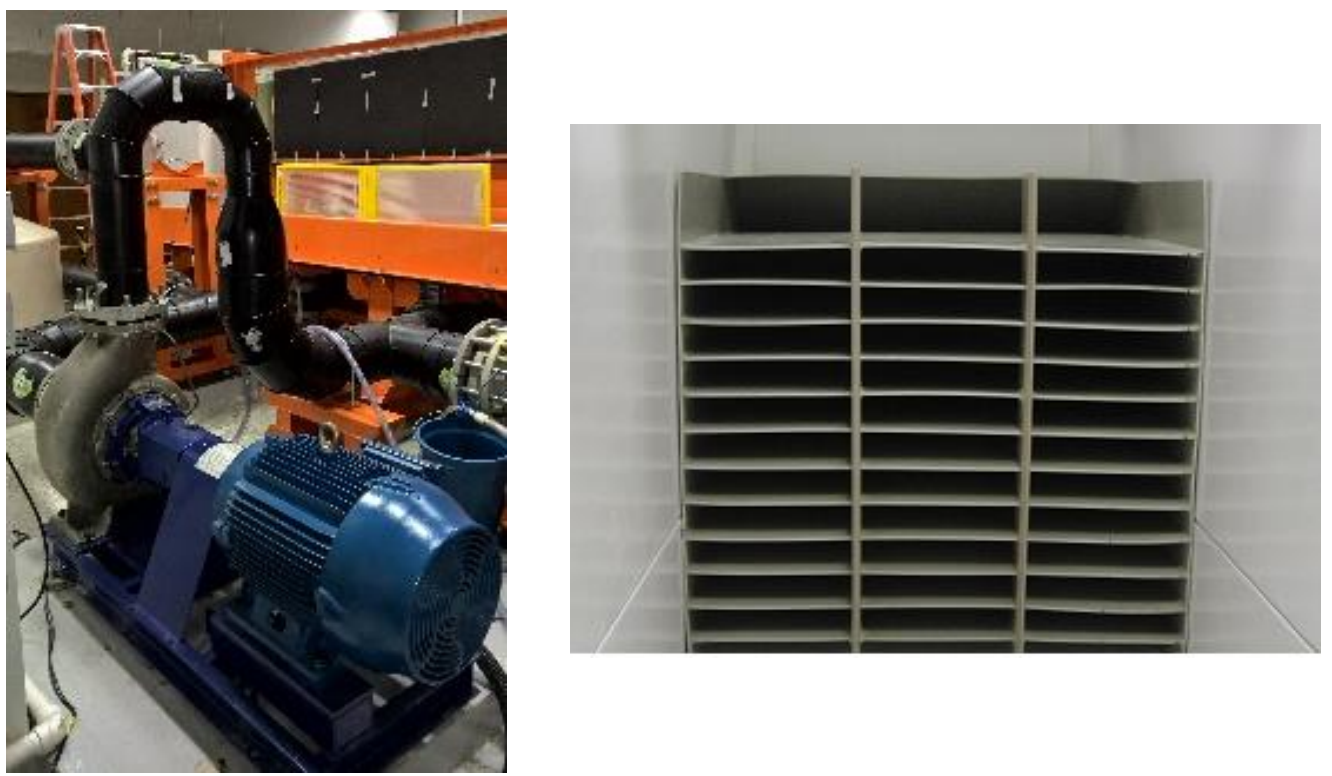

Figura 16 - Bomba centrífuga (esquerda) e retificadores de escoamento (direita)

\section{2.}

\section{Técnicas e equipamentos de medição}

Nesta seção, são apresentadas as técnicas de medição empregadas neste trabalho. São descritas duas técnicas de medição, a Velocimetria por Imagens de Partículas e a técnica de detecção de sombras. A combinação das duas técnicas permite que o escoamento seja caracterizado detalhadamente e informações relevantes do escoamento da fase dispersa sejam extraídas. A técnica PIV permite avaliar em uma área relativamente grande o campo de velocidades do escoamento.

\subsection{1.}

\section{Velocimetria por Imagem de Partícula}

A Velocimetria por Imagem de Partícula compreende uma técnica óptica de medição com a qual se pode identificar o campo de velocidades do escoamento. A Figura 17 mostra uma típica configuração do sistema PIV, que consiste em um plano de laser pulsátil e sincronizado com câmeras de alta velocidade. A luz do 
laser incide numa região de interesse no escoamento que contém partículas traçadoras. Estas partículas devem possuir densidade próxima à do fluido onde estão inseridas (assume-se que elas adquirem a mesma velocidade da partícula fluida e seguem a trajetória do escoamento). Além disso, estas partículas devem refletir a luz do laser, de modo que a câmera obtenha imagens bem definidas.

Ao longo do intervalo de tempo de pulso do laser, a luz refletida pelas partículas traçadoras é capturada pelas câmeras. Pares de imagens das partículas são adquiridos para que o deslocamento das partículas possa ser identificado e, por conseguinte a velocidade do escoamento, caso o intervalo entre as imagens seja conhecido.

Conhecida a posição da partícula no tempo $t$, do primeiro pulso de laser e a posição da partícula $t^{\prime}$, do segundo pulso de laser, é possível determinar a velocidade da partícula:

$$
\vec{V}=\frac{\overrightarrow{\Delta S}}{\Delta t}
$$

Onde $\overrightarrow{\Delta S}$ é a variação da posição da partícula entre os dois pulsos de laser e $\Delta t$ o intervalo de tempo entre os dois pulsos de laser $\left(t^{\prime}-t\right)$.

O sistema de avaliação do PIV divide as imagens captadas pela câmera em pequenas subáreas chamadas "janelas de interrogação". O vetor deslocamento das partículas traçadoras entre a primeira e a segunda iluminação é determinada para cada janela de interrogação por meio de métodos estatísticos.

O deslocamento de grupos de partículas é estimado através de ferramentas estatísticas. Uma ferramenta bastante utilizada é a correlação cruzada. Dessa forma, estima-se a magnitude e a direção do deslocamento e, consequentemente, do vetor velocidade de um grupo de partículas. Aplicando-se essa técnica em várias janelas de interrogação das imagens é possível obter uma medida do campo instantâneo de velocidades do escoamento.

O uso do sistema de Velocimetria por Imagem de Partícula possui algumas vantagens em relação a outras técnicas de medição de velocidade de fluidos, dentre elas, o fato de ser considerada uma técnica não intrusiva. Embora partículas traçadoras sejam adicionadas ao escoamento, respeitando-se o tamanho e a densidade destas, a interferência no escoamento pode ser desprezível. A técnica se 
caracteriza, também, por permitir a medição de um campo de velocidades. Entretanto, apesar de apresentar uma boa resolução espacial, sua resolução temporal é limitada devido a restrições tecnológicas (Jahanmiri, 2011), associadas principalmente às fontes de iluminação.

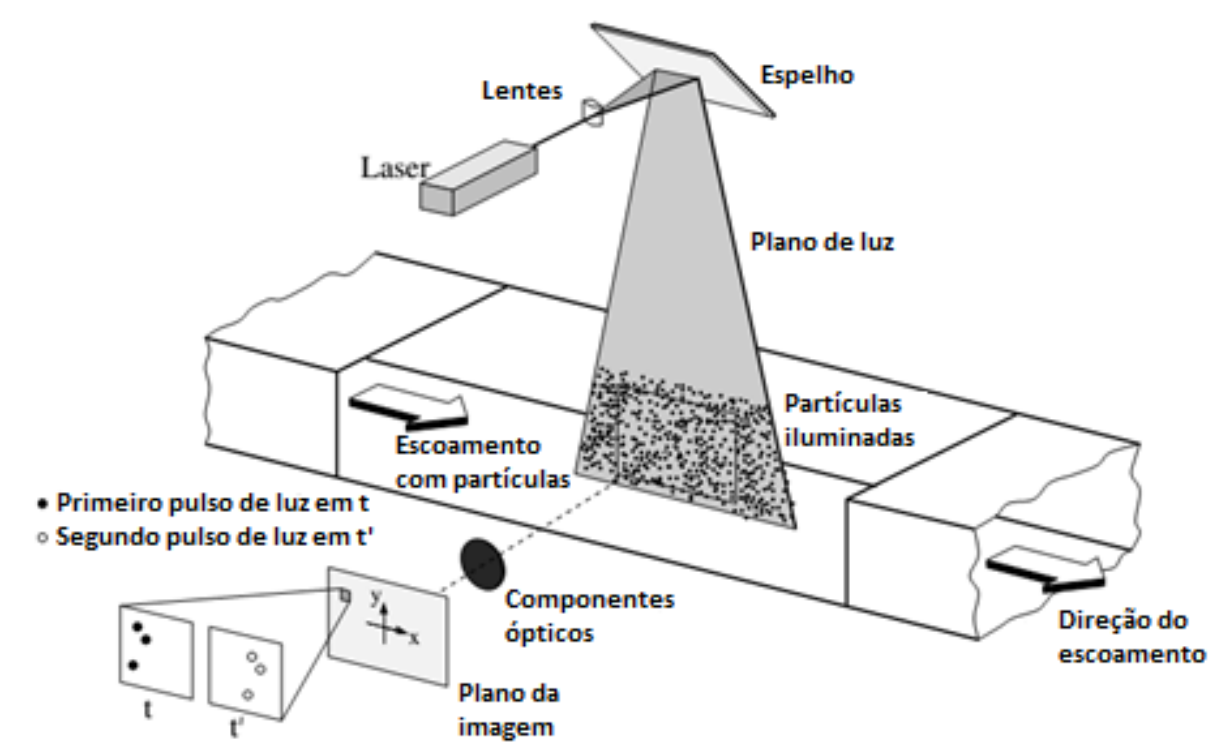

Figura 17 - Configuração de um sistema PIV (Raffel, et al, 2007)

\subsubsection{1. \\ Partículas traçadoras}

A inserção de partículas no meio fluido é necessária para a utilização da técnica PIV, principalmente quando não há partículas naturais dispersas em quantidade suficiente. Além disso, é necessário que as partículas possam refletir grande parte da luz incidida pelo laser.

A técnica PIV mede a velocidade indireta do escoamento, pois determina a velocidade da partícula ao invés da velocidade do fluido. Porém, considerando que as partículas traçadoras possuem massa específica próxima à do fluido de trabalho e pequeno tamanho (pouca inércia), considera-se que não há deslizamento entre o fluido e as partículas e, consequentemente, a velocidade da partícula é a mesma do fluido. Para garantir que essa condição seja satisfeita, utiliza-se partículas de pequeno diâmetro e com densidade próxima a do fluido.

As partículas utilizadas neste trabalho: Rodamina (PMMA-Rhodamine BParticles), presentes em suspensão aquosa de concentração 100 g/ $400 \mathrm{ml}$ e com 
tamanho compreendido na faixa de 20 a $50 \mu \mathrm{m}$; e partículas esféricas ocas de vidro revestidas de prata. As partículas fluorescentes foram utilizadas quando bolhas de gás estavam presentes nas imagens, enquanto que as de prata foram usadas quando somente a fase líquida era observada nas imagens.

\subsubsection{2.}

Fonte de luz (Laser)

Os lasers são amplamente utilizados nos sistemas PIV, principalmente por causa da capacidade de emissão de luz monocromática com alta densidade de energia em um intervalo curto de tempo. Além disso, feixes de laser podem facilmente ser manipulados com lentes para criar planos de luz para iluminar as partículas na região de interesse do escoamento.

A duração de cada pulso de laser é da ordem de nano segundos. Como consequência, uma partícula se deslocando em alta velocidade no escoamento é "congelada" durante a exposição possibilitando uma imagem minimamente borrada. Os lasers pulsados são adequados para o PIV porque liberam toda potência do laser exatamente no instante desejado e permitem uma sincronização precisa.

O sistema de laser utilizado nos experimentos foi o da LaVision, que inclui um laser "Big Sky Ultra PIV 120, 2 x $120 \mathrm{~mJ} /$ pulse at $532 \mathrm{~nm}, 15 \mathrm{~Hz}$ pulse rate, mini ICE power supplies" do tipo Nd:YAG (neodymium-doped yttrium aluminium garnet; $\left.\mathrm{Nd}: \mathrm{Y}_{3} \mathrm{Al}_{5} \mathrm{O}_{12}\right)$.

\subsubsection{3. \\ Câmeras de alta resolução}

Para a captura das imagens utiliza-se, normalmente, câmeras de alta resolução da ordem de alguns Mega pixels. Neste trabalho utilizou-se uma câmera com sensor CCD, que converte a luz (fótons) em carga elétrica (elétrons). No sensor da câmera existe uma matriz retangular de sensores individuais. Cada elemento do sensor é chamado de pixel. A Figura 18 apresenta a configuração de uma câmera CCD. A câmera utilizada neste trabalho foi uma "FlowSense 4M Mk2" com resolução de 2048 x 2048 pixels e tamanho de pixel igual 7,4 microns. 


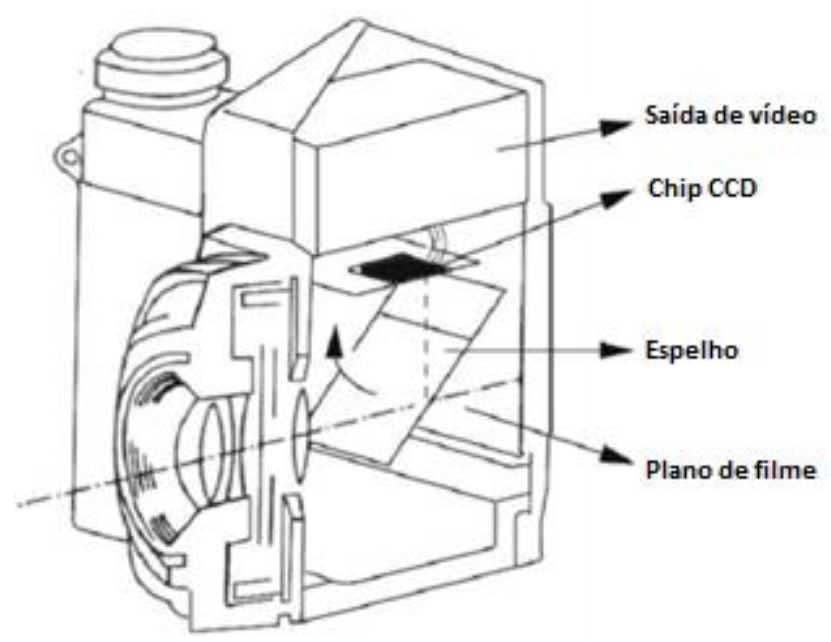

Figura 18 - Câmera CCD (Raffel, et al, 2007)

\subsubsection{4.}

\section{Cálculo dos campos vetoriais de velocidade}

O principal método de cálculo dos campos vetoriais é a correlação cruzada. Neste caso, as "janelas de interrogação" da primeira e da segunda imagem são representadas por uma função de intensidade de pixels $I(m, n)$ e $I^{\prime}(m, n)$ respectivamente, como mostra a Figura 19. O vetor deslocamento dos grupos de partículas de cada janela pode ser calculado considerando a existência de uma função de transferência $d(m, n)$ entre a imagem inicial e a imagem final. A Figura 19 ilustra o processo. 


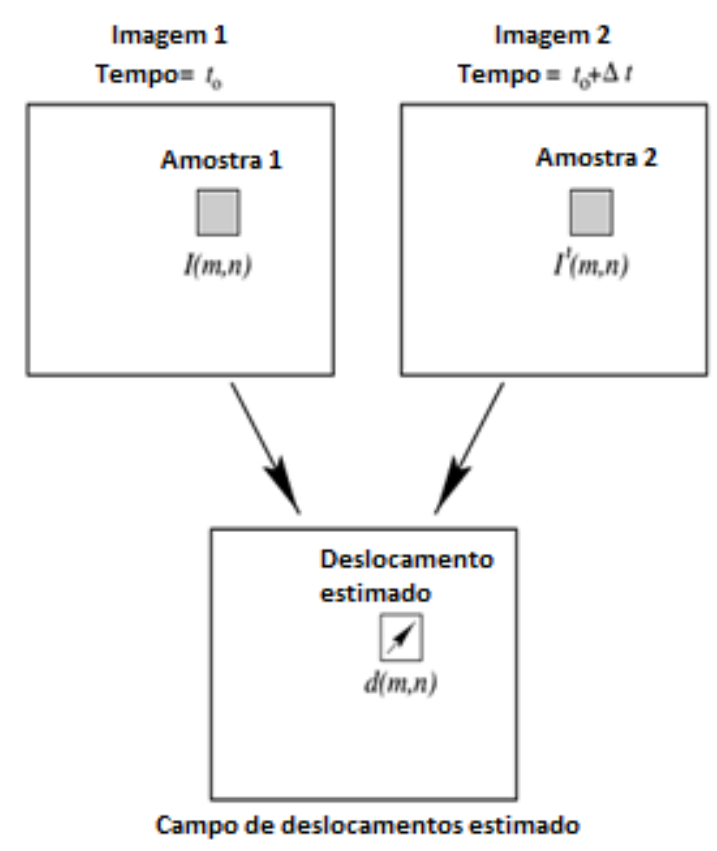

Figura 19 - Funções associadas às janelas de interrogação nas imagens dos instantes inicial $\left(t_{0}\right)$ e final $\left(t_{0}+\Delta t\right)$ (Zotin, 2009)

A função a ser calculada no desenho esquemático é a $d(m, n)$. Em linhas gerais, o método estatístico de correlação cruzada equivale à geração de uma série de deslocamentos na segunda imagem e, em seguida, na sobreposição da imagem deslocada à primeira imagem. $\mathrm{O}$ deslocamento que gerar uma melhor correlação entre as imagens sobrepostas corresponde ao deslocamento mais provável das partículas. Na função de correlação esse deslocamento ótimo é visto como um pico de amplitude, conforme ilustrado na Figura 20. 


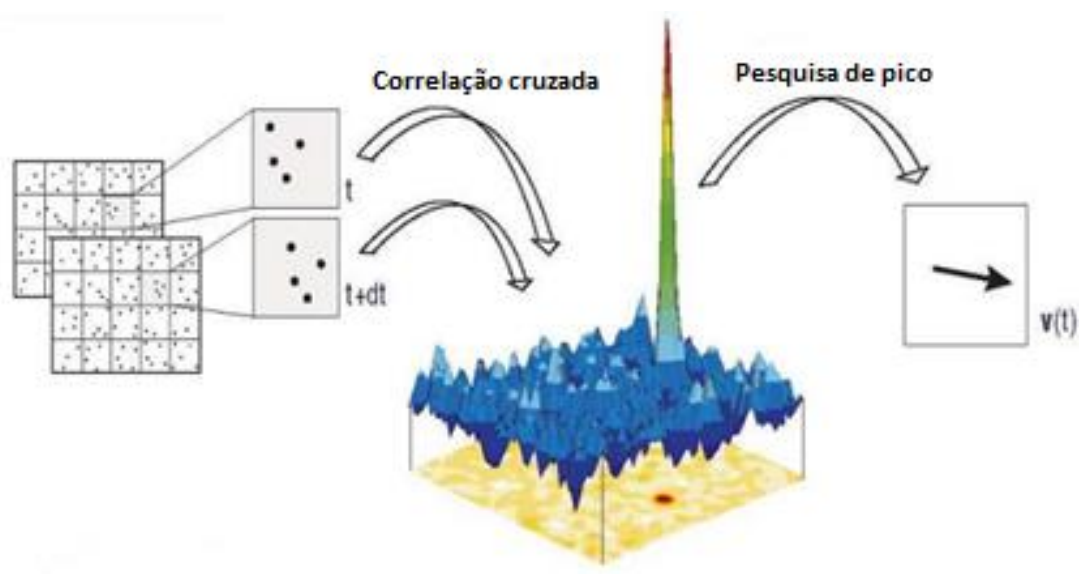

Figura 20 - Pico gerado no método de cálculo de correlação cruzada (Zotin, 2009)

Existem outros dois métodos de cálculo dos vetores de velocidade, o de auto correlação e correlação adaptativa. O método de auto correlação, diferentemente da correlação cruzada, é aplicado em somente uma imagem que contém as partículas capturadas no tempo $t$ e no tempo $t+\Delta t$. Para o cálculo dos vetores de velocidade, o operador deve indicar o sentido do escoamento e a imagem é copiada, sobreposta e deslocada em diferentes posições no sentido do escoamento da imagem original.

A correlação adaptativa difere dos outros dois métodos pela capacidade de refinamento da janela de interrogação, porém a base de cálculo é a mesma da correlação cruzada (Zotin, 2009). Inicialmente é escolhido o tamanho da janela de interrogação e o refinamento é a possibilidade de processar os dados aquisitados utilizando-se janelas de interrogação diferentes da usada inicialmente. Por exemplo, o usuário pode iniciar o cálculo com uma janela de interrogação de 128 x 128 pixels com três passos de refinamento, sendo assim, o segundo passo será feito com uma janela de 64 x 64 e a última com 32 x 32 pixels (configurações possíveis com a utilização do software DynamicStudio, pertencente à Dantec Dynamics S.A.). Quanto menor o tamanho das janelas, maior será a quantidade de vetores no resultado final. A vantagem de se utilizar as diferentes janelas de interrogação entre os pares de imagens é a possibilidade de se capturar as eventuais partículas que tenham saído da primeira janela. Assim, aumenta-se os vetores válidos sem haver a necessidade de se aumentar a densidade de partículas no fluido. 


\subsection{2.}

\section{Técnica de detecção de sombras}

O princípio de medição da técnica de deteç̧ão de sombras, tipicamente conhecida pelo nome em inglês, Shadowgraph, é baseado nas imagens das sombras dos objetos. Uma fonte de luz, normalmente um led pulsado, é usado para iluminar uma região do escoamento em que estão presentes partículas ou bolhas. Do lado oposto ao do led, posiciona-se uma câmera de alta velocidade sincronizada com os pulsos do led. As imagens obtidas pelo sistema (Figura 21) são compostas pela sombra das bolhas, partículas ou qualquer objeto opaco. Posteriormente, essas imagens são analisadas com uso de algoritmos de detecção de contorno para extrair as informações do formato, tamanho e velocidade do objeto.

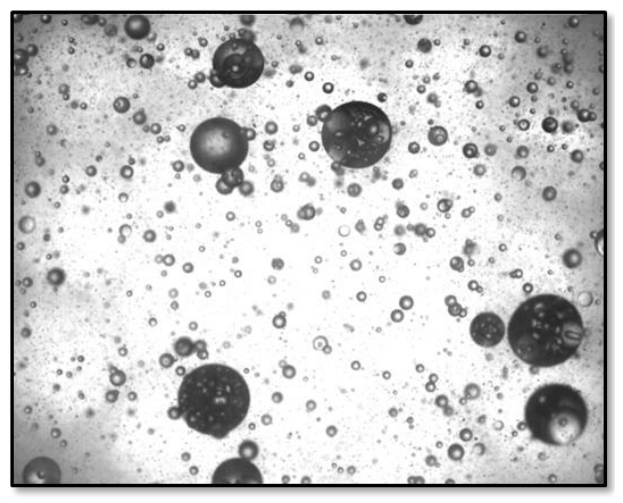

Figura 21 - Típica imagem obtida da técnica de detecção de sombras (extraído de SeparadoresCompactos (2016))

\section{3.}

\section{Montagem do sistema PIV no canal de água}

O sistema PIV 2D (sistema utilizando somente uma câmera) foi o escolhido para os experimentos na bancada, já que as principais componentes de velocidade do sistema a serem investigadas se concentravam principalmente na direção longitudinal e vertical do canal de circulação de água. Uma estrutura de aço foi montada para servir de suporte à câmera e dois posicionadores manuais foram fixados nesta mesma estrutura para a movimentação da câmera nos eixos vertical e horizontal, conforme mostrado na Figura 22. 


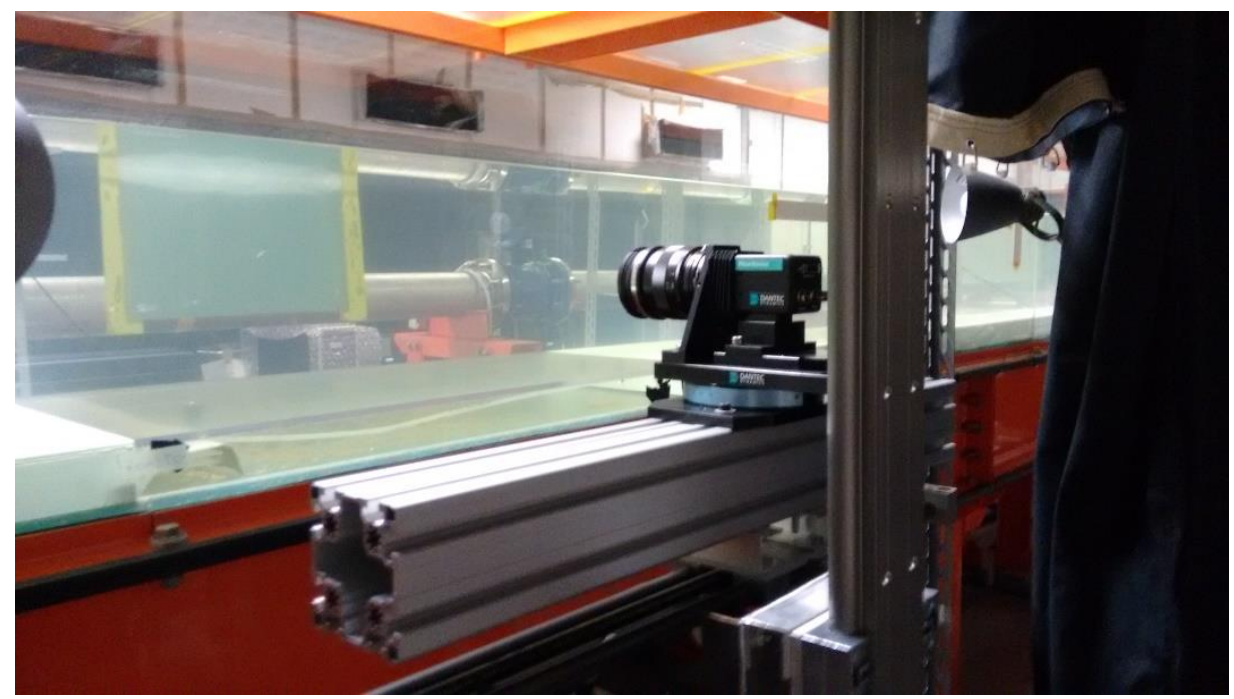

Figura 22 - Câmera CCD alinhada com o canal de circulação de água

Para que fosse possível iluminar toda a região da pluma de bolhas, o laser foi posicionado na parte inferior do canal de circulação da água de forma que o feixe de emissão ficasse inclinado em relação a base do canal (Figura 23). Desta maneira, reduz-se o efeito de sombras na região de medição, causadas pelo bocal de injeção de gás, conforme apresentado na Figura 24.

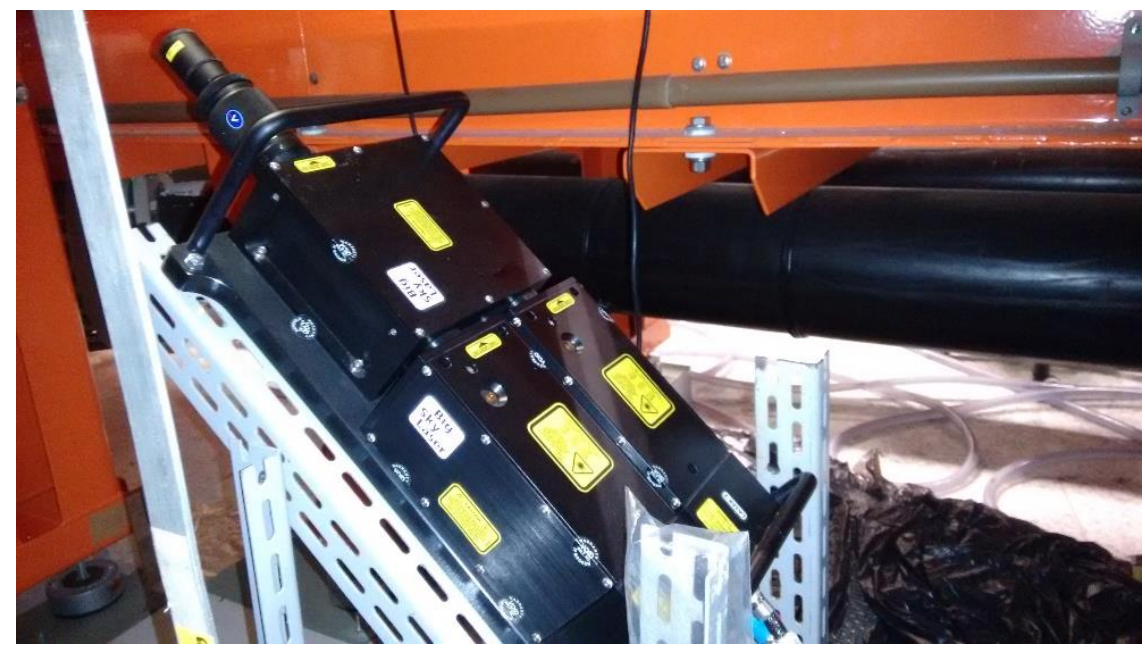

Figura 23 - Laser alinhado com o canal 


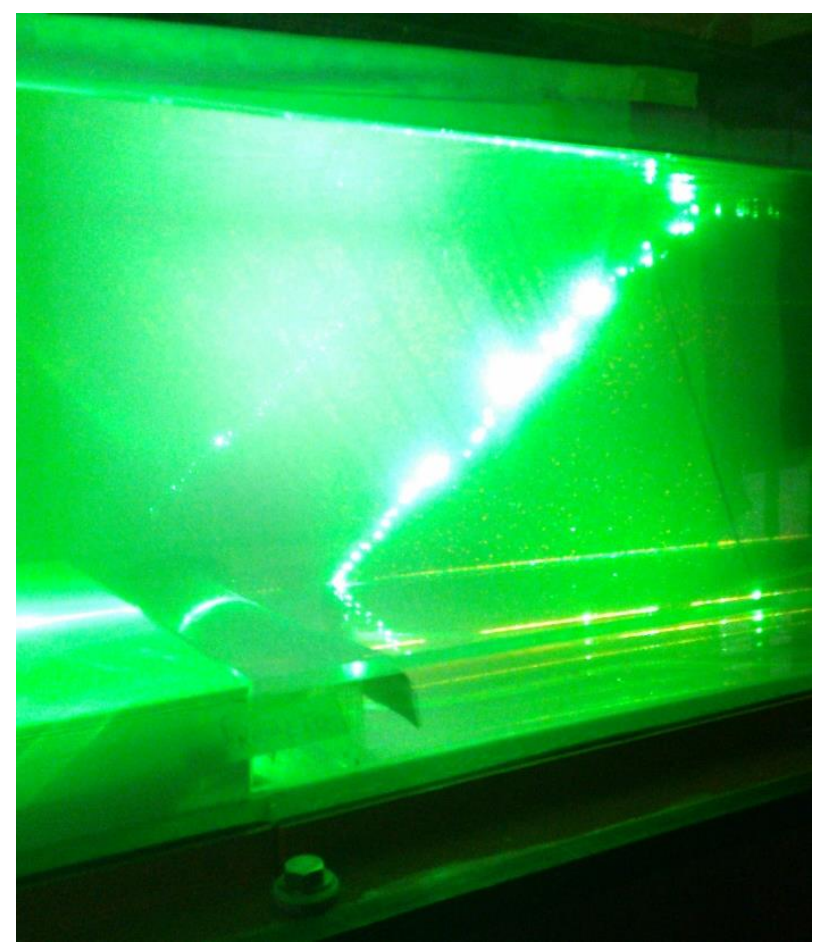

Figura 24 - Emissão do plano de laser

A câmera usada no sistema PIV precisa ser calibrada com relação as dimensões físicas da região da imagem. A conversão de pixels das imagens para $\mathrm{mm}$, foi feita colocando-se um alvo de calibração na região de escoamento. $\mathrm{O}$ alvo consiste em uma placa plana com várias marcações onde as distâncias entre os pontos de marcação são conhecidas. O alvo foi inserido na região do escoamento com a presença do fluido e, para que o dispositivo ficasse alinhado com o plano de luz emitido pelo laser, o feixe de iluminação iluminou os planos dos pontos do alvo de calibração, como ilustrado na Figura 25. A partir das imagens de calibração obteve-se o fator de conversão de pixels da imagem para mm no plano do objeto, que foi de aproximadamente $0,095 \mathrm{~mm} /$ pixel. 


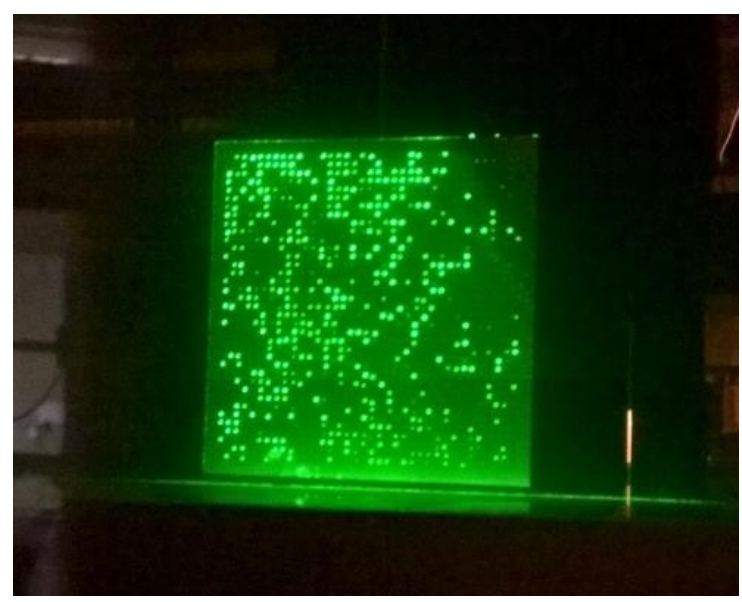

Figura 25 - Alvo iluminado pelo laser

\subsection{1.}

\section{Adequação do Led no canal de água}

Uma fonte de iluminação pulsada, do tipo Led, foi adaptada para a utilização combinada com a técnica PIV. Para que a luz do led estivesse presente nas imagens, foi necessário posicioná-lo do lado oposto do canal ao que foi colocada a câmera. Para a movimentação do sistema de Led's foi utilizado um sistema de posicionadores de três eixos, que fixado sobre uma mesa de isolação de vibração, como mostra a Figura 26.

Para que a luz emitida pelo led não ficasse concentrada na região central das imagens, utilizou-se um difusor de luz que foi fixado na parede lateral do canal de água. O difusor utilizado é composto por uma combinação de duas folhas de papel, sendo uma do tipo TNT e outra de papel manteiga. Assim, foi possível difundir a luz da fonte de led e criar uma iluminação de fundo quase uniforme nas imagens. 


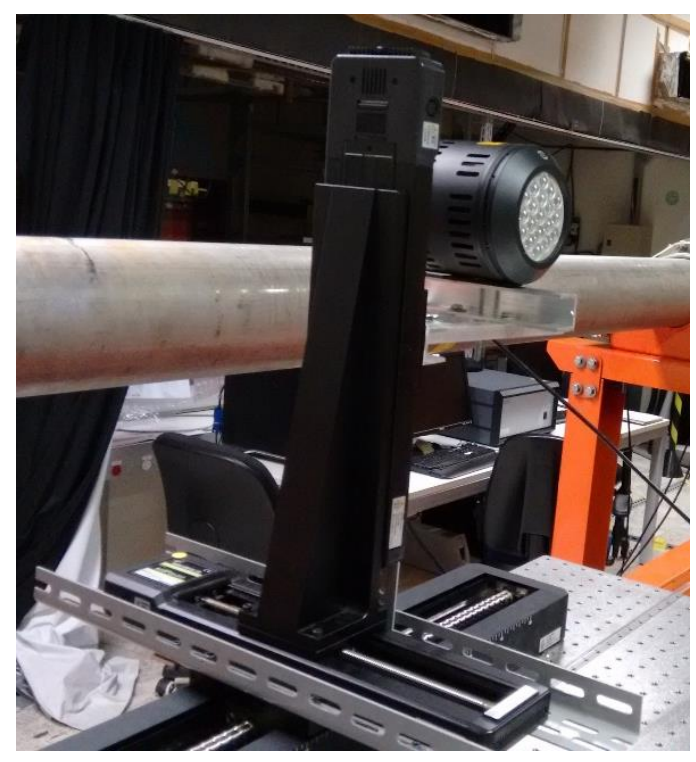

Figura 26 - Suporte de posicionadores para o led

\subsection{2.}

\section{Sincronização Led-Laser}

A aquisição das imagens a partir da combinação das técnicas PIV e detecção de sombra demanda uma sincronização das luzes do laser e do led com a aquisição das imagens. Como os dois sistemas de iluminação são independentes, foi necessário elaborar um método para sincronizar os pulsos das luzes do laser e do led a fim de se iluminar as imagens no mesmo instante de tempo. O procedimento adotado é baseado no trabalho de Nogueira et al. (2003).

Um circuito de sincronização foi construído para esta etapa. O primeiro passo foi definir como seria feita a lógica do sistema. O laser do sistema PIV possui duas cavidades e a luz do primeiro pulso ilumina somente o primeiro quadro da câmera e, consequentemente, a luz do segundo pulso ilumina o segundo quadro. Para garantir que a luz do led crie uma iluminação de fundo nos dois quadros, é necessário que para cada pulso do laser haja também um pulso do led.

Para sincronização dos pulsos das fontes de iluminação utilizou-se uma porta lógica digital do tipo OR (modelo HD74LS32). A escolha do circuito integrado do tipo OR foi baseada na lógica do problema, onde os pulsos de cada uma das cavidades de laser devem disparar um pulso do led. Isso porque o led possui somente uma porta de sincronização. O desenho esquemático do circuito integrado (CI) utilizado é apresentado na Figura 27. A alimentação do circuito provém de 
cabo USB, ligado a um computador. Os conectores BNC destinados às entradas e saída do sinal foram fixados em uma caixa de plástico, como mostrado na imagem da Figura 28. Dois conectores foram usados como entrada de sinal (um para cada laser) e o outro para a saída do sinal (LED). Todos os conectores BNC também foram devidamente aterrados.

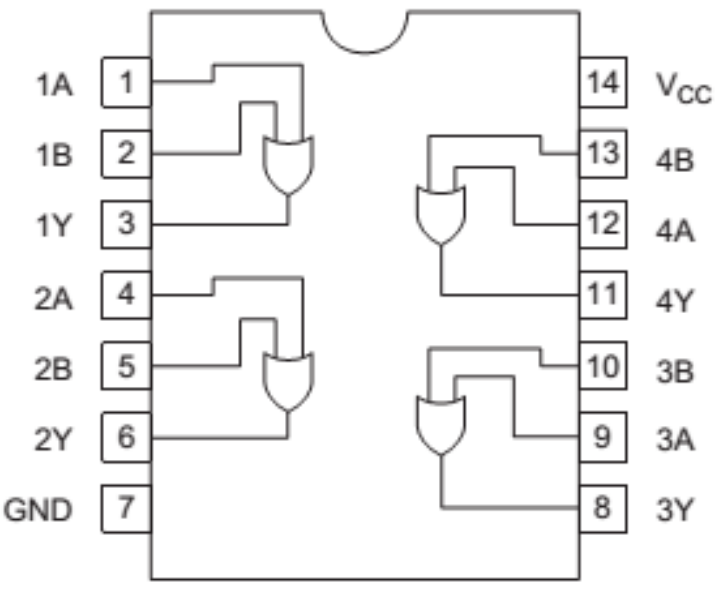

(Top view)

Figura 27 - Desenho esquemático dos pinos do CI

Uma vez pronto o sincronizador (Figura 28), foi feita a escolha do sinal dos lasers responsáveis por fornecer o gatilho para o led. Os sinais de sincronização disponíveis no laser são, o gatilho do Q-Switch ou da Flashlamp.
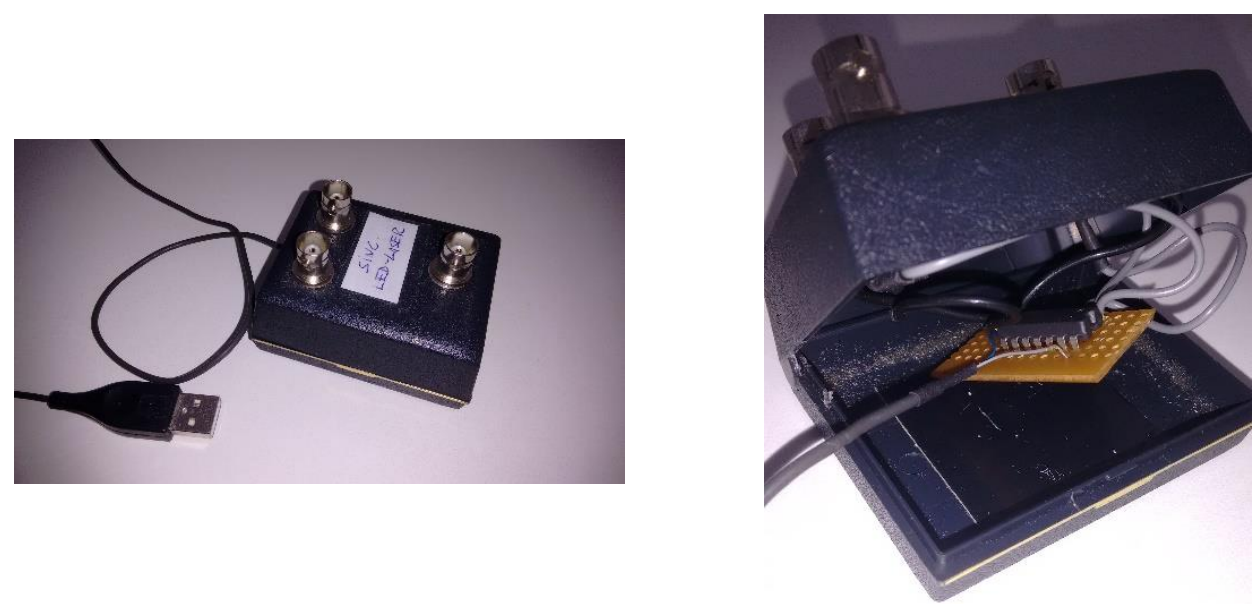

Figura 28 - Sincronizador Led/Laser 
Foram realizados testes utilizando-se em um dos casos os gatilhos dos Qswitch do laser e outro utilizando-se os gatilhos das Flashlamps para a sincronização do led. Nesses testes, foi observado que, usando o sinal do Q-Switch trigger do laser, as imagens do primeiro quadro ficaram sem a iluminação do led, enquanto que as do segundo quadro ficaram muito iluminadas. Mesmo com a alteração no tempo de exposição do primeiro quadro, não foi possível garantir a iluminação do led no primeiro quadro. Já no caso da sincronização feita com o sinal do gatilho da Flashlamp, ambos os quadros ficaram iluminados pela luz do led. Para garantir uma iluminação uniforme nos dois quadros, foi necessário aumentar o tempo de exposição do primeiro quadro de $90 \mu$ s para $200 \mu$ s. Assim, as intensidades luz nos dois quadros ficaram bem próximas. O diagrama lógico da Figura 29, auxilia no entendimento do processo.

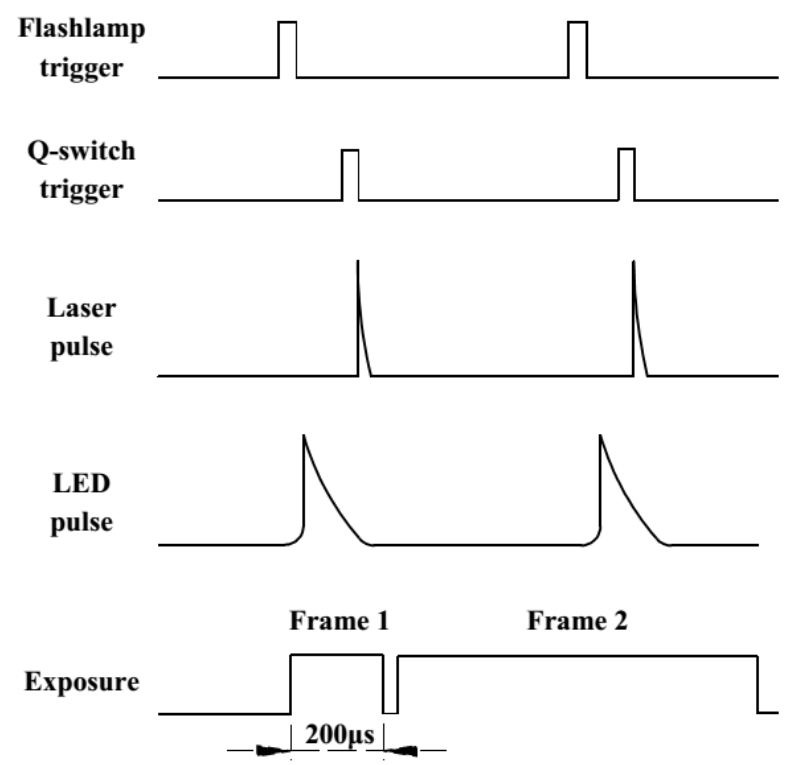

Figura 29 - Esquema de sincronização (Massari, et al. (2016))

\section{4.}

\section{Injeção de ar}

Estudos que envolvem a injeção de ar no canal de água necessitam de um sistema de injeção a partir do fundo do canal. Para viabilizar esse tipo de estudo, existe um "fundo falso", que foi confeccionado em PVC branco, e que fica instalado sobre o fundo de vidro do canal de água. O fundo de PVC permite que sejam feitos furos para que injetores de ar possam ser acoplados em determinadas posições. 
Assim, as mangueiras que levam o ar até o injetor passam por dentro do fundo falso, não interferindo no escoamento do canal. A Figura 30 mostra a passagem de mangueiras por dentro do fundo falso em uma montagem anterior a este trabalho (Garcia, 2015).

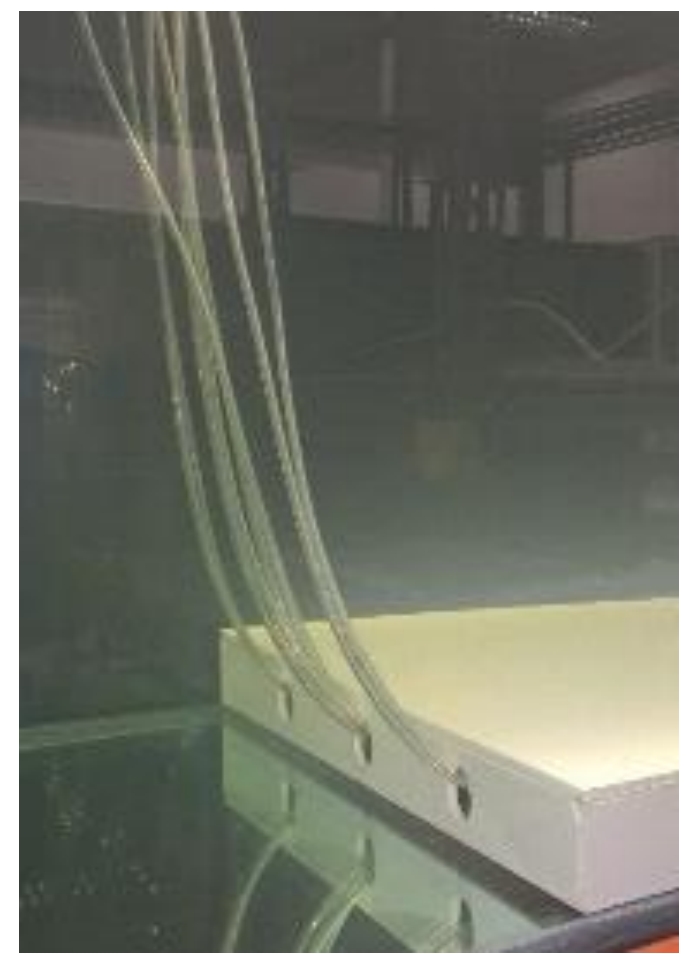

Figura 30 - Alocação das mangueiras no fundo falso (Garcia, 2015)

Apesar da grande utilidade, o fundo falso de PVC branco impossibilita a iluminação ou a visualização do escoamento por baixo do canal. Uma alternativa utilizada em trabalhos anteriores era a iluminação do escoamento pela parte de cima do canal através da superfície livre de líquido. No entanto, neste trabalho pretendese perturbar a superfície do líquido, de modo que o feixe de iluminação pode sofrer distorções devido à refração na superfície irregular, fazendo com que a luz não se mantenha uniforme na região de interesse. Para contornar este problema, parte do fundo falso foi montada em acrílico transparente, com um furo para inserção do injetor, permitindo a inserção do plano de luz do laser pela parte inferior do canal, conforme mostrado na Figura 31. 


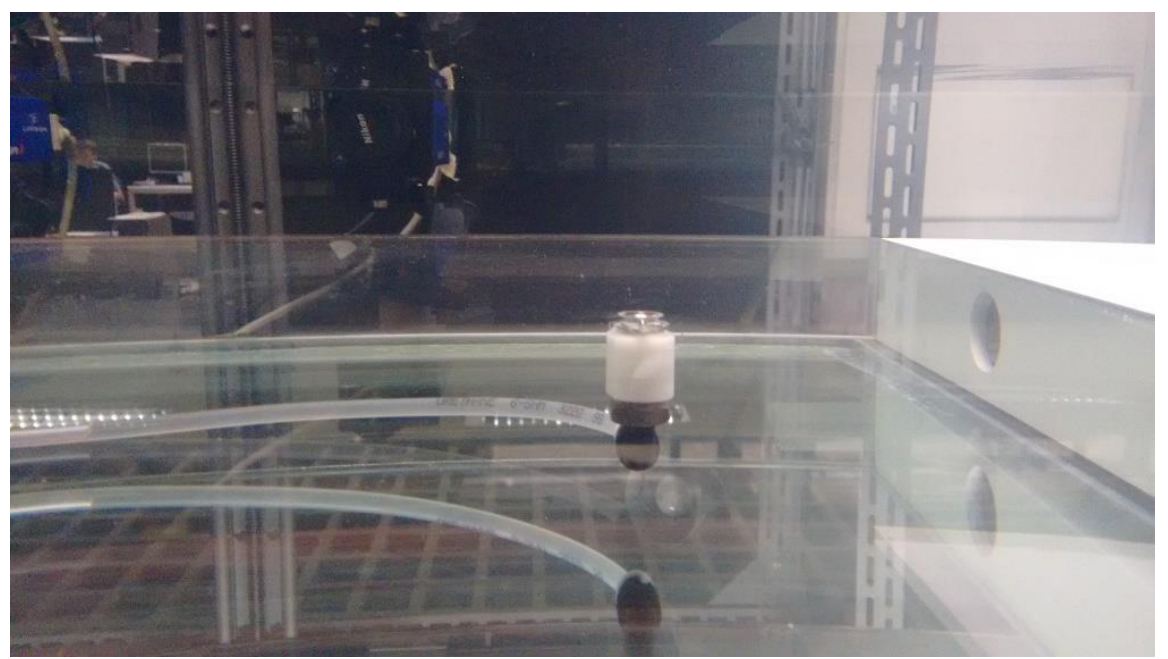

Figura 31 - Injetor de ar fixado na placa de acrílico

\section{5.}

\section{Sistema de injeção de partículas traçadoras}

Devido à reflexão de luz na interface entre gás e líquido, foi necessário utilizar partículas dopadas com corante fluorescente. Assim, comprimentos de luz refletidos pela interface gás-líquido e pelas partículas ficam diferentes e com isso é possível discernir entre eles nas imagens (Lindken e Merzkirch, 2002). Porém, devido ao grande volume de água presente no canal e ao custo das partículas fluorescentes, foi proposto o uso de dois tipos de partículas traçadoras nos experimentos. Nos estudos envolvendo somente a fase líquida foram utilizadas as esferas ocas de vidro revestidas de prata, e para os estudos que compreendiam as fases líquida e gasosa, utilizou-se partículas fluorescentes dopadas com Rodamina.

Para minimizar a quantidade de partículas de Rodamina utilizada, foi feito um sistema de injeção de partículas. O sistema consiste em um reservatório com capacidade de aproximadamente 90 litros, uma bomba do tipo helicoidal (HD15, Weatherford, Geremia ${ }^{\circledR}$ ), um medidor de vazão eletromagnético $\left(\right.$ Conaut $^{\circledR}$ ), tubos e acessórios de PVC. O reservatório foi posicionado ao lado do canal de circulação de água e, na parte inferior do reservatório um trecho reto de PVC liga a saída do reservatório na sucção da bomba. A linha de descarga da bomba segue até o medidor de vazão e continua até a parte superior do canal de água, neste ponto o tubo de acrílico de $6 \mathrm{~mm}$ é fixado verticalmente dentro do canal de água. Ao longo do tubo de acrílico foram feitos vários furos de $1 \mathrm{~mm}$, compreendendo somente a região que está submersa na água. 
Primeiro, o reservatório é preenchido com alguns litros de água filtrada e, em seguida são adicionadas as partículas (Figura 32). A solução é então agitada para homogeneizar as partículas. Em seguida, a bomba é ligada e a vazão monitorada no medidor eletromagnético. A solução de partículas é elevada até a parte superior do canal de água e sai pelos pequenos furos ao longo do tubo de acrílico, encontrando a corrente principal do canal. Este processo só é realizado quando estão sendo feitas as aquisições das imagens com o sistema PIV, controlando a quantidade de partículas a serem adicionadas no canal.

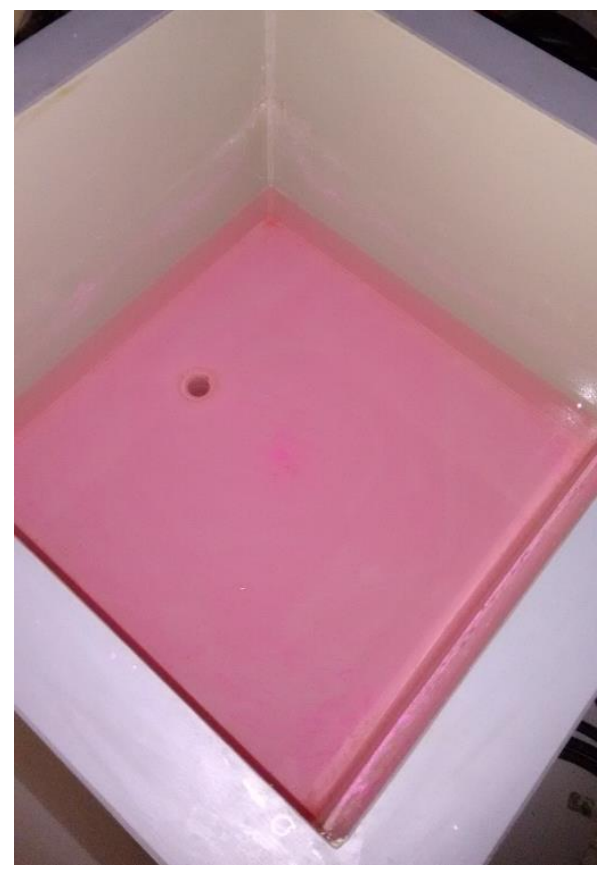

Figura 32 - Reservatório com solução de Rodamina

Uma vez que um cilindro está inserido em um escoamento, a perturbação gerada pela presença do objeto pode influenciar no escoamento à jusante. Dependendo do número de Reynolds do escoamento, a esteira do cilindro pode ser laminar ou turbulenta, influenciando na distribuição das partículas no canal. Para as faixas de velocidade de trabalho no canal, o número de Reynolds para o escoamento ao redor do cilindro está compreendido na faixa de 900 a 1.800 . Comparando-se esta faixa de Reynolds com a literatura (Figura 33), pode-se perceber que a esteira teórica apresenta uma distribuição dos vórtices de Von Kármán. 


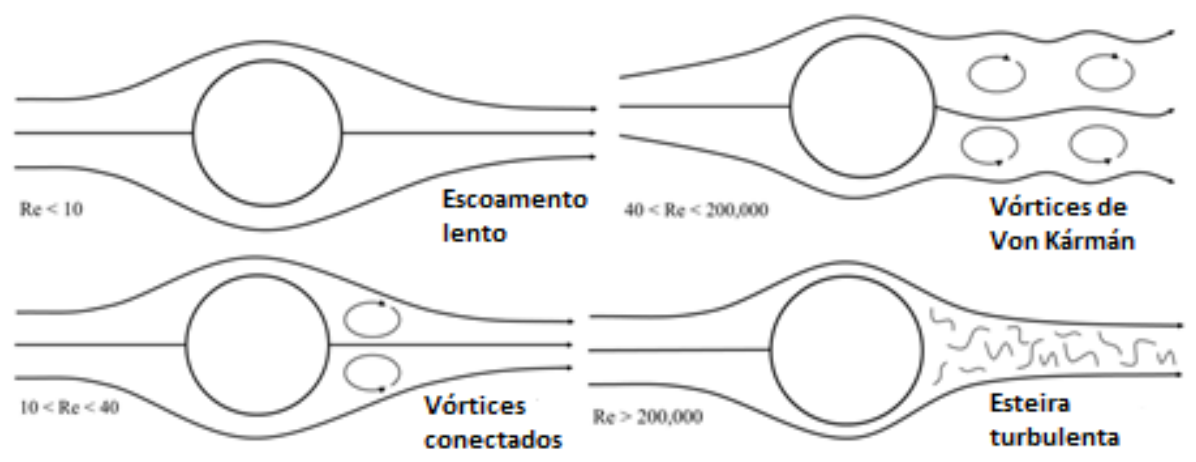

Figura 33 - Variações dos perfis de esteiras para um cilindro em diferentes números de Reynolds (extraído de ET4U.org (2016))

Para a verificação da esteira, um teste prático de visualização por corante foi realizado (Figura 34). Um corante do tipo alimentício foi misturado com água e injetado com uma seringa diretamente no tubo de acrílico. A partir do teste, foi constatado que a distribuição das partículas ao encontrar a corrente principal do canal fica concentrada em alguns pontos devido ao desprendimento de vórtices de Von Kármán ao redor do cilindro.

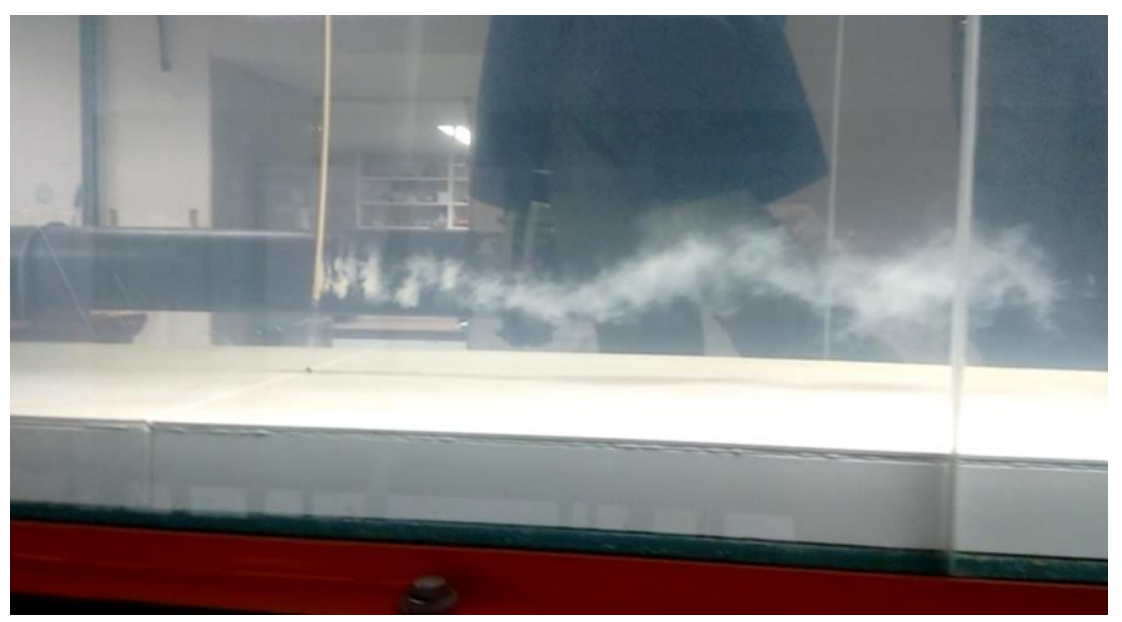

Figura 34 - Teste de visualização com corante

Considerando que uma distribuição ideal das partículas seria alcançada a partir da redução do número de Reynolds, o único parâmetro a ser alterado para reduzir este número e trabalhar na faixa de regime de Stokes seria o diâmetro do tubo de acrílico. Porém, para alcançar um número de Reynolds menor do que 40, o diâmetro do novo tubo teria de ser igual ou menor do que $1,3 \cdot 10^{-4} \mathrm{~m}$, o que é 
praticamente impossível de se obter. A fim de solucionar esta dificuldade, foi adquirida uma chapa plana fina de aço inoxidável de 6 por $40 \mathrm{~cm}$. Esta chapa foi dobrada de modo que ela ficasse em formato de "gota". O tubo de acrílico é então colocado dentro da dobra da chapa, de forma que a chapa envolva o tubo. Os pequenos furos do tubo ficam posicionados de frente para a fenda da dobra da chapa, permitindo a saída das partículas no escoamento do canal. Assim, o escoamento ao redor do perfil de "gota" se difere do escoamento ao redor de um cilindro, se tornando laminar e, consequentemente, livre dos efeitos dos vórtices de Von Kármán. A Figura 35 mostra a chapa inoxidável dobrada envolvendo o tubo de acrílico.

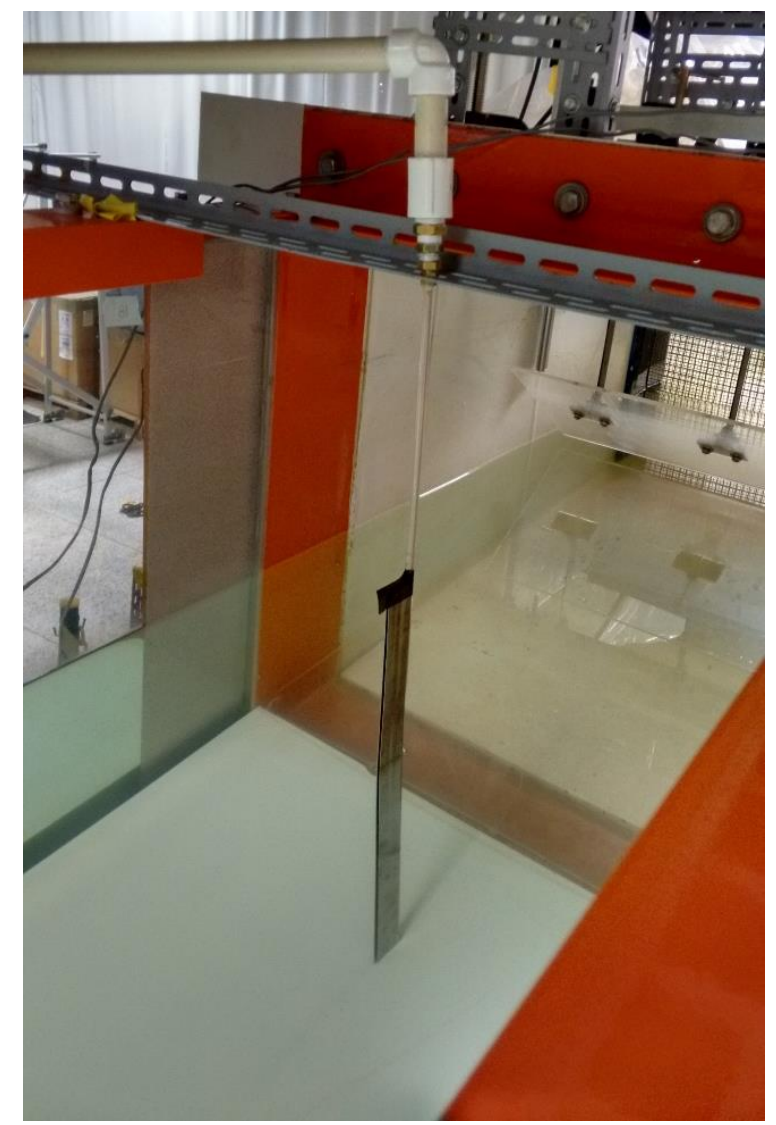

Figura 35 - Injetor de partículas

\subsection{1.}

\section{Partículas fluorescentes em escoamento bifásico}

A utilização das partículas fluorescentes, juntamente com a combinação das técnicas PIV e a técnica por detecção de sombras, tem grande importância na 
investigação de escoamentos bifásicos. Para este trabalho, em particular, é possível demonstrar a importância do uso da Rodamina com base no diagrama da Figura 36. O laser emite a luz com um comprimento de onda igual a $532 \mathrm{~nm}$, enquanto que o led emite em aproximadamente $675 \mathrm{~nm}$. Ao iluminar a região de interesse, as partículas fluorescentes presentes no escoamento dispersam a luz na faixa de 555 a $585 \mathrm{~nm}$ e as bolhas de ar dispersam a luz no mesmo comprimento de onda da luz do laser, em $532 \mathrm{~nm}$. Utilizando um filtro passa alta de $570 \mathrm{~nm}$ na lente da câmera, é possível bloquear os comprimentos de onda abaixo de $570 \mathrm{~nm}$, permitindo que somente as luzes emitidas pelo led e dispersada pelas partículas cheguem ao sensor CCD da câmera. Assim, as imagens serão constituídas pelas partículas traçadoras, pela iluminação do led e regiões de sombras onde existem bolhas de ar.

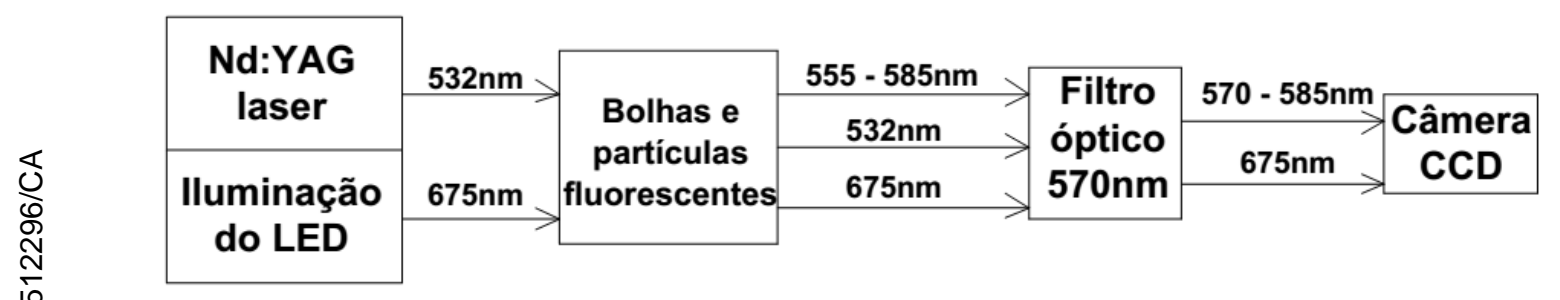

Figura 36 - Princípio da combinação das técnicas PIV/Shadowgraph 


\section{4 \\ Projeto e construção de um gerador de ondas}

Neste capítulo são apresentados alguns conceitos teóricos de propagação de ondas na água. Algumas abordagens acerca de mecanismos utilizados para geração de ondas são discutidas. Ao final deste capítulo, é feita uma descrição do mecanismo utilizado para a geração de ondas e sincronização com a aquisição dos dados.

\section{1.}

\section{Conceitos Básicos de Ondas}

A distância horizontal correspondente ao período da onda, corresponde ao comprimento de onda $(\lambda)$. A inclinação da onda é dada pela razão da altura da onda $(H)$ pelo comprimento de onda:

$$
I_{o}=\frac{H}{\lambda}
$$

De acordo com Thurman e Trujillo (1997), ondas com inclinação maior que 1/7 tendem a se quebrar pois se tornam mais íngremes e são incapazes de se sustentar. Essa razão determina a máxima altura da onda. No presente trabalho, buscou-se avaliar o efeito de ondas com inclinações menores que 1/7.

O tempo necessário para que um comprimento de onda passe por uma posição fixa no espaço corresponde ao período da onda $(T)$. A frequência $(f)$ é definida como sendo o inverso do período.

$$
f=\frac{\omega}{2 \pi}=\frac{1}{T}
$$


Onde $\omega$ é a frequência angular. O número de onda, representado por $k$, é o número de comprimentos de onda por unidade de distância e é obtido pela expressão:

$$
k=\frac{2 \pi}{\lambda}
$$

\subsection{1. Movimento Orbital}

À medida em que a onda se movimenta, a água transmite a energia se movendo em uma trajetória circular. Este movimento é chamado de "movimento orbital" (Dean e Darlymple, 1991).

O movimento de um objeto flutuando nas ondas revela que as ondas não se movem somente para cima e para baixo, mas também, um pouco para frente e para trás com cada onda sucessiva. A Figura 37 mostra a movimentação de uma partícula durante a passagem de um período de onda. A trajetória dessa partícula é descrita por um movimento circular.

De acordo com a Figura 37, a órbita circular de um objeto circulando na superfície tem o diâmetro equivalente à altura da onda $(H)$. A figura também mostra que o movimento circular orbital se dissipa logo abaixo da superfície. Em uma determinada profundidade abaixo da superfície, a órbita circular pode se tornar tão pequena que o movimento, nesse caso, é desprezível. Esta profundidade é chamada de "base da onda", e é igual à metade do comprimento de onda $(\lambda / 2)$ medido a partir do nível normal de água. Somente o comprimento de onda controla a profundidade da base da onda, portanto, quanto maior o comprimento de onda, mais profunda será o efeito da onda.

A redução do movimento orbital com a profundidade tem muitas aplicações práticas. Por exemplo, submarinos podem evitar os efeitos das ondas oceânicas simplesmente submergindo abaixo da base da onda. Pontes flutuantes e plataformas de petróleo flutuantes são construídas de forma que a maior parte da massa que constitui a estrutura está posicionada abaixo da base da onda, portanto, não será afetada pelo movimento das ondas. 


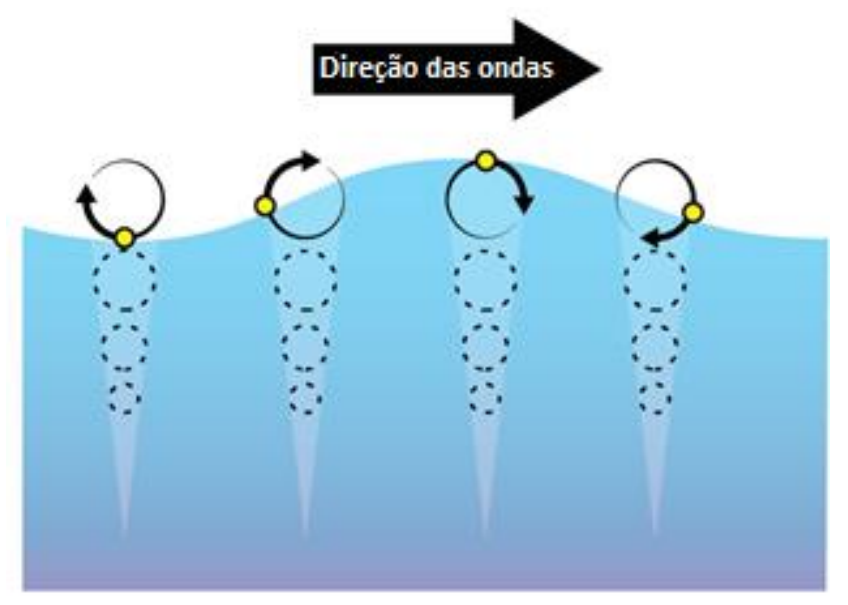

Figura 37 - Ilustração do movimento circular orbital (extraído de Manoa.Hawaii.Edu (2016))

\subsection{2.}

\section{Ondas de Águas Profundas}

Para determinar se a velocidade na base das ondas é de fato desprezível, ou seja, se as ondas são ondas de águas profundas, a profundidade da água $(h)$ e o comprimento de onda devem respeitar a seguinte relação:

$$
\frac{h}{\lambda}>\frac{1}{2}
$$

As ondas de águas profundas não interferem no fundo do oceano. Neste tipo de onda estão incluídas as ondas geradas pelo vento no oceano livre, onde a profundidade da água excede a base da onda.

A velocidade da onda $\left(C_{p}\right)$ é dada pela seguinte relação:

$$
C_{p}=\sqrt{\frac{g \lambda}{2 \pi}}
$$

Onde $g$ é a aceleração da gravidade e $\lambda$ é o comprimento de onda. 


\subsection{3.}

\section{Ondas de Águas Rasas}

No caso de leitos muito rasos em comparação com o comprimento das ondas, as ondas são consideradas como de água rasa, nesse caso a seguinte relação deve prevalecer:

$$
\frac{h}{\lambda}<\frac{1}{20}
$$

As ondas de águas rasas exercem influência e são influenciadas pelo leito. A velocidade das ondas de águas rasas $\left(C_{r}\right)$ é influenciada somente pela gravidade e pela profundidade da água:

$$
C_{r}=\sqrt{g h}
$$

Portanto, a velocidade das ondas de águas rasas varia somente com a profundidade do leito.

As ondas de águas rasas incluem ondas geradas pelo vento que tenham se movido para regiões mais rasas; ondas geradas por fontes sísmicas, como terremotos no fundo dos oceanos; e as marés, as quais são um tipo de onda geradas pela atração gravitacional da lua e do sol. Tsunami e marés são ondas com comprimento muito longo, que podem exceder facilmente a profundidade de um oceano.

\subsection{4.}

\section{Ondas de Águas Intermediárias}

As ondas que apresentam algumas características de ondas de águas rasas e ondas de águas profundas são chamadas de ondas transicionais ou de águas intermediárias. A relação que determina as ondas de águas intermediárias é:

$$
\frac{1}{20}<\frac{h}{\lambda}<\frac{1}{2}
$$


Como a velocidade das ondas profundas é dependente do comprimento de onda, e a velocidade das ondas de águas rasas é dependente da profundidade, a velocidade das ondas transicionais depende parcialmente do comprimento de onda e da profundidade.

O movimento das partículas nas ondas de águas rasas difere das órbitas circulares das partículas nas ondas de águas intermediárias, que também se diferem das órbitas das ondas de águas profundas (Figura 38). Nas ondas de águas rasas, o movimento das partículas é mais achatado e com órbitas elípticas o que aproxima de uma oscilação horizontal. A componente vertical do movimento da partícula diminui com o aumento da profundidade, fazendo com que a órbita se torne cada vez mais plana.

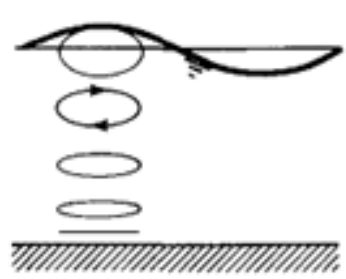

$k h<\frac{\pi}{10}$

$\left(\frac{h}{i}<\frac{1}{20}\right)$

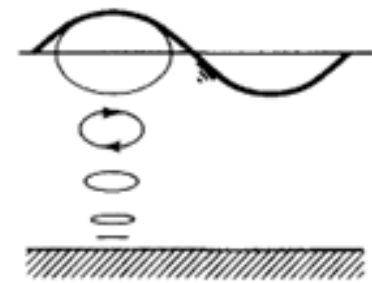

$\frac{\pi}{10}<k h<\pi$

$\left(\frac{1}{20}<\frac{h}{\lambda}<\frac{1}{2}\right)$

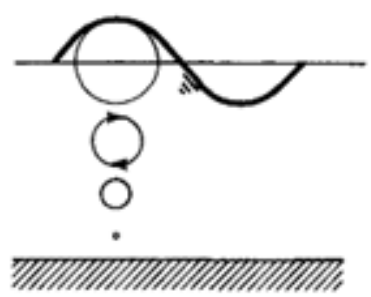

$k h>\pi$

$\left(\frac{h}{i}>\frac{1}{2}\right)$

Figura 38 - Trajetórias das partículas da água sob ondas de diferentes alturas relativas (Dean e Darlymple, 1991)

\section{2.}

\section{Gerador de Ondas}

Para os estudos do presente trabalho, foi necessário projetar e construir um gerador de ondas, visto que o canal de circulação de água do Inmetro não fora projetado para os tipos de estudo que representam um ambiente oscilatório.

Primeiramente foi necessário avaliar os tipos de ondas que poderiam ser analisados no aparato utilizado, pois o tipo de onda estudado influencia o arranjo do gerador de perturbações. No caso de ondas de água profunda, placas geradoras do tipo "flap” ((Figura 39) são comumente empregadas. Já para ondas de água rasa, é necessário que o perturbador crie oscilações de velocidade horizontal desde o leito até a superfície. Nesse caso, perturbadores do tipo pistão são mais adequados 
(Figura 40). Os dois dispositivos descritos são usualmente empregados em tanques e tem aplicação restrita para canais de água, como é o caso do aparato utilizado nos ensaios deste trabalho. Considerando então que o gerador de perturbações não poderia bloquear a passagem de água do canal, optou-se por um dispositivo alternativo para geração de ondas.

No arranjo proposto, as ondas foram geradas na superfície do líquido por uma placa horizontal oscilatória. Assim, o movimento da placa induz perturbações no escoamento principal e na superfície, mas não causa o bloqueio da seção do canal. Além disso, o perturbador gera as mesmas amplitudes de oscilação próximo da interface e as perturbações tendem a zero próximo ao leito. Esse tipo de perturbador é adequado somente para geração de ondas de água profunda. Logo, no presente estudo, ondas de água rasa não foram investigadas. Um detalhe construtivo do perturbador utilizado é que a placa oscilatória deve ser ligeiramente inclinada para favorecer a geração de ondas que se propagam na direção do escoamento.

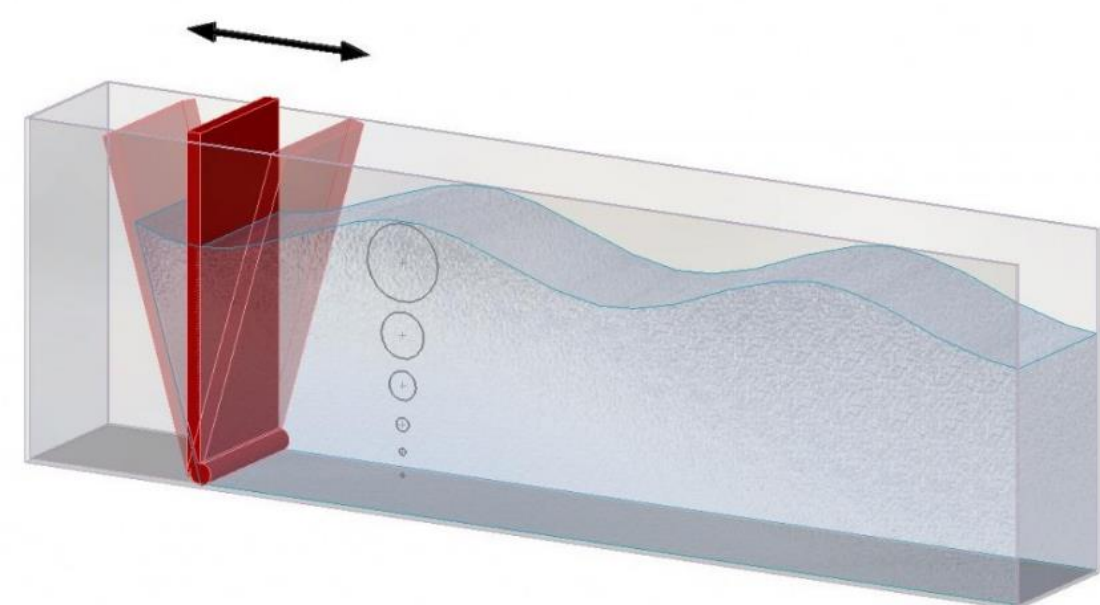

Figura 39 - Placa geradora de ondas do tipo flap (extraído de EdimburghDesign (2016)) 


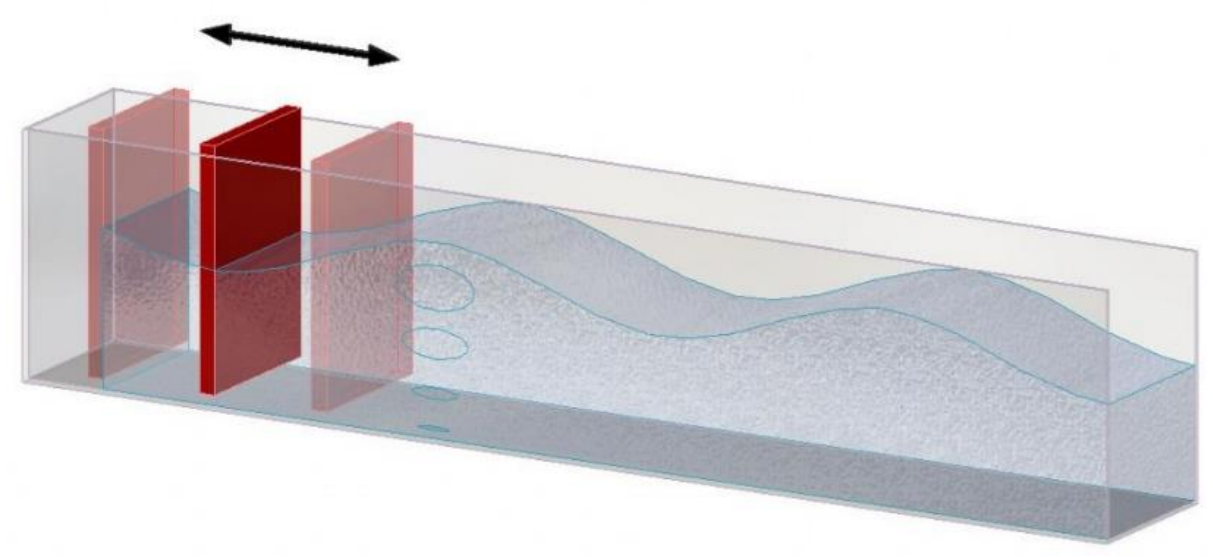

Figura 40 - Placa geradora de ondas do tipo pistão (extraído de EdimburghDesign (2016))

O dimensionamento da placa geradora de ondas foi feito com base na frequência $(f)$ das ondas. A frequência foi estabelecida a partir da Figura 41, onde estão representados os espectros das ondas oceânicas. Visto que as ondas geradas pelo vento representam a maioria das ondas presentes na natureza e apresentam uma energia considerável por período de onda, foi estabelecida uma frequência de estudo igual a aproximadamente $0,7 \mathrm{~Hz}$ para o presente trabalho. Este valor está compreendido na faixa de maior energia no gráfico da Figura 41. Na faixa de ondas geradas por ventos em lagos e rios espera-se frequências e comprimentos de onda similares.

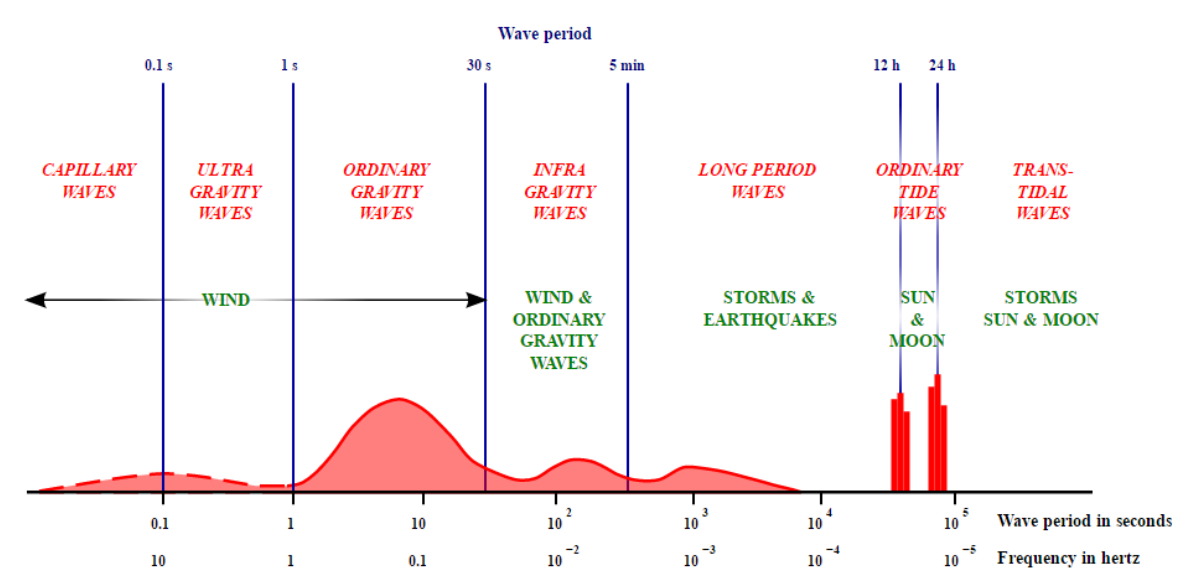

Figura 41 - Classificação do espectro de ondas oceânicas de acordo com o período da onda (Munk, 1950) 
Para o dimensionamento da placa, foi considerado que a velocidade média da corrente de água do canal $(0,2 \mathrm{~m} / \mathrm{s})$ é igual a velocidade da onda $(C)$. Sabe-se que a relação entre o comprimento de onda, velocidade da onda e frequência, é dada pela seguinte fórmula:

$$
k=\frac{1}{\lambda}=\frac{\omega}{C}
$$

Portanto, comprimento da placa geradora de ondas foi estimado com base neste valor de comprimento de onda encontrado na relação.

$$
\frac{1}{\lambda}=\frac{0.7}{0.2} ; \lambda \approx 0,35 \mathrm{~m}
$$

A largura da placa foi dimensionada de acordo com a largura máxima do canal de água, que era de 0,6 m. Assim, a dimensão da placa foi estimada em 0,35 $\mathrm{m}$ de comprimento por $0,58 \mathrm{~m}$.

O nível de água estabelecido para os estudos foi de $30 \mathrm{~cm}$. Considerando este nível e o comprimento de onda teórico gerado pela placa, o efeito das ondas geradas equivale às ondas de águas profundas. De acordo com a Figura 41, ondas geradas por vento podem ter períodos fixos na faixa de 0,1 a 30 s. Na condição de velocidade do escoamento base igual a $0,2 \mathrm{~m} / \mathrm{s}$, isso corresponde a ondas que podem variar de $2 \mathrm{~cm}$ à $6 \mathrm{~m}$. Considerando a frequência fundamental de geração de ondas juntamente com as frequências harmônicas e a razão entre comprimento de onda e altura do leito variando entre 1 a 2 , nota-se que o presente estudo está mais relacionado com ondas em lagos e rios do que leitos marinhos. Ainda assim, é possível que alguns dos fenômenos observados neste trabalho possam ocorrer também para ondas oceânicas.

\subsection{1.}

\section{Projeto do gerador de ondas}

Com base na ideia principal de geração de ondas por meio da oscilação de uma placa retangular inclinada na superfície da água, foi feito um levantamento de peças estruturais disponíveis no laboratório. Todas as dimensões das peças foram 
medidas e, assim, foi possível reproduzir todas as peças no software SolidWorks ${ }^{\circledR}$. O uso do software permitiu o projeto estrutural do gerador de ondas, ou seja, dimensionar toda a estrutura rígida que mantém o gerador estável a vibrações e as estruturas móveis que permitem a entrada e saída da placa na água. Os estudos de movimento foram realizados dentro da interface do software com a finalidade de estabelecer o melhor posicionamento para cada parte do gerador.

A Figura 42 mostra o desenho esquemático do projeto inicial do gerador de ondas. Em ambos os lados da caixa de entrada foram posicionados duas guias lineares, no qual é possível mover um cursor. Para que a estrutura suba e desça, consequentemente a placa também, o clássico movimento da mecânica de bielamanivela foi implementado. Assim, um motor gira um disco acoplado em seu eixo e uma haste, com uma extremidade fixa em um determinado ponto radial do disco e a outra extremidade fixa na barra de curso da guia, transformando o movimento circular em movimento retilíneo.

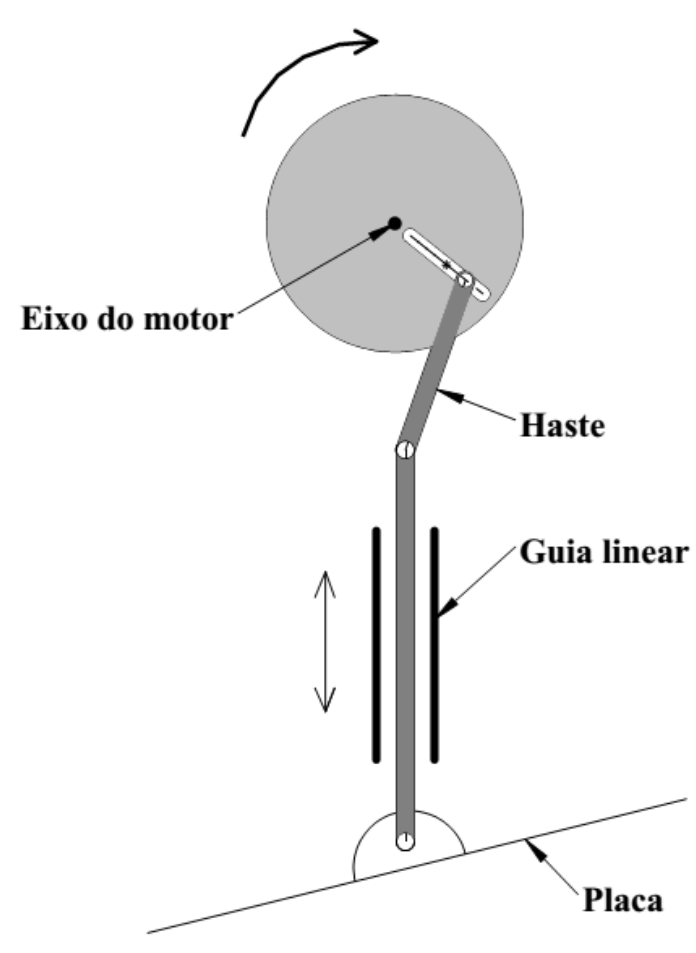

Figura 42 - Desenho esquemático dos componentes do sistema de geração de ondas

O primeiro componente do sistema de geração de ondas escolhido foi o motor (Figura 43), o qual já estava disponível no laboratório, porém, não estava sendo 
utilizado. O motor utilizado foi um servo motor AC trifásico $220 \mathrm{~V}$ da $\mathrm{GSK}^{\circledR}$ destinado para máquinas $\mathrm{CNC}$ com torque de 7,5 N.m em 2.500 rpm. A rotação do motor é controlada por um inversor de frequências.

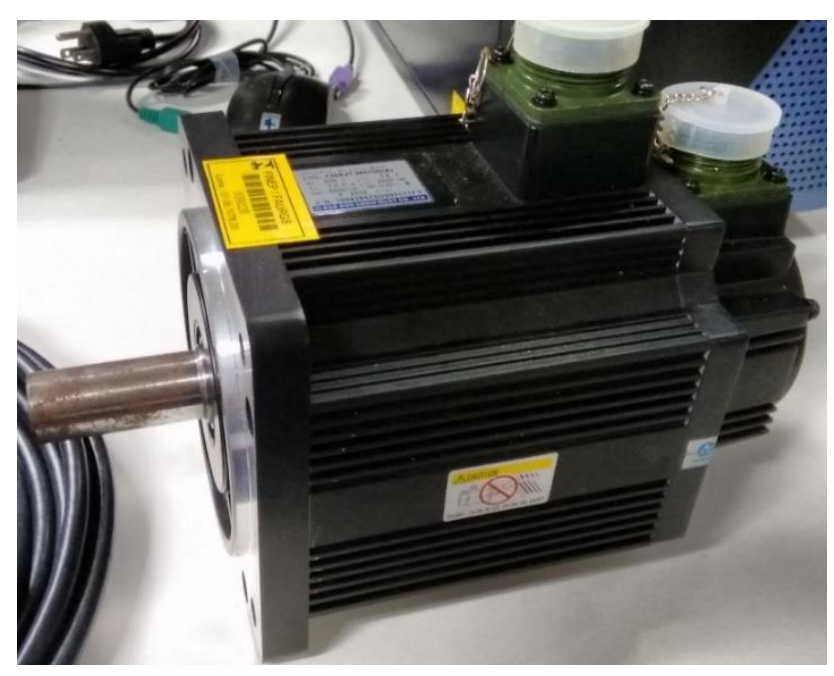

Figura 43 - Motor usado no sistema de geração de ondas

\subsection{2. \\ Estrutura do gerador de ondas}

Para a primeira etapa da montagem do gerador de ondas, foi considerada a largura da seção de entrada do canal de circulação de água. Duas guias lineares de aço inoxidável foram dispostas distanciadas da largura medida. Estas guias de aço permitem o deslizamento de pequenas peças que percorrem toda a extensão da guia. Para que a distância entre as duas guias permanecesse fixa, dois perfis em $U$ de alumínio foram parafusados nas peças de deslizamento de cada guia, unindo as duas guias de aço, como mostra a Figura 44. 


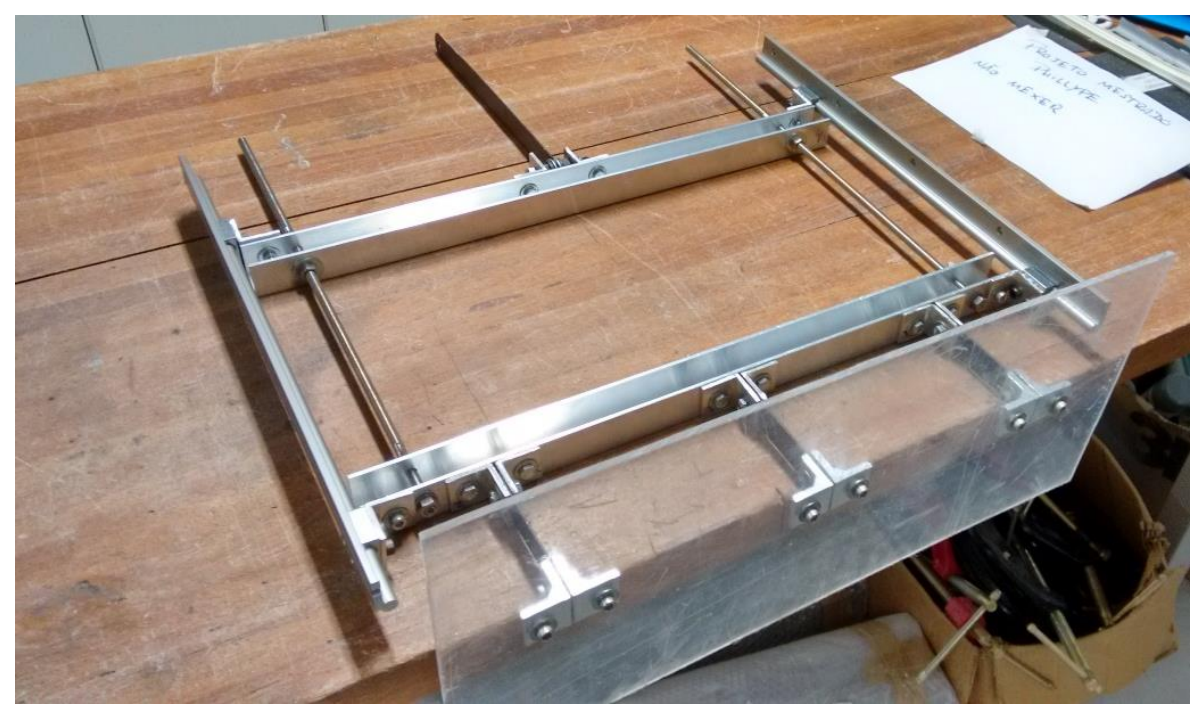

Figura 44 - Estrutura inicial do gerador de ondas

Para conferir rigidez e unir os dois perfis de alumínio foram utilizadas duas barras roscáveis de aço inox passando por furos nos dois lados de cada perfil. Assim, foi possível deslizar os perfis de alumínio e acoplar o seu movimento. Além disso, a barra roscada permite variar a distância entre os dois perfis. No perfil de alumínio superior foram fixados dois pequenos perfis de alumínio em L, de forma que um parafuso do tipo "estojo" passasse de um perfil ao outro sem travar a haste ligada ao eixo do motor. Na região central do parafuso, onde não existe rosca, uma haste de aço com furos nas extremidades foi posicionada entre os dois pequenos perfis de alumínio. Desta forma, a haste permanece presa à superfície lisa do parafuso, porém com livre movimento na parte anular do furo devido a uma pequena folga.

$\mathrm{Na}$ barra de alumínio inferior foram parafusados três pequenos perfis de alumínio em L, onde foram fixadas hastes de aço. O conjunto permite o ajuste do ângulo de incidência da placa de acrílico quando os três parafusos de fixação são soltos.

Como as guias de aço inox não podiam ser parafusados diretamente nas paredes das laterais do canal, dois perfis de alumínio em $U$ foram cortados e fixados nas guias para que fosse possível utilizá-los de suporte para apoio na parte superior da entrada do canal. Ainda, uma barra longa de alumínio com perfil em L foi utilizada para unir estas os dois suportes, permitindo que houvesse mais pontos de fixação da estrutura na parte de cima do canal. 
Todo o conjunto estrutural do gerador de ondas foi fixado na seção de entrada do canal de circulação de água em pontos de apoio preestabelecidos, como mostra a Figura 45. Mesmo assim, foi necessário reforçar a rigidez da estrutura, visto que o simples movimento com as mãos para deslizar as peças nas guias causava uma certa vibração na estrutura podendo ocasionar possíveis travamentos durante a geração das ondas. O reforço estrutural foi realizado com pequenas hastes de alumínio as quais foram parafusadas em forma de treliças tanto na direção longitudinal quanto na direção transversal do canal.

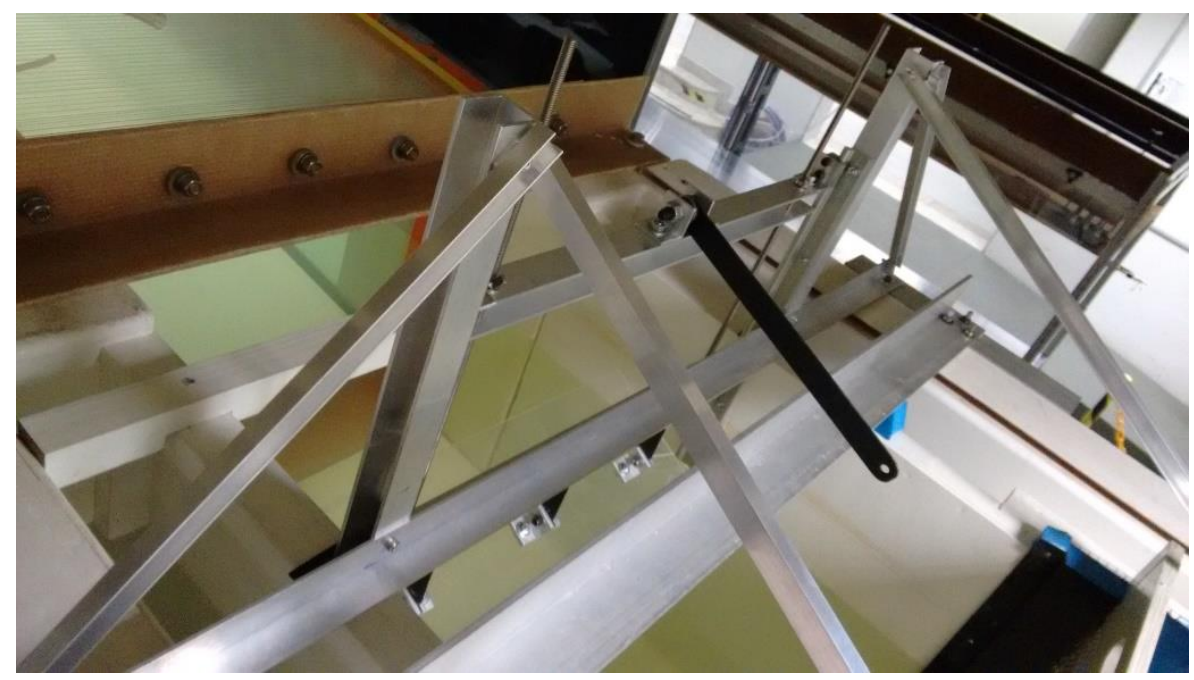

Figura 45 - Estrutura do gerador de ondas fixada no canal

Com a estrutura do gerador de ondas devidamente instalada no canal de circulação de água, a próxima etapa consistia na adaptação do servo motor ao componente móvel do gerador de ondas, bem como a adaptação ao canal. O motor foi colocado sobre um suporte de aço com o centro do eixo do motor alinhado com a linha de centro da haste que foi conectada ao perfil de alumínio superior do gerador de ondas (Figura 46).

O movimento rotativo do motor foi transformado em movimento de translação com o auxílio de um disco de alumínio com 5 mm de espessura e 200 $\mathrm{mm}$ de diâmetro. O disco possui um rasgo na direção radial onde fixa-se a haste que fica ligada ao gerador de ondas. A haste de giro pode, então, ser fixada ao longo de qualquer posição dentro do rasgo no disco com o auxílio de um pino, fazendo com que seja possível a variação do curso de subida e descida do gerador de ondas. Assim, é possível variar a amplitude da onda. 
Para reduzir as reflexões das ondas geradas pelo sistema ao atingirem o final do canal, instalou-se uma placa inclinada na seção de saída do canal, se assemelhando à inclinação do relevo submarino das praias. Assim, as ondas ganham amplitude à medida em que se aproximam do final da placa até se quebrarem, reduzindo o choque com a parede final do canal. Isso faz com que as ondas se dissipem e a reflexão seja reduzida. A Figura 47 mostra a geração de ondas no canal de água.

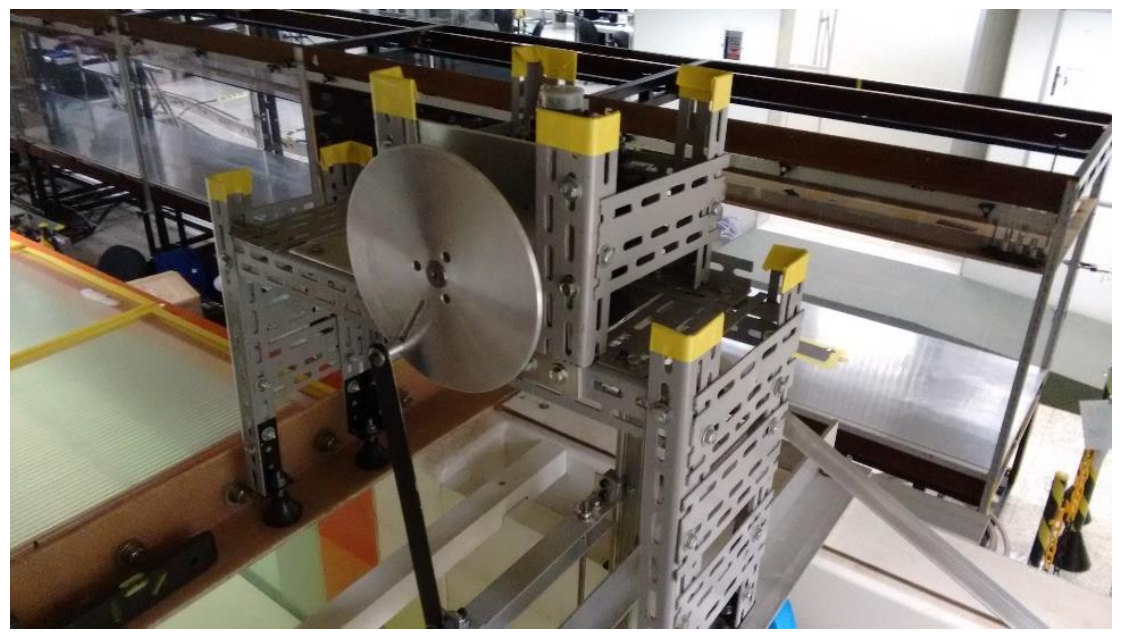

Figura 46 - Conjunto motor, disco e haste devidamente instalados

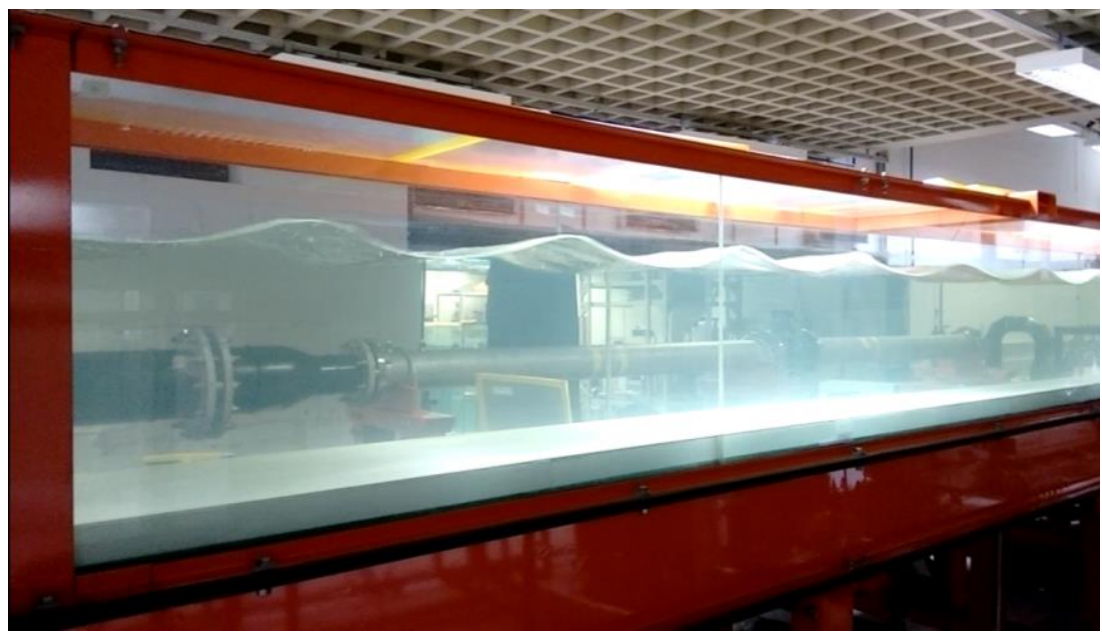

Figura 47 - Ondas geradas no canal 


\subsection{3.}

\section{Sensoriamento de fase das ondas}

Conhecendo a fase das ondas, é possível reconstruir os campos de velocidades medidos com o sistema PIV para todas as janelas de medição. Para acompanhar a fase durante as aquisições das imagens, um sistema de gatilho foi implementado. $\mathrm{O}$ sistema consiste de uma chave de fim de curso, um cabo USB, um cabo BNC e um resistor de $100 \mathrm{k} \Omega$. Quando a chave de final de curso é acionada, fecha-se contato com uma fonte de $5 \mathrm{~V}$ e esse sinal é usado como gatilho para o disparo dos demais equipamentos de medição. O circuito do sensor de final de curso é ilustrado na Figura 48.

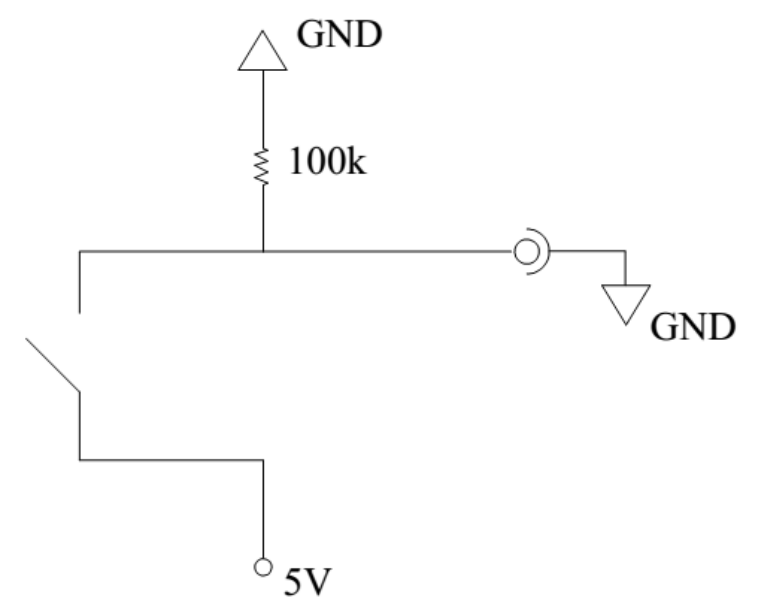

Figura 48 - Circuito de funcionamento do sensor

O sensor de fim de curso foi fixado em uma das guias de movimento do gerador de ondas, a uma distância muito curta do dispositivo móvel que se movimenta para cima e para baixo durante a geração de ondas (Figura 49). Para que o botão do sensor fosse acionado durante uma volta completa do disco nas duas amplitudes de trabalho, um aparato para o ajuste de posição de cada amplitude foi montado e fixado na parte superior da guia linear. Assim, quando o motor é acionado, o disco gira e o próprio movimento de subida da estrutura do gerador aperta o botão em cada ciclo do motor do gerador de ondas. 

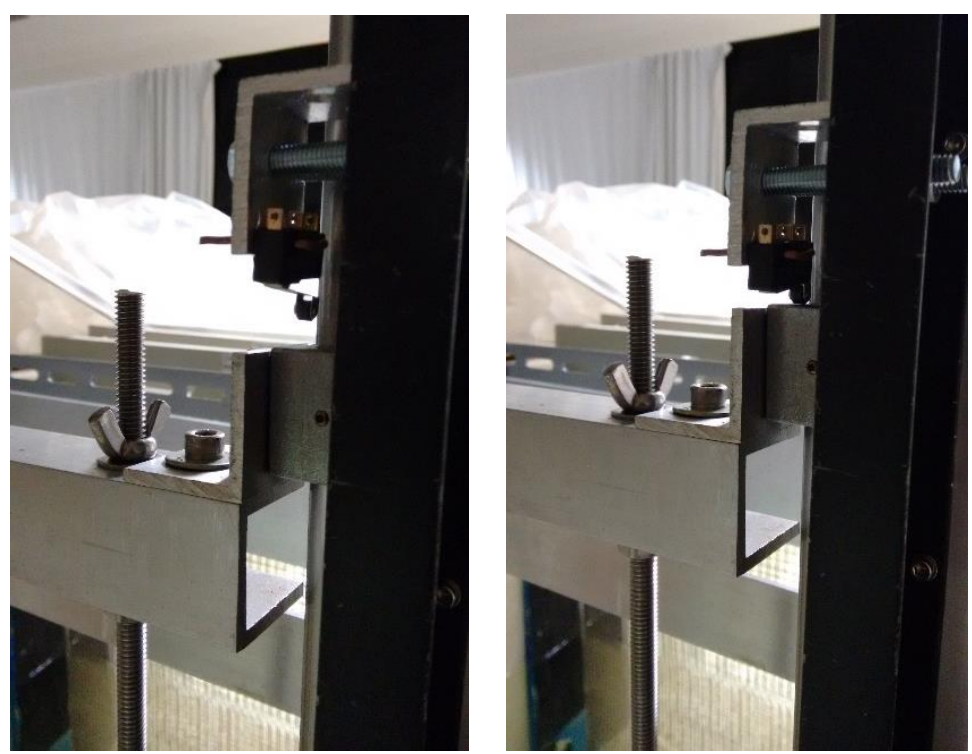

Figura 49 - Sensor com contato aberto (esquerda) e com contato fechado (direita)

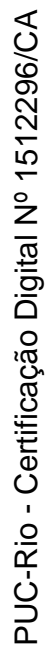

A extremidade que contém o conector BNC foi conectado na entrada do TimerBox do sistema PIV, permitindo um trigger externo quando o botão do sensor for acionado. 


\section{5 Metodologia de processamento e análise das imagens}

As metodologias empregadas no processamento das imagens são descritas neste capítulo. Primeiramente, é feita uma apresentação de algumas características das imagens obtidas nos experimentos e como elas são importantes para a distinção entre bolhas e partículas. Em seguida, são descritas as rotinas de pré-processamento utilizadas para identificação das bolhas nas imagens. A metodologia para a separação das fases líquida e gasosa são apresentadas na terceira seção. Na quarta seção é abordada a rotina de processamento para identificação das interfaces das ondas e, no último tópico, expõe-se brevemente os conceitos da transformada rápida de Fourier, que foram aplicados aos campos de velocidade.

\section{1. Pré-processamento das imagens}

As imagens obtidas através da utilização da técnica PIV foram processadas diretamente no software de correlação. Contudo, quando se trabalha com escoamento bifásico o software não faz uma distinção entre as duas fases durante o processamento das imagens, o que pode acarretar em medições erradas dos campos de velocidade. Portanto, é necessário realizar um pré-processamento das imagens para distinção entre bolhas de gás e partículas no líquido e consequente remoção da fase que não for de interesse. Com isso, busca-se garantir que o algoritmo de correlação possa fornecer respostas corretas acerca das velocidades medidas.

Para a distinção entre as bolhas e partículas traçadoras foi implementada uma rotina de processamento de imagem no software Matlab ${ }^{\circledR}$. As regiões ocupadas pelas bolhas foram identificadas no software e nelas foram geradas máscaras dinâmicas, o que permite o posterior processamento pelo software do sistema PIV sem que a fase dispersa do escoamento interfira na fase contínua.

A Figura 50 mostra um exemplo de imagem obtida durante os ensaios preliminares. A imagem está ampliada para que as bolhas e partículas possam ser identificadas. Na imagem, nota-se uma baixa concentração de partículas, isso se 
deve ao fato das imagens terem sido adquiridas em ensaios preliminares realizados para que as rotinas de processamento pudessem ser elaboradas. É possível observar que a imagem apresenta três informações principais: as bolhas que se apresentam como regiões mais escuras na imagem; as partículas de Rodamina, que correspondem aos pequenos pontos brancos; e o fundo da imagem iluminada pela luz de led.

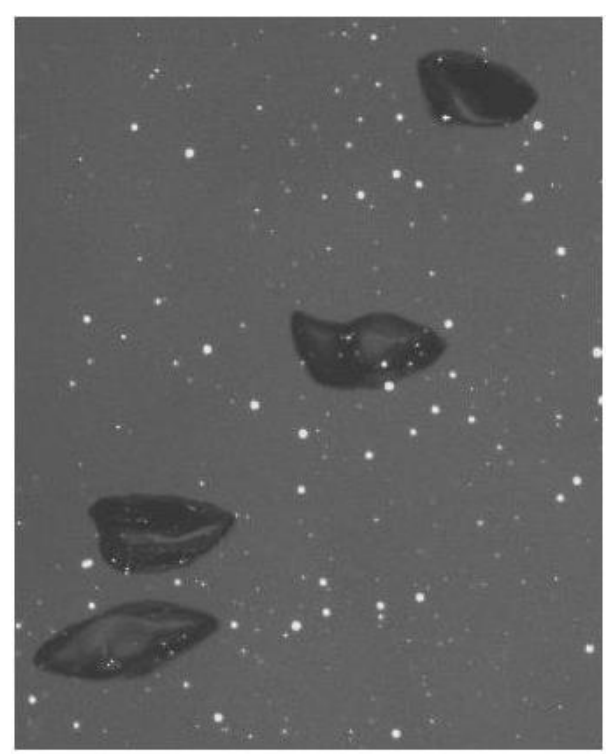

Figura 50 - Típica imagem obtida nos experimentos

Aplicando-se um histograma de escala de cinza desta imagem, apresentado na Figura 51, pode-se observar estas três informações pela intensidade dos pixels. O fundo da imagem representa a maior parte da imagem com uma intensidade média igual a 100 na escala de cinza. As bolhas são facilmente identificadas localizando-se nas intensidades mais baixas do histograma e as partículas traçadoras são representadas pelas intensidades mais altas da escala de cinza, próximo ao branco, porém em menor quantidade. 


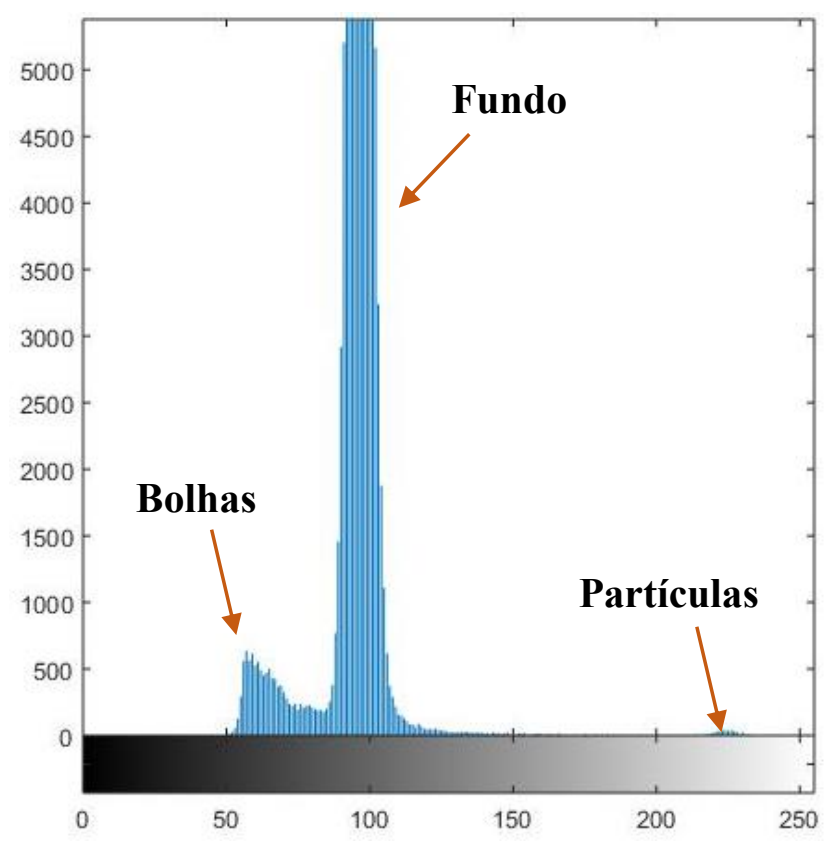

Figura 51 - Histograma da imagem original

\section{2.}

\section{Detecção das bolhas}

A rotina de pré-processamento implementada no Matlab considera uma sequência lógica para detectar as bolhas nas imagens. Primeiramente, todas as imagens que contém bolhas são exportadas do software comercial da Dantec para o diretório do Matlab. As imagens são trabalhadas na extensão Tagged Image File Format (TIFF), pois neste formato não há nenhum tipo de compressão das imagens.

A primeira função aplicada à imagem é um filtro mediano de 12 por 12 pixels para a remoção das partículas na imagem, Figura 52 (a). Na sequência, o fundo (background) da imagem é obtido através do fechamento morfológico com um elemento estrutural no formato de disco de 20 por 20 pixels, como mostra a Figura 52 (b). Ao realizar a subtração do background a partir da imagem original, chegase a uma imagem em que as bolhas ficam mais destacadas do fundo, ainda, porém com descontinuidade em certas regiões (Figura 52 (c)).

A partir deste ponto, as imagens resultantes da subtração do background são binarizadas, ou seja, os valores de pixels deixam de ser apresentados na escala de cinza e passam a ser representados somente com valores de pixels iguais a 0 ou 1 . $\mathrm{O}$ valor de pixel igual a 1 representa um pixel totalmente branco, enquanto o valor de pixel igual a 0 representa um pixel sem cor, ou seja, preto. O sistema de 
binarização leva em consideração um algoritmo de threshold em que um valor predeterminado na escala de cinza é definido como ponto de corte (ou valor limiar) da imagem. Exemplificando, para a imagem em questão, o valor de threshold escolhido foi igual a 249 na escala de cinza, sendo que, somente os valores abaixo deste ponto de corte serão mostrados.

Durante o processo de binarização, o fundo da imagem apresenta um ruído devido à escolha do valor de threshold (Figura 52 (d)). Embora seja possível alterar este valor para que o ruído desapareça, é inconveniente realizá-lo, pois isso acarretaria em perdas de informações importantes nas regiões ocupadas pelas bolhas. O ruído de fundo foi removido com a passagem de um filtro que remove todos os componentes conectados que têm menos de 50 pixels na imagem binária, sendo uma margem razoável para a não remoção de pixels correspondentes às bolhas (Figura $52(\mathrm{e})$ ).

Após a remoção do ruído, a imagem contém somente as bolhas e o fundo preto. Porém, as regiões das bolhas apresentam falhas de conectividade dos pixels no seu interior. Para fazer esta correção, foi necessário aplicar algumas funções morfológicas do Matlab. Primeiro, utilizou-se a função de preenchimento automático de buracos. Após o preenchimento dos buracos utilizou-se a função de fechamento de regiões, com elementos estruturais de 7 por 7 pixels. Em seguida, foram empregadas as funções "dilate" e "erode" para expandir os pixels iguais a 1 e depois expandir os pixels iguais a 0 . O procedimento elimina pequenas partes das bolhas que não foram preenchidas.

A imagem resultante do processamento é uma imagem binária das bolhas representadas por pixels iguais a 1 (branco) e um fundo preto, definindo a região ocupada pelas bolhas (Figura 52 (f)). A partir desta imagem é possível estimar algumas propriedades das bolhas. Para isso, foi usada uma função do Matlab que rotula cada bolha a partir de uma intensidade na escala de cinza. Para facilitar na visualização, esta função é ajustada para que cada bolha seja identificada com cores no código RGB (Red-Green-Blue). Ao serem identificadas automaticamente pela rotina, as bolhas são numeradas (Figura $52(\mathrm{~g})$ ) e suas propriedades calculadas. 
(a)

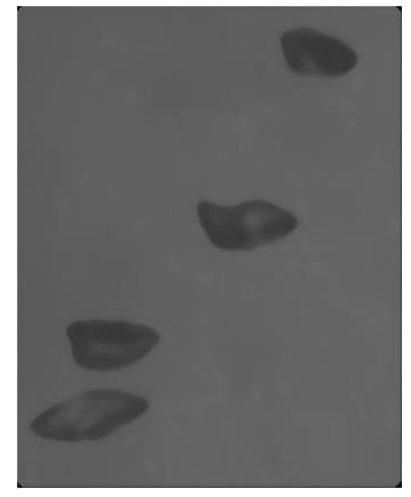

(d)

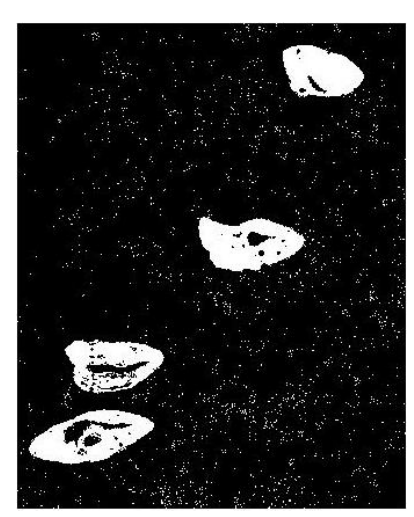

(g)

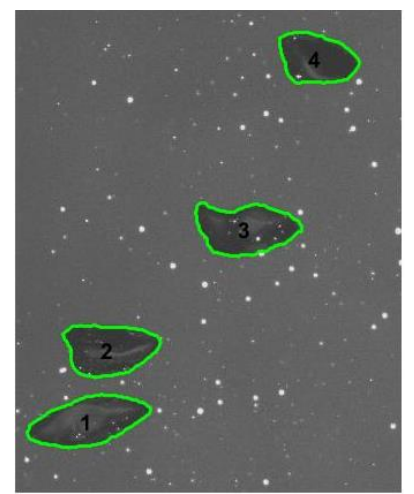

(e)

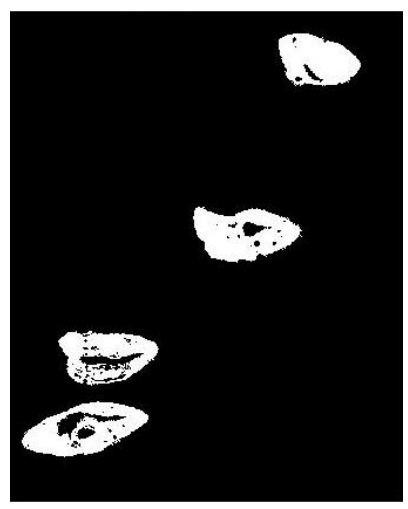

(c)

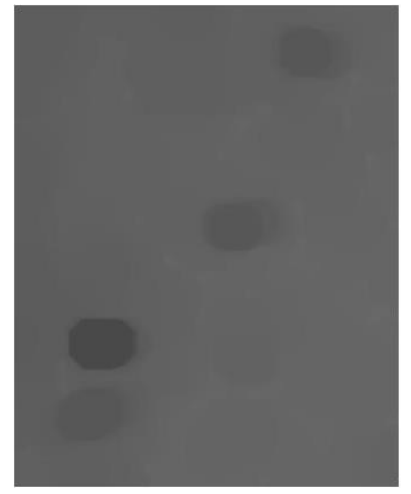

(f)

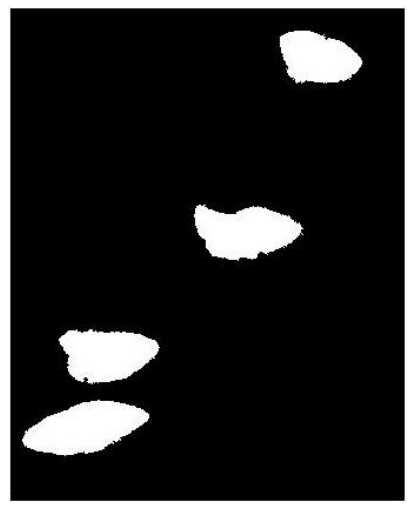

(b)

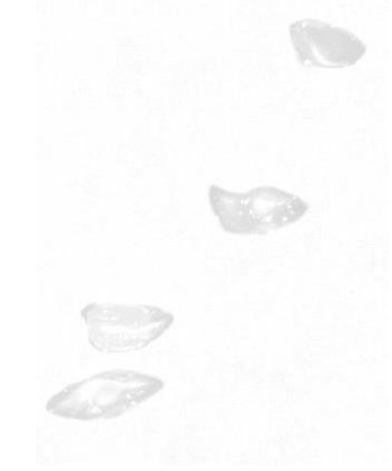

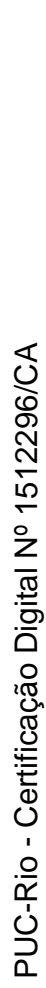

Figura 52 - Sequência de passos para identificação das regiões de bolhas

\subsection{1.}

\section{Cálculo do diâmetro das bolhas}

A estimativa do diâmetro das bolhas foi feita na mesma rotina de préprocessamento. Para cada região ocupada pelas bolhas calculou-se a área, o perímetro e o centroide com base no número de pixels de cada região. Como as 
imagens mostram somente um plano da área das bolhas, a estimativa de cálculo do diâmetro é feita usando as informações contidas no plano da bolha.

Duas aproximações foram usadas para o cálculo do diâmetro, a primeira baseada na área $(A)$ ocupada pela bolha na imagem, sendo que:

$$
D_{\text {circular }}=\sqrt{\frac{4 A}{\pi}}
$$

Desta forma, $D_{\text {circular }}$ representa o diâmetro circular equivalente da área projetada de cada bolha nas imagens binarizadas. A outra metodologia de cálculo do diâmetro é fundamentada na premissa de que muitas das bolhas aparentam ter o formato de uma elipse. Considerando isso, a rotina se utiliza de duas funções que identificam o maior eixo $(a)$ e o menor eixo $(b)$ da região das bolhas. $\mathrm{O}$ diâmetro baseado no volume de um elipsoide $\left(D_{\text {eliptico }}\right.$ ) pode ser calculado a partir da seguinte fórmula:

$$
D_{\text {eliptico }}=\left(a b^{2}\right)^{1 / 3}
$$

\subsection{2.}

\section{Cálculo da velocidade das bolhas}

A velocidade instantânea de subida das bolhas foi calculada no software Wolfram Mathematica ${ }^{\circledR}$. As informações das posições dos centroides de cada bolha nos frames 1 e 2 de cada imagem foram computadas e exportadas para um código implementado no Mathematica. O código faz uma iteração de todas as posições do centroide do frame $1 \mathrm{com}$ as posições do centroide do frame 2 e armazena somente as menores distâncias para cada iteração. Como o tempo entre frames é muito curto, a menor distância calculada se torna adequada para garantir que o deslocamento do centroide do frame 1 para o frame 2 seja correspondente à mesma bolha.

Após o cálculo da distância Euclidiana entre os dois centroides, o resultado é dividido pelo tempo entre os dois pulsos de laser (igual a $3 \mathrm{~ms}$ ), obtendo-se assim a velocidade de cada bolha. 


\section{3. \\ Separação de partículas e bolhas}

Durante o cálculo dos vetores velocidade das partículas traçadoras, é necessário que as bolhas não estejam presentes nas imagens para que não haja influência das intensidades das bolhas no processo de correlação das janelas de interrogação. Portanto, é necessário que as imagens a serem processadas no software comercial contenham somente as partículas traçadoras.

A separação das partículas das bolhas é feita na mesma rotina de préprocessamento das bolhas. Após a identificação das regiões ocupadas pelas bolhas, a imagem binária é então invertida, ou seja, as áreas das bolhas ficam pretas e o fundo fique branco. O propósito desta inversão é para fazer a imagem binarizada ser a máscara dinâmica. Nesse caso, a região das bolhas fica igual a 0 e a do fundo igual a 1. Multiplicando-se a imagem original por essa imagem invertida, tem-se que a região das bolhas fica totalmente preta.

Embora seja possível processar a imagem da esquerda da Figura 53, ainda é necessário o preenchimento das regiões escuras para que seja possível extrair uma imagem média de fundo. Para o preenchimento das bolhas, interpolou-se as intensidades dos pixels ao redor das máscaras. Com isso, gerou-se a imagem da direita na Figura 53. Após esse procedimento, foi feita uma média do conjunto de imagens e depois, cada imagem foi subtraída da média, para o posterior processamento no software comercial da Dantec.
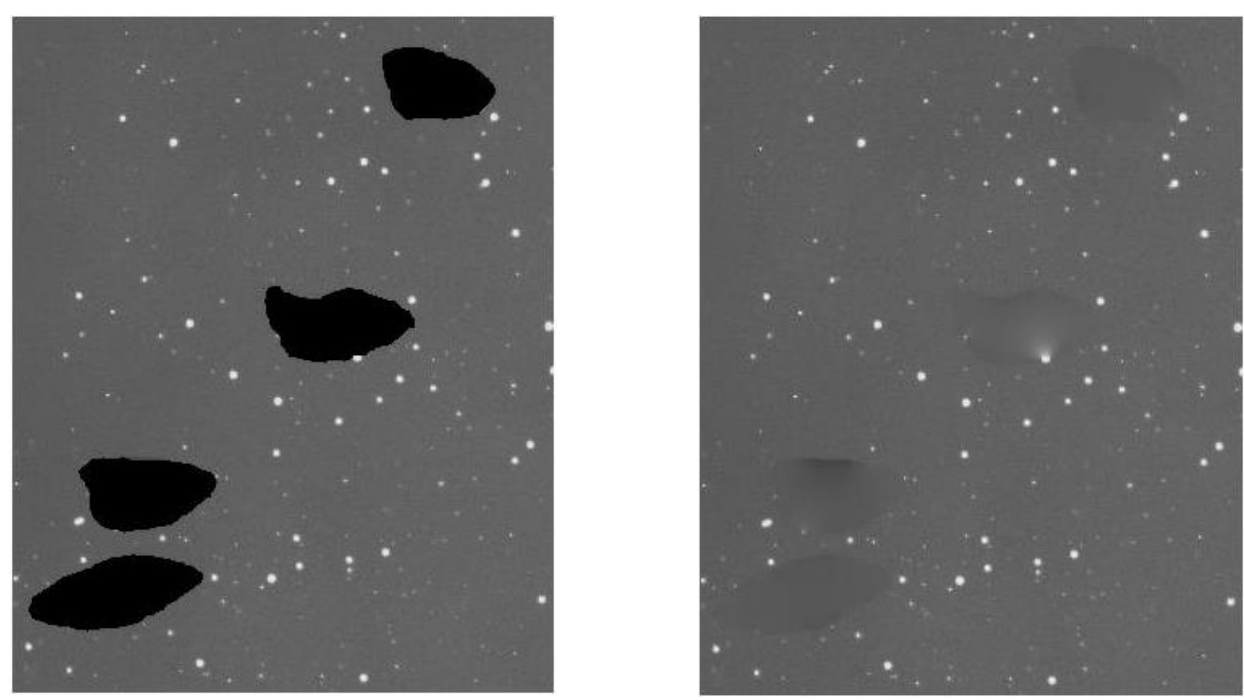

Figura 53 - Máscaras dinâmicas aplicadas 
Para efeitos de verificação da influência do procedimento adotado sobre os campos de velocidade obtidos com o software comercial, processou-se os campos de velocidade a partir de imagens sem pré-processamento e com préprocessamento. Os campos instantâneos de velocidade foram calculados e plotados, sendo que a Figura 54 representa o resultado sem o pré-processamento das imagens e a Figura 55 mostra o resultado quando o pré-processamento é aplicado. É perceptível que existe uma diferença considerável nos resultados, sendo que os vetores de velocidade gerados na Figura 55 são mais coerentes com a movimentação somente das partículas traçadoras na região do escoamento. A Figura 54 mostra que a presença das bolhas nas imagens influencia no cálculo dos vetores.

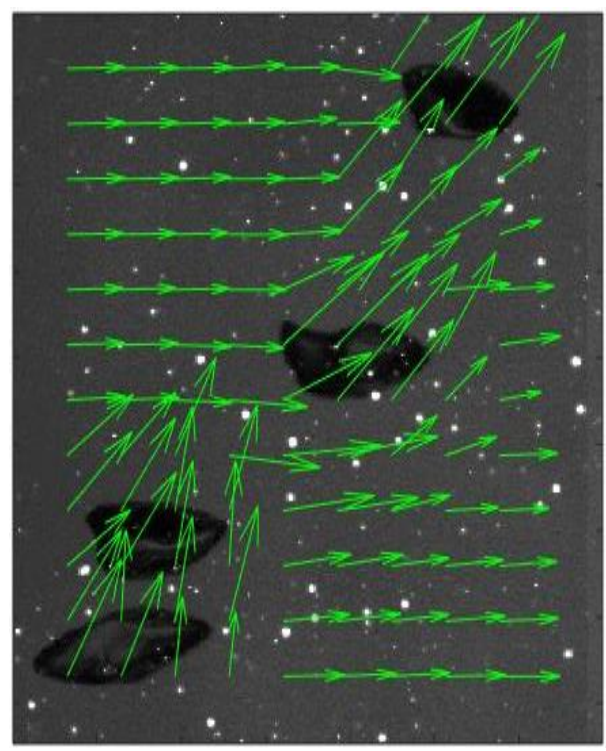

Figura 54 - Campo vetorial resultante de imagens sem pré-processamento 


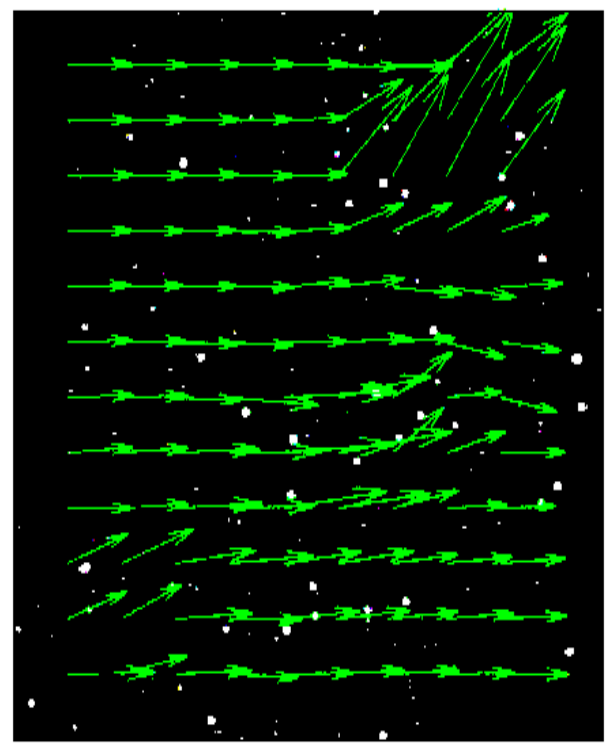

Figura 55 - Campo vetorial resultante de imagens com pré-processamento

\section{4 . Detecção da interface}

As imagens da região de interface ar-água também foram pré-processadas em rotina desenvolvidas em linguagem Matlab. A metodologia de processamento se assemelha àquela usada para a detecção das bolhas, mas agora o interesse foi produzir máscaras dinâmicas na linha de interface entre o ar e água. A Figura 56 mostra um exemplo de uma imagem da interface, na qual foi utilizada partículas de vidro revestidas de prata, durante a geração de ondas.

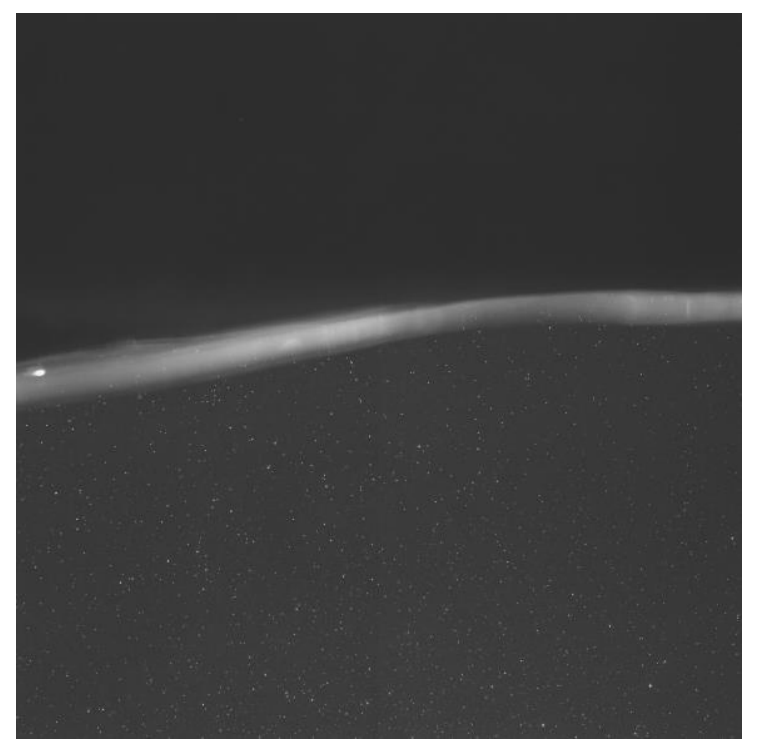

Figura 56 - Imagem da interface ar-água 
É possível observar na Figura 56 que existem intensidades de pixels correspondentes à parte do ar na região superior da imagem, onde os pixels são mais escuros, outros correspondentes à fase líquida em que as partículas traçadoras estão presentes, o fundo apresenta uma cor mais acinzentada e a região de interface em que os pixels são de alta intensidade, muito próximo, ou até mesmo igual, da intensidade dos pixels das partículas. O processamento desta imagem sem uma máscara na região de interface faz com que o sistema gere uma quantidade grande de vetores espúrios naquela região, ocasionando em erros sistemáticos em todos os campos instantâneos o que compromete o resultado final.

Como a interface se move, devido às ondas, é preciso que o código identifique a interface, mesmo que ela esteja em posições diferentes durante uma sequência de imagens. $\mathrm{O}$ algoritmo desenvolvido se inicia com a aplicação de um filtro mediano de 12 por 12 pixels para remoção das partículas nas imagens, como mostrado na Figura 57 (a). Após o uso do filtro, foi empregado um algoritmo de detecção de limiar (threshold) para que a imagem binária resultante mostre valores menores do que 75 na escala de cinza. Em seguida, foi feita uma inversão nos valores dos pixels para que a região de interface ficasse preta (Figura 57 (b)). Os possíveis ruídos gerados durante o processo de binarização das imagens foram removidos com a utilização de um filtro que eliminou todos os componentes conectados abaixo de 50 pixels.

Para a aplicação das máscaras dinâmicas nas regiões de interface, as imagens originais foram multiplicadas pelas imagens binarizadas correspondentes (Figura 57 (c)). Assim, a interface, que antes apresentava altas intensidades de pixels, ficou totalmente preta com valores de pixels iguais a zero. Esta nova imagem pode ser aperfeiçoada para o posterior processamento aplicando-se uma subtração do background para que o fundo da imagem resultante permaneça com uma intensidade homogênea. Dessa forma, aplicou-se um novo limiar de corte (threshold) para que somente valores de pixels maiores do que 40 fossem mostrados. Assim, a nova imagem apresentou as partículas traçadoras sem a região da interface, conforme mostrado na Figura 57 (d). 
(a)

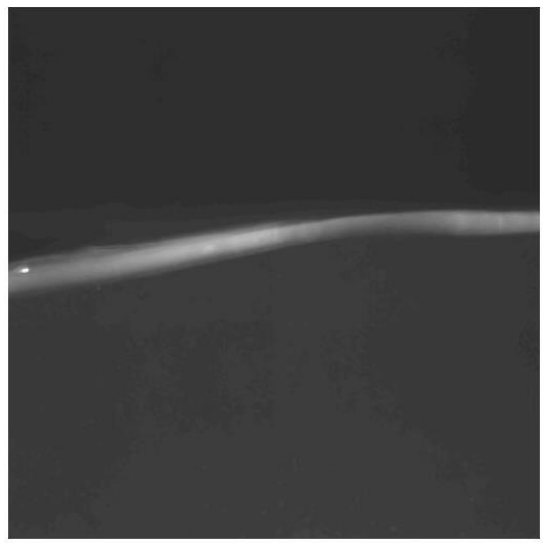

(c)

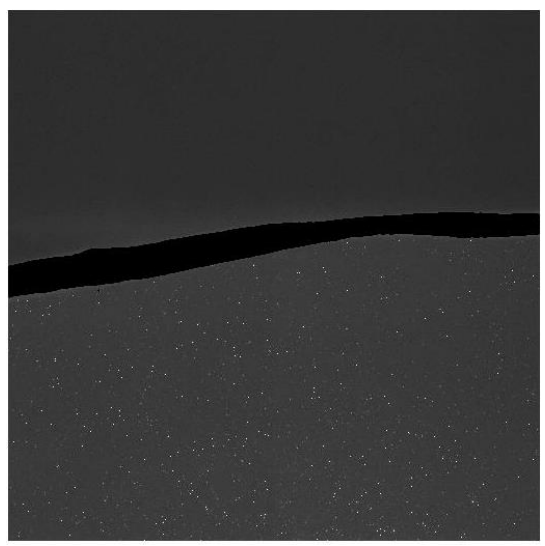

(b)

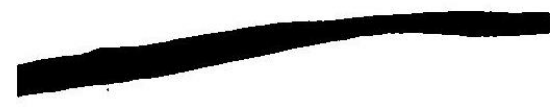

(d)

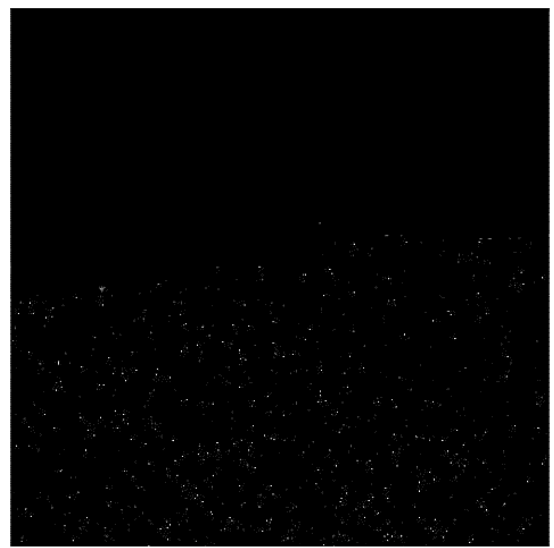

Figura 57 - Sequência de processamento da interface

\section{5.}

\section{Processamento dos campos de velocidade}

A análise espectral é amplamente empregada na análise de sinais, pois a ferramenta permite a decomposição dos sinais temporais em termos das frequências contidas no sinal. Assim, perturbações relacionadas às ondas podem ser estudadas separadamente. No presente estudo, isso é particularmente interessante, pois permite separar os efeitos relacionados às ondas daqueles aleatórios.

Diferentes métodos existem para determinar a função de densidade espectral de dados obtidos no tempo. A transformada rápida de Fourier (TRF), a qual é um algoritmo para calcular a transformada discreta de Fourier (TDF), é a mais usada (Casas, 2009).

A equação abaixo dá a forma contínua da transformada de Fourier de uma função no tempo $y(t)$. 


$$
Y(f)=\int_{-\infty}^{\infty} y(t) e^{-i 2 \pi f t} d t
$$

A transformada de Fourier, $Y(f)$, descreve o sinal contínuo no tempo como um sinal contínuo no domínio da frequência. Se $y(t)$ é uma função do tempo conhecida ou medida, então sua transformada de Fourier fornecerá as propriedades amplitude-frequência do sinal, que não estariam prontamente perceptíveis na forma da função baseada no tempo (Figliola e Beasley, 2007).

O resultado da transformação de Fourier é um número do tipo complexo:

$$
Y(f)=|Y(f)| e^{i \Phi(f)}=A(f)-i B(f)
$$

Onde a magnitude de $Y(f)$, também chamada de módulo, é dada por:

$$
|Y(f)|=\sqrt{\operatorname{Re}[Y(f)]^{2}+\operatorname{Im}[Y(f)]^{2}}
$$

E a fase é dada por:

$$
\phi(f)=\tan ^{-1} \frac{\operatorname{Im}[Y(f)]}{\operatorname{Re}[Y(f)]}
$$

Todos os campos instantâneos de velocidade gerados pelo sistema PIV foram processados em uma rotina elaborada no Matlab. O algoritmo faz a leitura de velocidade de todos os campos vetoriais. Em seguida, os tratamentos dos dados foram feitos separadamente para cada componente da velocidade do escoamento ( $U$ e $V$ ). A transformada rápida de Fourier foi aplicada nos vetores de cada janela de interrogação para uma sequência de imagens. Desta forma, as relações e características da dispersão da pluma de bolhas e da propagação das ondas puderam ser correlacionadas. 


\section{6}

\section{Avaliação do comportamento do escoamento cruzado}

Neste capítulo são apresentadas as condições experimentais selecionadas para os estudos e, em seguida, os resultados obtidos experimentalmente. Primeiramente, foi feita uma caracterização detalhada do escoamento sem a presença da pluma de bolha, com o objetivo de mostrar como as ondas mudam as características do escoamento base. Depois, são apresentados os resultados referentes a investigação da influência da injeção de ar no escoamento cruzado sem a presença das ondas, revelando como a pluma de bolhas afeta o escoamento base. Em seguida, mostrase uma comparação entre o escoamento da pluma de bolhas sem ondas e com a presença das ondas, mostrando o efeito da presença de ondas sobre o escoamento da pluma.

\section{1.}

\section{Matriz de ensaios e parâmetros de medição}

Os parâmetros ajustados para as medições com o sistema de medição PIV foram definidos com base em testes preliminares e estão apresentados na Tabela 1:

Tabela 1 - Parâmetros usados no sistema PIV

\begin{tabular}{|c|c|}
\hline Tempo entre pulsos & $3 \mathrm{~ms}$ \\
\hline Tempo de exposição do frame 1 & $200 \mu \mathrm{s}$ \\
\hline Frequência de aquisição & $7,4 \mathrm{~Hz}$ \\
\hline Número de imagens & 500 (caracterização) e 1000 (pluma) \\
\hline Método de cálculo dos vetores & Correlação adaptativa \\
\hline Janelas de interrogação & $128 \times 128 \rightarrow 64 \times 64 \rightarrow 32 \times 32$ \\
\hline
\end{tabular}

O intervalo de tempo entre pulsos foi ajustado de modo que o deslocamento das partículas nas imagens entre os quadros fosse pequeno (menor do que 8 pixels). 
Além disso, o número de imagens foi escolhido com base em testes de convergência dos campos de velocidade médios.

Para os experimentos, foram escolhidas duas amplitudes de onda $(0,5 \mathrm{~cm}$ e $2,0 \mathrm{~cm})$ e uma frequência de oscilação $(0,67 \mathrm{~Hz})$. Além disso, foram escolhidas duas velocidades médias de corrente $\left(U_{C}=U_{m e d}\right)$ do escoamento do canal de água $(0,14$ e $0,27 \mathrm{~m} / \mathrm{s}$ ). Os testes foram realizados somente com uma vazão de injeção de ar $(0,2 \mathrm{~L} / \mathrm{min})$.

A matriz de testes investigada foi dividida em duas partes. A primeira parte está relacionada à caracterização do escoamento base (Tabela 2), em que a pluma de bolhas não está presente, neste caso é usada a sigla CR ao longo do texto para simplificar essa condição. E a segunda etapa considera a dispersão da pluma de bolhas no escoamento (Tabela 3), referenciada pela sigla PB.

Tabela 2 - Experimentos da caracterização

\begin{tabular}{|c|c|c|c|c|c|c|}
\hline Caracterização (CR) & Caso 1 & Caso 2 & Caso 3 & Caso 4 & Caso 5 & Caso 6 \\
\hline$U_{C}=0,14 \mathrm{~m} / \mathrm{s}$ & $\mathrm{xxx}$ & $\mathrm{xxx}$ & $\mathrm{xxx}$ & & & \\
\hline$U_{C}=0,27 \mathrm{~m} / \mathrm{s}$ & & & & $\mathrm{xxx}$ & $\mathrm{xxx}$ & $\mathrm{xxx}$ \\
\hline Pluma 0,2 L/min & & & & & & \\
\hline Amplitude $=0,5 \mathrm{~cm}$ & & $\mathrm{xxx}$ & & & $\mathrm{xxx}$ & \\
\hline Amplitude $=2,0 \mathrm{~cm}$ & & & $\mathrm{xxx}$ & & & $\mathrm{xxx}$ \\
\hline
\end{tabular}

Tabela 3 - Experimentos da pluma de bolhas

\begin{tabular}{|c|c|c|c|c|c|c|}
\hline $\begin{array}{c}\text { Pluma de bolhas } \\
(\mathrm{PB})\end{array}$ & Caso 1 & Caso 2 & Caso 3 & Caso 4 & Caso 5 & Caso 6 \\
\hline$U_{C}=0,14 \mathrm{~m} / \mathrm{s}$ & $\mathrm{xxx}$ & $\mathrm{xxx}$ & $\mathrm{xxx}$ & & & \\
\hline$U_{C}=0,27 \mathrm{~m} / \mathrm{s}$ & & & & $\mathrm{xxx}$ & $\mathrm{xxx}$ & $\mathrm{xxx}$ \\
\hline Pluma 0,2 L/min & $\mathrm{xxx}$ & $\mathrm{xxx}$ & $\mathrm{xxx}$ & $\mathrm{xxx}$ & $\mathrm{xxx}$ & $\mathrm{xxx}$ \\
\hline Amplitude $=0,5 \mathrm{~cm}$ & & $\mathrm{xxx}$ & & & $\mathrm{xxx}$ & \\
\hline Amplitude $=2,0 \mathrm{~cm}$ & & & $\mathrm{xxx}$ & & & $\mathrm{xxx}$ \\
\hline
\end{tabular}

Com estas variações de parâmetros e com a informação da resolução da câmera usada na técnica PIV, foi possível predefinir as posições do campo de visualização da câmera. Para cada caso experimental das tabelas 2 e 3 foram realizadas medições nos seis campos de visualização da câmera do sistema PIV, conforme ilustrado na Figura 58. 


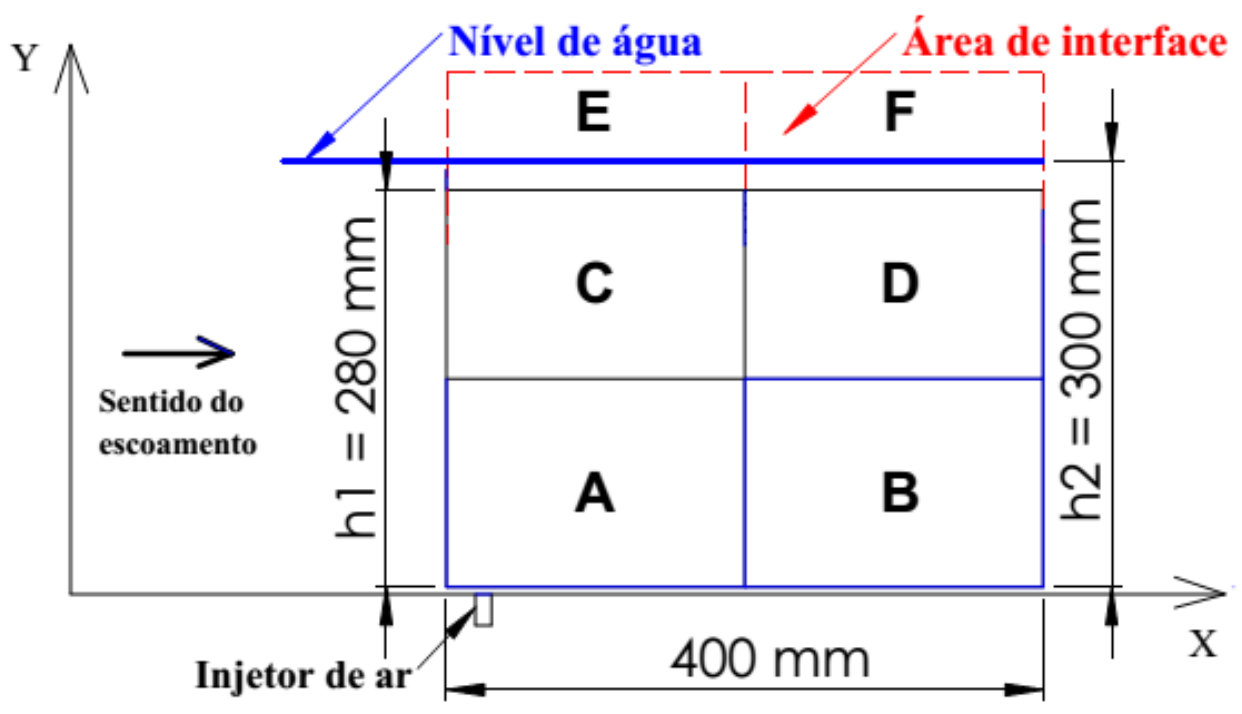

Figura 58 - Campos de visualização da câmera do sistema PIV

Com o nível da água mantido em $300 \mathrm{~mm}$, foram definidas seis posições de medição: A, B, C, D, E e F. As regiões E e F permitem visualizar a interface arágua, para isso a câmera foi deslocada para estas duas regiões somente para a caracterização do escoamento com ondas. Quando a pluma de bolhas estava presente, a máxima altura de visualização da câmera foi de h1 $=280 \mathrm{~mm}$, de modo a não capturar a interface.

\section{2. \\ Caracterização do escoamento sem ondas e sem pluma}

A média dos campos vetoriais instantâneos de velocidade foi plotada para as condições de escoamento sem ondas, como mostrado na Figura 59 e na Figura 60. A escala de cores representa as intensidades da componente de velocidade horizontal $(U)$ do escoamento. Os campos vetoriais de cada janela de visualização da câmera foram unidos para formar o campo de visualização total das janelas A, B, C e D. A densidade de vetores no campo foi diminuída em 40\% (mostrando 1 vetor a cada $8 \mathrm{~mm}$ ) para melhorar a visualização. Além disso, todos os campos resultantes foram plotados considerando-se $\mathrm{Y}=\mathrm{h} 1$, sem a amostra da região de interface. É possível observar na Figura 59 e na Figura 60, que os vetores se apresentam de maneira uniforme, todos no sentido principal do escoamento. $\mathrm{Na}$ região superior à direita, correspondente ao campo de visualização D da câmera, 
existe uma pequena região pouco iluminada pela luz do laser, por isso as imagens estão mostradas com o limite da escala horizontal até $300 \mathrm{~mm}$. Além disso, é possível notar na região inferior esquerda do campo, um pequeno conjunto de vetores com magnitudes diferentes dos demais, isso se deve a uma região de sombra causada pelo injetor de ar.

Analisando os campos, é possível observar que próximo a parede há uma redução da velocidade devido a camada limite sobre a placa inferior.
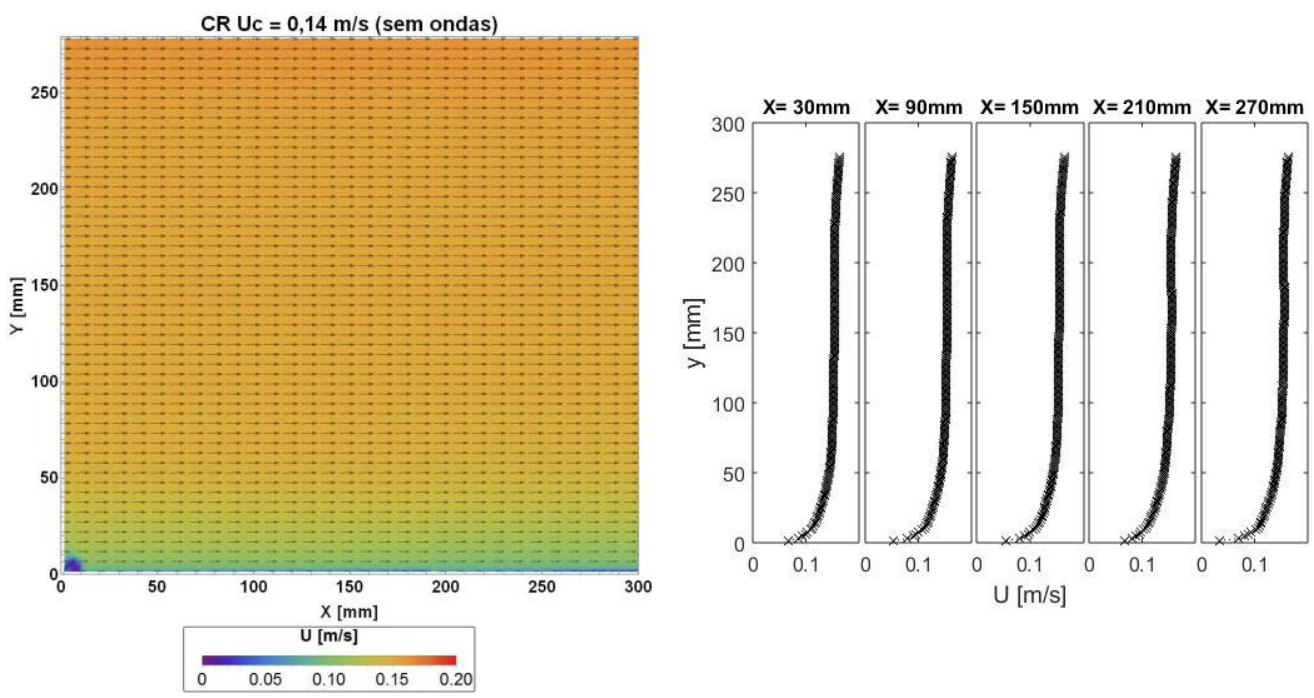

Figura 59 - Campo vetorial médio para $\mathrm{U}_{\mathrm{C}}=0,14 \mathrm{~m} / \mathrm{s}$ (sem ondas)
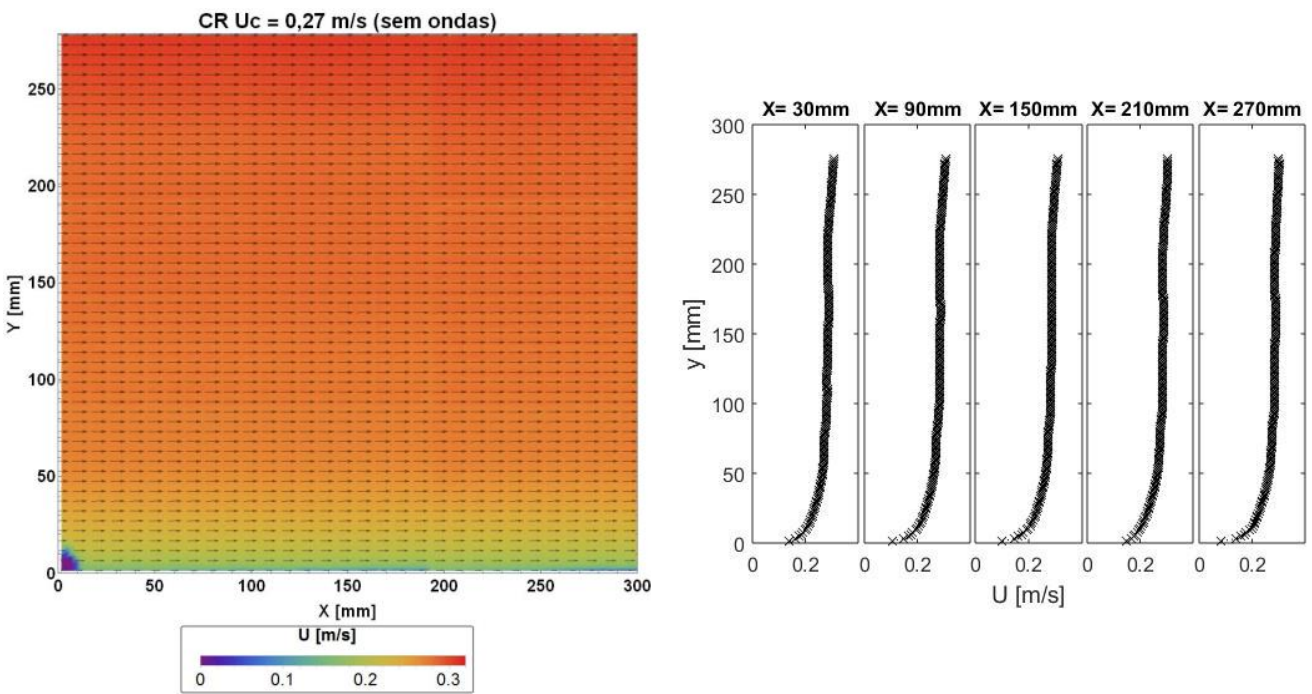

Figura 60 - Campo vetorial médio para $\mathrm{U}_{\mathrm{C}}=0,27 \mathrm{~m} / \mathrm{s}$ (sem ondas) 
Para quantificar as flutuações de velocidade do escoamento base sem ondas, foram traçados os perfis de intensidade turbulenta juntamente com o campo de turbulência das componentes de velocidade na direção do escoamento e na direção normal à parede (X e Y respectivamente). Dessa forma, as flutuações de velocidade nas duas componentes podem ser analisadas no plano de medição. A intensidade de turbulência foi calculada dividindo-se o desvio padrão da velocidade ( $U_{r m s}$ ou $\left.V_{r m s}\right)$ pela velocidade média da componente horizontal do escoamento $\left(U_{m e d}\right)$. Assim, os valores resultantes da divisão são apresentados como uma fração da velocidade média do escoamento base.

Os campos das intensidades turbulenta, $U_{r m s} / U_{m e d}$ e $V_{r m s} / U_{m e d}$, e os respectivos perfis em diferentes posições, estão apresentados na Figura 61, Figura 62, Figura 63 e na Figura 64. Como esperado, as flutuações verticais e horizontais de velocidade no escoamento sem ondas são da ordem do nível de turbulência do canal. É possível perceber que a magnitude da intensidade turbulenta é maior próximo à parede, devido à camada limite turbulenta. Pequenas variações sistemáticas são observadas nos campos de velocidade. Tais variações são causadas pela sobreposição das imagens que foram capturadas em momentos diferentes ao longo do dia. Com isso, variações nas medições, causadas por alterações de temperatura do sistema de bombeamento, do fluido de trabalho, além de mudanças nas condições de iluminação do ambiente acabam sendo observadas nas regiões de sobreposição das imagens. Ainda assim, as diferenças observadas foram pequenas e não afetaram a análise dos resultados. 

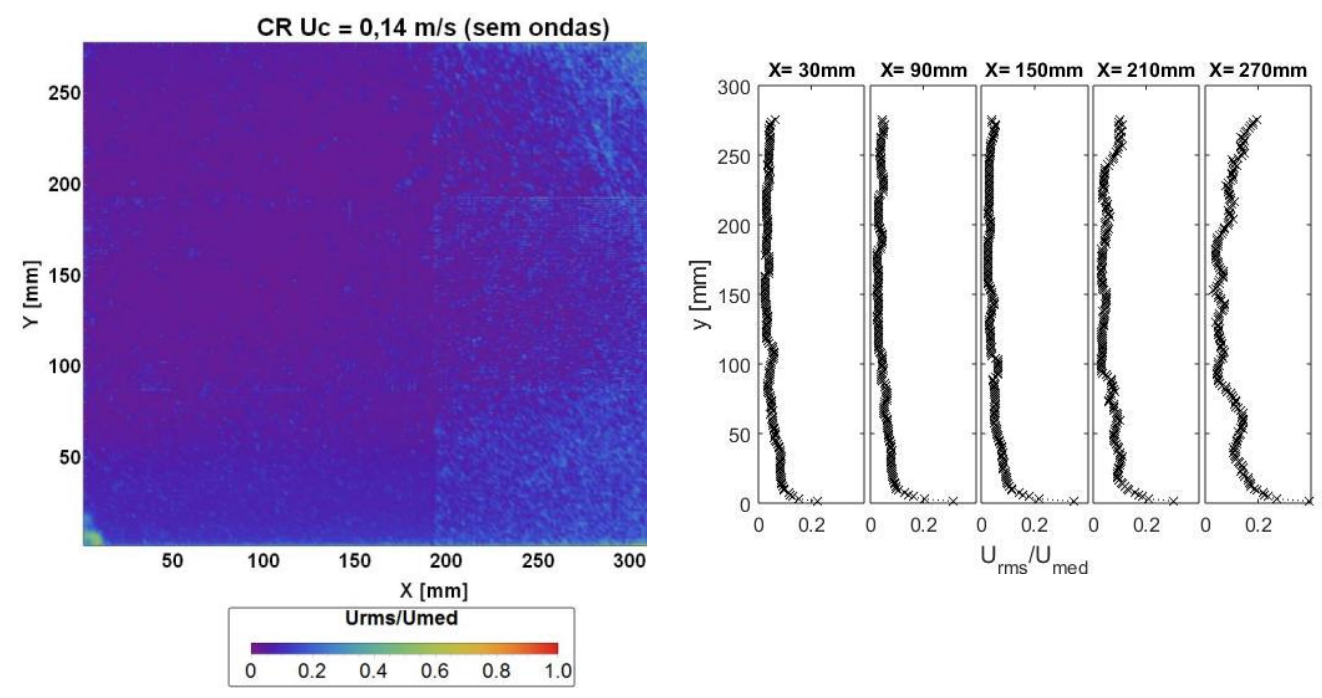

Figura 61 - Campo de flutuações horizontais para $U_{C}=0,14 \mathrm{~m} / \mathrm{s}(\mathrm{sem}$ ondas)
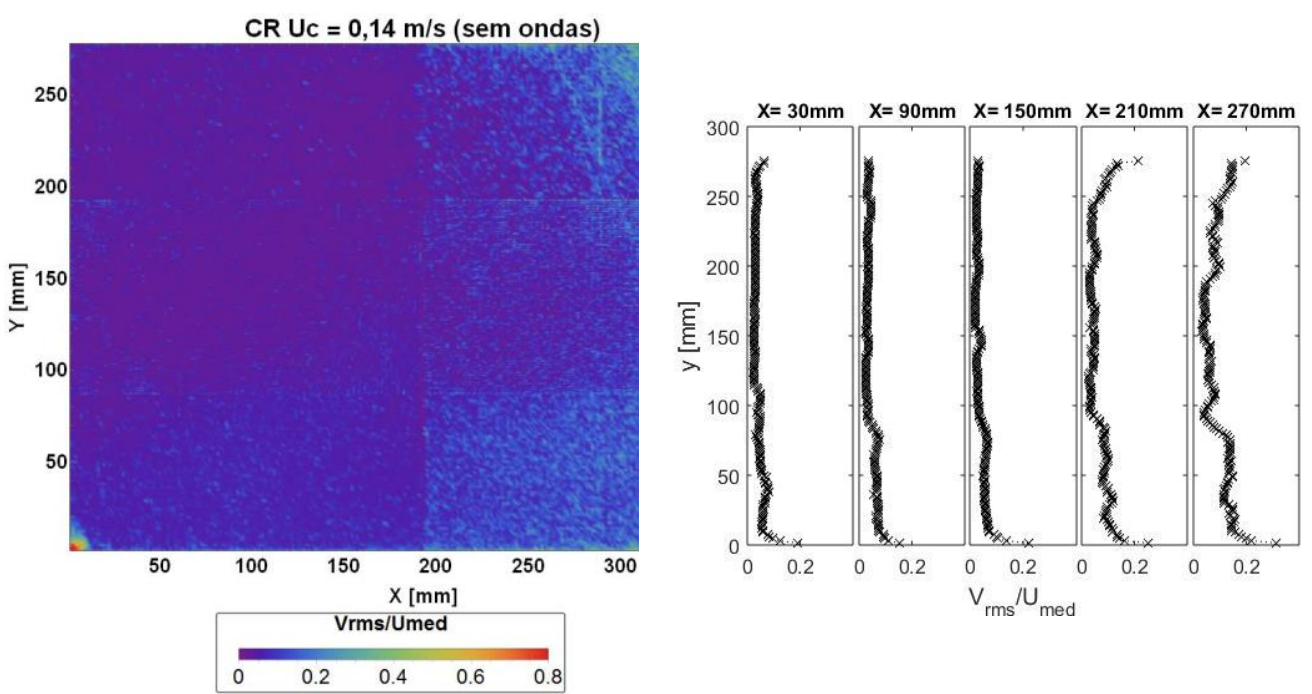

Figura 62 - Campo de flutuações verticais para $U_{C}=0,14 \mathrm{~m} / \mathrm{s}$ (sem ondas) 

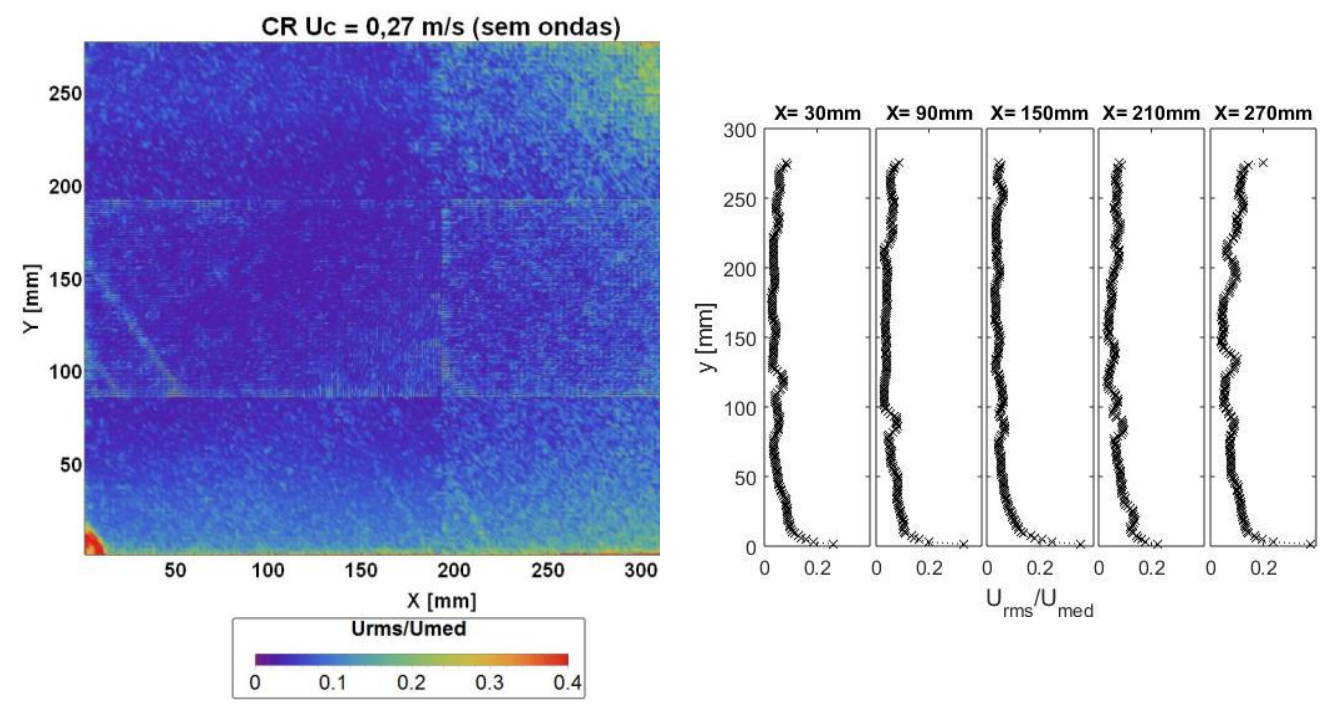

Figura 63 - Campo de flutuações horizontais para $\mathrm{U}_{\mathrm{C}}=0,27 \mathrm{~m} / \mathrm{s}(\mathrm{sem}$ ondas)
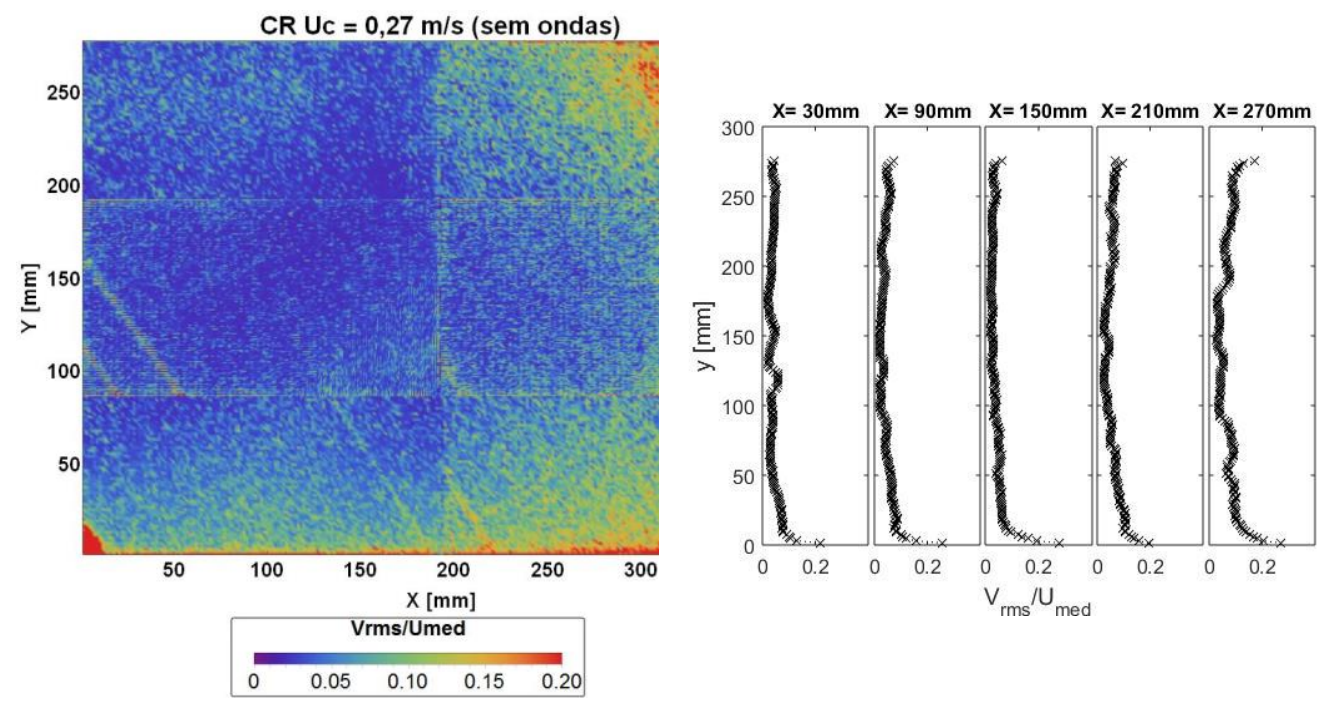

Figura 64 - Campo de flutuações verticais para $U_{C}=0,27 \mathrm{~m} / \mathrm{s}$ (sem ondas)

\section{3.}

\section{Caracterização do escoamento com ondas}

Nesta seção, é apresentada a caracterização do escoamento base com ondas. Os tópicos estão separados para as ondas de baixa amplitude $(0,5 \mathrm{~cm})$ e ondas de alta amplitude $(2,0 \mathrm{~cm})$, juntamente com os respectivos efeitos causados pelas ondas na região próxima a interface. São analisados, também, os espectros de frequência para cada condição empregada. O último item desta seção apresenta uma 
comparação da flutuação de velocidades entre os casos sem ondas e com ondas, mostrando os principais efeitos das ondas no escoamento.

\subsection{1.}

\section{Ondas de amplitude $=0,5 \mathrm{~cm}$}

Os campos vetoriais médios de velocidade para as condições de velocidades da corrente do canal iguais a 0,14 e $0,27 \mathrm{~m} / \mathrm{s}$ e amplitude da onda igual a $0,5 \mathrm{~cm}$ estão apresentadas na Figura 65 e na Figura 66. Observando-se os campos, é possível perceber que a intensidade da componente horizontal de velocidade é pouco alterada devido às ondas.
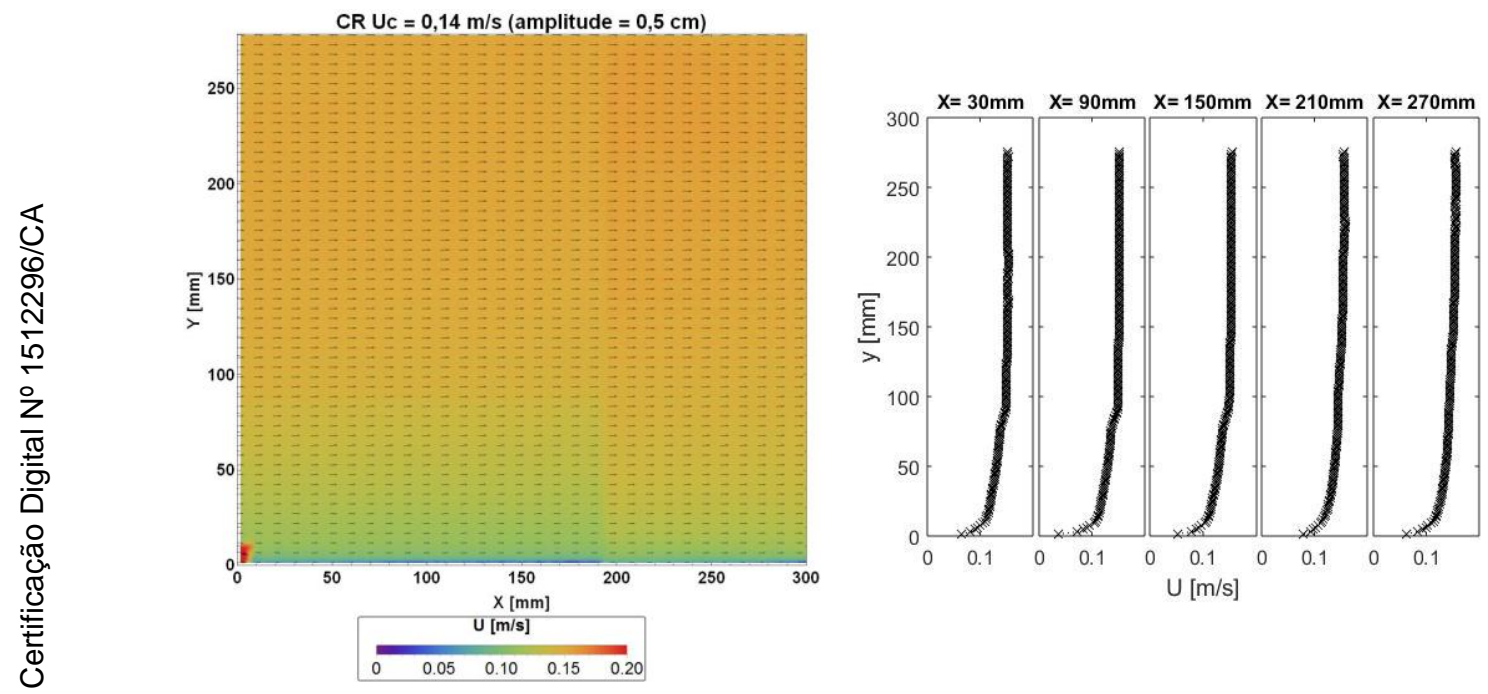

Figura 65 - Campo vetorial médio para $\mathrm{U}_{\mathrm{C}}=0,14 \mathrm{~m} / \mathrm{s}($ amplitude $=0,5 \mathrm{~cm})$ 

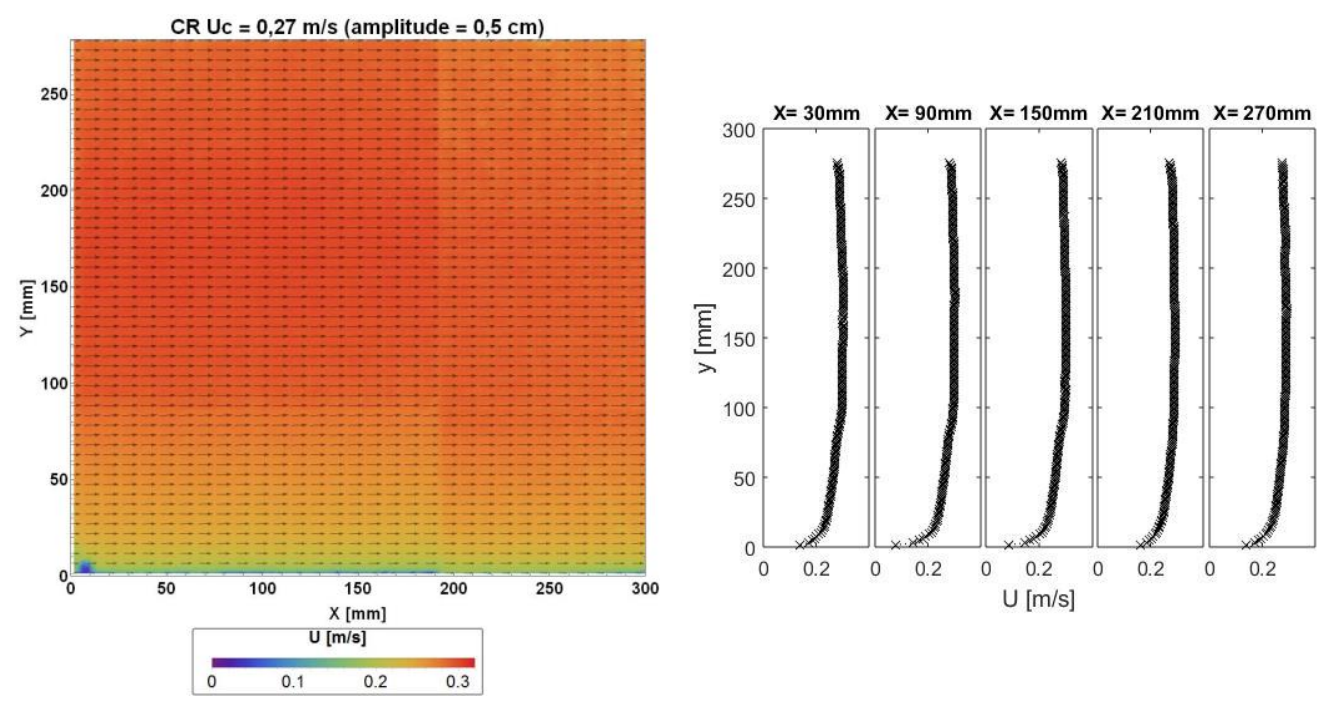

Figura 66 - Campo vetorial médio para $\mathrm{U}_{\mathrm{C}}=0,27 \mathrm{~m} / \mathrm{s}($ amplitude $=0,5 \mathrm{~cm})$

Os campos de flutuação de velocidade nas componentes horizontal e vertical de velocidade para as condições com ondas, são mostrados na Figura 67, Figura 68, Figura 69 e Figura 70. Aparentemente, as flutuações de velocidade na presença de ondas de amplitude igual a $0,5 \mathrm{~cm}$ apresentam um leve aumento de magnitude na região próxima à superfície, comparada com a Figura 61 .
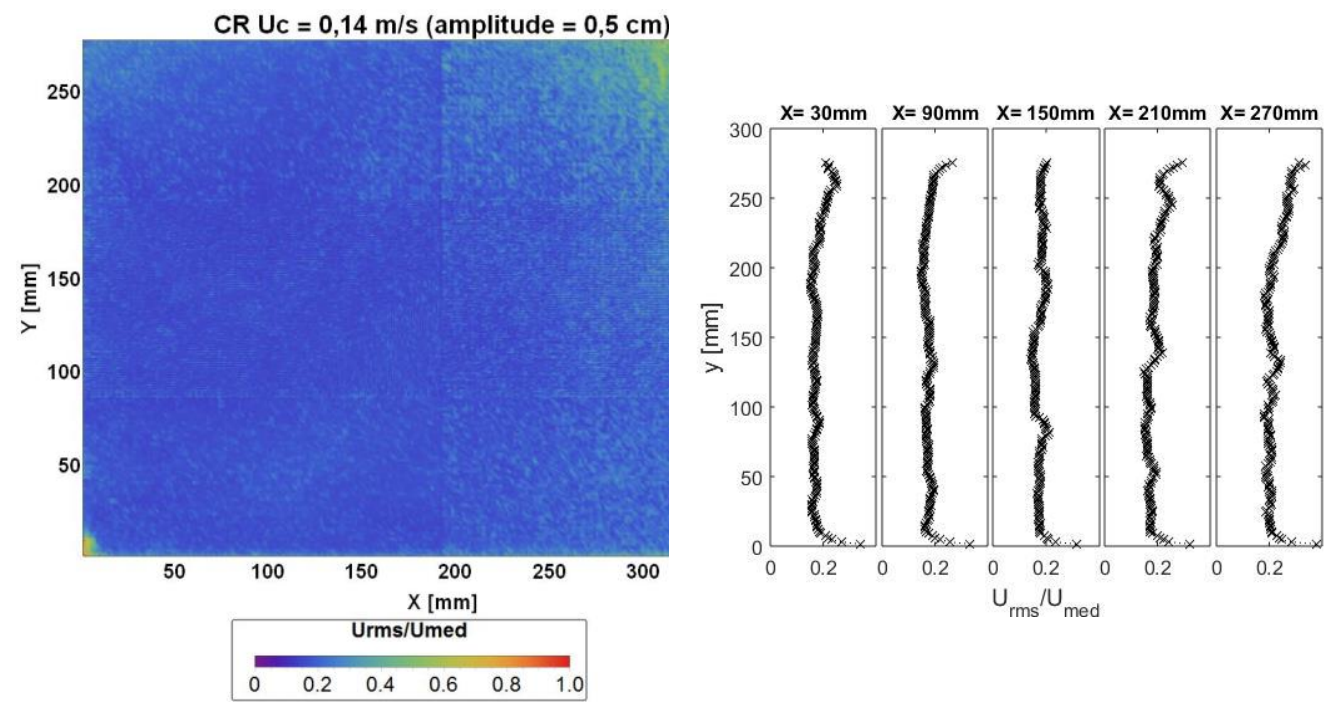

Figura 67 - Campo de flutuações horizontais para $U_{C}=0,14 \mathrm{~m} / \mathrm{s}$ (amplitude

$$
=0,5 \mathrm{~cm})
$$



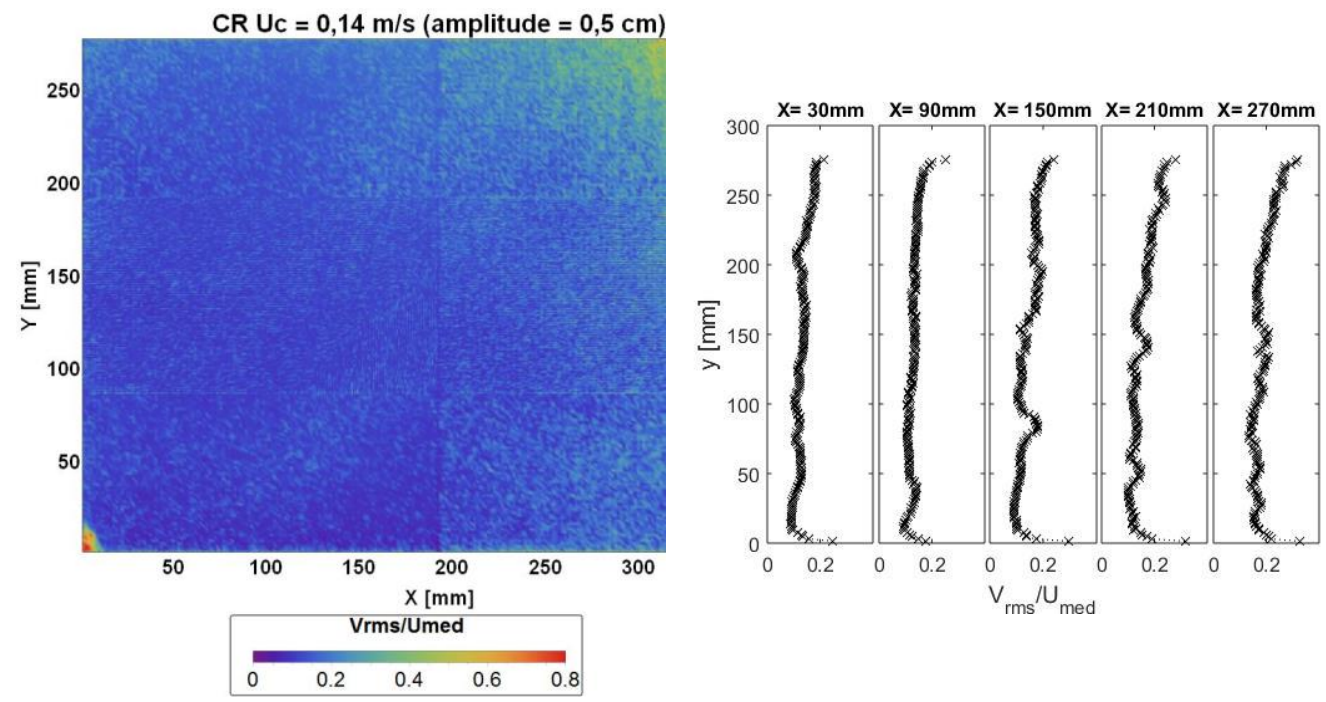

Figura 68 - Campo de flutuações verticais para $\mathrm{U}_{\mathrm{C}}=0,14 \mathrm{~m} / \mathrm{s}$ (amplitude $=$

$$
0,5 \mathrm{~cm})
$$

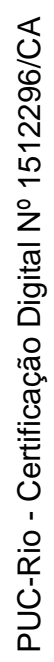

Nos casos com velocidade do escoamento cruzado igual a $0,27 \mathrm{~m} / \mathrm{s}$, nota-se uma menor influência das ondas sobre as flutuações do escoamento quando se compara os resultados com o caso com velocidade de $0,14 \mathrm{~m} / \mathrm{s}$. Isso pode ser qualitativamente observado comparando-se as figuras 69 e 70 com as figuras 63 e 64.
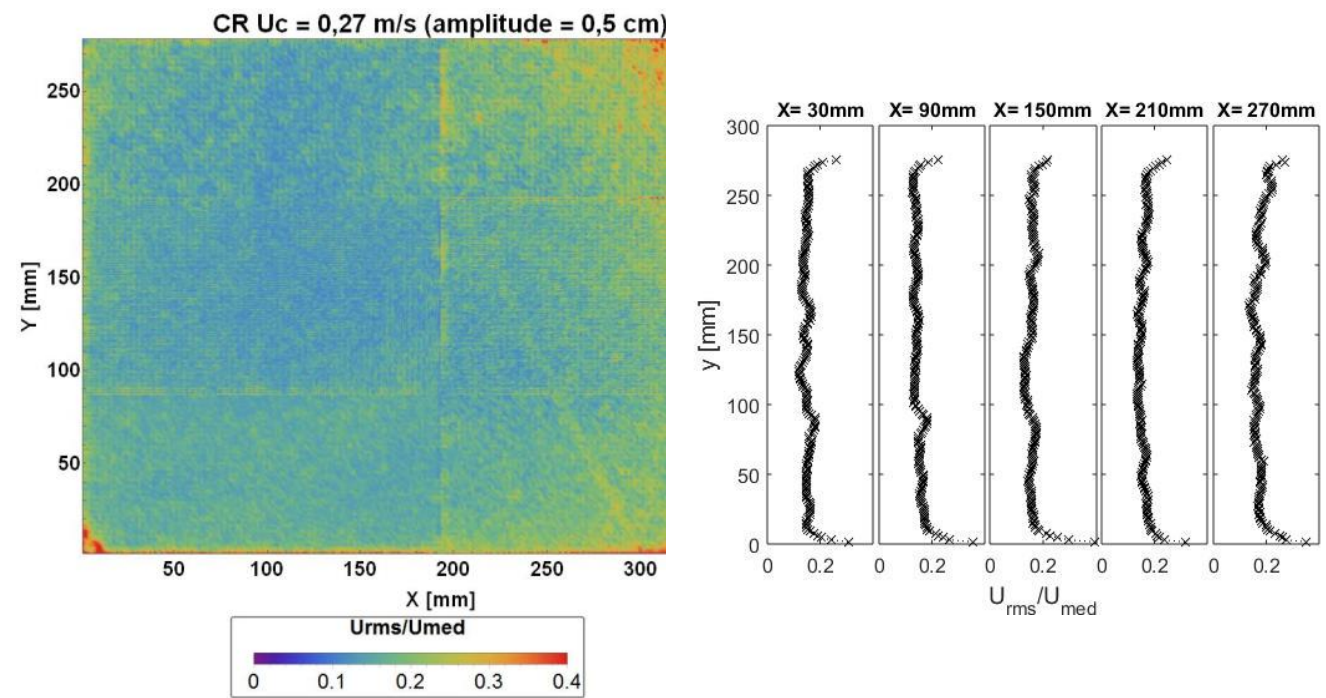

Figura 69 - Campo de flutuações horizontais para $U_{C}=0,27 \mathrm{~m} / \mathrm{s}$ (amplitude

$$
=0,5 \mathrm{~cm})
$$



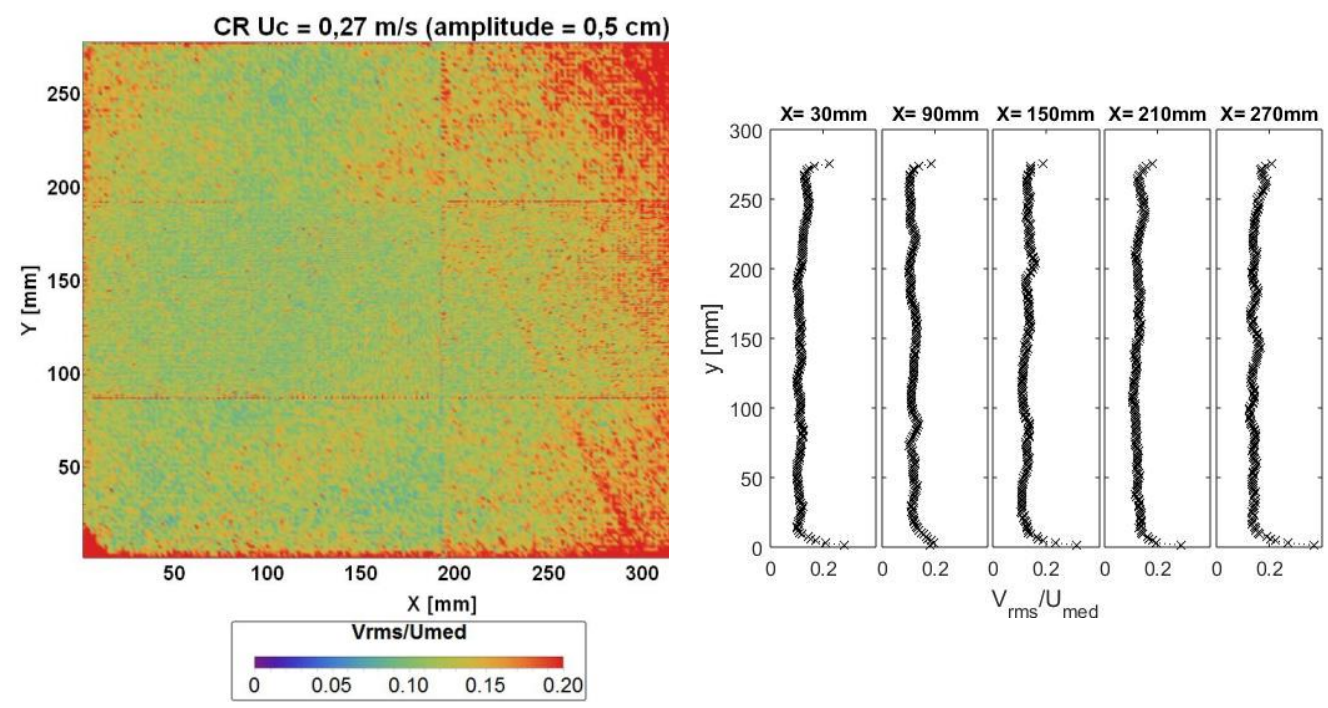

Figura 70 - Campo de flutuações verticais para $\mathrm{U}_{\mathrm{C}}=0,27 \mathrm{~m} / \mathrm{s}$ (amplitude $=$ $0,5 \mathrm{~cm})$

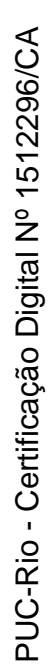

\subsection{2.}

\section{Ondas de amplitude $=2,0 \mathrm{~cm}$}

Os campos de velocidade média obtidos para as condições de velocidades da corrente do canal iguais a 0,14 e $0,27 \mathrm{~m} / \mathrm{s}$ e amplitude da onda igual a 2,0 cm são apresentados na Figura 71 e na Figura 72. Os campos de velocidade apresentam características qualitativamente semelhantes àqueles do caso com ondas de amplitude igual a $0,5 \mathrm{~cm}$.
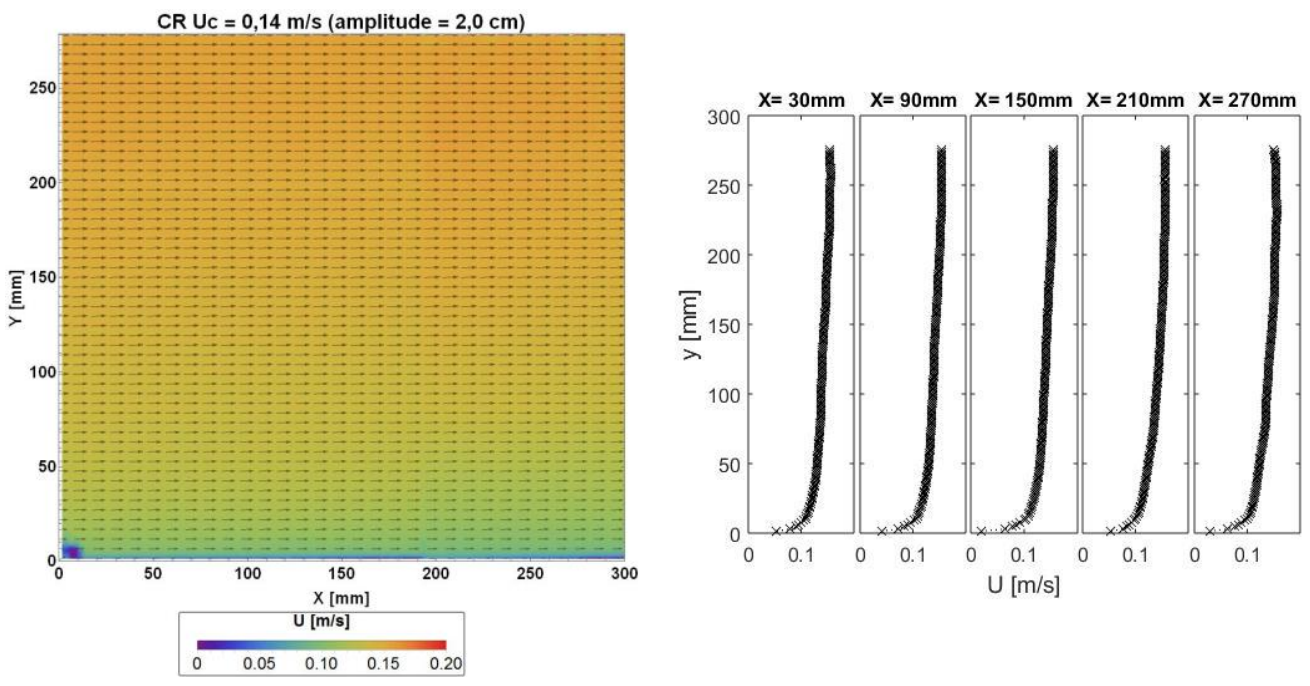

Figura 71 - Campo vetorial médio para $\mathrm{U}_{\mathrm{C}}=0,14 \mathrm{~m} / \mathrm{s}($ amplitude $=2,0 \mathrm{~cm})$ 

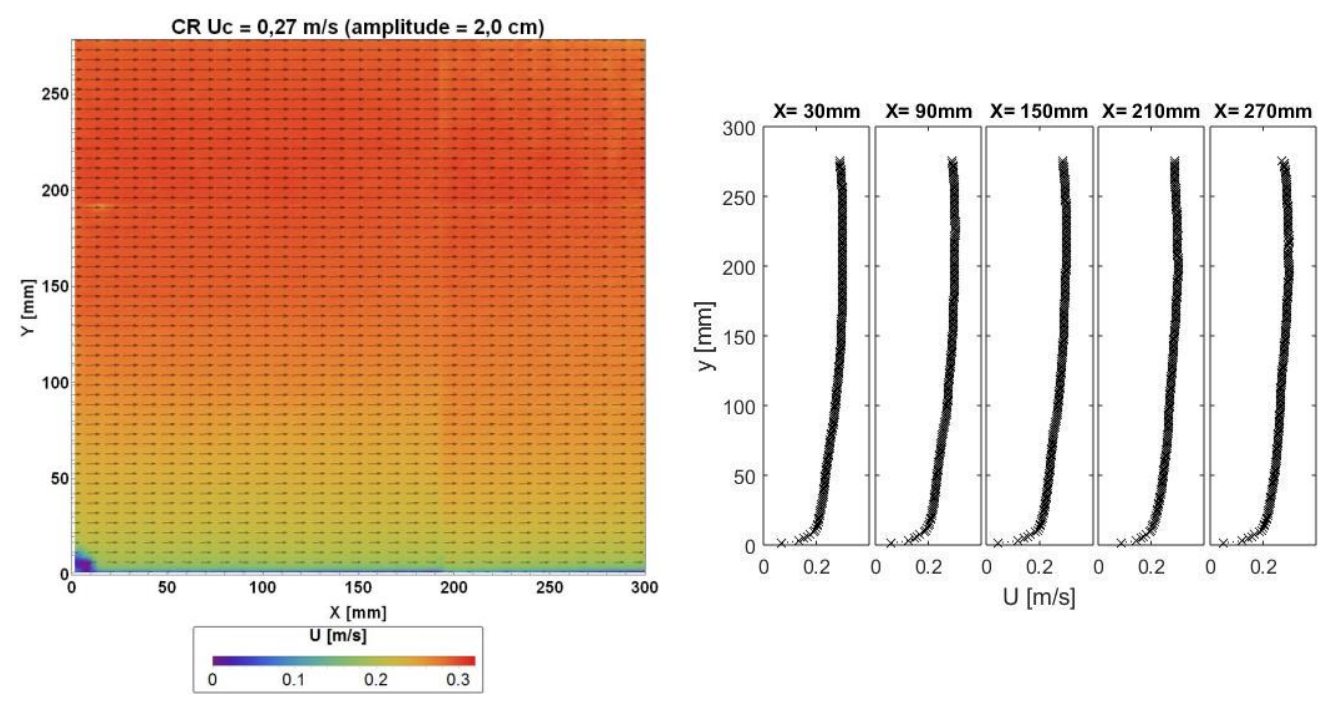

Figura 72 - Campo vetorial médio para $\mathrm{U}_{\mathrm{C}}=0,27 \mathrm{~m} / \mathrm{s}($ amplitude $=2,0 \mathrm{~cm})$

$\mathrm{Na}$ condição de ondas de amplitude igual a 2,0 cm, existe um aumento de turbulência na região superior da área de medição, tanto para as componentes horizontais $\left(U_{r m s} / U_{m e d}\right)$, quanto para as componentes verticais $\left(V_{r m s} / U_{m e d}\right)$. Para a condição $U c=0,14 \mathrm{~m} / \mathrm{s}$, isso pode ser observado na Figura 73 e na Figura 74 pela inclinação das curvas de flutuação de velocidade em todas as posições do escoamento. Essas características dos perfis de flutuação de velocidades são esperadas de acordo com os modelos de ondas progressivas (Dean e Darlymple, 1991). Mais adiante no texto, na seção 6.3.6, uma comparação com os perfis de ondas será realizada. Para os casos com $U c$ igual a $0,27 \mathrm{~m} / \mathrm{s}$, apresentadas na Figura 75 e na Figura 76, os perfis são menos inclinados em relação ao eixo vertical. Isso indica que a turbulência do canal tem magnitude similar às flutuações induzidas pelas ondas. 

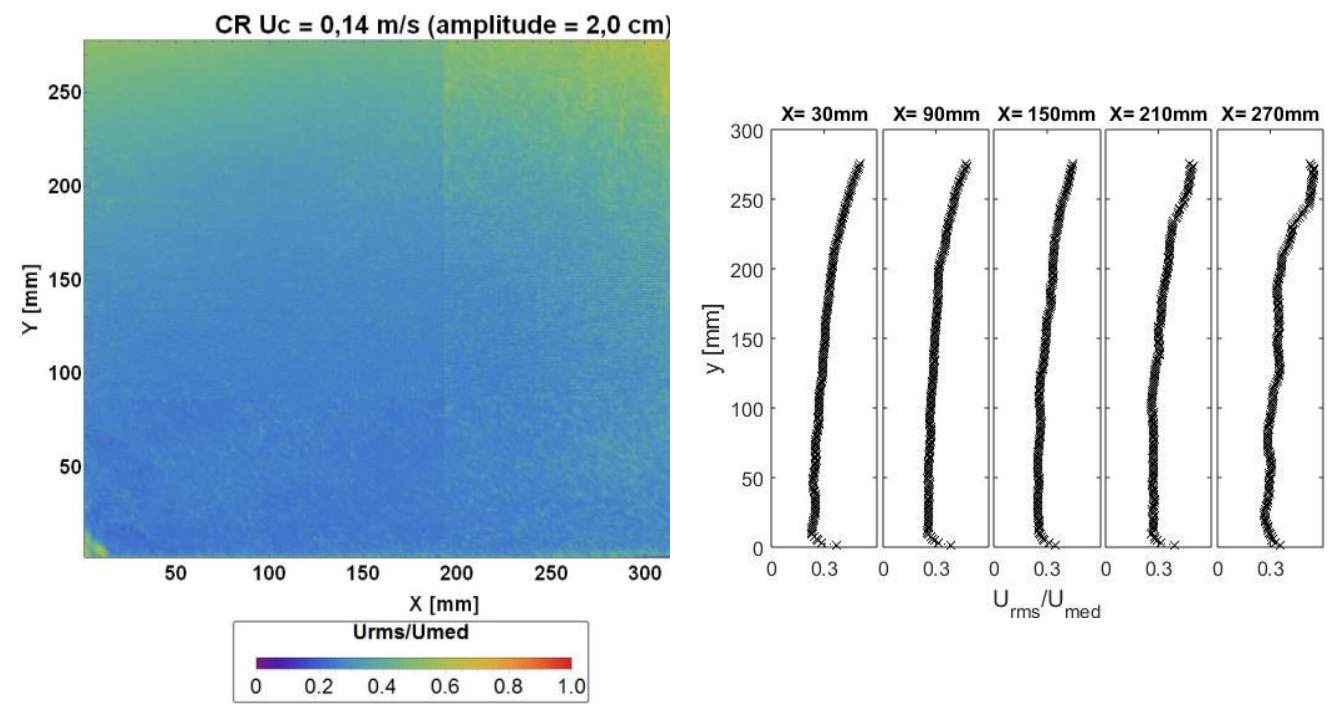

Figura 73 - Campo de flutuações horizontais para $U_{C}=0,14 \mathrm{~m} / \mathrm{s}$ (amplitude $=2,0 \mathrm{~cm})$

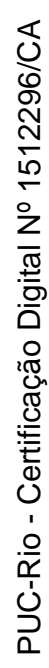
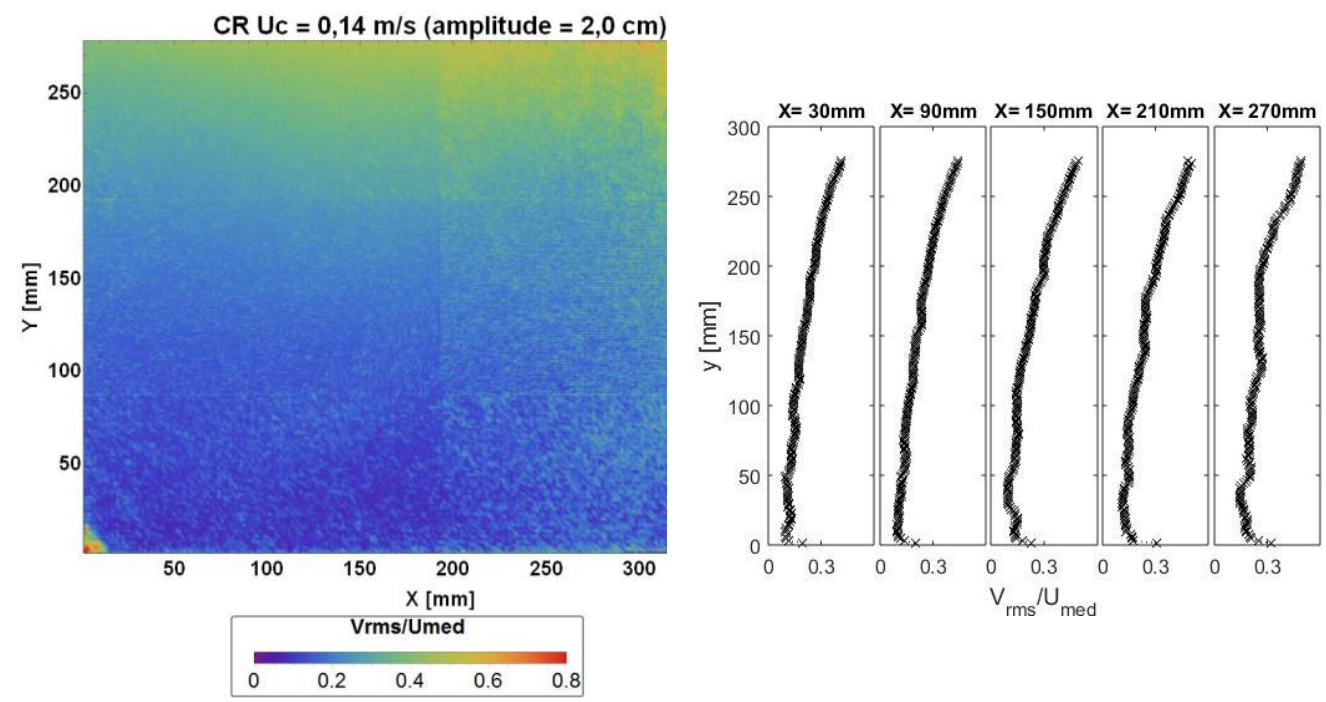

Figura 74 - Campo de flutuações verticais para $\mathrm{U}_{\mathrm{C}}=0,14 \mathrm{~m} / \mathrm{s}$ (amplitude $=$ $2,0 \mathrm{~cm})$ 

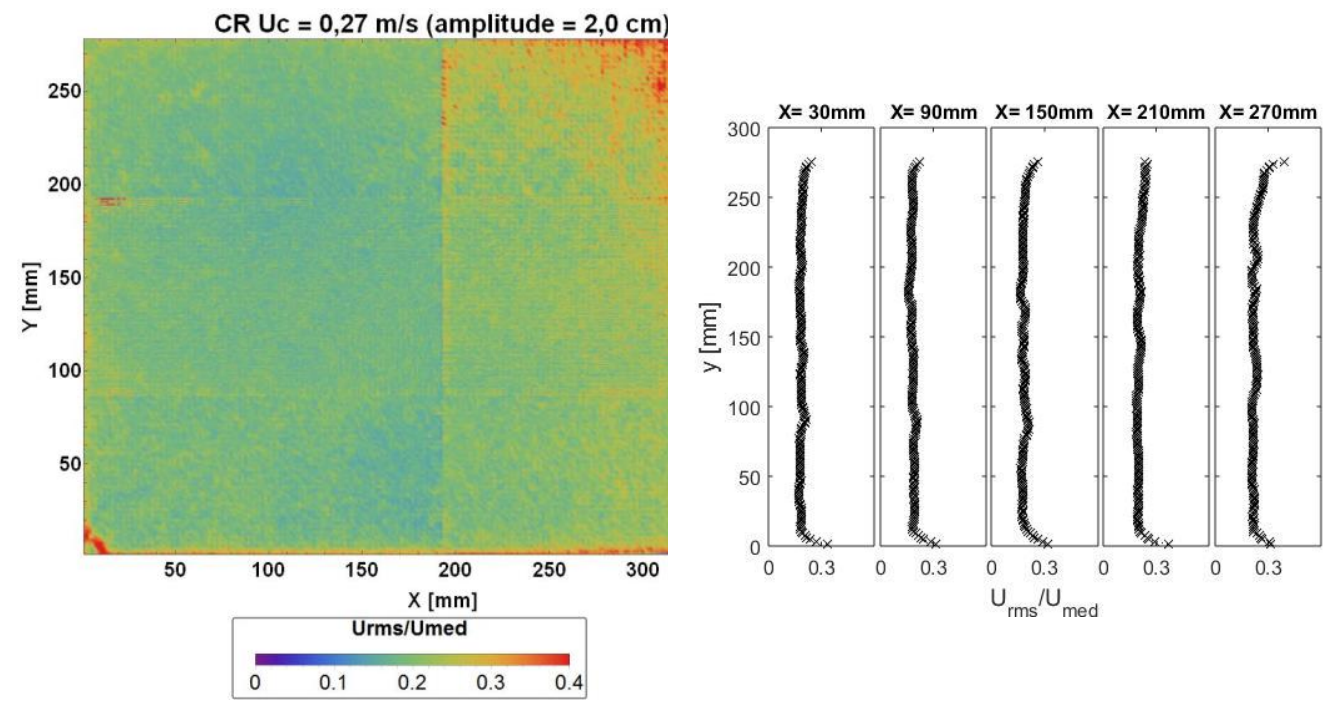

Figura 75 - Campo de flutuações horizontais para $\mathrm{U}_{\mathrm{C}}=0,27 \mathrm{~m} / \mathrm{s}$ (amplitude $=2,0 \mathrm{~cm})$
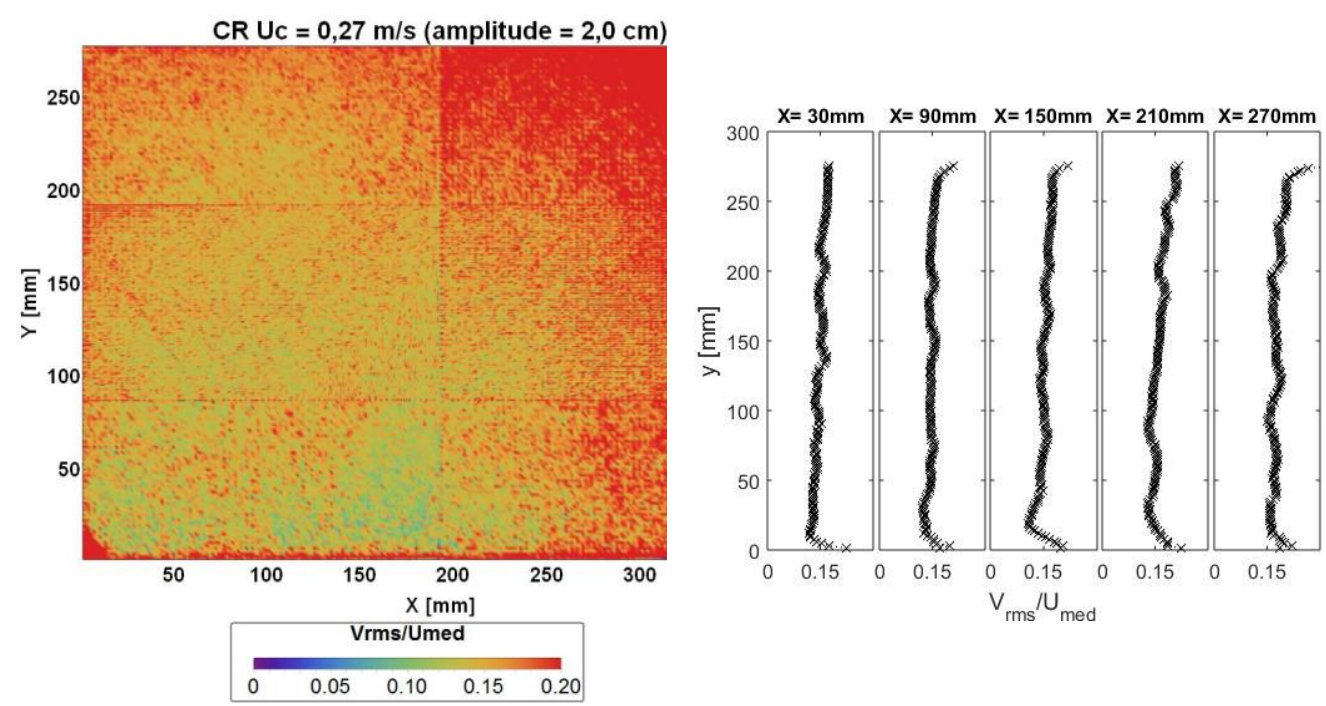

Figura 76 - Campo de flutuações verticais para $U_{C}=0,27 \mathrm{~m} / \mathrm{s}$ (amplitude $=$

$$
2,0 \mathrm{~cm})
$$

\subsection{3.}

\section{Efeito das ondas na interface}

Para verificar os efeitos das ondas na região bem próxima à interface, também foram traçados perfis de flutuação de velocidade considerando os dados obtidos nesta região $(\mathrm{Y}=\mathrm{h} 2)$. Foram escolhidas três posições no plano longitudinal para ilustrar o comportamento dos perfis, sendo uma mais próxima ao ponto de injeção 
de $\operatorname{ar}(X=30 \mathrm{~mm})$, uma estação intermediária $(X=120 \mathrm{~mm})$ e uma região mais afastada do ponto de injeção $(X=210 \mathrm{~mm})$.

Os perfis apresentados na Figura 77, mostram que as componentes de flutuação de velocidade atingem amplitudes consideráveis na região próxima à superfície da água. Outra característica, até mesmo imprevista, é em relação ao efeito da onda comparando-se as duas amplitudes. O caso com amplitude de onda mais baixa $(0,5 \mathrm{~cm})$ apresenta um efeito concentrado na superfície e com amplitude maior do que o caso com onda de amplitude mais alta $(2,0 \mathrm{~cm})$. Entretanto, o escoamento é afetado até bem próximo a parede inferior do canal no caso com onda de maior amplitude, ou seja, nesse caso a energia das ondas é distribuída em toda a altura do canal.

Na Figura 78, para $U c=0,27 \mathrm{~m} / \mathrm{s}$, o efeito da onda de amplitude igual a 2,0 $\mathrm{cm}$ é maior do que o efeito causado pela onda de menor amplitude $(0,5 \mathrm{~cm})$. Ainda assim, em ambos os casos as maiores perturbações causadas pelas ondas ficaram restritas à superfície.

A Figura 79 e a Figura 80, mostram aos perfis de flutuação da componente vertical de velocidade $v$. Analisando-se os gráficos, nota-se que os efeitos da flutuação vertical da velocidade também apresentam maior intensidade na região próxima à superfície. Aqui também se observa que os efeitos das ondas mais baixas são maiores do que os efeitos da onda de maior amplitude na região próxima à superfície, para o caso $U c=0,14 \mathrm{~m} / \mathrm{s}$. Para a velocidade de escoamento cruzado $U c$ $=0,27 \mathrm{~m} / \mathrm{s}$, apresentada na Figura 80, os níveis de intensidade de turbulência são similares para as duas amplitudes de onda.

Apesar da amplitude das perturbações induzidas pelas ondas ser muito mais alta em regiões próximas à superfície, neste trabalho buscou-se avaliar a interação entre a pluma e as ondas nas regiões mais próximas a região de injeção das bolhas. Neste trabalho optou-se pelo enfoque nessa região pelo fato de que as oscilações do escoamento induzidas pelas ondas, nas regiões mais profundas do leito, tendem a ter maior influência na dispersão das bolhas. Isso porque, pequenos desvios de trajetória em regiões mais profundas tendem a gerar grandes deslocamentos próximos a superfície. Além disso, espera-se que próximo a superfície o escoamento seja dominado pelas ondas e com isso espera-se que as bolhas sigam a trajetória do escoamento oscilatório. Já nas regiões mais próximas ao leito, não é claro o efeito que as ondas devem ter sobre as bolhas, já que as flutuações de 
velocidade induzidas pelas ondas e pelas plumas devem ter ordem de magnitude semelhantes. Outro fator que influenciou a decisão de dar maior enfoque a regiões próximas ao leito é a dificuldade do processamento de imagens das bolhas na região da interface. Nessa região é difícil realizar o processamento para identificação de bolhas e da interface automaticamente.

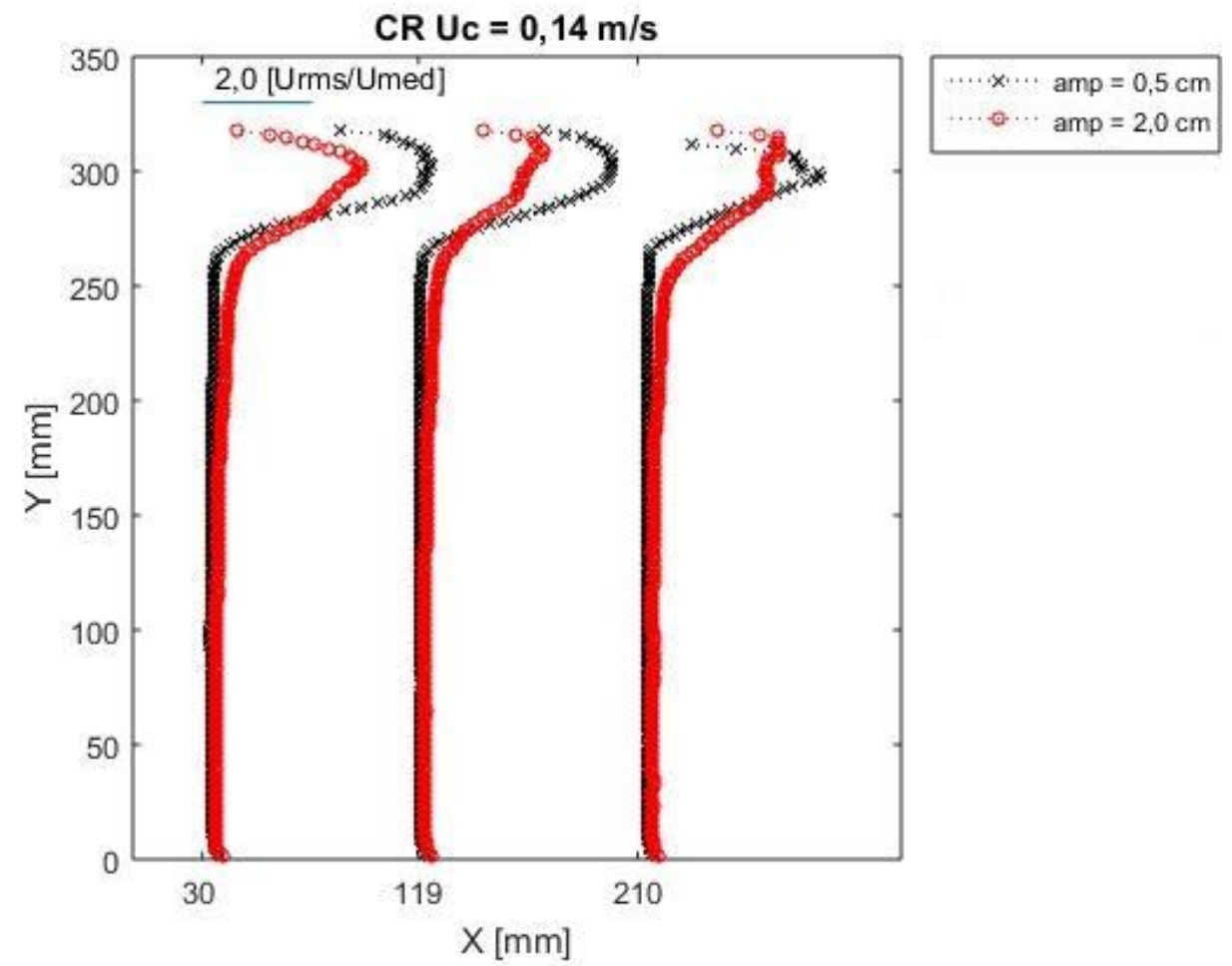

Figura 77 - Flutuação de velocidade $U_{r m s}$ para $U_{C}=0,14 \mathrm{~m} / \mathrm{s}$ 


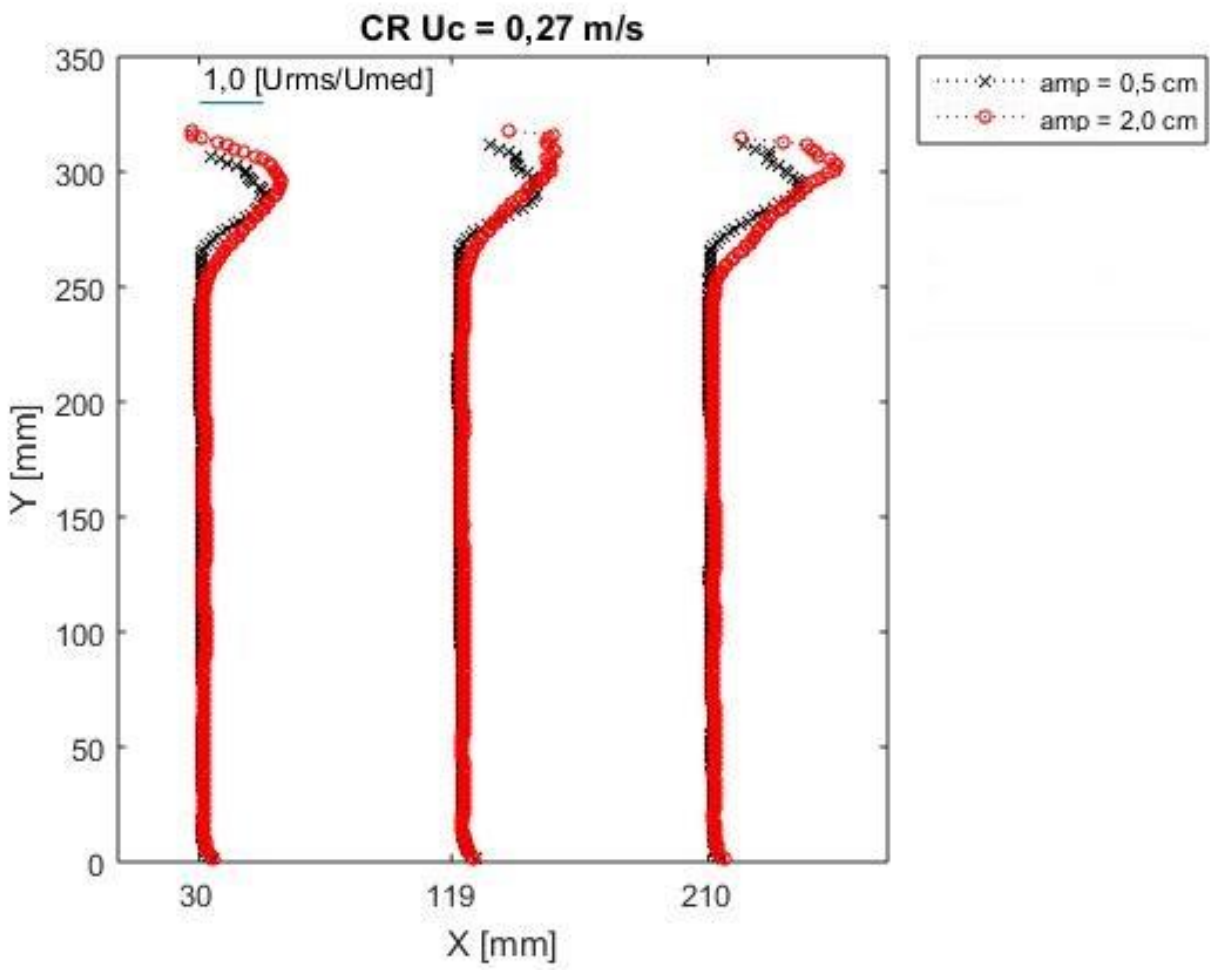

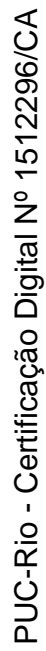

Figura 78 - Flutuação de velocidade $U_{r m s}$ para $U_{C}=0,27 \mathrm{~m} / \mathrm{s}$

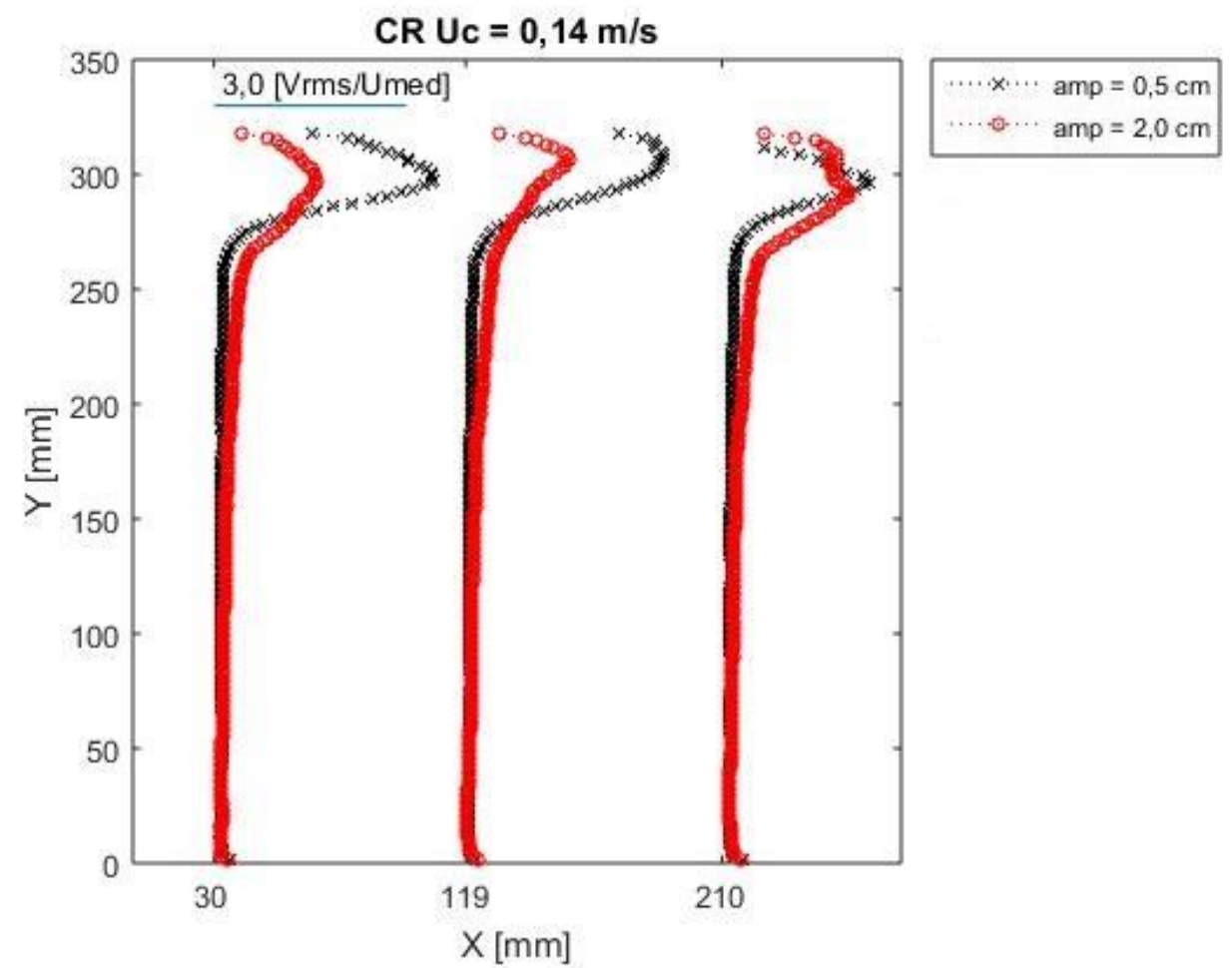

Figura 79 - Flutuação de velocidade $V_{r m s}$ para $U_{C}=0,14 \mathrm{~m} / \mathrm{s}$ 


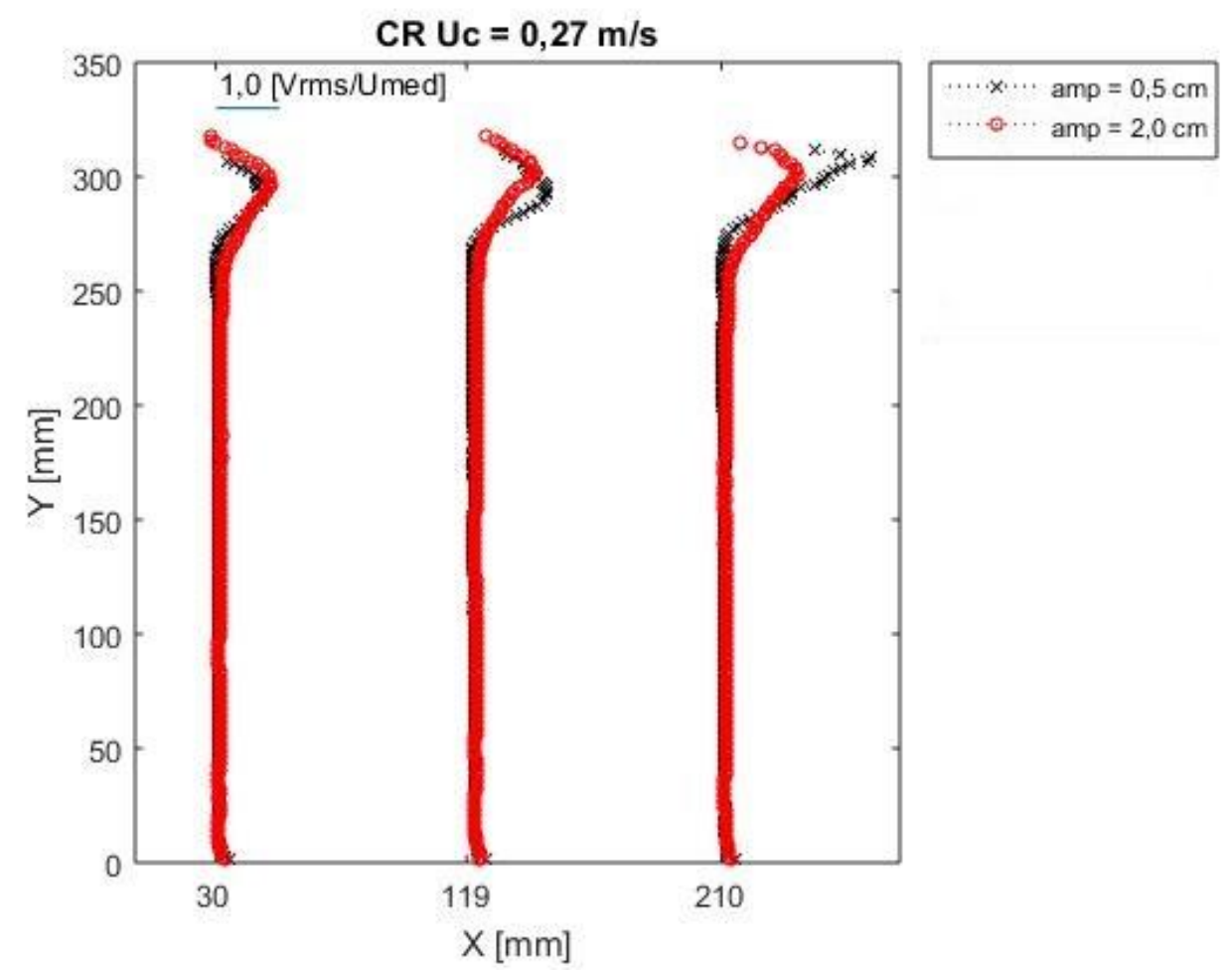

Figura 80 - Flutuação de velocidade $V_{r m s}$ para $U_{C}=0,27 \mathrm{~m} / \mathrm{s}$

\subsection{4.}

\section{Análise das flutuações de velocidade}

Nesta seção são analisados os espectros de frequência das flutuações de velocidade do escoamento (ver Figura 81, Figura 82, Figura 83 e na Figura 84). Nas figuras são identificadas as frequências dominantes dos espectros em cada posição do plano de medição. Os espectros em posições específicas dentro da região de medição, que foram marcadas nas figuras 81a, 82a, 83a e 84a por círculos em vermelho, são apresentados em detalhe nas figuras $81 \mathrm{~b}, 82 \mathrm{~b}, 83 \mathrm{~b}$ e $84 \mathrm{~b}$. Observase em quase todos os casos, que existem dois picos de frequência bem definidos, nas frequências de $0,67 \mathrm{~Hz}$ e 1,34 Hz. A primeira frequência, já esperada, corresponde à frequência de geração de ondas pelo motor. A segunda frequência é um harmônico da primeira. Esse modo aparece no espectro porque o gerador de perturbações não era capaz de gerar perturbações puramente senoidais. As figuras mostram que próximo da interface as maiores perturbações do espectro possuem relação com as frequências das ondas. Já próximo à parede, essa relação não é observada e as flutuações provavelmente estão mais relacionadas com a turbulência da camada limite do canal. Para a condição de velocidade do escoamento cruzado 
$U c$ igual a $0,27 \mathrm{~m} / \mathrm{s}$ (Figuras 83a e 84a) os picos de amplitude dos espectros não se localizam em frequências tão bem definidas como nos outros casos. Isso provavelmente se deve ao fato da perturbação induzida pela onda ser da mesma ordem da turbulência do escoamento.

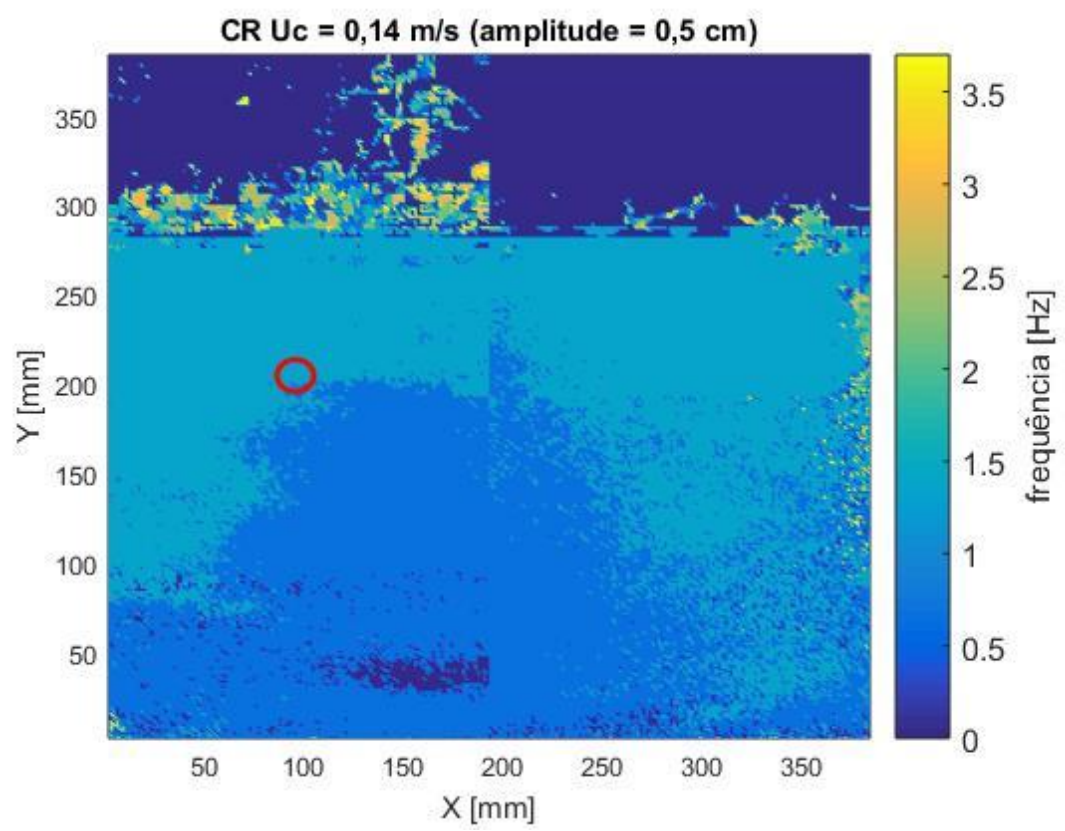

(a)

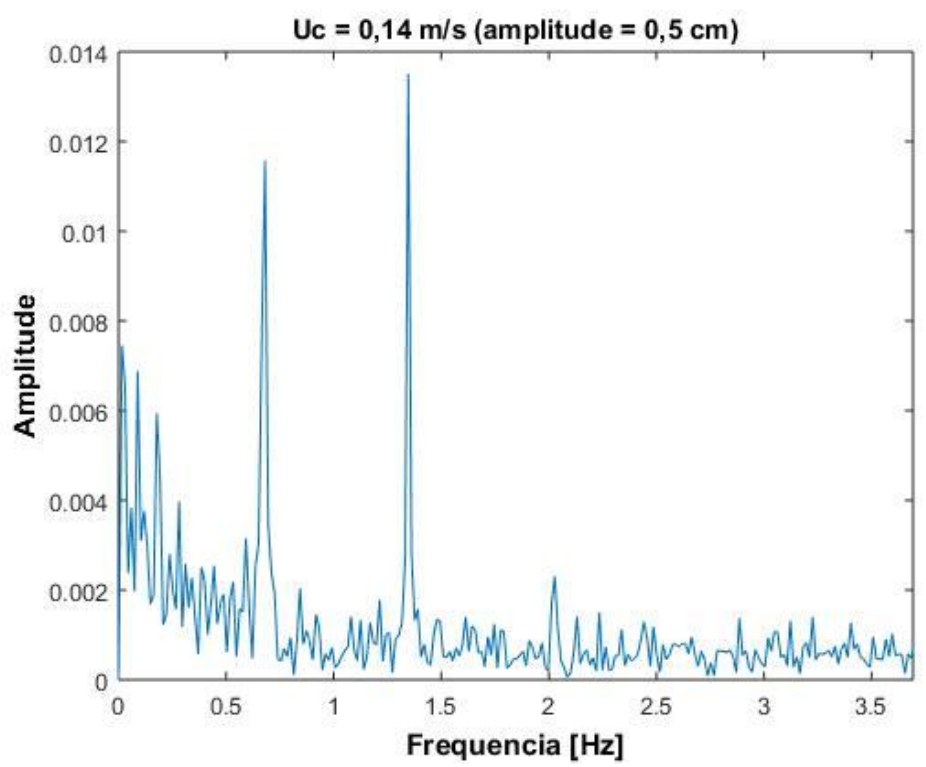

Figura 81 - Espectro de frequências para $U c=0,14 \mathrm{~m} / \mathrm{s}$ (amplitude $=0,5$

$\mathrm{cm})$ 


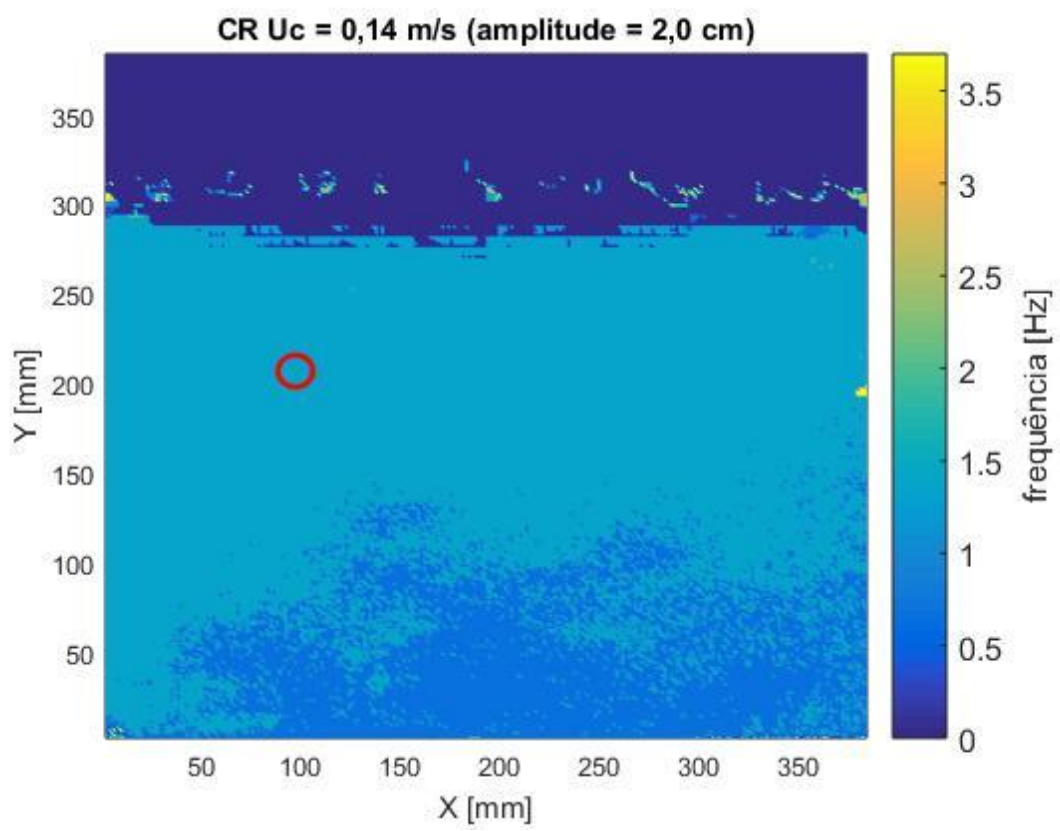

(a)

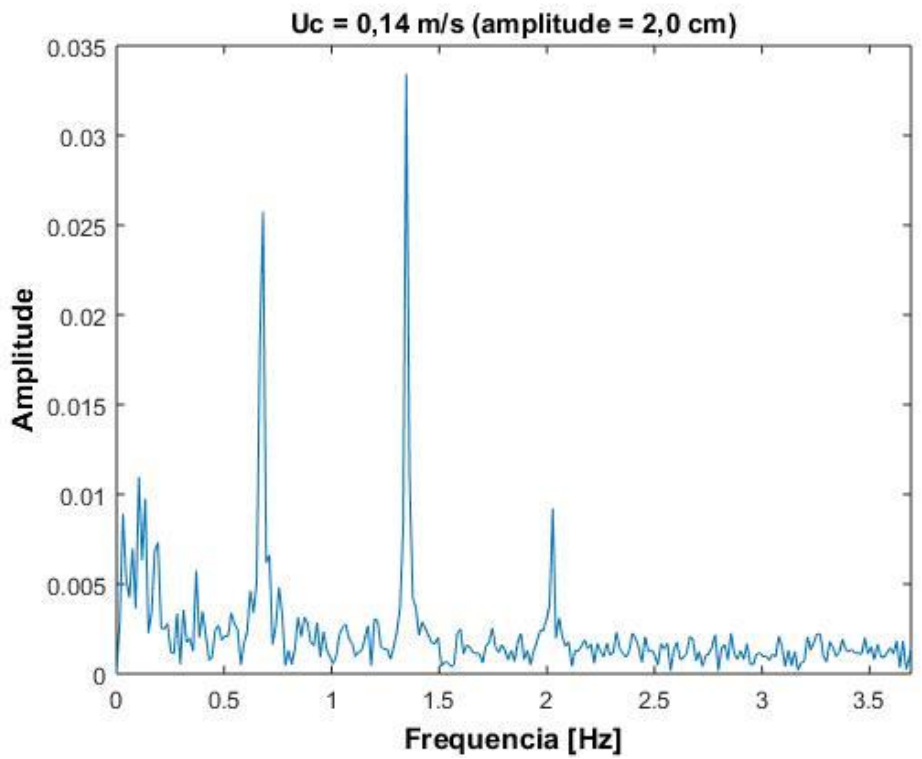

Figura 82 - Espectro de frequências para $U c=0,14 \mathrm{~m} / \mathrm{s}$ (amplitude $=2,0$ $\mathrm{cm})$ 
(a)

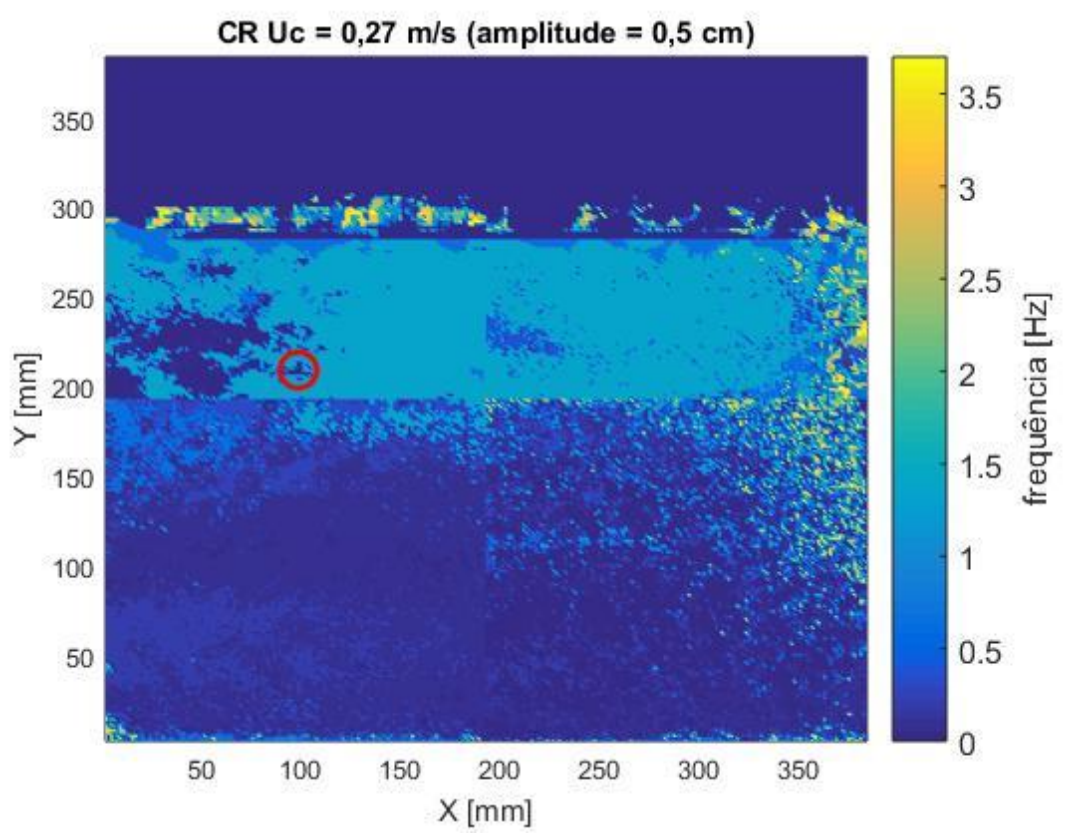

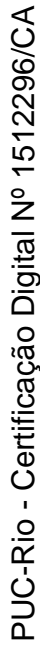

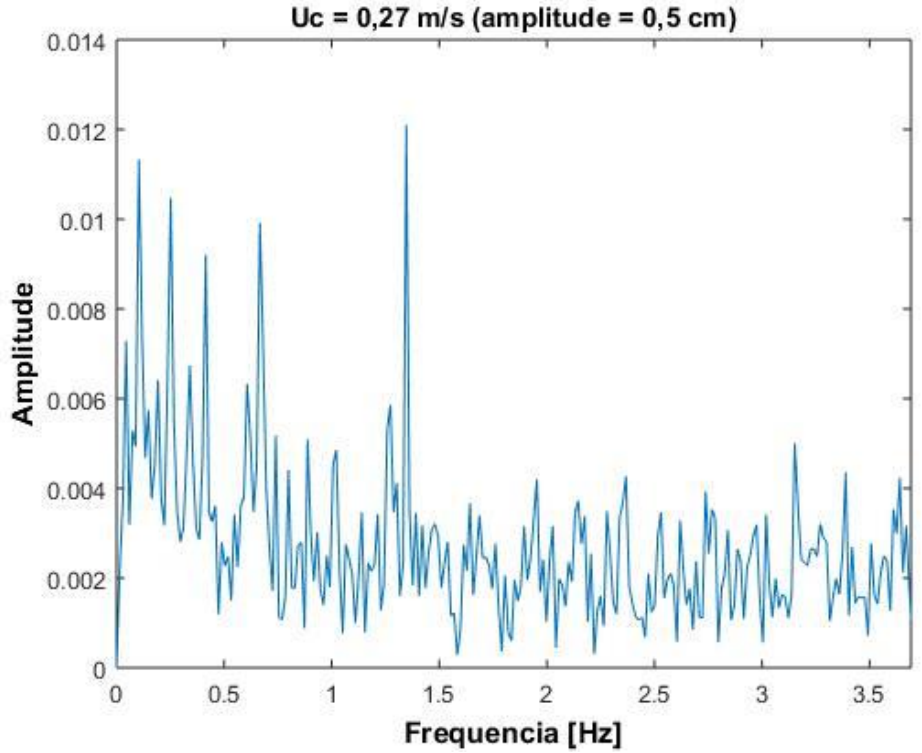

Figura 83 - Espectro de frequências para $U c=0,27 \mathrm{~m} / \mathrm{s}$ (amplitude $=0,5$ $\mathrm{cm})$ 


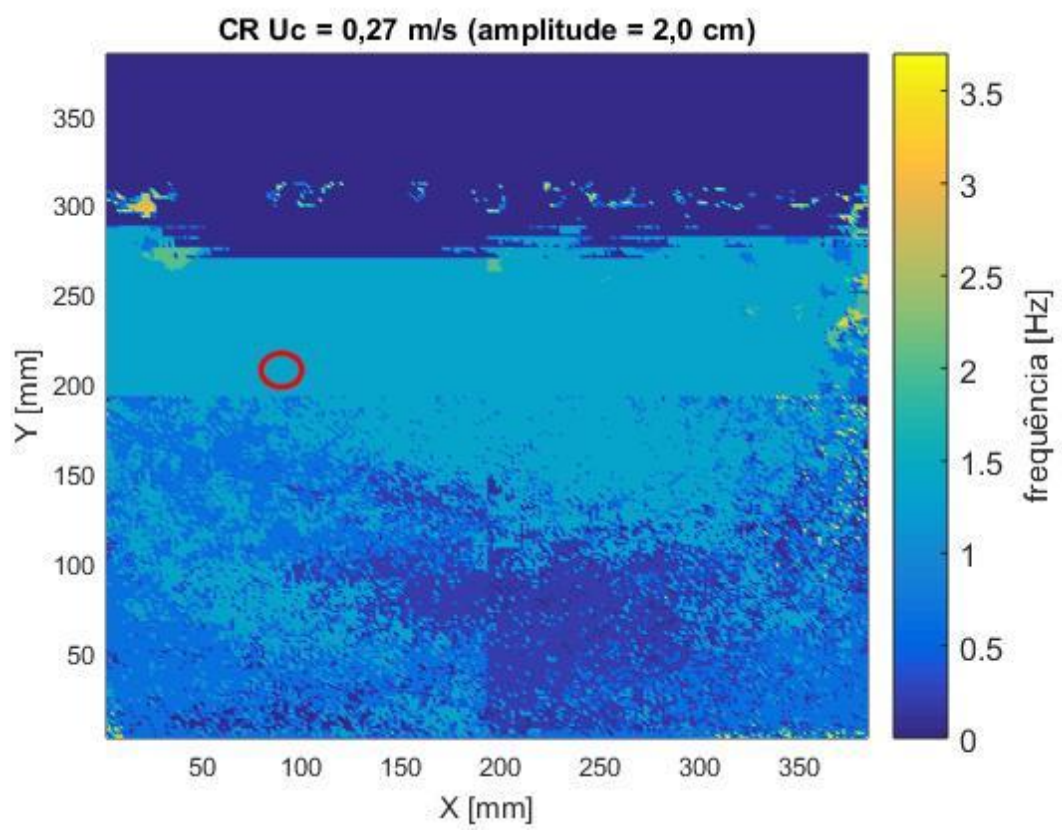

(a)

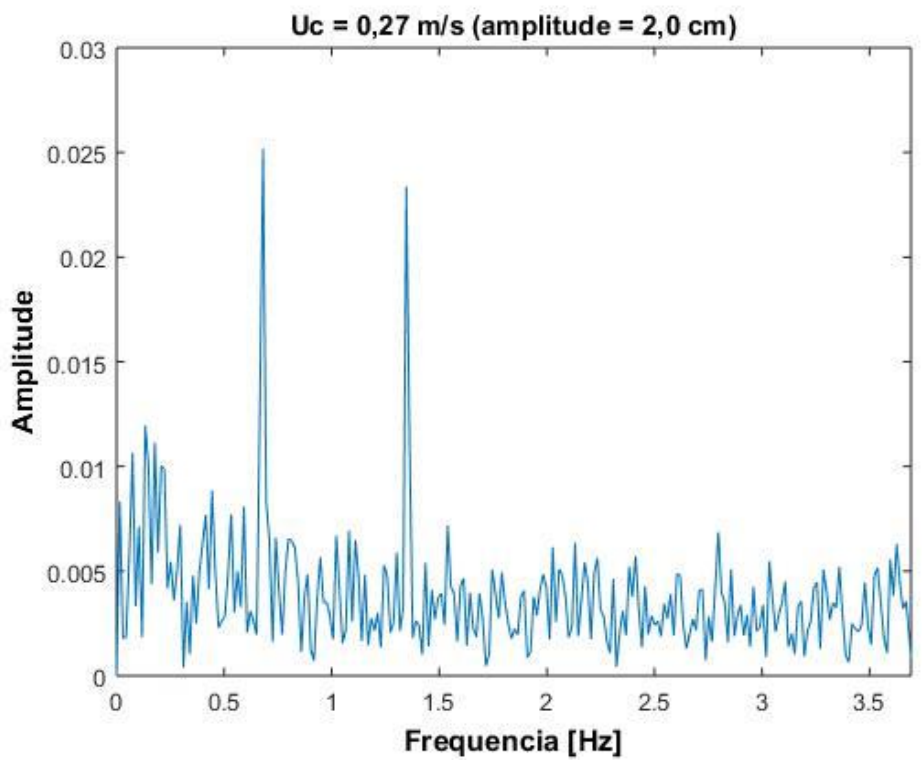

Figura 84 - Espectro de frequências para $U c=0,27 \mathrm{~m} / \mathrm{s}$ (amplitude $=2,0$

$\mathrm{cm})$

\subsection{5.}

\section{Caracterização das ondas}

A Figura 85 ilustra a relação entre a fase da onda para $U_{C}=0,14 \mathrm{~m} / \mathrm{s}$ (amplitude $=2,0 \mathrm{~cm}$ ) com o comprimento ao longo das janelas de visualização $\mathrm{C} \mathrm{e}$ $\mathrm{D}$, considerando-se a frequência de $1,34 \mathrm{~Hz}$, que foi a de maior amplitude dos espectros. Como todas as medições do escoamento foram feitas sincronizando-se as ondas com a aquisição das imagens, foi possível observar a continuidade da fase 
da onda de uma janela para outra. É possível visualizar no gráfico da Figura 85, que existe um salto nos valores do ângulo da fase $\Phi$ de $-\pi$ rad até $+\pi$ rad, representando que nesta posição fecha-se um ciclo da onda $(2 \pi)$.

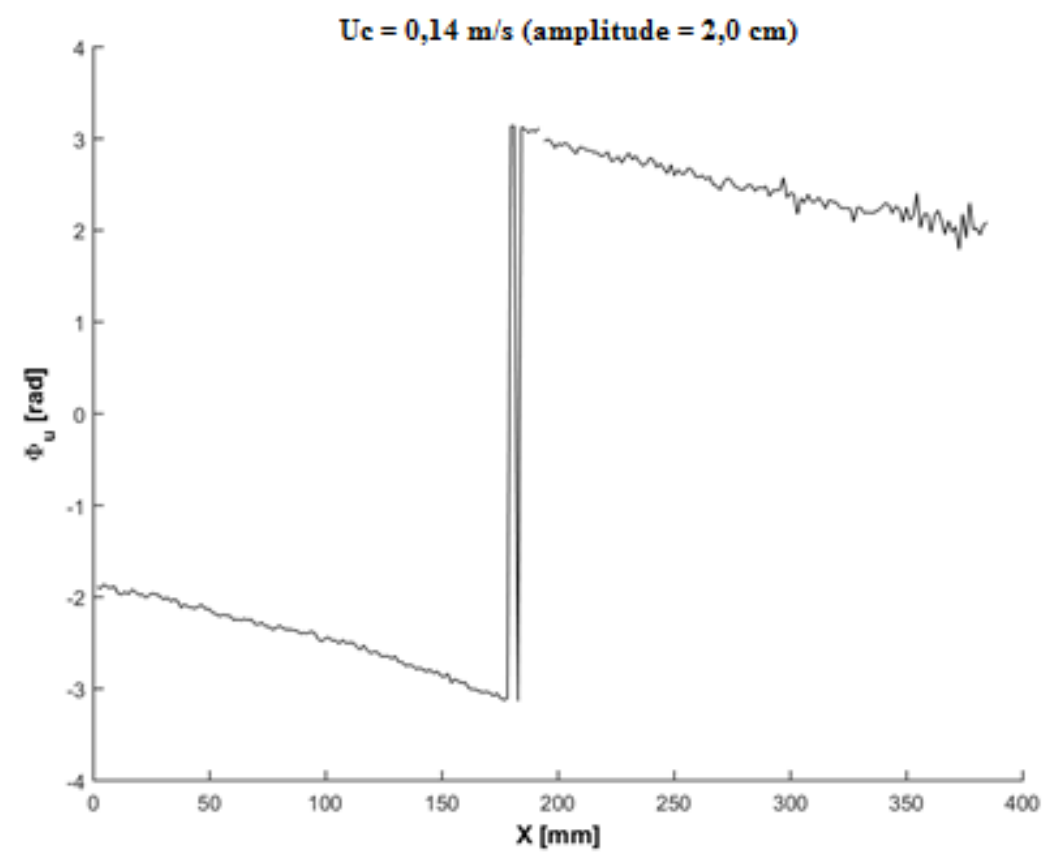

Figura 85 - Variação do ângulo de fase $\Phi$ com a distância longitudinal

Para a determinação das características das ondas, apresentadas na Tabela 4, foi necessário utilizar uma ferramenta do Matlab para que a fase da onda, apresentada na Figura 85, fique contínua quando completa um ciclo de $360^{\circ}$. A função do Matlab (unwrap) corrige o ângulo de fase da onda quando ocorrem os "pulos" correspondentes ao fechamento de um ciclo da onda. Assim, aplica-se o módulo da fase $\Phi$ para representação positiva do ângulo e uma regressão linear é utilizada para encontrar a reta correspondente aos pontos da fase, como mostra a Figura 86. O coeficiente angular dessa reta representa o número de onda $(k)$ em $\mathrm{rad} / \mathrm{mm}$. Com o número de onda, o comprimento de onda $(\lambda)$ pode ser facilmente encontrado aplicando-se a Eq. (4-3) e a velocidade da onda $\left(V_{o}\right)$ encontrada a partir da equação:

$$
V o=\frac{2 \pi f}{k}
$$


Onde $f$ é a frequência da onda. Os valores de comprimento de onda, velocidade da onda e da relação $h / \lambda$ para cada caso estão representados na Tabela 4. Observando-se os valores da relação $h / \lambda$, é possível afirmar que as ondas investigadas neste trabalho podem ser consideradas como intermediárias, conforme a classificação de ondas descrita na seção 4.1.4.

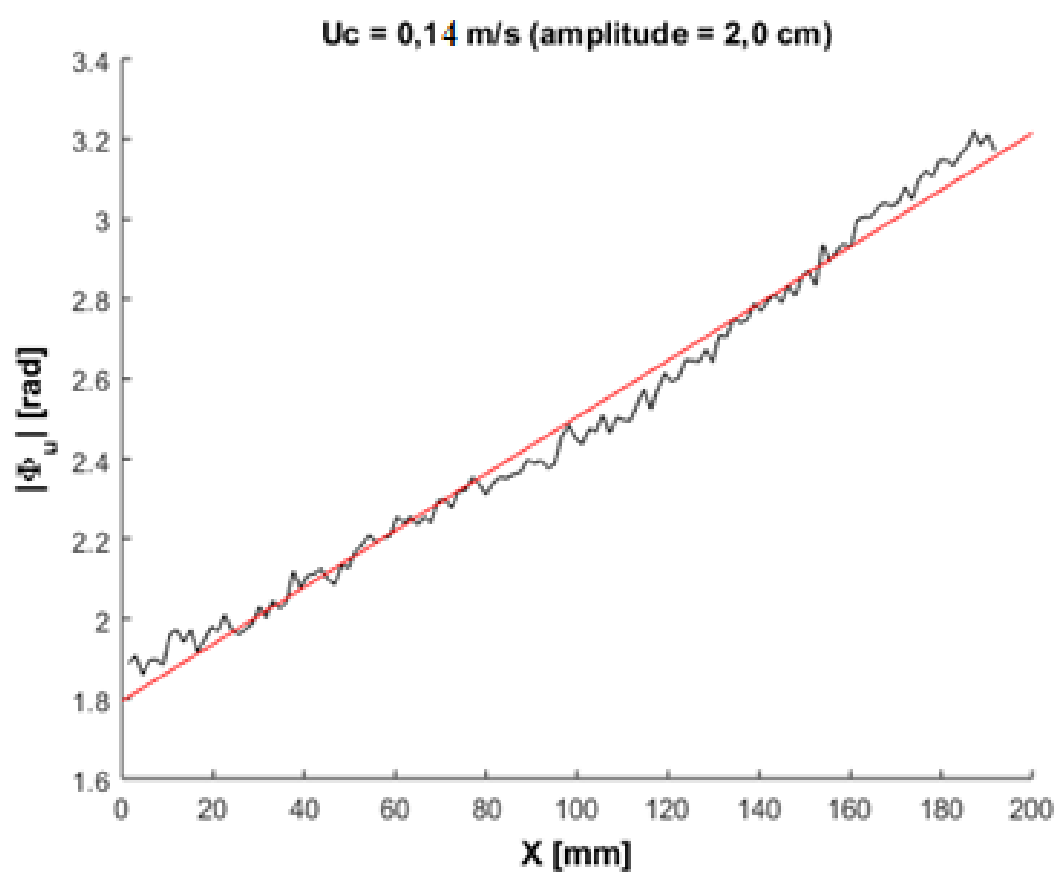

Figura 86 - Valores absolutos da fase $\Phi$ com regressão linear

Tabela 4 - Características das ondas estudadas

\begin{tabular}{|c|c|c|c|}
\hline & $\begin{array}{c}\text { Velocidade da onda } \\
\left(\boldsymbol{V}_{\boldsymbol{o}}\right)\end{array}$ & $\begin{array}{c}\text { Comprimento da } \\
\text { onda }(\lambda)\end{array}$ & Relação $(\boldsymbol{h} / \lambda)$ \\
\hline $\begin{array}{c}\boldsymbol{U}_{\boldsymbol{C}}=\mathbf{0 , 1 4} \mathbf{~ m} / \mathbf{s} \\
\text { Amplitude = 0,5 cm } \\
(\mathbf{0 , 6 7} \mathbf{~ H z})\end{array}$ & $2,82 \mathrm{~m} / \mathrm{s}$ & $4,14 \mathrm{~m}$ & 0,07 \\
\hline $\begin{array}{c}\boldsymbol{U}_{\boldsymbol{C}}=\mathbf{0 , 1 4} \mathbf{~ m} / \mathbf{s} \\
\text { Amplitude = 0,5 cm } \\
(\mathbf{1 , 3 4} \mathbf{~ H z})\end{array}$ & $1,30 \mathrm{~m} / \mathrm{s}$ & $0,97 \mathrm{~m}$ & 0,31 \\
\hline $\begin{array}{c}\boldsymbol{U}_{\boldsymbol{C}}=\mathbf{0 , 1 4} \mathbf{~ m} / \mathbf{s} \\
\text { Amplitude = 2,0 cm } \\
(\mathbf{0 , 6 7} \mathbf{~ H z})\end{array}$ & $2,00 \mathrm{~m} / \mathrm{s}$ & $2,95 \mathrm{~m}$ & 0,10 \\
\hline
\end{tabular}




\begin{tabular}{|c|c|c|c|}
\hline $\begin{array}{c}U_{C}=0,14 \mathrm{~m} / \mathrm{s} \\
\text { Amplitude }=2,0 \mathrm{~cm} \\
(1,34 \mathrm{~Hz})\end{array}$ & $1,94 \mathrm{~m} / \mathrm{s}$ & $0,89 \mathrm{~m}$ & 0,34 \\
\hline $\begin{array}{c}U_{C}=0,27 \mathrm{~m} / \mathrm{s} \\
\text { Amplitude }=0,5 \mathrm{~cm} \\
(0,67 \mathrm{~Hz})\end{array}$ & $0,51 \mathrm{~m} / \mathrm{s}$ & $0,76 \mathrm{~m}$ & 0,39 \\
\hline $\begin{array}{c}U_{C}=0,27 \mathrm{~m} / \mathrm{s} \\
\text { Amplitude }=0,5 \mathrm{~cm} \\
(1,34 \mathrm{~Hz})\end{array}$ & $1,00 \mathrm{~m} / \mathrm{s}$ & $0,74 \mathrm{~m}$ & 0,41 \\
\hline $\begin{array}{c}U_{C}=0,27 \mathrm{~m} / \mathrm{s} \\
\text { Amplitude }=2,0 \mathrm{~cm} \\
(0,67 \mathrm{~Hz})\end{array}$ & $2,34 \mathrm{~m} / \mathrm{s}$ & $3,44 \mathrm{~m}$ & 0,09 \\
\hline $\begin{array}{c}U_{C}=0,27 \mathrm{~m} / \mathrm{s} \\
\text { Amplitude }=2,0 \mathrm{~cm} \\
(1,34 \mathrm{~Hz})\end{array}$ & $1,38 \mathrm{~m} / \mathrm{s}$ & $1,00 \mathrm{~m}$ & 0,30 \\
\hline
\end{tabular}

\subsection{6.}

\section{Comparação entre os casos sem ondas e com ondas}

Os perfis médios da componente horizontal de velocidade foram plotados para as posições $X=30,120$ e $210 \mathrm{~mm}$ e estão apresentados na Figura 87 ( $U c=$ $0,14 \mathrm{~m} / \mathrm{s})$ e na Figura $88(U c=0,27 \mathrm{~m} / \mathrm{s})$. A magnitude da referência de velocidade é representada por uma barra horizontal no gráfico.

Observando-se a Figura 87, é possível dizer que existe uma pequena diferença no perfil de velocidade do escoamento base sem ondas para o escoamento com ondas, mostrando que as ondas podem, de fato, alterar a velocidade média do escoamento base. Os perfis apresentam pouca variação ao longo da direção do escoamento. Isso sugere que a camada limite era bem desenvolvida, ou seja, longe da região de crescimento rápido observada normalmente próximo de bordos de ataque. Os resultados sugerem também que as variações mais significativas são observadas próximo da superfície e da parede. 


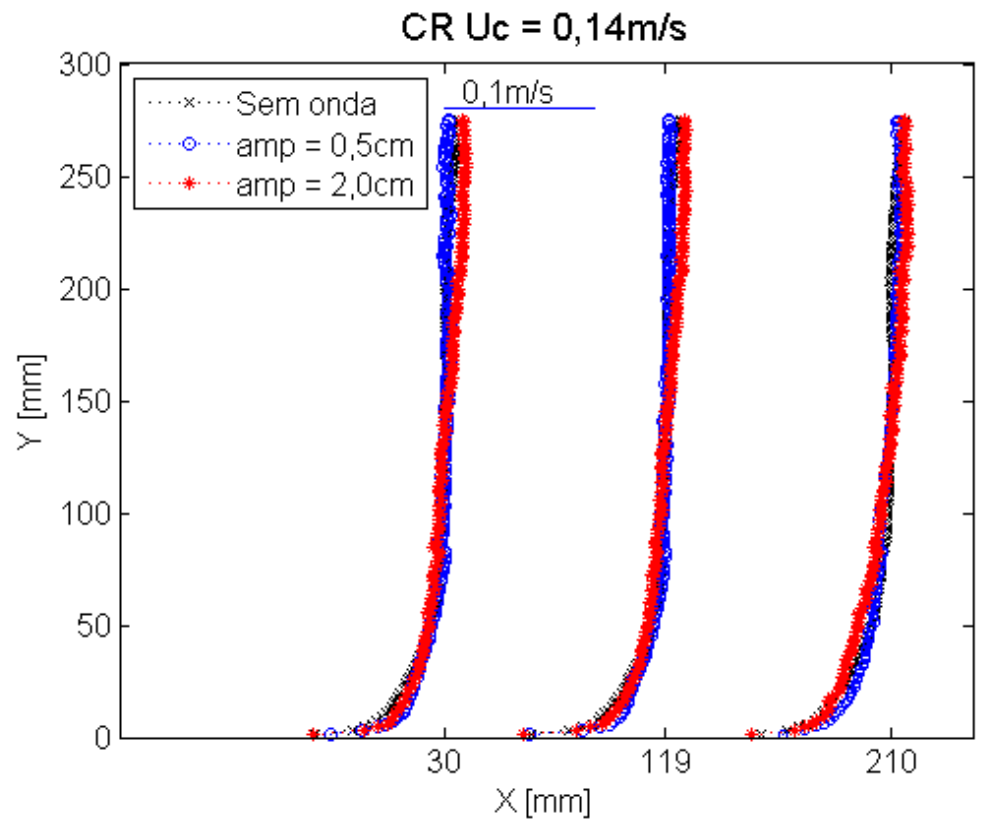

Figura 87 - Perfis de velocidade média para $U_{C}=0,14 \mathrm{~m} / \mathrm{s}$

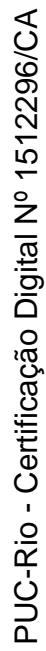

A Figura 88 mostra os perfis médios de velocidade para $U c=0,27 \mathrm{~m} / \mathrm{s}$. Da mesma forma que na condição de velocidade do escoamento cruzado mais baixa, os perfis correspondentes ao escoamento com ondas e sem ondas se assemelham. Diferenças são mais perceptíveis nas regiões próximas à superfície e a parede.

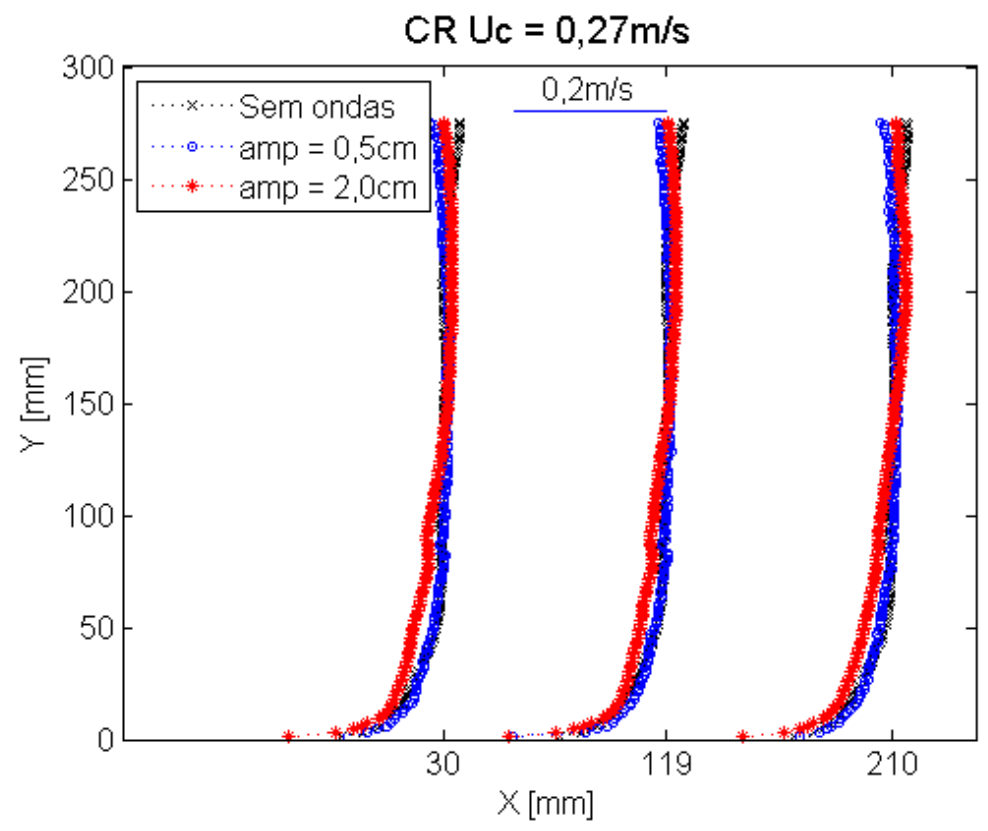

Figura 88 - Perfis de velocidade média para $U_{C}=0,27 \mathrm{~m} / \mathrm{s}$ 
A Figura 89 mostra a comparação entre os perfis de flutuação vertical do escoamento sem ondas, com ondas de amplitude igual a $0,5 \mathrm{~cm}$ e com ondas de 2,0 $\mathrm{cm}$ de amplitude. Nessa figura analisa-se o caso com velocidade mais baixa do escoamento, onde a flutuação induzida pelas ondas foi mais perceptível. A figura 89 mostra os perfis para uma única posição, localizada a $90 \mathrm{~mm}$ do bocal de injeção, visto que os perfis medidos não apresentam grande variação ao longo da direção longitudinal do canal. Além disso, são mostrados também alguns perfis teóricos, calculados de acordo com o modelo de ondas progressivas de águas intermediárias descrito no livro de Dean e Darlymple (1991). Percebe-se que, os perfis experimentais se assemelham aos perfis teóricos. Diferenças mais significativas entre modelo e experimento são observadas próximo à parede devido a turbulência da camada limite. Como o modelo só prevê oscilações induzidas por ondas em leito estagnado (sem escoamento cruzado e sem turbulência), já era de se esperar que próximo à parede o modelo não representasse bem as oscilações do escoamento. Ainda assim, os resultados indicam que as ondas investigadas eram de fato ondas progressivas de águas intermediárias.

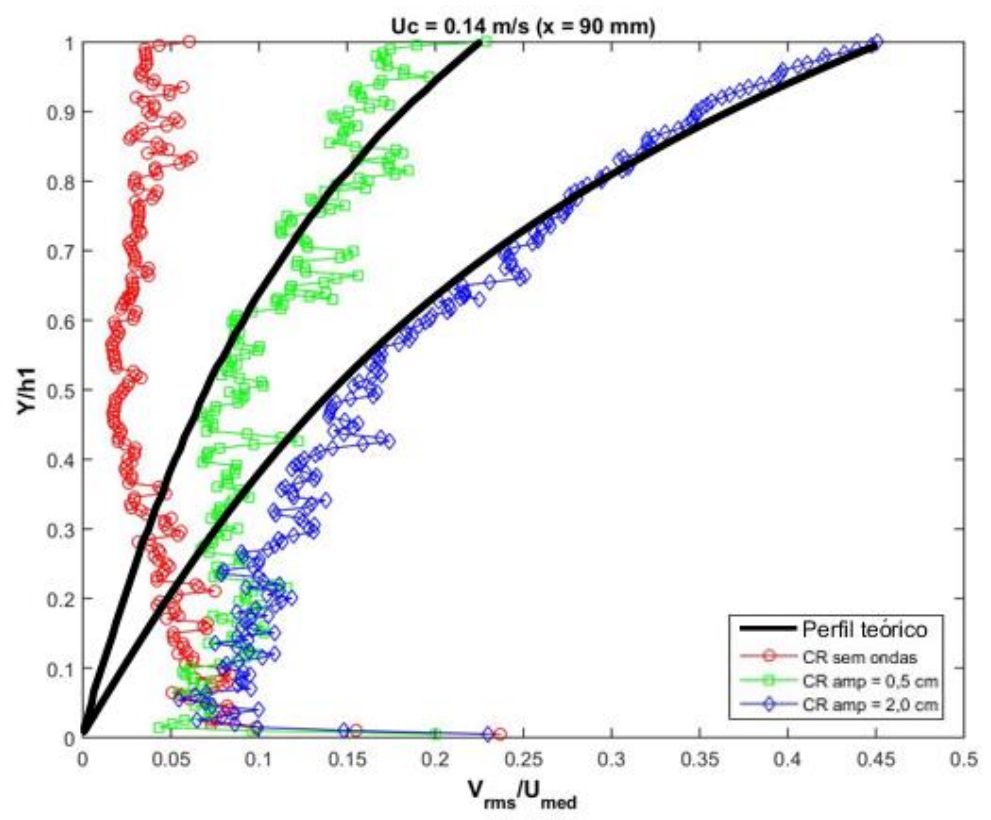

Figura 89 - Comparação entre perfis de $V_{r m s}$ para $U_{C}=0,14 \mathrm{~m} / \mathrm{s}$ e x $=90$ $\mathrm{mm}$ 
As comparações dos perfis de turbulência entre os casos com ondas e o caso sem ondas são mostradas na Figura 90, Figura 91, Figura 92 e na Figura 93, para as diferentes velocidades de corrente do canal. Valores de referência estão representados nas figuras como barras horizontais.

Observando-se a Figura 90, percebe-se um aumento, de aproximadamente $15 \%$ na flutuação da componente $u$ do escoamento para ondas de amplitude igual a $0,5 \mathrm{~cm}$ em relação ao escoamento sem ondas. Para ondas de amplitude igual a 2,0 $\mathrm{cm}$, o aumento na flutuação horizontal é maior, de aproximadamente $30 \%$, aumentando ainda mais a partir da metade da altura do nível de líquido, podendo chegar a uma diferença da ordem $40 \%$ na região próxima à superfície.

$\mathrm{Na}$ Figura 91, as diferenças das flutuações verticais dos casos com ondas começam a aparecer a partir de $\mathrm{Y}=100 \mathrm{~mm}$ em relação ao fundo do canal. Podese dizer que existe uma diferença de aproximadamente $15 \%$ na flutuação vertical para o caso de ondas de amplitude igual a $0,5 \mathrm{~cm}$ com relação ao escoamento sem ondas. Já para o caso de amplitude igual a $2,0 \mathrm{~cm}$, há uma tendência de crescimento à medida em que se aproxima da superfície da água, podendo chegar a uma diferença de $40 \%$ em relação ao escoamento sem ondas.

Para a velocidade mais alta da corrente do canal $(U c=0,27 \mathrm{~m} / \mathrm{s})$, as flutuações de velocidade dos dois casos com ondas apresentam valores próximos, conforme mostrado na Figura 92 e na Figura 93. Já o caso sem ondas apresenta um nível de turbulência aproximadamente $15 \%$ menor em relação aos casos com ondas. Isso mostra que as duas amplitudes da onda têm efeitos semelhantes na turbulência do escoamento com alta velocidade de corrente. 


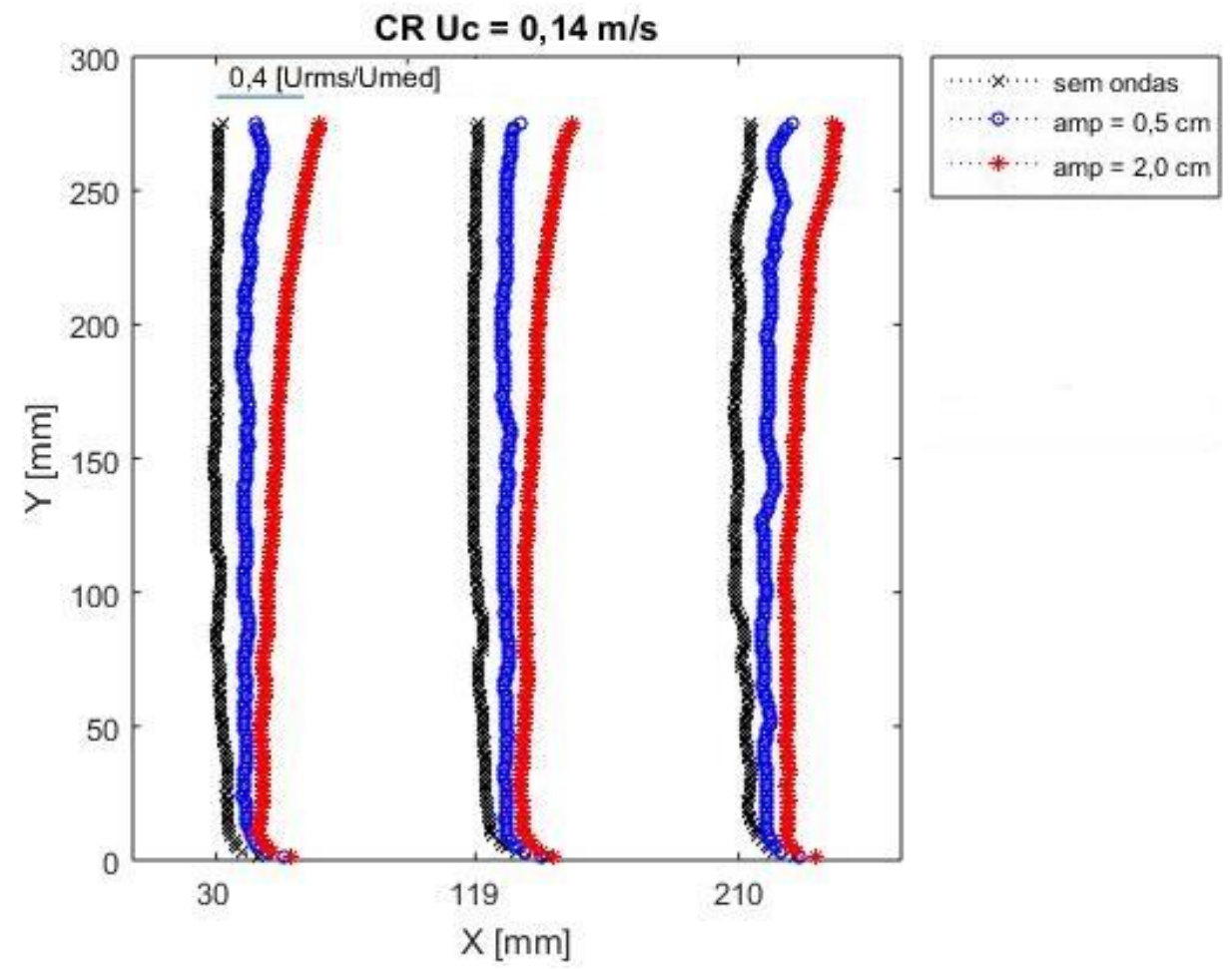

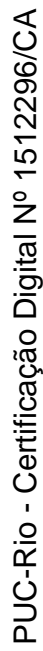

Figura 90 - Comparação entre perfis de $U_{r m s}$ para $U_{C}=0,14 \mathrm{~m} / \mathrm{s}$

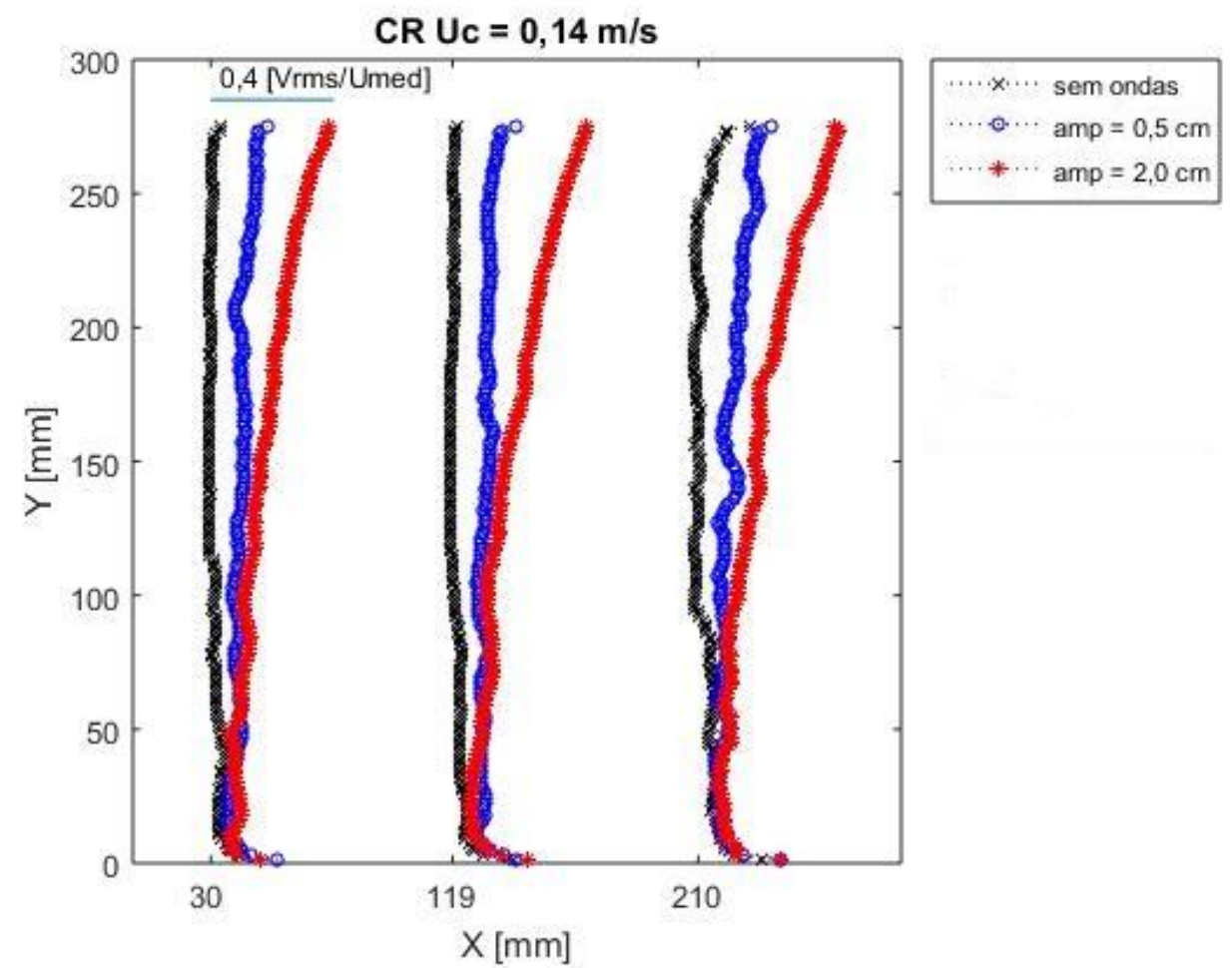

Figura 91 - Comparação entre perfis de $V_{r m s}$ para $U_{C}=0,14 \mathrm{~m} / \mathrm{s}$ 


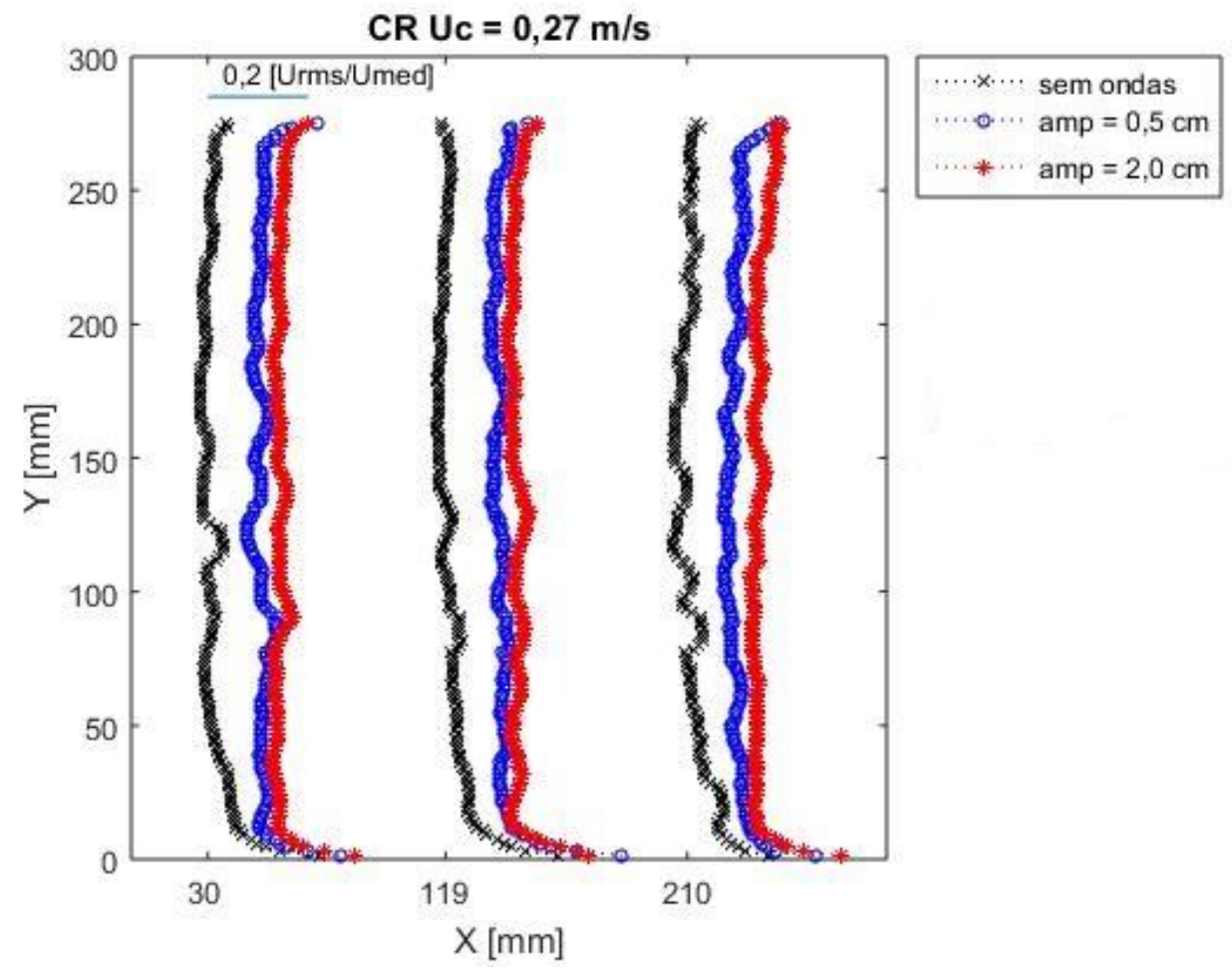

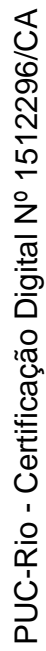

Figura 92 - Comparação entre perfis de $U_{r m s}$ para $U_{C}=0,27 \mathrm{~m} / \mathrm{s}$

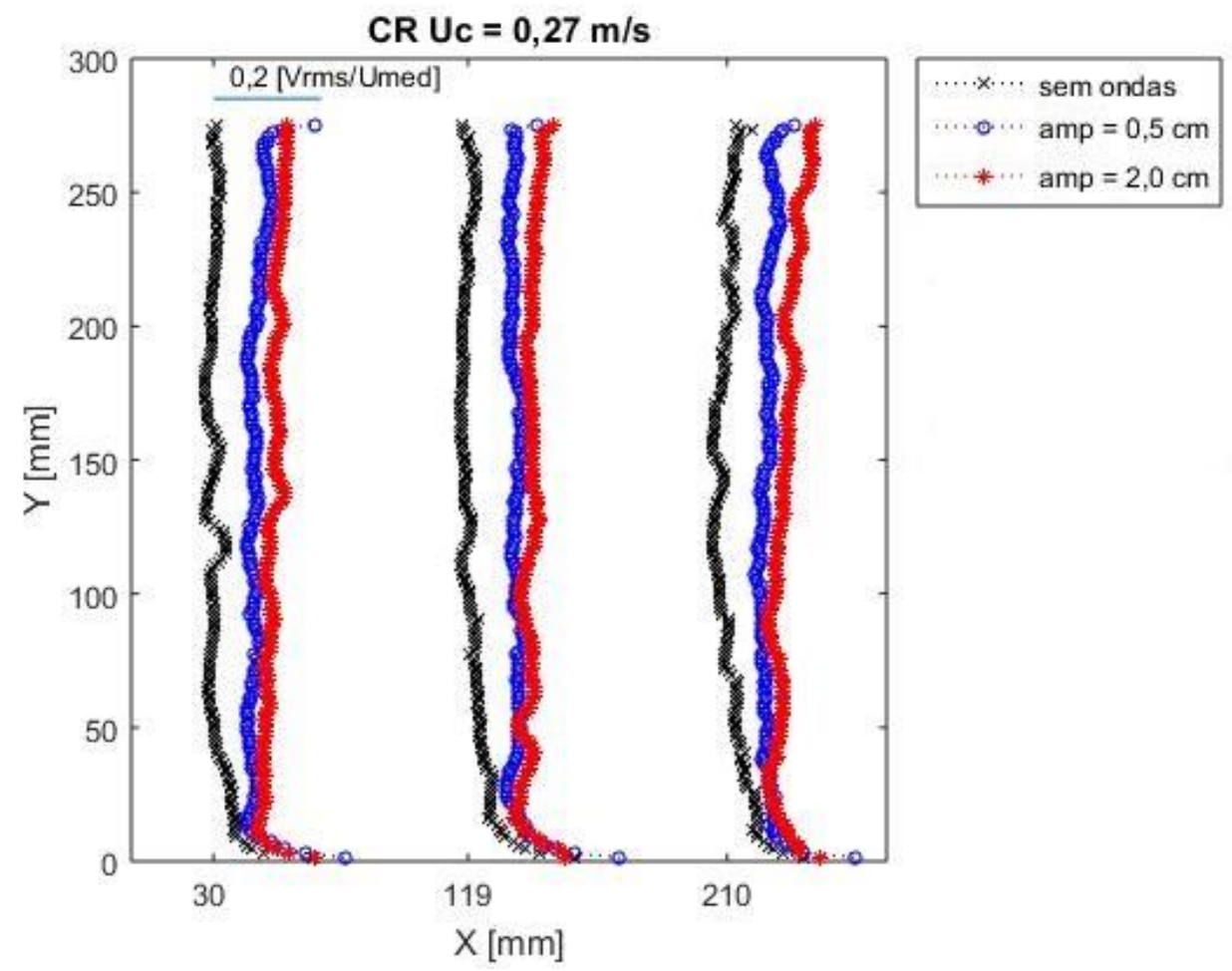

Figura 93 - Comparação entre perfis de $V_{r m s}$ para $U_{C}=0,27 \mathrm{~m} / \mathrm{s}$ 
Os resultados apresentados nesta seção sugerem que as ondas têm pequeno efeito sobre o escoamento médio e um efeito significativo na magnitude das flutuações de velocidade do escoamento. As alterações induzidas pelas ondas são mais perceptíveis nos casos com maior amplitude, como era de se esperar. A priori, não é possível identificar qual a influência dessas mudanças sobre as plumas de bolha. Portanto, realizou-se também a investigação para o caso da pluma de bolhas com e sem ondas e os resultados são descritos nas seções seguintes.

\section{4 .}

\section{Caracterização do escoamento com pluma de bolhas e sem ondas}

Os campos velocidade média das componentes $U$ e $V$ do escoamento, correspondentes aos casos com injeção de gás na forma de pluma de bolhas, estão apresentados na Figura 94 e na Figura 95, para $U c$ igual a $0,14 \mathrm{~m} / \mathrm{s}$. Os casos apresentados na Figura 98 e na Figura 99 correspondem a velocidade do escoamento cruzado $(U c)$ igual a $0,27 \mathrm{~m} / \mathrm{s}$. Nesta seção são apresentados somente resultados obtidos sem a presença de ondas. É perceptível que há uma grande variação de velocidade do escoamento na região próxima à injeção de bolhas. Essa variação induzida pela pluma é mais perceptível nos casos com baixa velocidade do escoamento (Figura 94 e Figura 95). É possível observar, também, que a pluma tende a apresentar uma dispersão na forma de um cone ao longo do escoamento. Esse comportamento é reportado no trabalho de Garcia (2015).

Na Figura 96 e na Figura 97 estão apresentados os campos de turbulência das componentes horizontal e vertical do escoamento para $U c$ igual a $0,14 \mathrm{~m} / \mathrm{s}$ e na figura 100 e na figura 101 para a condição de $U c$ igual 0,27 m/s. Em ambos os casos é possível observar que a turbulência é maior na direção vertical. Além disso, nos casos de menor velocidade da corrente do canal, a pluma aparenta ter maior influência sobre a turbulência do escoamento na região da trajetória das bolhas. 

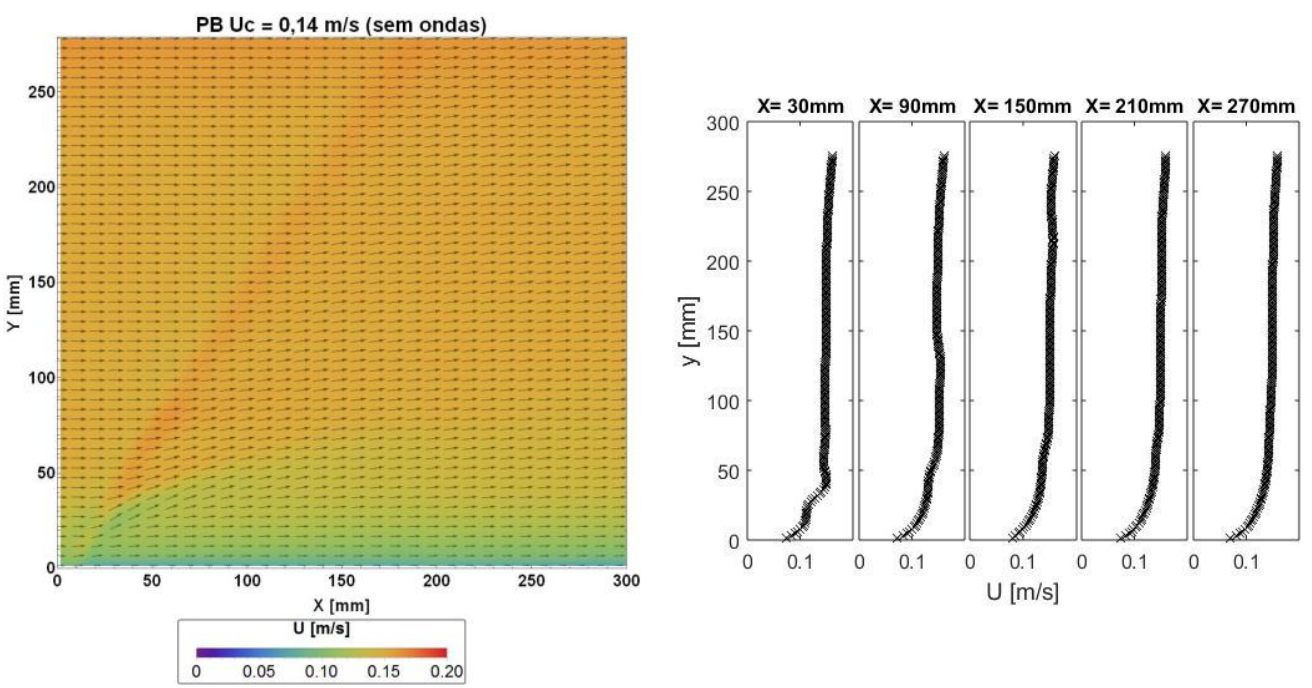

Figura 94 - Campo de $U$ médio com pluma de bolhas para $\mathrm{U}_{\mathrm{C}}=0,14 \mathrm{~m} / \mathrm{s}$ (sem ondas)

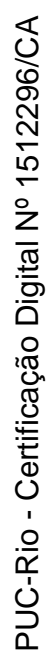
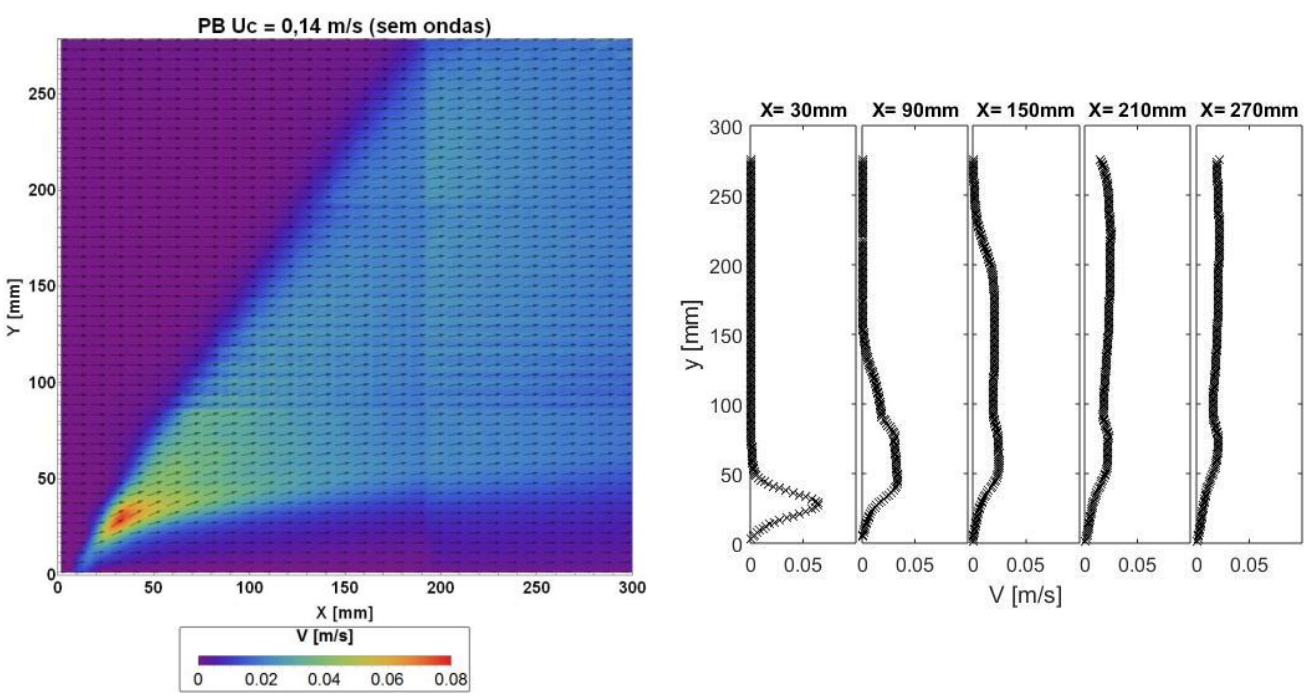

Figura 95 - Campo de $V$ médio com pluma de bolhas para $U_{C}=0,14 \mathrm{~m} / \mathrm{s}$ (sem ondas) 


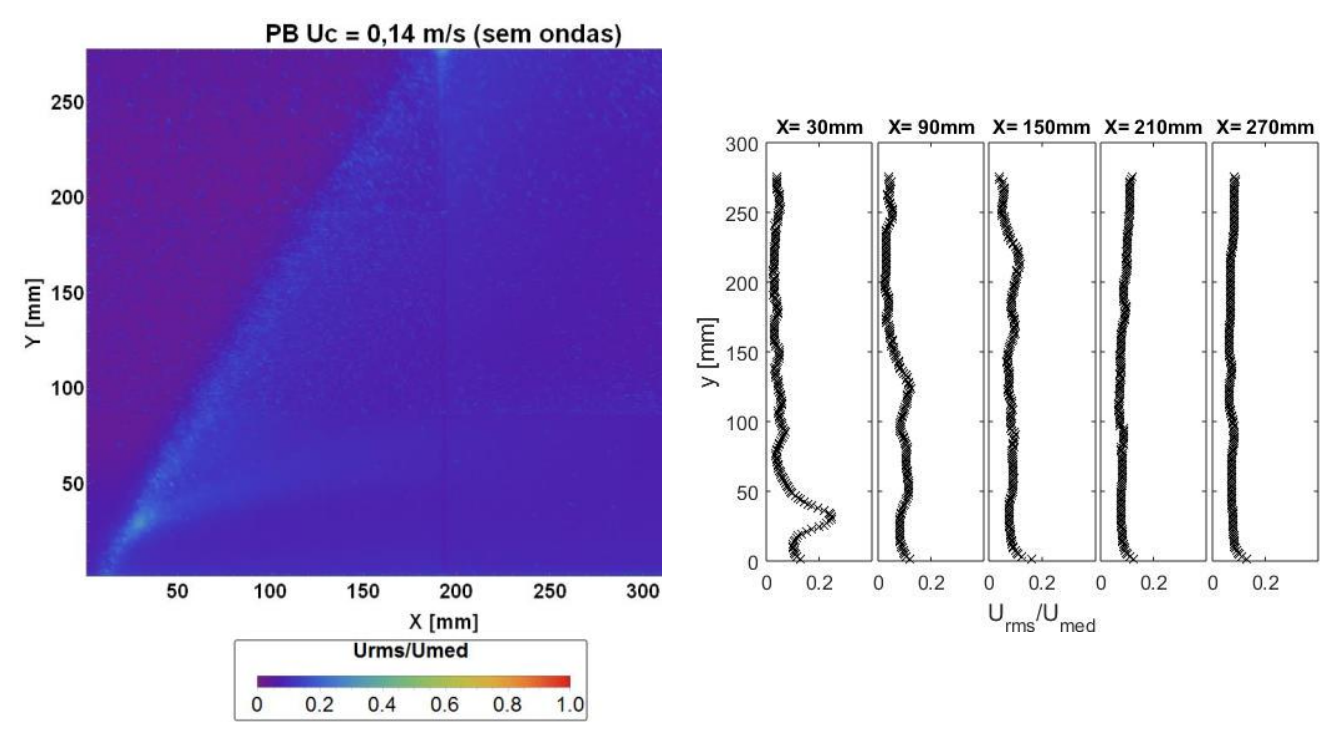

Figura 96 - Campo de flutuações horizontais para $U_{C}=0,14 \mathrm{~m} / \mathrm{s}(\mathrm{sem}$ ondas)

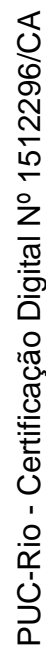
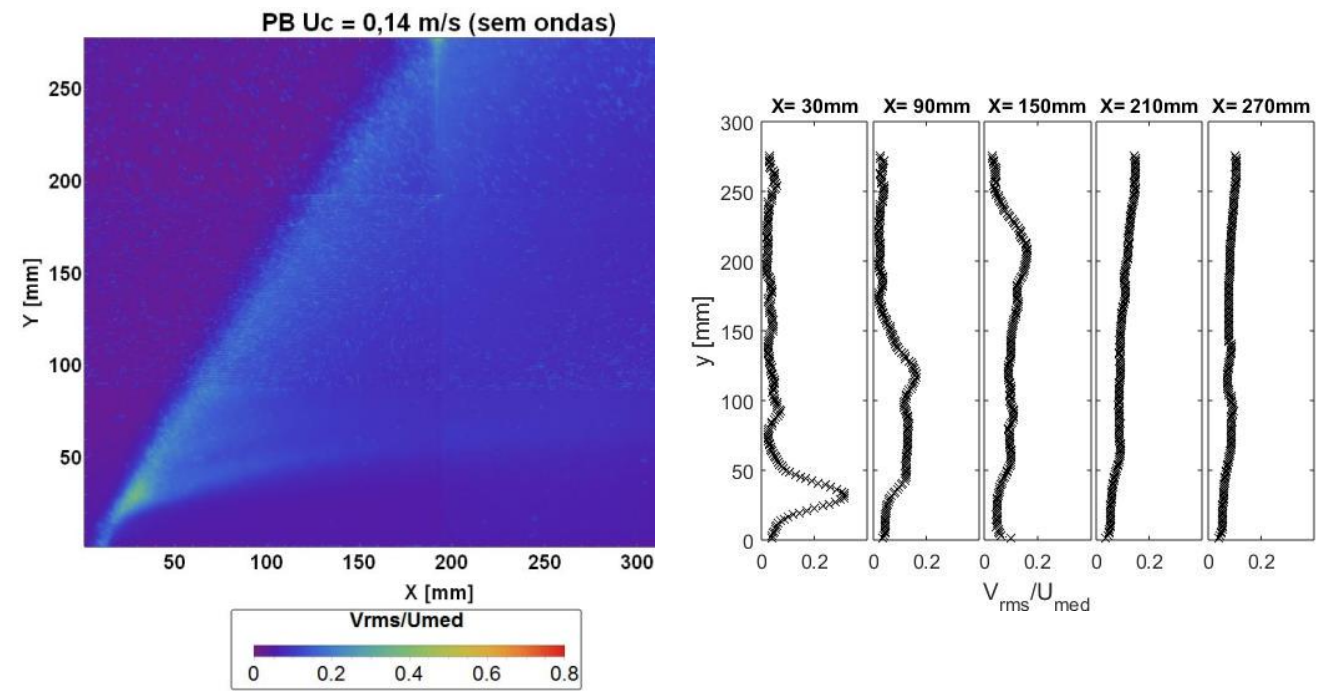

Figura 97 - Campo de flutuações verticais para $U_{C}=0,14 \mathrm{~m} / \mathrm{s}$ (sem ondas) 

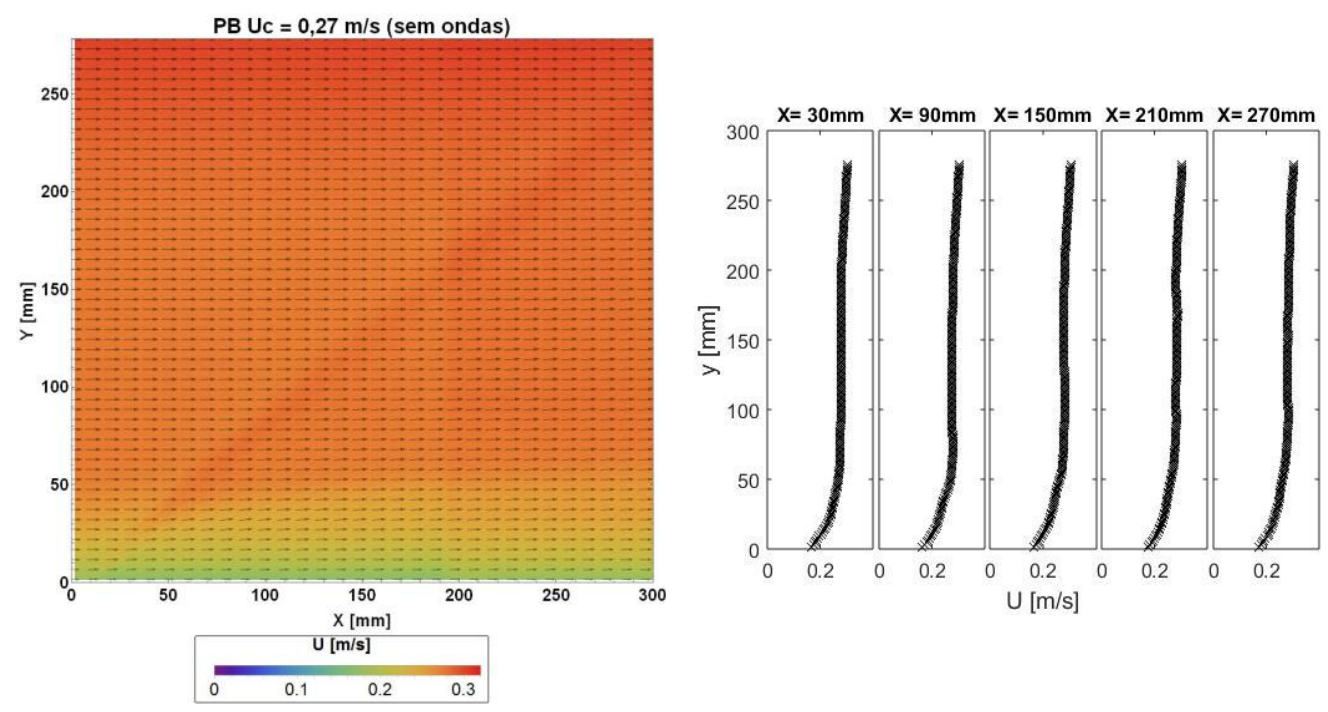

Figura 98 - Campo de $U$ médio com pluma de bolhas para $\mathrm{U}_{\mathrm{C}}=0,27 \mathrm{~m} / \mathrm{s}$ (sem ondas)

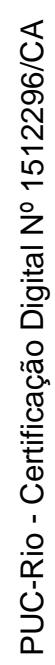
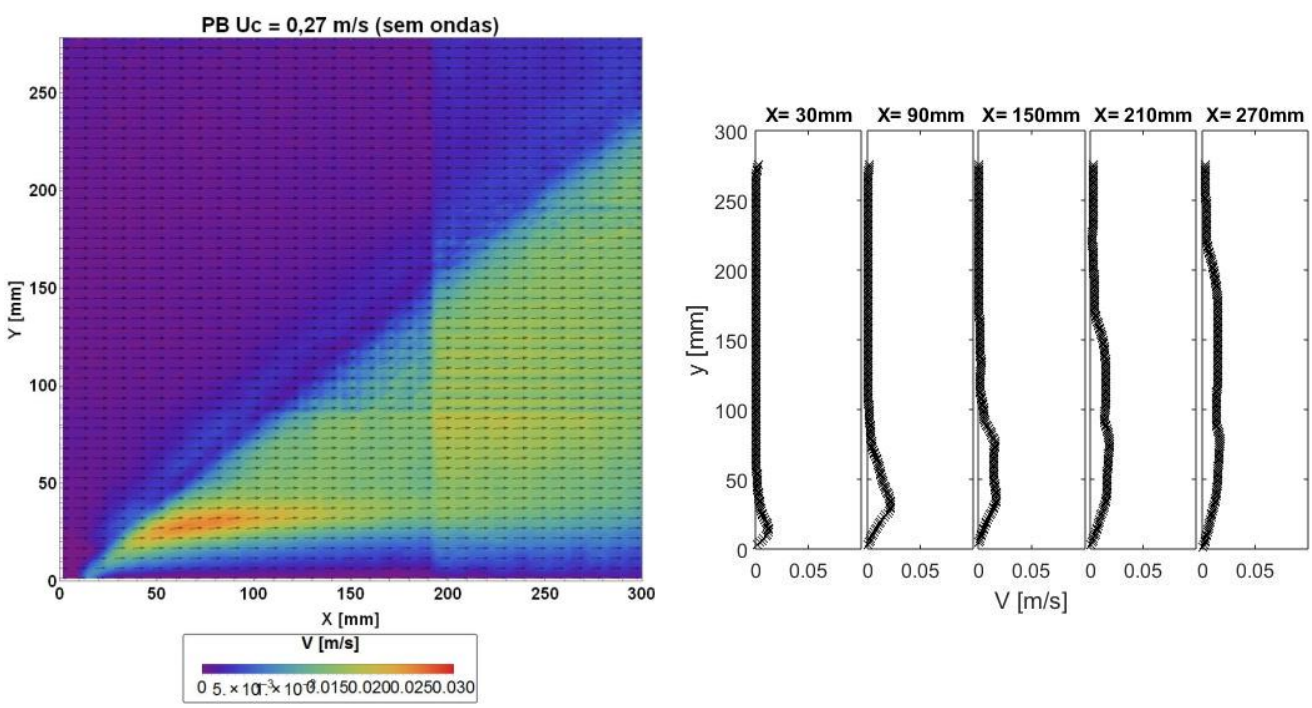

Figura 99 - Campo de $V$ médio com pluma de bolhas para $\mathrm{U}_{\mathrm{C}}=0,27 \mathrm{~m} / \mathrm{s}$ (sem ondas) 

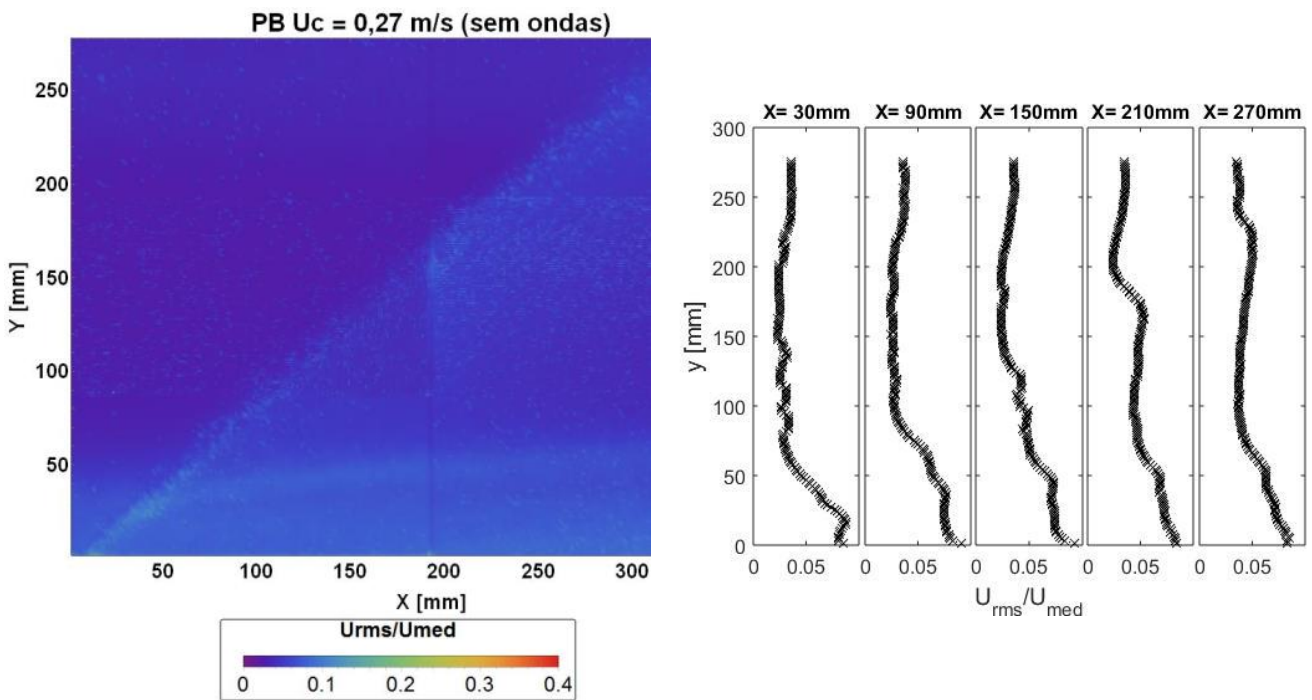

Figura 100 - Campo de flutuações horizontais para $U_{C}=0,27 \mathrm{~m} / \mathrm{s}(\mathrm{sem}$ ondas)
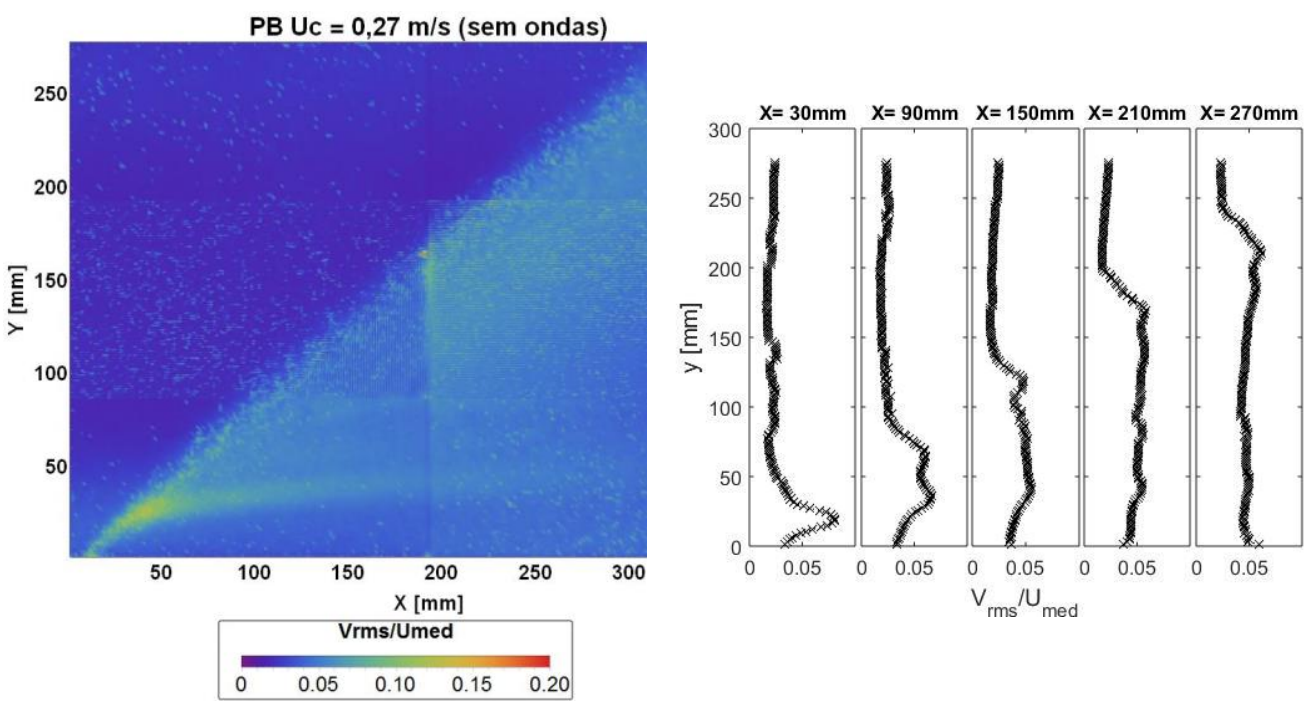

Figura 101 - Campo de flutuações verticais para $U_{C}=0,27 \mathrm{~m} / \mathrm{s}$ (sem ondas)

\subsection{1.}

\section{Comparação entre o escoamento cruzado sem ondas e o escoamento sem ondas e sem pluma}

Comparações entre os perfis de flutuação de velocidade medidos na presença e na ausência de plumas de bolhas são apresentadas na Figura 102, na Figura 103, na Figura 104 e na Figura 105.

É possível observar na Figura 102, que o escoamento base é afetado principalmente na região de trajetória das bolhas. No caso com plumas, nota-se uma 
elevada intensidade de turbulência próxima à parede e $\mathrm{X}=30 \mathrm{~mm}$. A medida que a pluma se dispersa a diferença na intensidade de turbulência diminui, mas permanece mais elevada em quase toda a altura do canal. Nos casos de velocidade do escoamento cruzado igual a $0,27 \mathrm{~m} / \mathrm{s}$, nota-se um pequeno aumento da turbulência na região afetada da pluma.

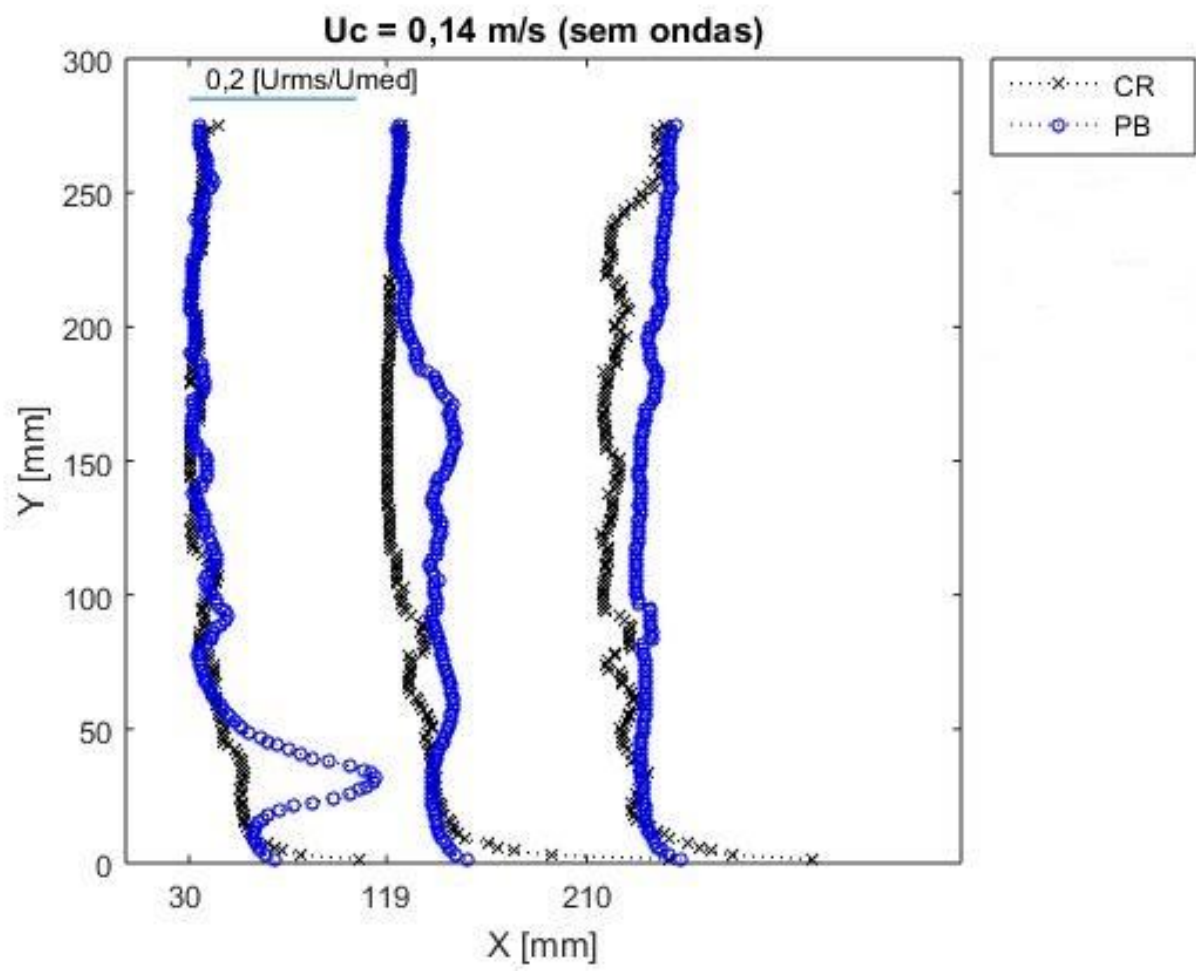

Figura 102 - Comparação entre perfis de $U_{r m s}$ para $U_{C}=0,14 \mathrm{~m} / \mathrm{s}$ 


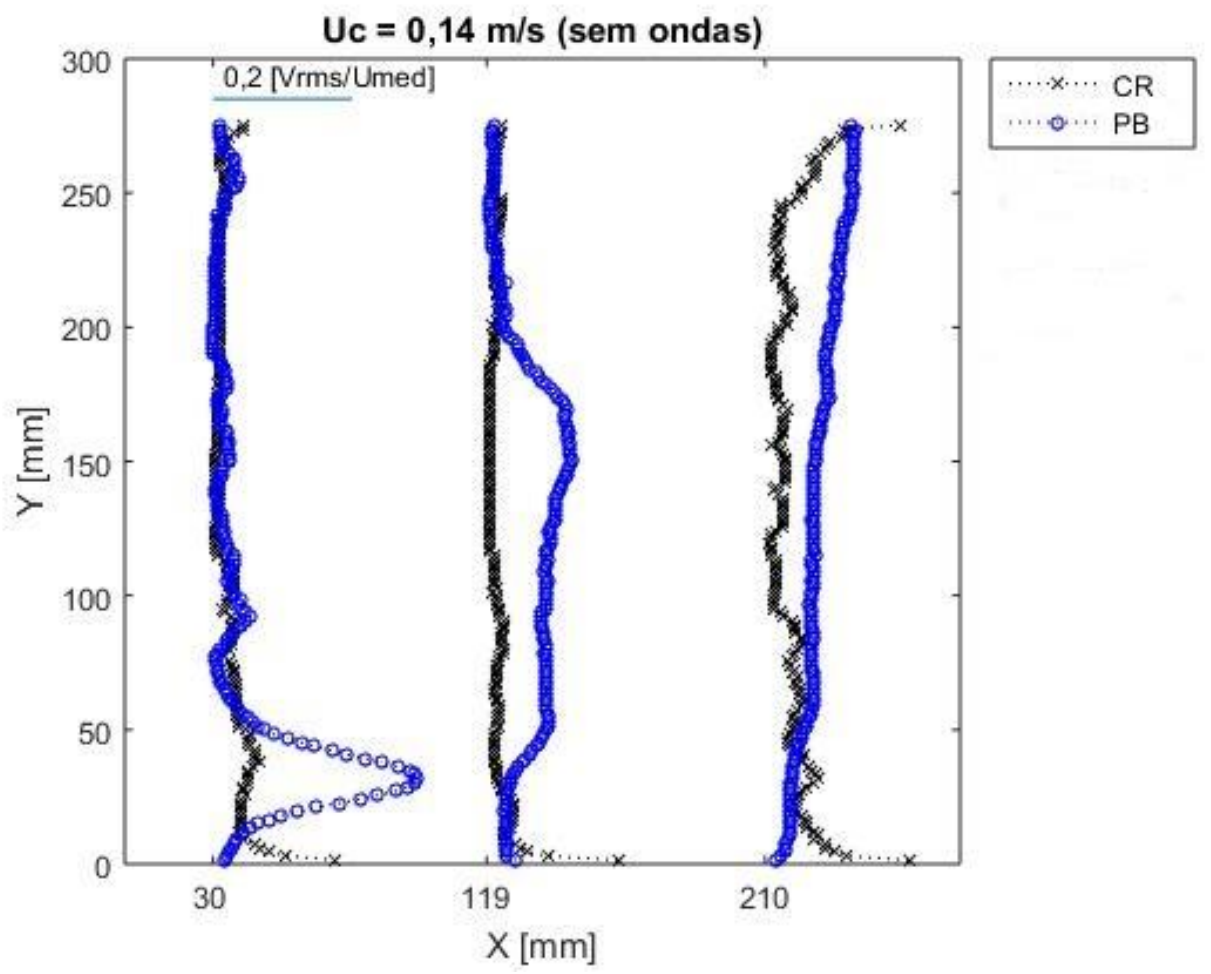

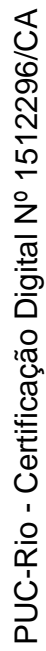

Figura 103 - Comparação entre perfis de $V_{r m s}$ para $U_{C}=0,14 \mathrm{~m} / \mathrm{s}$

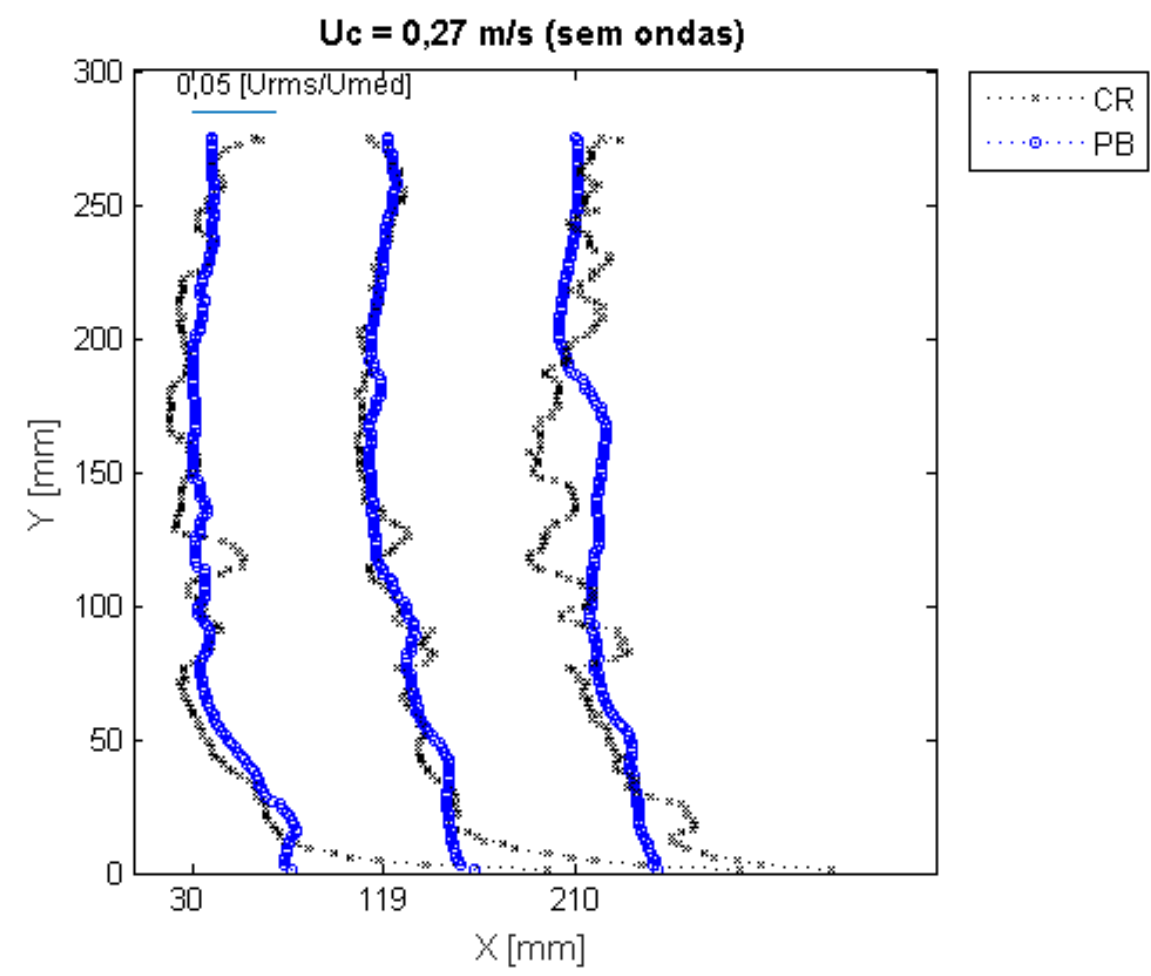

Figura 104 - Comparação entre perfis de $U_{r m s}$ para $U_{C}=0,27 \mathrm{~m} / \mathrm{s}$ 


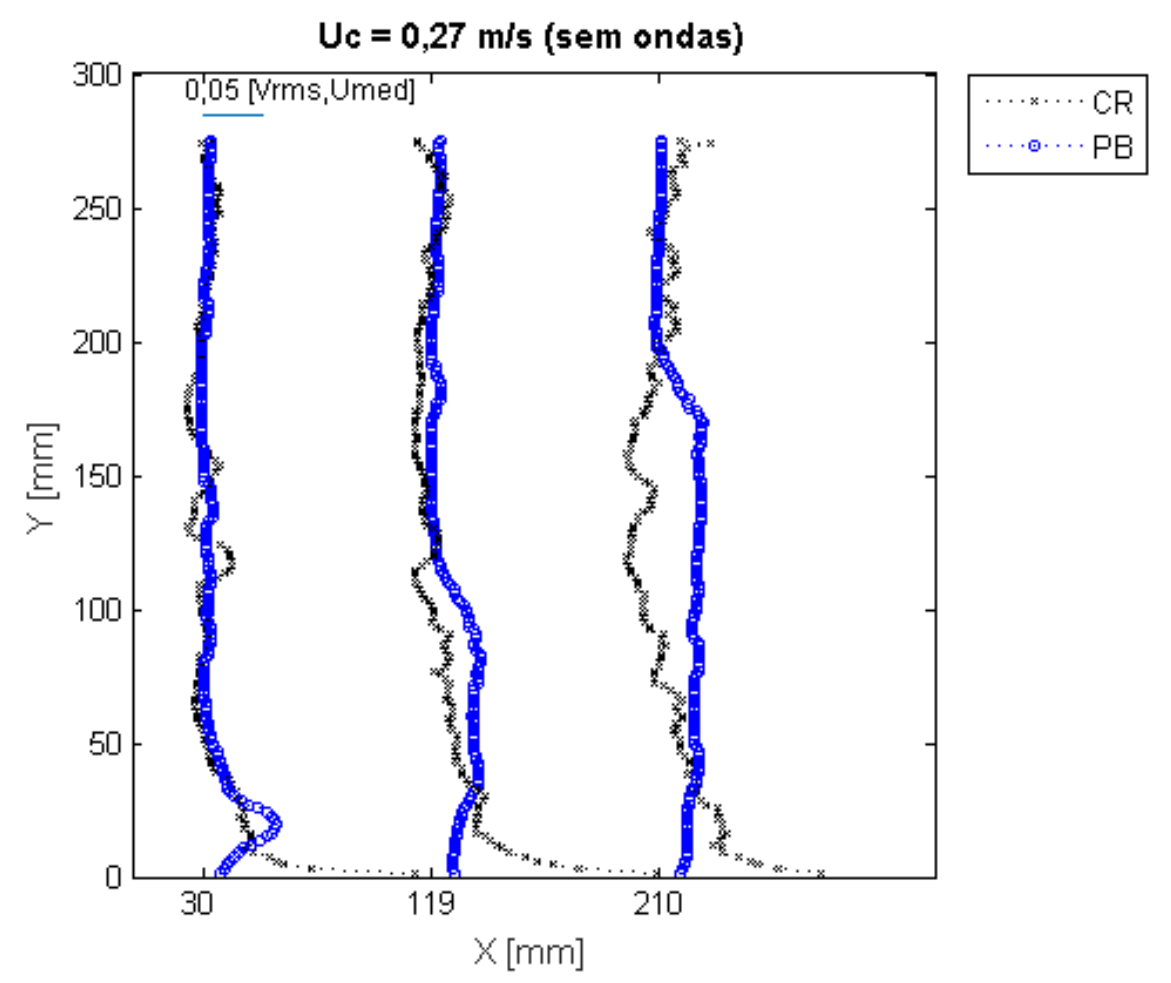

Figura 105 - Comparação entre perfis de $V_{r m s}$ para $U_{C}=0,27 \mathrm{~m} / \mathrm{s}$

\section{5. \\ Estudo do escoamento com pluma e com ondas}

Os campos de velocidade na direção do escoamento na presença de pluma de bolhas e ondas estão apresentados na figura 106, para ondas com amplitude igual a $0,5 \mathrm{~cm}$, e na figura 107, para ondas com amplitude de 2,0 cm. Já os campos da componente vertical do escoamento estão mostrados para amplitude de $0,5 \mathrm{~cm}$ e 2,0 cm na figura 108 e na figura 109, respectivamente. É possível observar que a presença das ondas, em termos qualitativos, não parece alterar significativamente o escoamento quando os resultados são comparados com os campos de velocidade obtidos sem a presença de ondas. Isso parece ser observado em todos os casos investigados. 

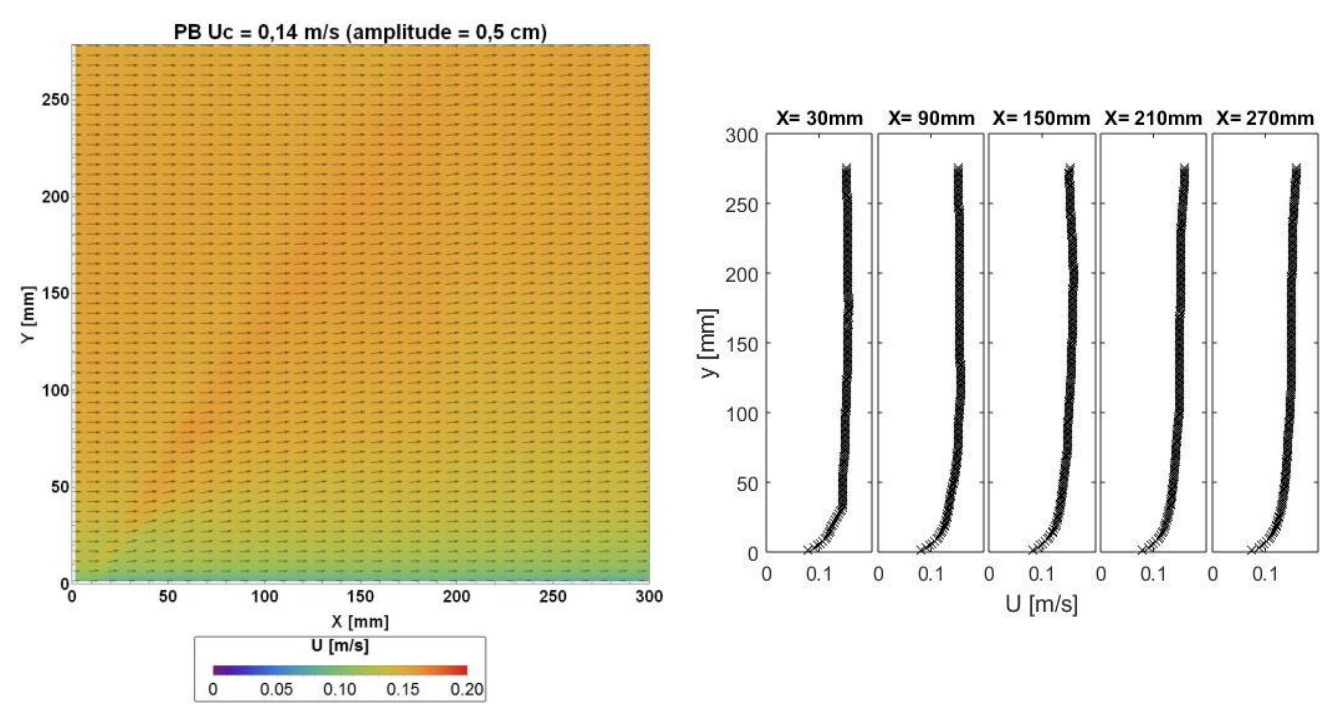

Figura 106 - Campo de $U$ médio com pluma de bolhas para $U_{C}=0,14 \mathrm{~m} / \mathrm{s}$ (amplitude $=0,5 \mathrm{~cm}$ )

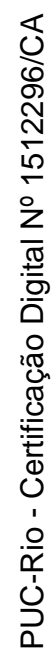
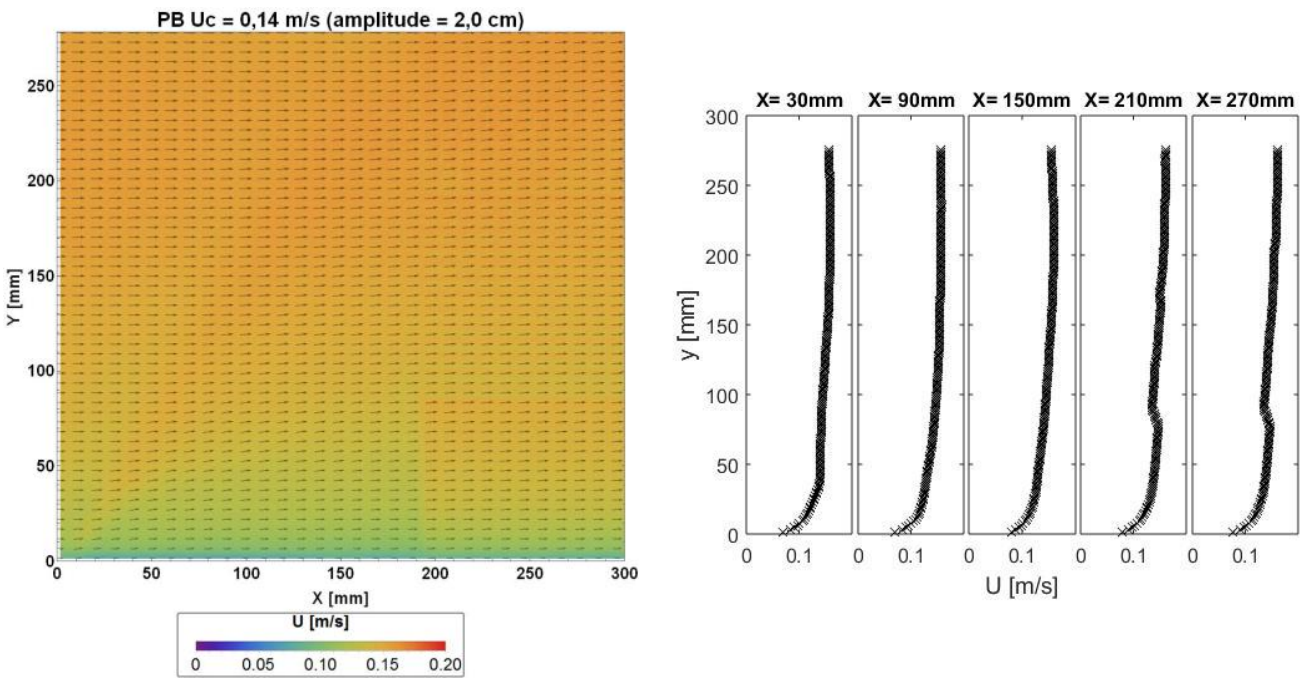

Figura 107 - Campo de $U$ médio com pluma de bolhas para $U_{C}=0,14 \mathrm{~m} / \mathrm{s}$ (amplitude $=2,0 \mathrm{~cm}$ ) 

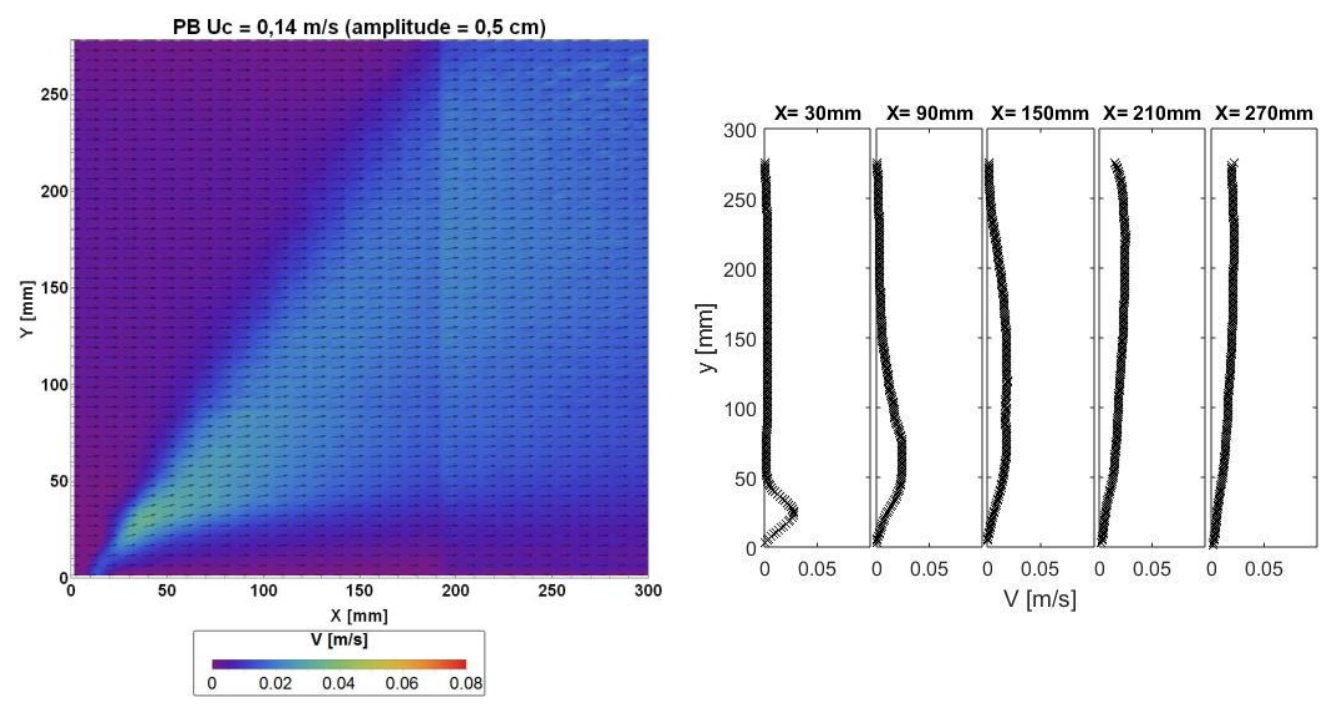

Figura 108 - Campo de $V$ médio com pluma de bolhas para $U_{C}=0,14 \mathrm{~m} / \mathrm{s}$ (amplitude $=0,5 \mathrm{~cm}$ )
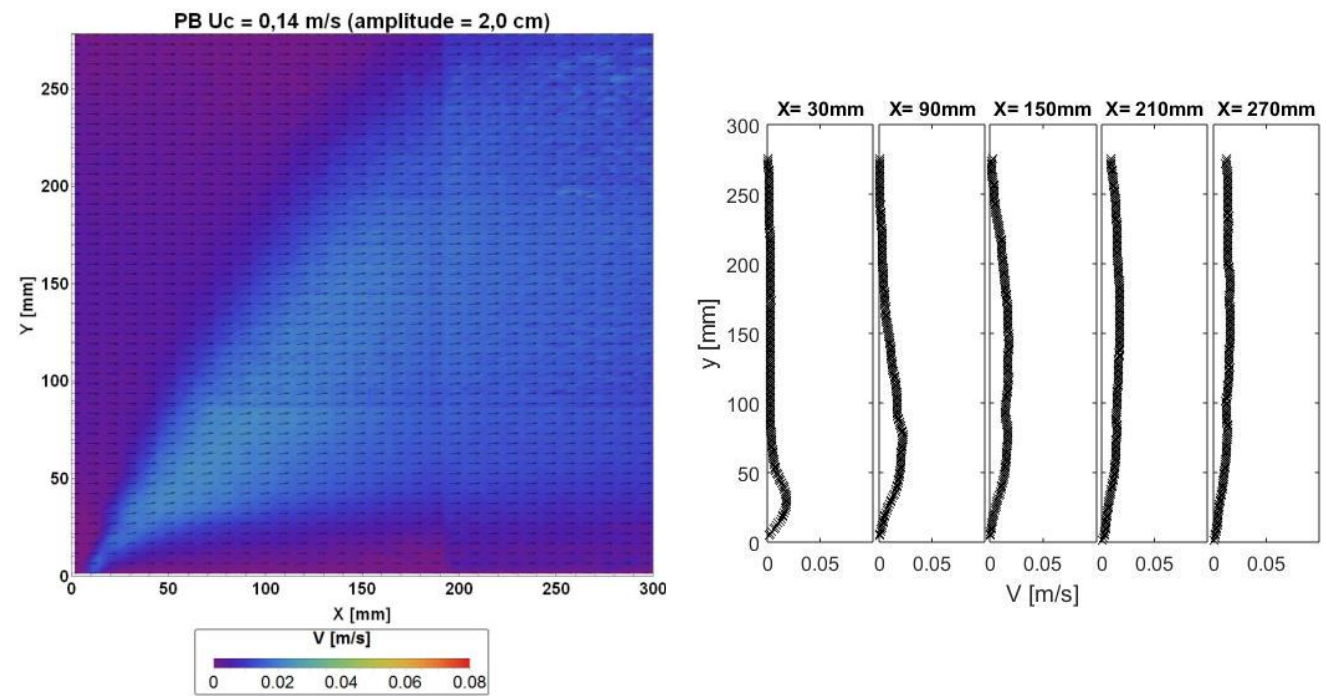

Figura 109 - Campo de $V$ médio com pluma de bolhas para $U_{C}=0,14 \mathrm{~m} / \mathrm{s}$ (amplitude $=2,0 \mathrm{~cm})$

Os campos de flutuações verticais de velocidade, para $U c=0,14 \mathrm{~m} / \mathrm{s}$, são apresentados na figura 110 e na figura 111 para amplitudes de $0,5 \mathrm{~cm}$ e $2,0 \mathrm{~cm}$, respectivamente. Observa-se nessas figuras uma mudança significativa no perfil de intensidade de flutuações entre o caso da pluma com ondas e sem ondas. Entretanto, os perfis nesses casos se assemelham àqueles já apresentados nas figuras 73 a 76, para o escoamento sem bolhas na presença de ondas. 

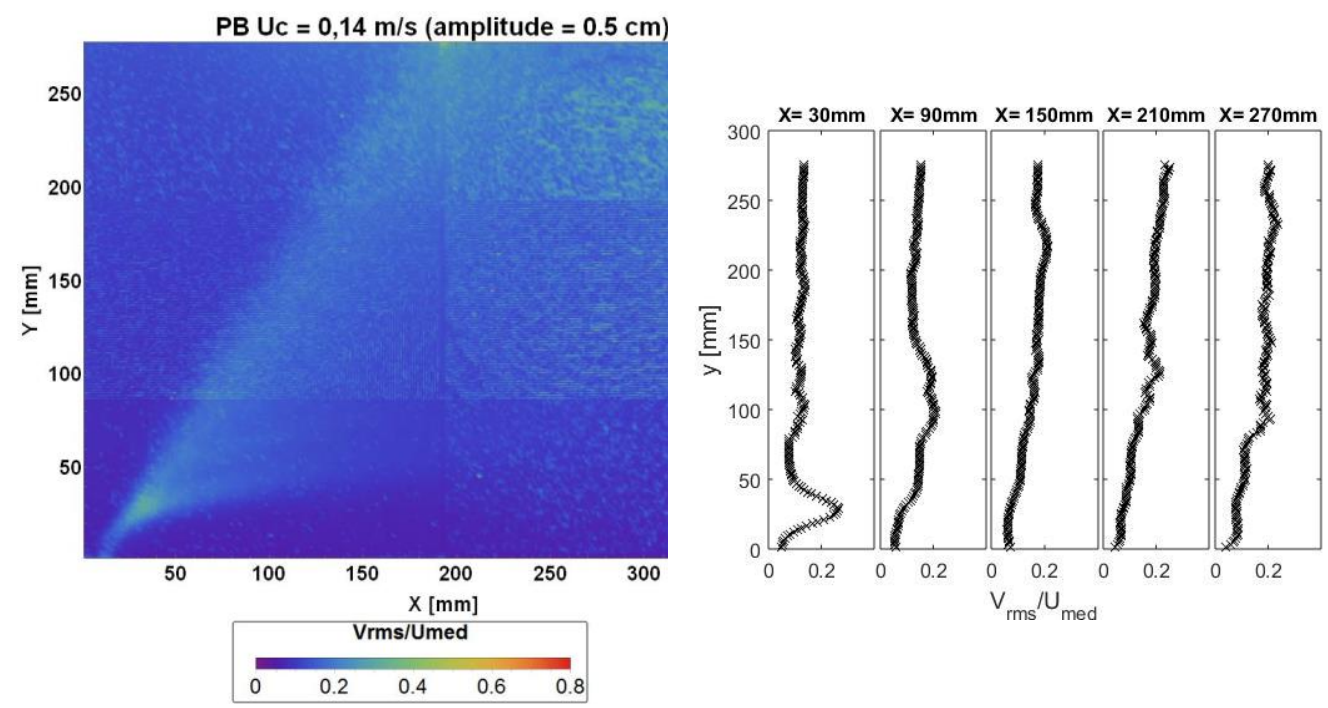

Figura 110 - Campo de flutuações verticais para $U_{C}=0,14 \mathrm{~m} / \mathrm{s}$ (amplitude $=$ $0,5 \mathrm{~cm})$
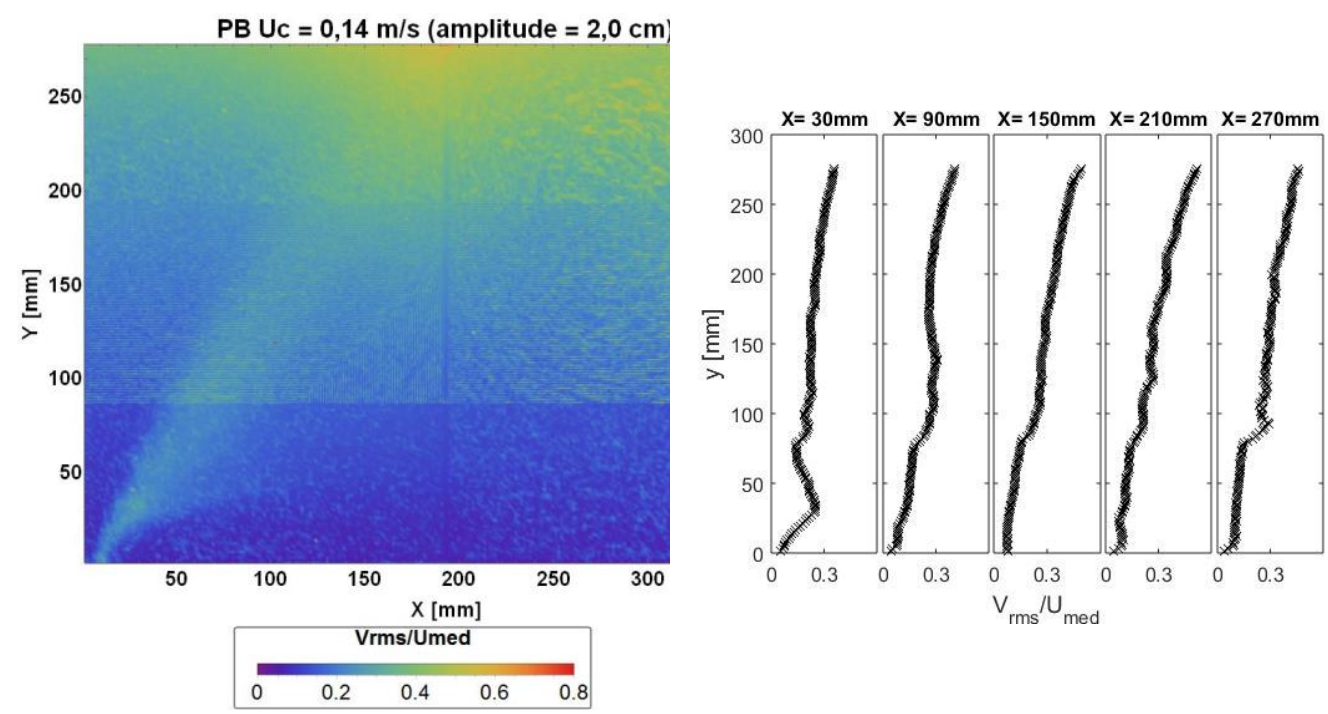

Figura 111 - Campo de flutuações verticais para $U_{C}=0,14 \mathrm{~m} / \mathrm{s}$ (amplitude $=$ $2,0 \mathrm{~cm})$

Os campos de flutuações verticais de velocidade, para $U c=0,27 \mathrm{~m} / \mathrm{s}$, estão apresentados na figura 112 e na figura 113 para as amplitudes de $0,5 \mathrm{~cm}$ e 2,0 cm, respectivamente. Observa-se que os perfis de turbulência são pouco alterados para o caso de velocidade mais alta da corrente do canal quando comparados àqueles obtidos com velocidade mais baixa $(U c=0,14 \mathrm{~m} / \mathrm{s})$. 
As comparações realizadas nesta seção sugerem que mesmo com a injeção de bolhas na presença de ondas, o escoamento se assemelha ao caso com somente a injeção de bolhas. Entretanto essa conjectura é bastante qualitativa e para se avaliar melhor o efeito das ondas sobre a pluma realizou-se uma comparação mais detalhada entre os casos com ondas e sem ondas na presença de injeção de gás.
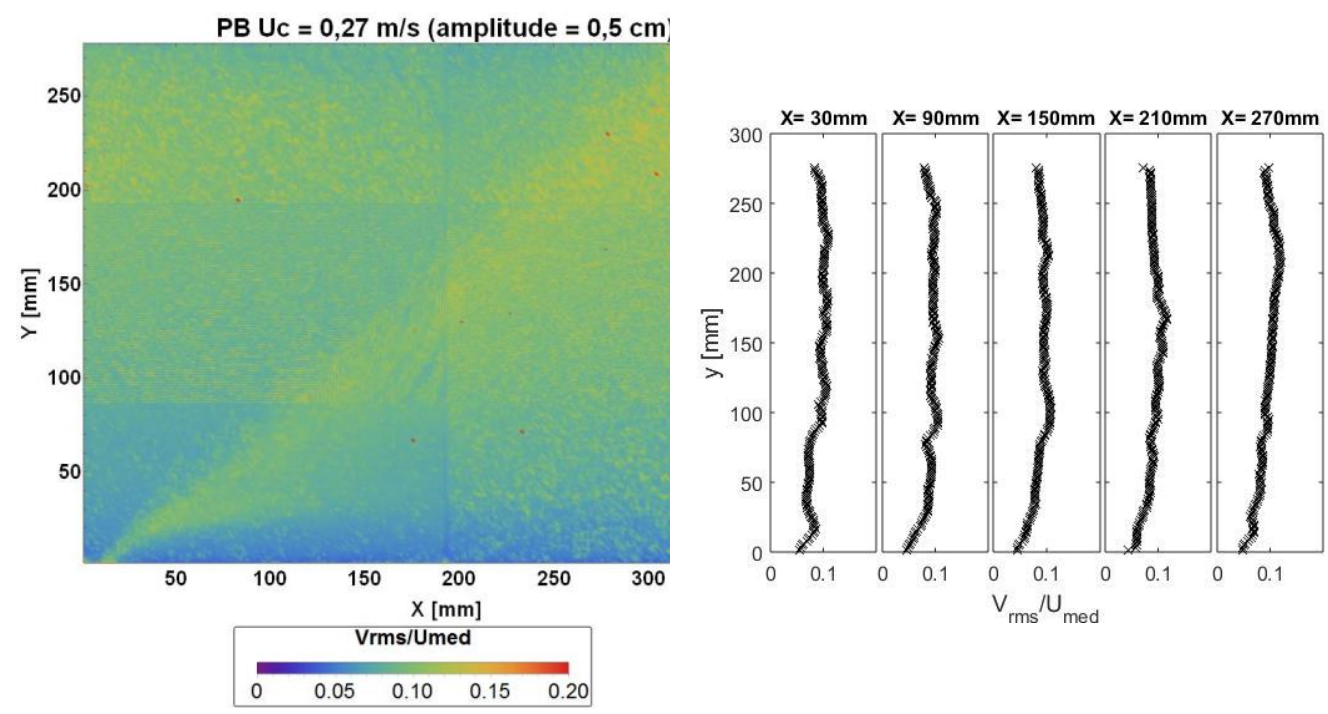

Figura 112 - Campo de flutuações verticais para $U_{C}=0,27 \mathrm{~m} / \mathrm{s}$ (amplitude $=$ $0,5 \mathrm{~cm})$
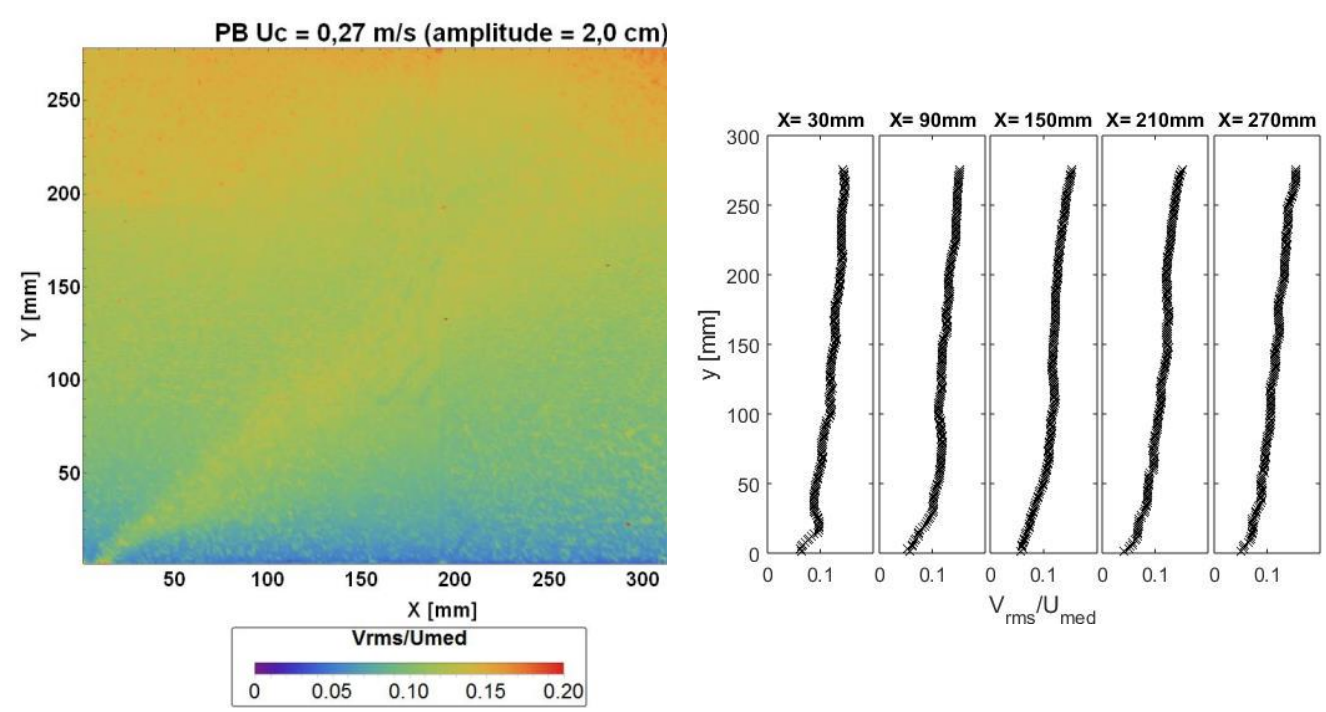

Figura 113 - Campo de flutuações verticais para $U_{C}=0,27 \mathrm{~m} / \mathrm{s}$ (amplitude $=$ $2,0 \mathrm{~cm})$ 


\subsection{1.}

\section{Comparação entre o escoamento cruzado sem ondas e com ondas}

A análise do escoamento a partir das imagens dos campos de velocidade e de turbulência não permite que se identifique, claramente, as diferenças entre os resultados obtidos sob as diferentes condições investigadas. Para se analisar conjuntamente os efeitos da geração de ondas sobre a dispersão da pluma de bolhas, realizou-se uma comparação detalhada entre os perfis de velocidade média e de intensidade de turbulência do escoamento.

As três curvas da Figura 114 representam os perfis de velocidade média (figura da esquerda) e de flutuação de velocidade (figura da direita) no sentido principal do escoamento com $U c=0,14 \mathrm{~m} / \mathrm{s}$ para as posições $X=30,120$ e 210 $\mathrm{mm}$. É possível observar que o escoamento médio é pouco afetado pela presença de ondas. No entanto, as flutuações de velocidades nos casos com ondas de baixa amplitude $(0,5 \mathrm{~cm})$ diferem em cerca de $20 \%$ em relação ao escoamento com pluma e sem ondas. Já para as ondas com amplitude de 2,0 cm, é perceptível um aumento em média de aproximadamente $40 \%$ da turbulência.
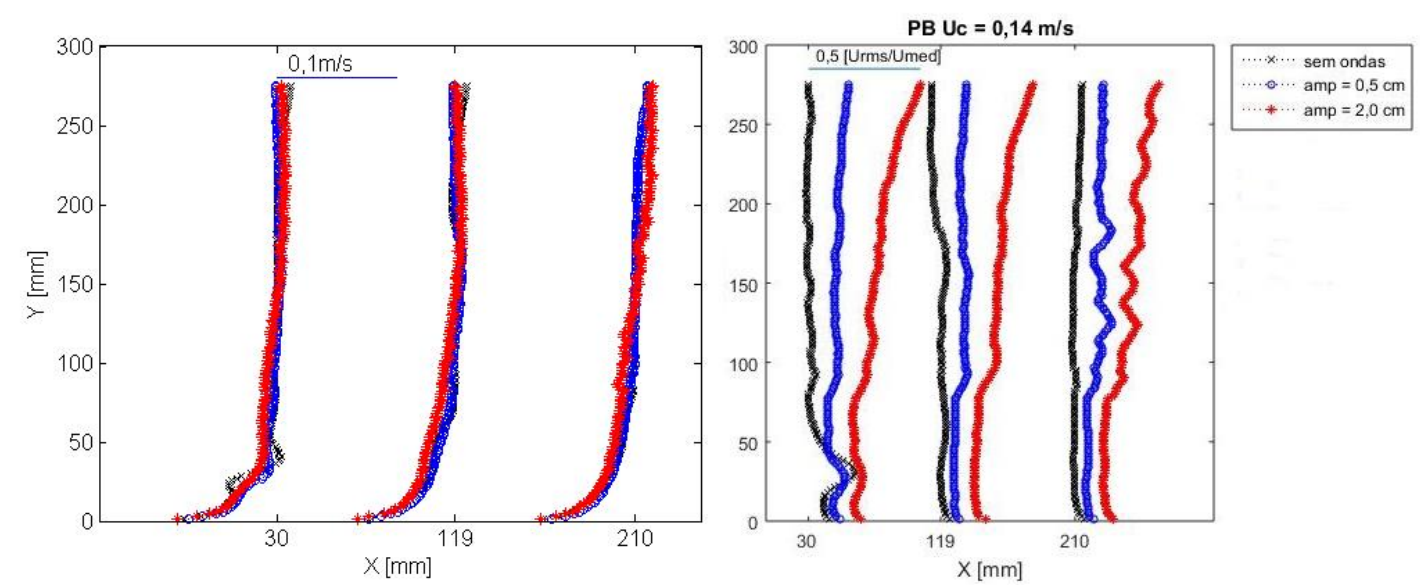

Figura 114 - Influência das ondas na média e na intensidade de flutuação da componente $U$ de velocidade do escoamento. Caso com $U_{C}$ igual a $0,14 \mathrm{~m} / \mathrm{s}$

Os perfis de $V_{r m s}$ nas posições $\mathrm{X}=30,120$ e $210 \mathrm{~mm}$ e $U c=0,14 \mathrm{~m} / \mathrm{s}$ estão apresentados na Figura 115. As curvas mostram que a dispersão da pluma apresenta uma flutuação vertical considerável na região mais próxima da parede inferior. Nota-se que as ondas têm pouca influência sobre o escoamento nessa região. A presença das ondas torna-se mais perceptível à medida que se desloca em direção a 
superfície. Essas observações são similares àquelas feitas para o caso sem pluma de bolhas na seção 6.3.6

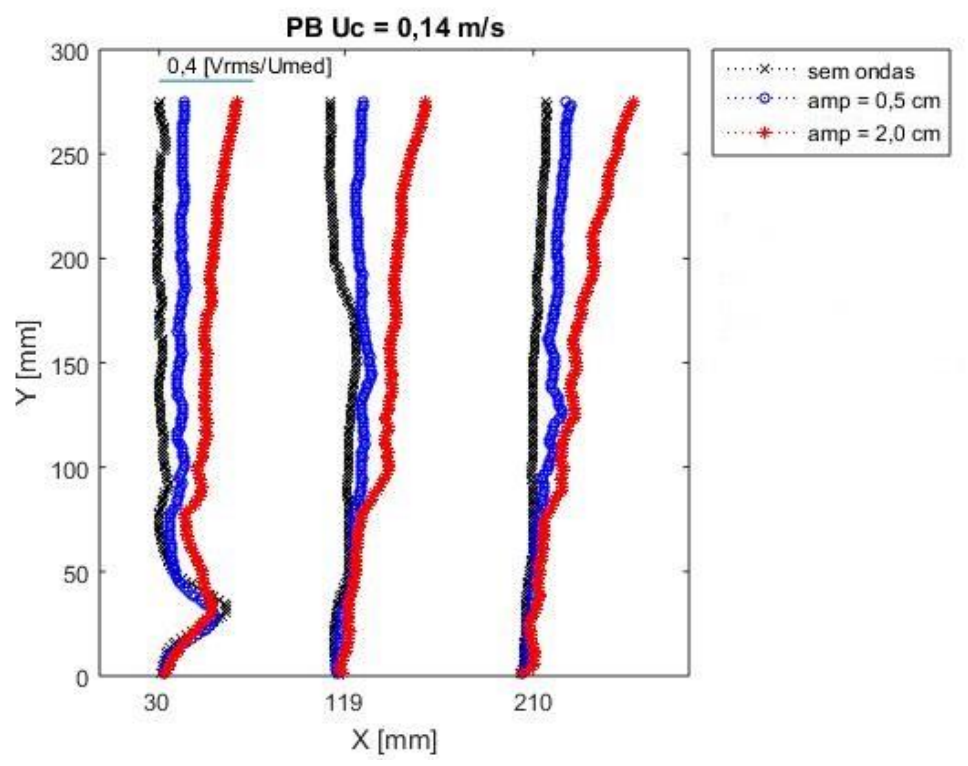

Figura 115 - Comparação de casos da flutuação de velocidade $V_{r m s}$ para $U_{C}$ $=0,14 \mathrm{~m} / \mathrm{s}$

A análise comparativa da influência das ondas no escoamento cruzado com velocidade $U c$ igual a $0,27 \mathrm{~m} / \mathrm{s}$ é apresentada na Figura 116. Os resultados mostrados na figura da esquerda correspondem a média da velocidade na direção do escoamento. Já os resultados da figura da direita correspondem a intensidade das flutuações. Assim como nos casos de velocidade mais baixa as ondas exercem pouca influência no perfil de velocidades médias. A figura da direita sugere que a intensidade das flutuações do escoamento é grande em relação as perturbações induzidas pela pluma. Isso porque os perfis de intensidade de turbulência exibem uma variação pequena a medida que a pluma se desloca ao longo da altura do canal. Nos casos com ondas, onde a intensidade das flutuações é ainda maior, o efeito das plumas quase não é perceptível.

Os perfis de flutuação de $u$, para condições com ondas, apresentam uma pequena variação de turbulência, em torno de $15 \%$, comparado ao mesmo caso sem ondas, como mostrado na Figura 116. Da mesma forma, a turbulência gerada na componente vertical $v$ da velocidade apresenta uma diferença percentual baixa, em 
torno de $10 \%$, comparando-se ao caso do escoamento de pluma sem ondas, de acordo com a Figura 117.
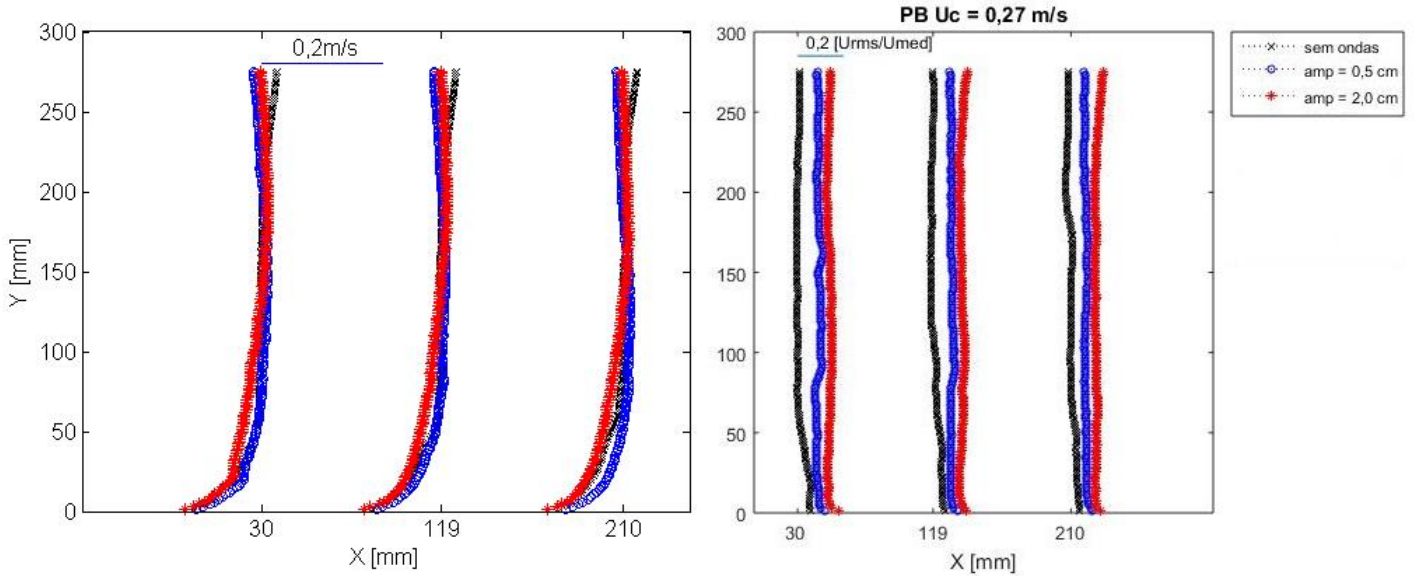

Figura 116 - Influência das ondas na média e na intensidade de flutuação da componente $U$ de velocidade do escoamento. Caso com $U_{C}$ igual a $0,27 \mathrm{~m} / \mathrm{s}$

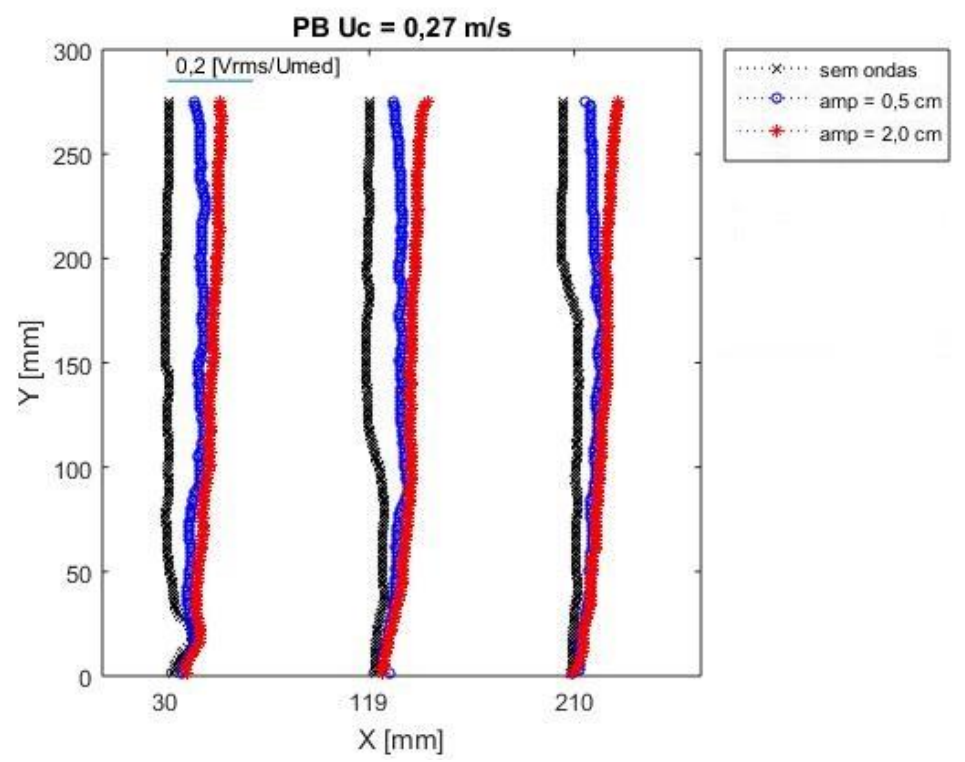

Figura 117 - Comparação de casos para flutuação de velocidade $V_{r m s}$ para

$$
U_{C}=0,27 \mathrm{~m} / \mathrm{s}
$$

Para analisar a existência de alguma relação cruzada entre as plumas de bolhas e as ondas, foram avaliadas as diferenças dos perfis de flutuação de velocidade em relação ao escoamento de referência sem a presença de ondas, de acordo com a Eq. 6-2 e a Eq. 6-3. Os perfis de velocidade média não foram 
analisados uma vez que não se notou nenhuma alteração significativa entre os casos investigados.

$$
C R \text { dif }=\operatorname{perfil}\left(C R_{\text {com ondas }}\right)-\operatorname{perfil}\left(C R_{\text {sem ondas }}\right)
$$

$$
P B \text { dif }=\operatorname{perfil}\left(P B_{\text {com ondas }}\right)-\operatorname{perfil}\left(P B_{\text {sem ondas }}\right)
$$

Onde $C R$ dif representa o perfil de flutuação resultante do perfil de flutuação da caracterização com ondas (perfil $\left(C R_{\text {com ondas }}\right)$ ) subtraído do perfil de flutuações da caracterização sem ondas (perfil $\left(C R_{\text {sem ondas }}\right)$ ). Enquanto que $P B$ dif é a resultante do perfil de flutuação da pluma de bolhas com ondas (perfil $\left(P B_{\text {com ondas }}\right)$ ) subtraído do perfil do de flutuações da pluma de bolhas sem ondas (perfil( $\left.\left(P B_{\text {sem ondas }}\right)\right)$. Em ambos os casos, a subtração aplicada permite remover a turbulência do escoamento de referência e analisar somente a influência das ondas.

A Figura 118 e a Figura 120 mostram os perfis de flutuações horizontais de velocidades e a Figura 119 e a Figura 121 apresentam os perfis de flutuações verticais. Todos são perfis resultantes das equações 6-2 e 6-3. Nota-se os perfis em todos os casos são bastante similares, indicando que o perfil do escoamento com ondas, de fato, é pouco alterado pela presença das plumas. Logo, apesar de cada efeito individual alterar significativamente a turbulência do escoamento, a interação entre os efeitos é fraca. Isso sugere que o problema pode ser modelado com a sobreposição dos efeitos de ondas sobre plumas em jatos cruzados sem oscilação. Isso tende a simplificar o problema no caso de simulações numéricas, pois soluções em regime permanente, que são mais baratas do ponto de vista de esforço computacional podem ser utilizadas para a simulação das plumas de bolhas em escoamento cruzado. A partir dos resultados dessas simulações, correções para as oscilações induzidas por ondas de superfície podem ser aplicadas. Do ponto de vista do escoamento a sobreposição de perturbações parece ser possível a partir dos resultados apresentados. No entanto, o mesmo ainda não pode ser dito para a dispersão, velocidade de subida, diâmetro e demais características das bolhas na pluma. Logo, essas características serão analisadas nas próximas seções deste trabalho. 


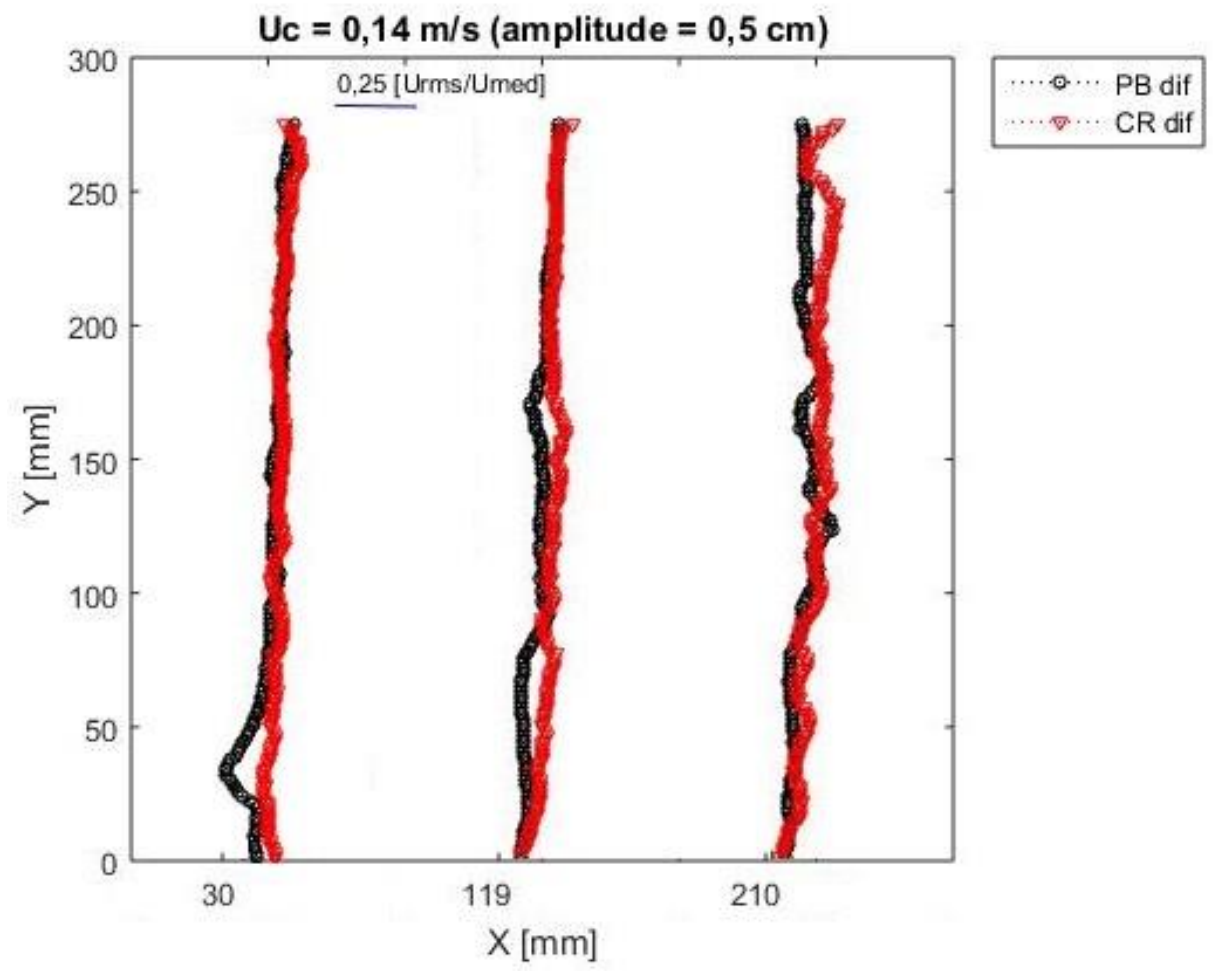

Figura 118 - Diferença de flutuação de velocidade $U_{r m s}$ para $U_{C}=0,14 \mathrm{~m} / \mathrm{s}$ (amplitude $=0,5 \mathrm{~cm}$ ) 


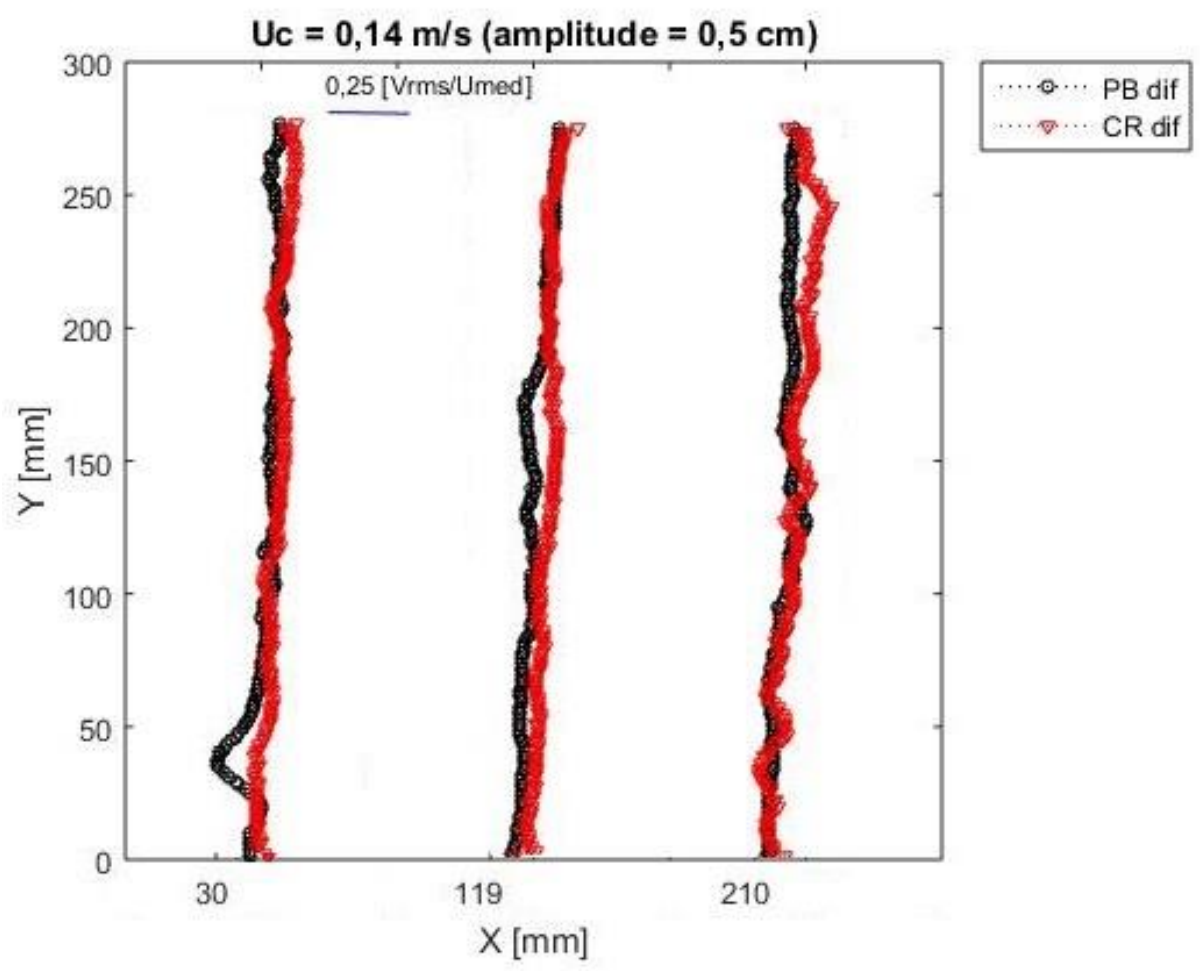

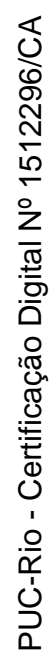

Figura 119 - Diferença de flutuação de velocidade $V_{r m s}$ para $U_{C}=0,14 \mathrm{~m} / \mathrm{s}$ (amplitude $=0,5 \mathrm{~cm}$ )
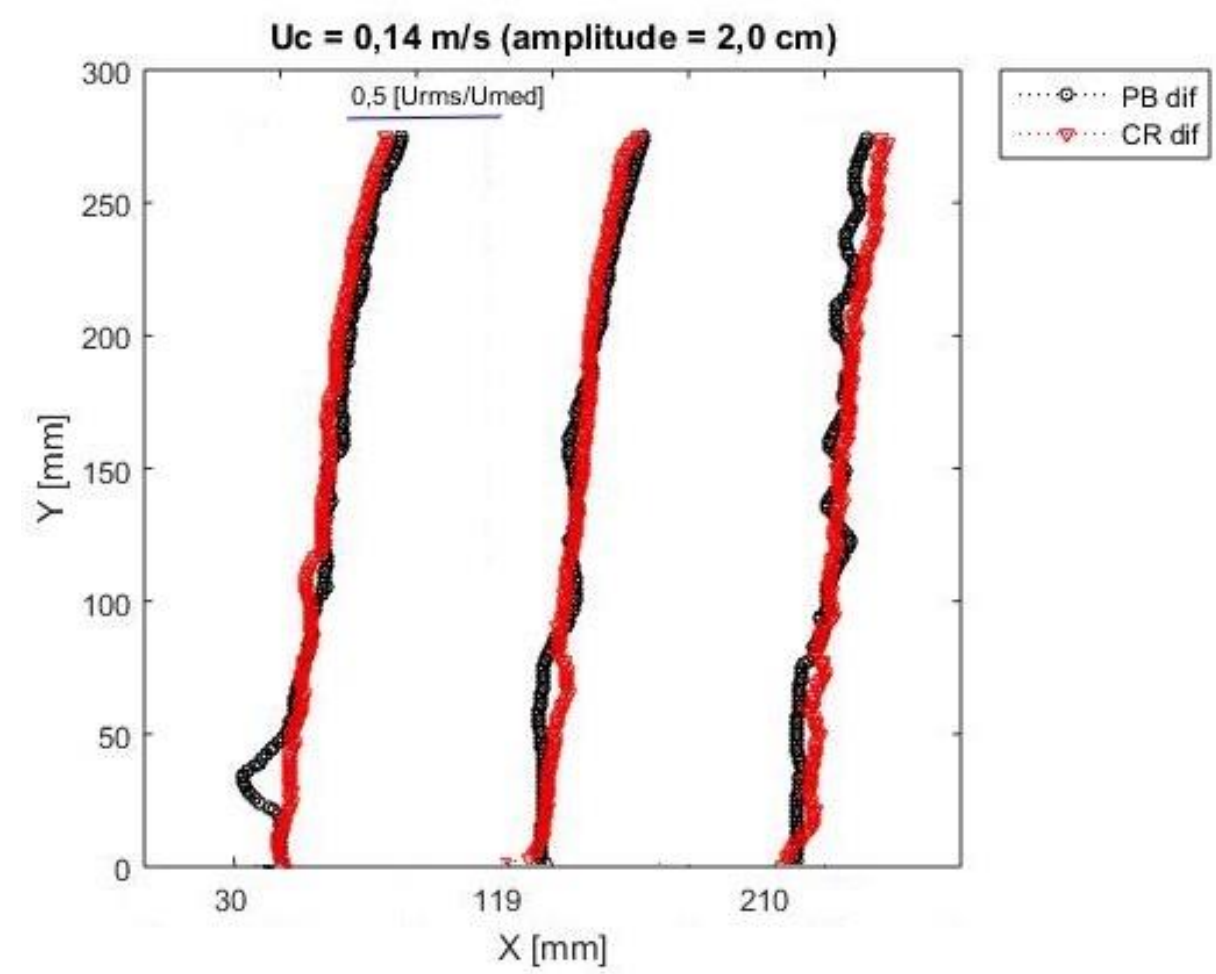

Figura 120 - Diferença de flutuação de velocidade $U_{r m s}$ para $U_{C}=0,14 \mathrm{~m} / \mathrm{s}$ (amplitude $=2,0 \mathrm{~cm}$ ) 


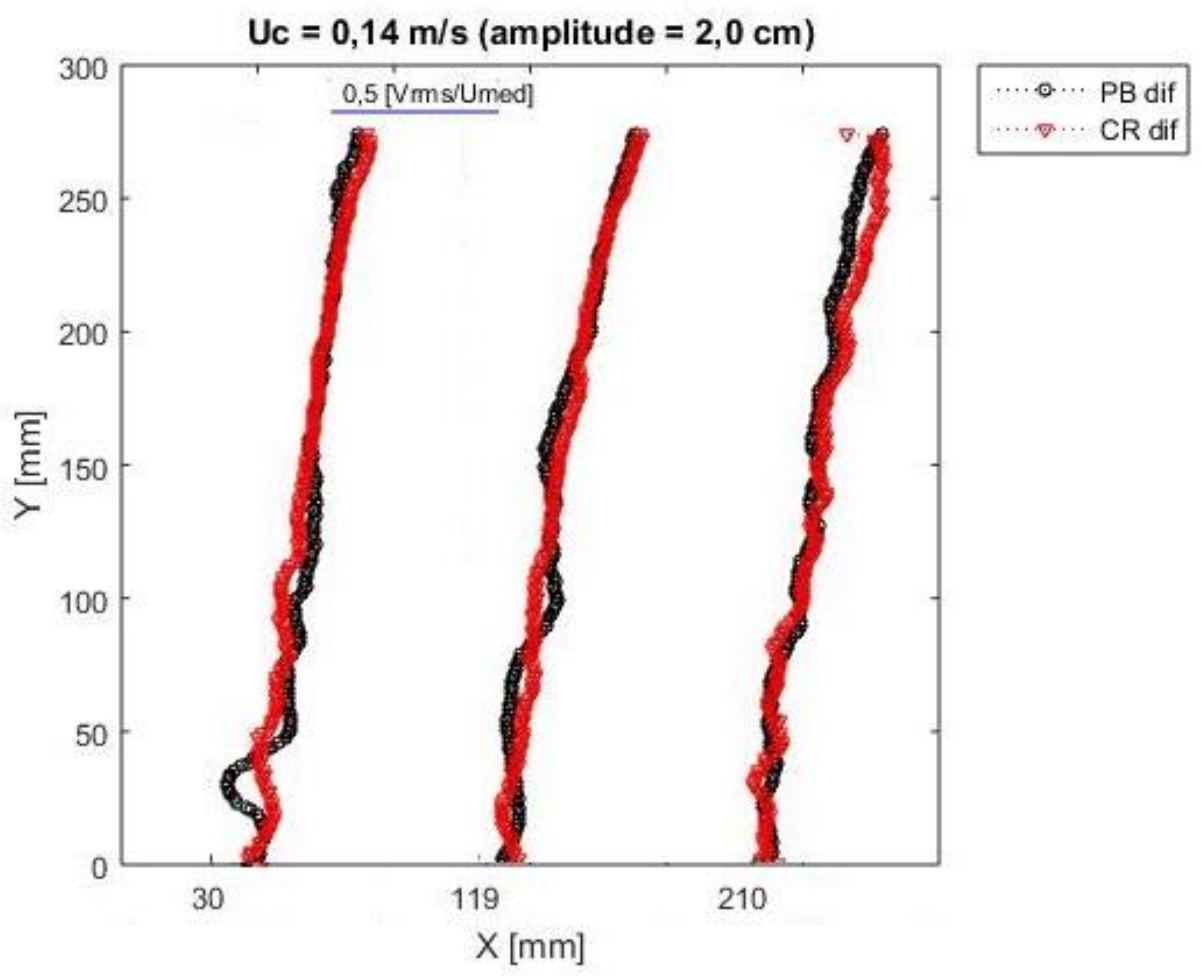

Figura 121 - Diferença de flutuação de velocidade $V_{r m s}$ para $U_{C}=0,14 \mathrm{~m} / \mathrm{s}$ (amplitude $=2,0 \mathrm{~cm}$ ) 


\section{7 \\ Influência do escoamento cruzado nas características e propriedades das bolhas}

Neste capítulo, são apresentados os resultados referentes às características e propriedades das bolhas no escoamento cruzado com e sem ondas. Ao longo deste capítulo são realizadas comparações com resultados da literatura afim de se identificar possíveis influências das ondas nas propriedades das bolhas. Além disso, as características de oscilação e dispersão das bolhas são apresentadas, mostrando como as ondas influenciam o movimento de subida das bolhas.

\section{1. Características e propriedades das bolhas}

No processamento realizado para a identificação de bolhas, é possível que tenham sido consideradas algumas regiões que continham bolhas muito próximas umas das outras como sendo uma única bolha. Ainda, algumas partículas que não foram totalmente eliminadas completamente pelo filtro, também podem ter sido identificadas como sendo bolhas muito pequenas. Para desconsiderar resultados associados a esses casos, foi adotado um critério para remover bolhas muito grandes ou muito pequenas.

O critério de eliminação foi baseado nos diâmetros calculados a partir das imagens. Foram analisadas diversas imagens manualmente. Regiões delimitadas por bolhas individuais foram identificadas e computadas como diâmetros válidos. Portanto, foi determinado um intervalo médio de diâmetro correspondente às regiões que realmente eram bolhas. Assim, somente bolhas com valores de diâmetro entre 3,5 $\mathrm{mm} \leq \mathrm{D}_{\text {circular/elíptico }} \leq 6,0 \mathrm{~mm}$, foram contabilizados para as análises.

A Figura 122 mostra a relação entre a diferença percentual dos dois métodos de cálculo do diâmetro para diferentes valores de $D_{\text {eliptico. }}$ Os pontos do gráfico representam as bolhas de 100 imagens analisadas para o campo de visualização A e C (os demais campos de visualização se assemelham com os resultados aqui 
apresentado) com os respectivos diâmetros equivalentes calculados pela rotina de processamento.

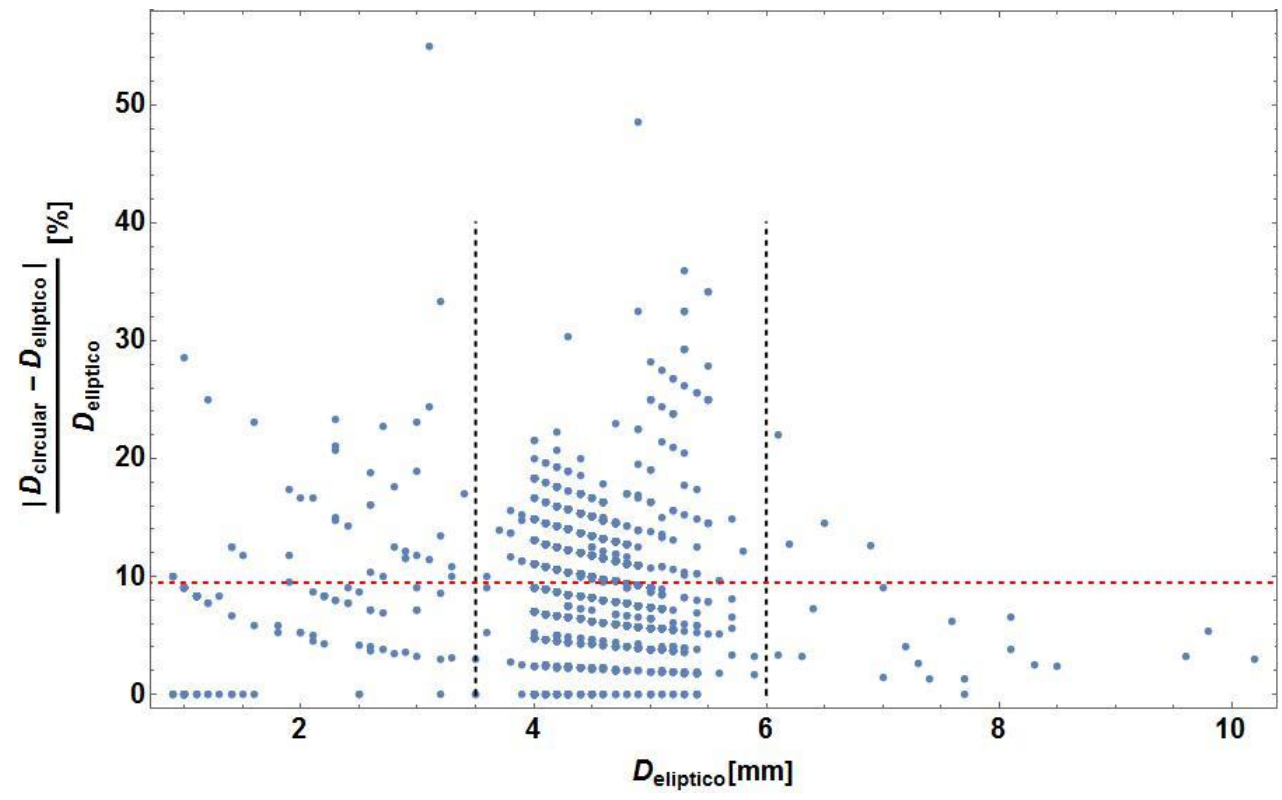

Figura 122 - Relação entre a porcentagem da diferença entre os diâmetros e Deliptico

Na Figura 122, as duas linhas verticais tracejadas delimitam a região estabelecida pelo critério. A linha horizontal tracejada em vermelho é a linha média da porcentagem da diferença entre os dois diâmetros calculados, com valor igual a aproximadamente $10 \%$. Observa-se na Figura 122 um espaçamento bem definido entre as curvas e que esse espaçamento diminui com o aumento de $D_{\text {eliptico. }}$ Isso se deve à resolução em pixel das imagens que resulta em valores discretos de diâmetros. A partir das amostras de imagens, nota-se que as bolhas tendem a apresentar um formato elíptico. Isso também foi observado no trabalho de Wang e Socolofsky (2015) para escoamento cruzado sem ondas. Sendo assim, somente os diâmetros elípticos equivalentes das bolhas $\left(d_{B}=D_{\text {eliptico }}\right)$ serão considerados nas análises realizadas nesta seção.

Para verificar possíveis oscilações das bolhas durante a subida até a superfície, foi aplicada a transformada rápida de Fourier na variação temporal da velocidade das bolhas. Os espectros de frequência apresentados na Figura 123, Figura 124, Figura 125 e na Figura 126 mostram que os picos de frequência mais evidentes correspondem aos mesmos picos de frequências da oscilação das ondas, 
em $0,67 \mathrm{~Hz}$ e $1,34 \mathrm{~Hz}$, exceto no caso de $U c=0,27 \mathrm{~m} / \mathrm{s}$ com amplitude igual a 0,5 cm onde a frequência de 0,67 Hz não está evidenciada. Portanto, pode-se afirmar que as ondas tendem a induzir a movimentação das bolhas de um modo oscilatório na mesma frequência de geração das ondas.

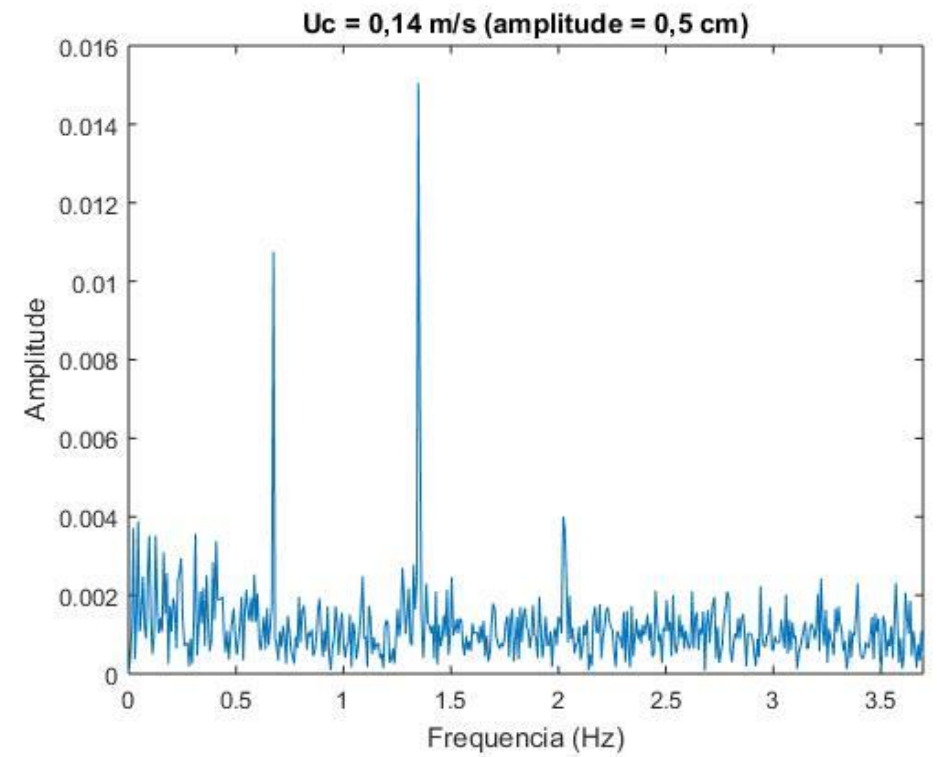

Figura 123 - Espectro de frequências das bolhas para $U c=0,14 \mathrm{~m} / \mathrm{s}$ (amplitude $=0,5 \mathrm{~cm}$ )

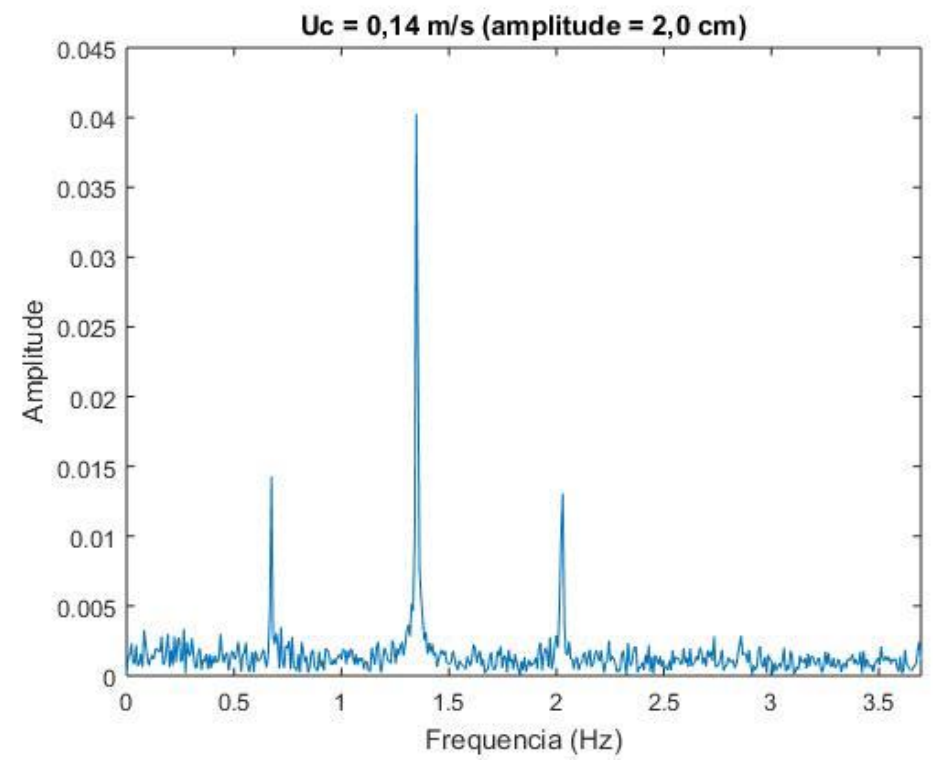

Figura 124 - Espectro de frequências das bolhas para $U c=0,14 \mathrm{~m} / \mathrm{s}$ (amplitude $=2,0 \mathrm{~cm}$ ) 


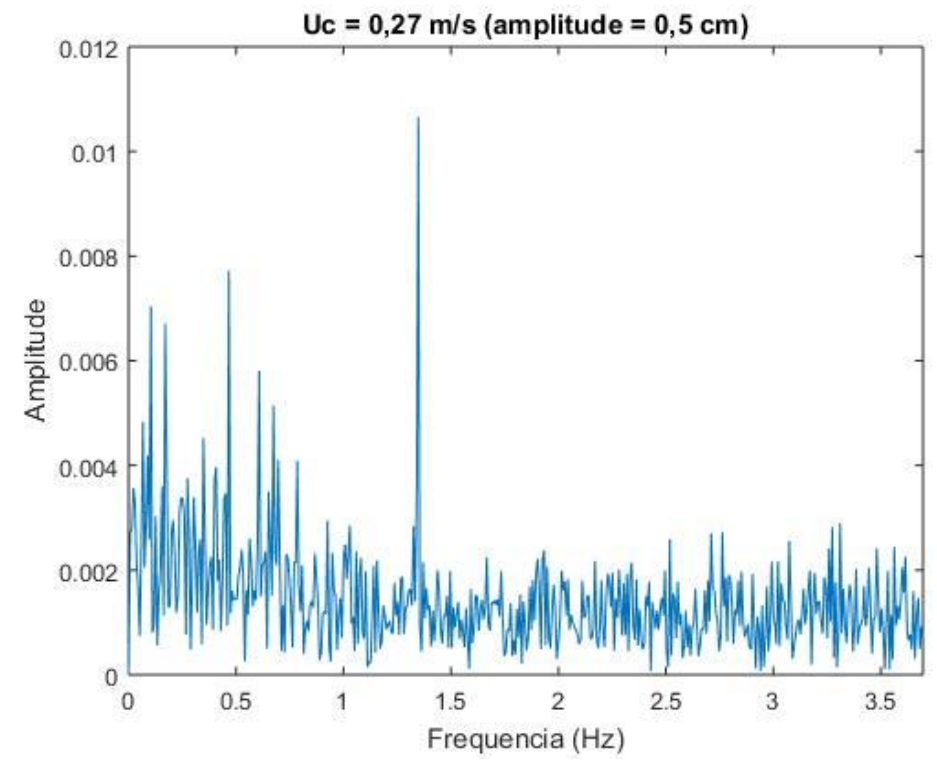

Figura 125 - Espectro de frequências das bolhas para $U c=0,27 \mathrm{~m} / \mathrm{s}$ (amplitude $=0,5 \mathrm{~cm}$ )

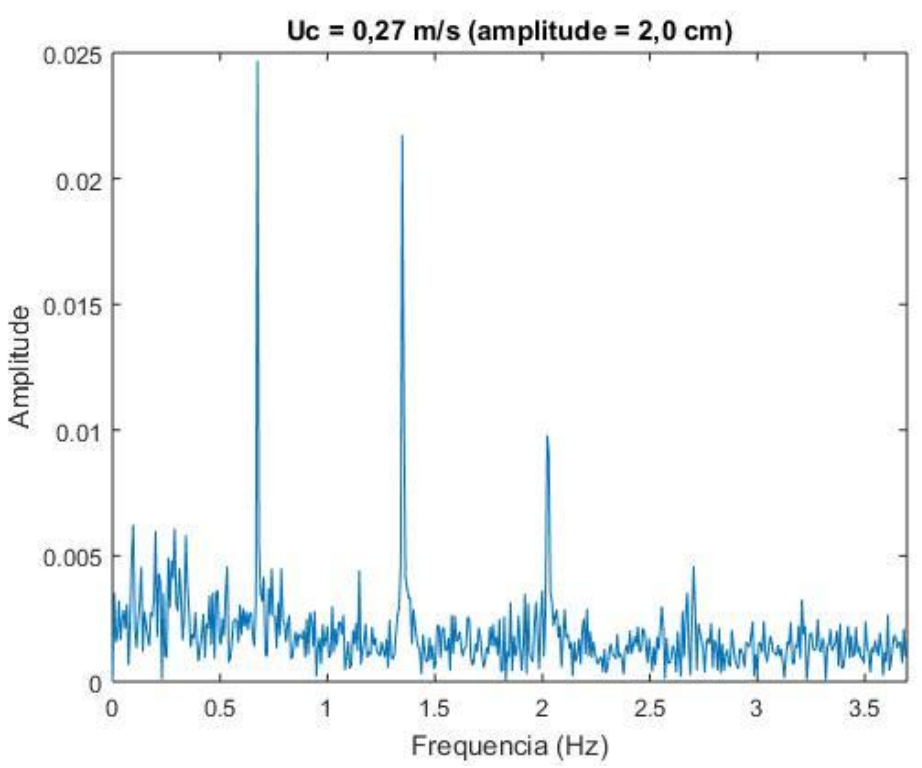

Figura 126 - Espectro de frequências das bolhas para $U c=0,27 \mathrm{~m} / \mathrm{s}$ (amplitude $=2,0 \mathrm{~cm}$ )

A seguir, são apresentados os resultados de intensidade de flutuação das componentes $u$ e $v$ da velocidade das bolhas no escoamento cruzado sem ondas, com ondas de amplitude de $0,5 \mathrm{~cm}$ e ondas de amplitude igual a $2,0 \mathrm{~cm}$. Analisando- 
se os casos com velocidade do escoamento cruzado $U c=0,14 \mathrm{~m} / \mathrm{s}$ (Figura 127), é perceptível que, a partir da metade da coluna d'água, as bolhas apresentam um aumento relativamente pequeno da componente de flutuação de velocidade $u$ no escoamento com ondas, porém, este aumento de flutuação pode ser considerado desprezível. O mesmo ocorre com a componente de flutuação vertical $v$ das bolhas, porém o aumento em relação ao caso sem ondas ocorre em uma região mais próxima à parede, como mostra a Figura 128.

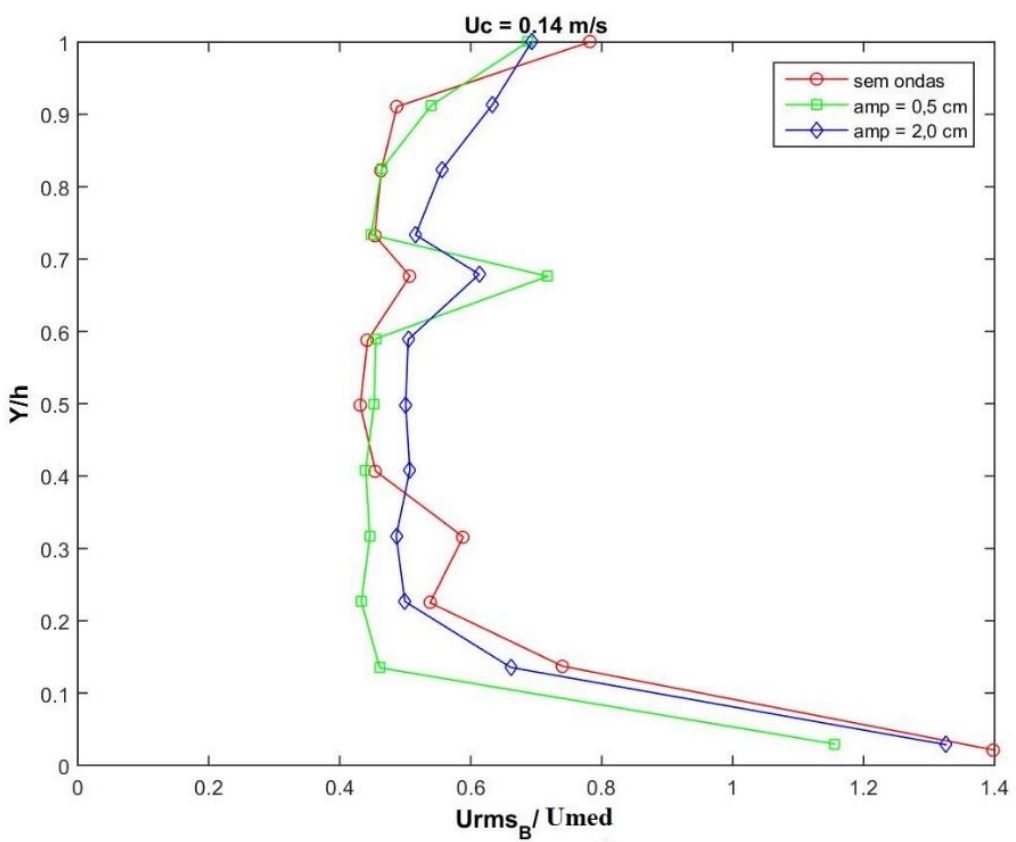

Figura 127 - Flutuação de velocidade $U_{r m s}$ das bolhas para $U_{C}=0,14 \mathrm{~m} / \mathrm{s}$ 


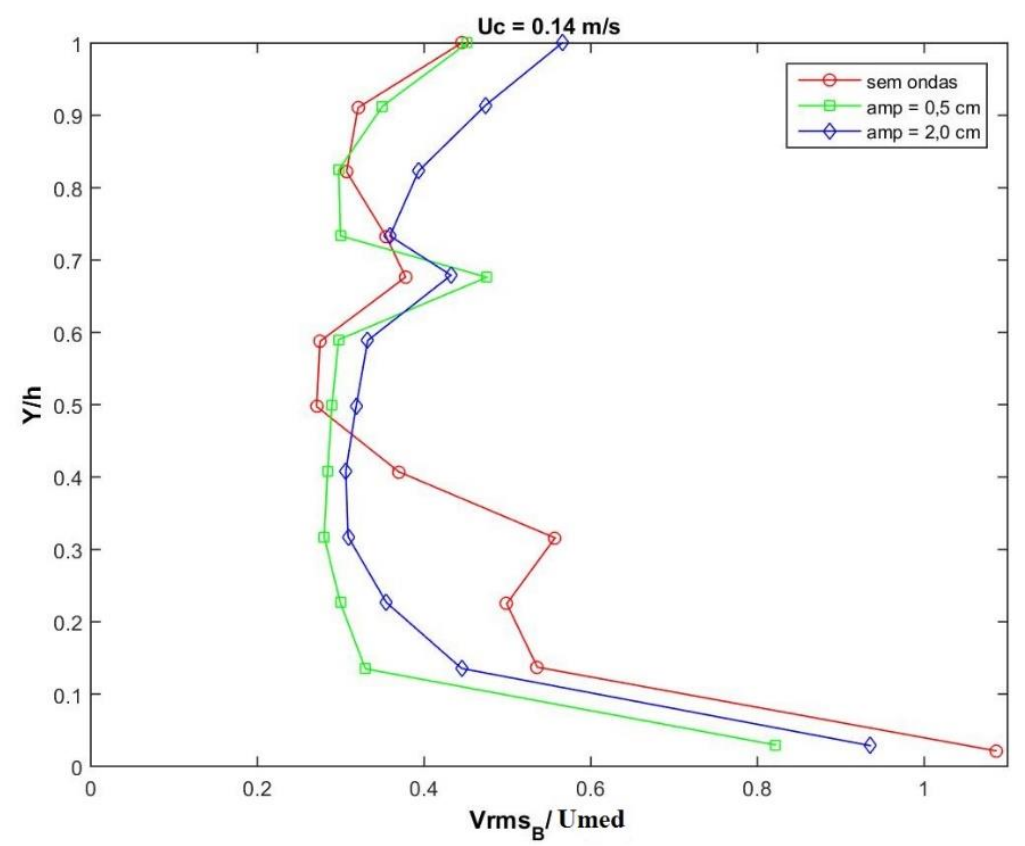

Figura 128 - Flutuação de velocidade $V_{r m s}$ das bolhas para $U_{C}=0,14 \mathrm{~m} / \mathrm{s}$

A mesma análise é feita para o caso de velocidade do escoamento cruzado igual a 0,27 m/s, como mostrado na Figura 129 e na Figura 130. A intensidade turbulenta em $u$ aumenta, principalmente no caso da onda com amplitude igual a $0,5 \mathrm{~cm}$, a partir de $20 \%$ da altura do canal relativo ao fundo. Isto mostra que ocorre um pequeno aumento de turbulência das bolhas já em regiões muito abaixo da superfície, quando as ondas são consideradas. 


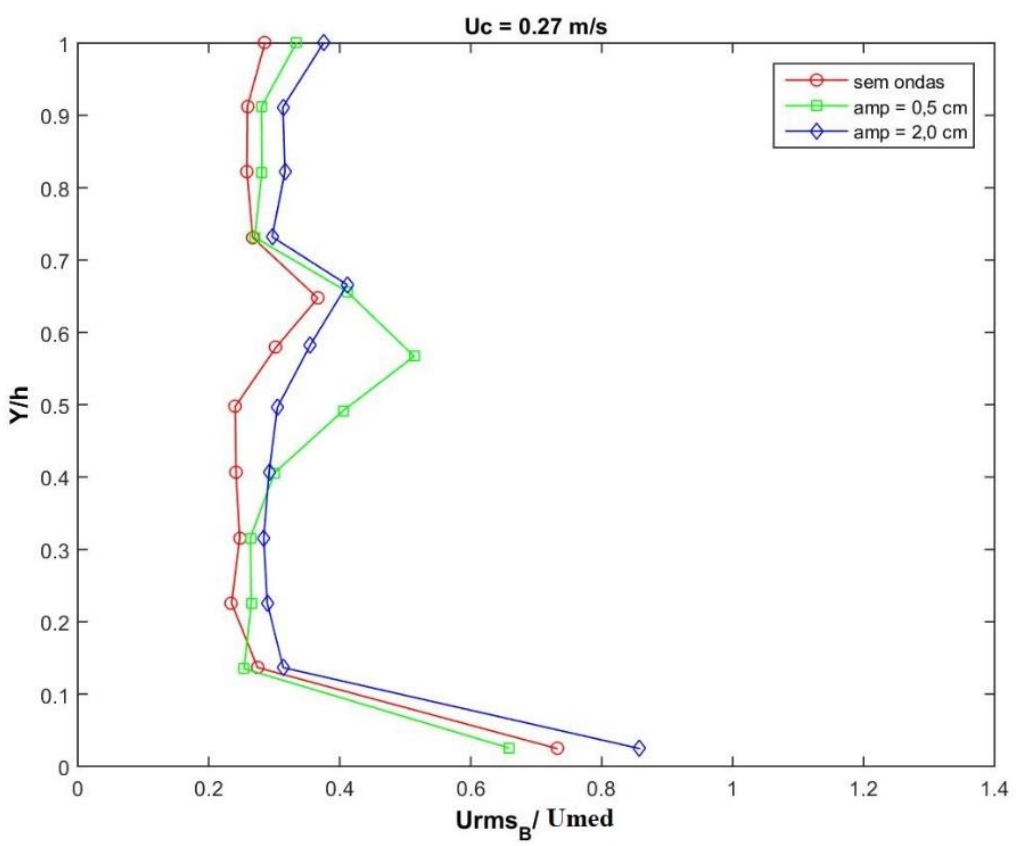

Figura 129 - Flutuação de velocidade $U_{r m s}$ das bolhas para $U_{C}=0,27 \mathrm{~m} / \mathrm{s}$

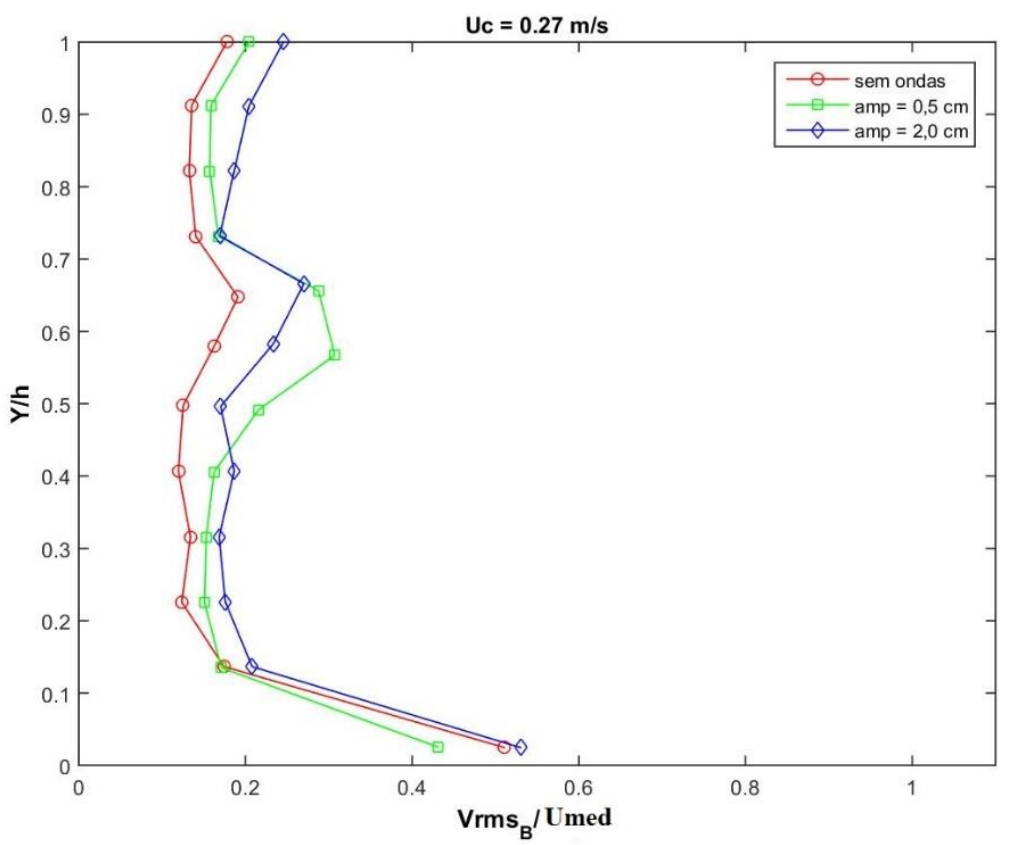

Figura 130 - Flutuação de velocidade $V_{r m s}$ das bolhas para $U_{C}=0,27 \mathrm{~m} / \mathrm{s}$

A fim de avaliar a dispersão das bolhas nos diferentes casos, foram analisadas as distribuições da população das bolhas ao longo da altura do canal. Os histogramas foram avaliados em diferentes intervalos ao longo da direção do escoamento $(\mathrm{X})$, variando desde regiões próximas ao ponto de injeção até regiões 
onda a pluma já se encontrava próxima à superfície. A Figura 131 mostra a relação entre a população das bolhas para o caso $U c=0,14 \mathrm{~m} / \mathrm{s}$ e a Figura 132 para o caso $U c=0,27 \mathrm{~m} / \mathrm{s}$. Analisando-se os casos, é perceptível que existem diferenças entre dispersões das bolhas nos casos com ondas e sem ondas. Isso mostra que, além da alteração do escoamento a jusante da pluma devido as ondas, a dispersão das bolhas também é afetada. Os gráficos mostram que as bolhas se espalham mais nos casos com ondas, o que pode ser justificado pela oscilação da corrente de bolhas induzida pelas ondas. Além disso, pode-se observar também, que próximo à parede a distribuição de bolhas é pouco sensível à presença de ondas e nas posições superiores o efeito das ondas é mais pronunciado. Pode-se dizer que o tempo de residência das bolhas no escoamento parece aumentar e, com isso, processos de dissolução de gás no líquido devem ter maior eficiência em casos com ondas.
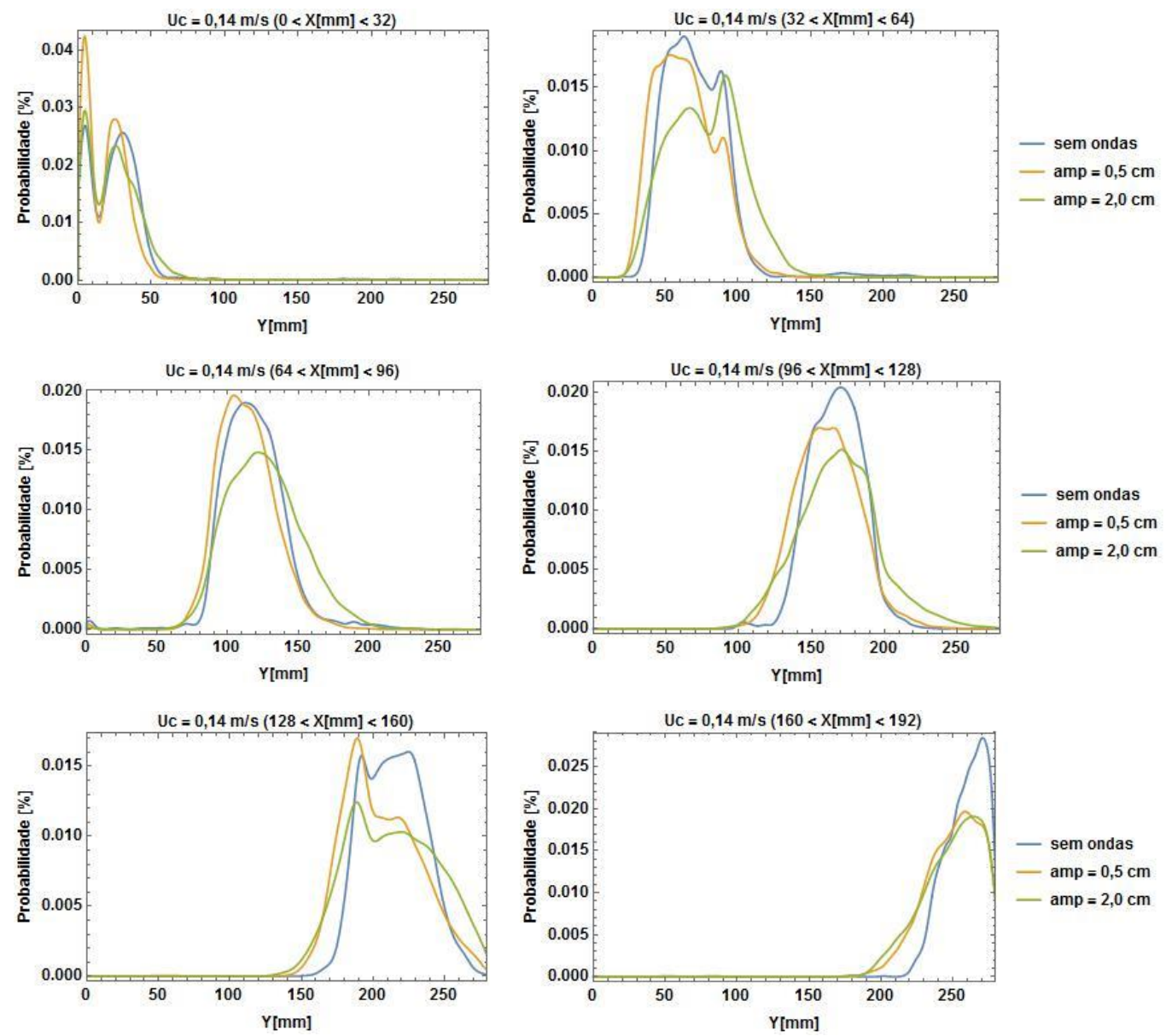

Figura 131 - Amostras da dispersão das bolhas para diferentes intervalos de $\mathrm{X}($ caso $U c=0,14 \mathrm{~m} / \mathrm{s})$ 

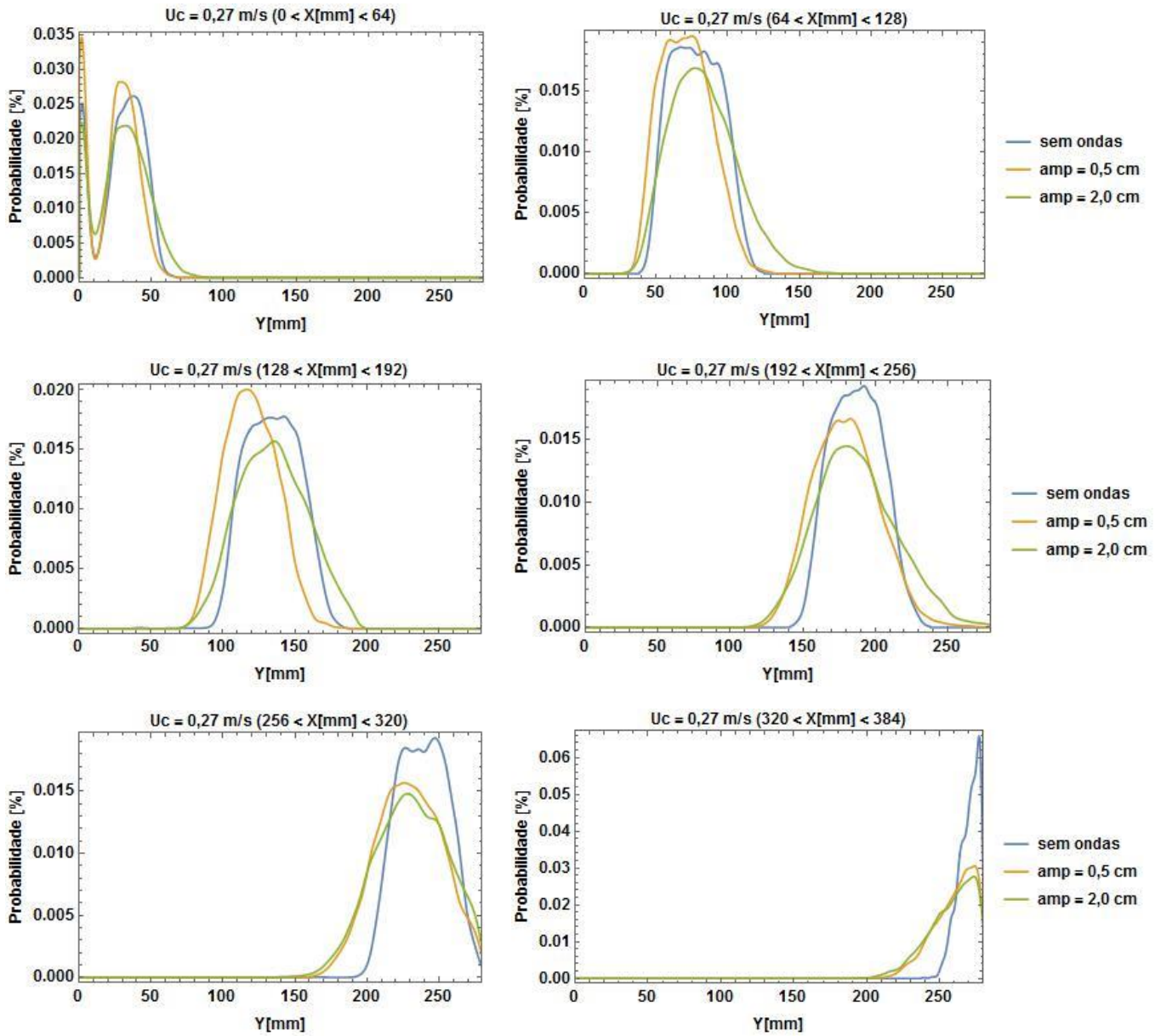

Figura 132 - Amostras da dispersão das bolhas para diferentes intervalos de $\mathrm{X}($ caso $U c=0,27 \mathrm{~m} / \mathrm{s})$

Os histogramas da densidade da população de diâmetros de bolhas em cada janela de visualização do PIV estão apresentados na Figura 133. Na figura somente estão representadas as janelas A e C, pois nestas janelas que se encontram a maior parte das bolhas. Nota-se que as ondas não têm influência sobre o diâmetro das bolhas.
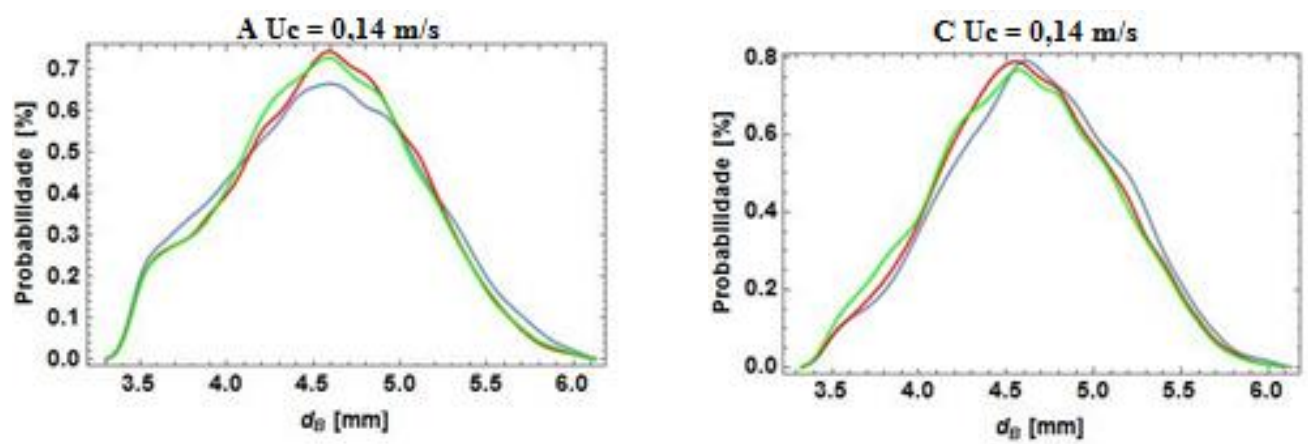

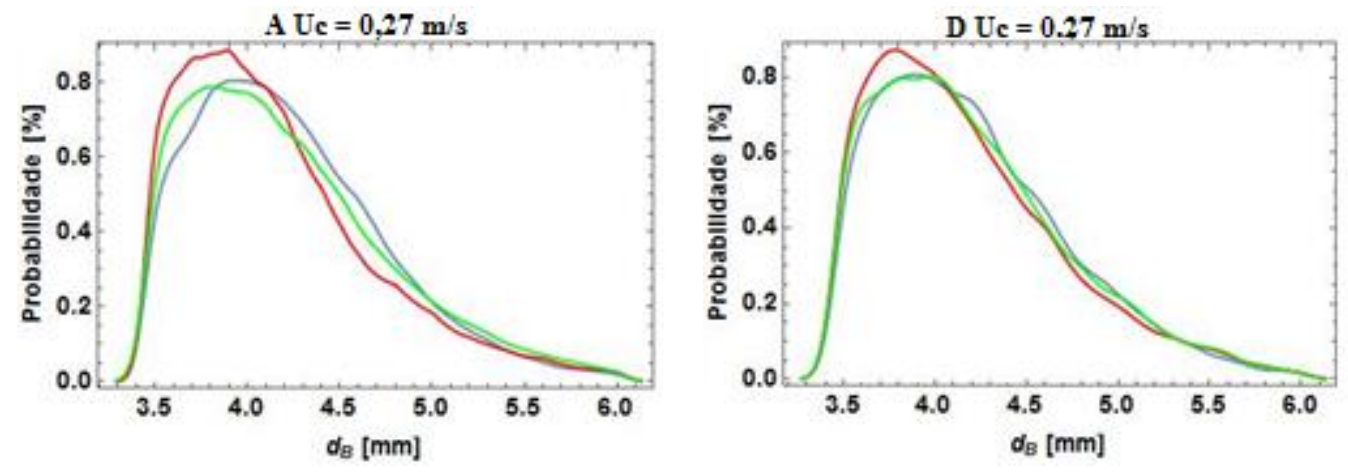

Figura 133 - Densidade de população pelo diâmetro das bolhas (Azul - sem ondas; Vermelho - amplitude $=0,5 \mathrm{~cm}$; Verde - amplitude $=2,0 \mathrm{~cm}$.

A mudança do diâmetro das bolhas, $d_{B}$, ao longo da linha de centro da pluma para as duas velocidades do escoamento cruzado, estão apresentadas na Figura 134 e na Figura 135. O diâmetro das bolhas parece não mudar significativamente ao longo da altura do canal, sugerindo que as bolhas são estáveis. Os valores de diâmetros obtidos neste trabalho se assemelham àqueles reportados no trabalho de Wang e Socolofsky (2015). Cabe ressaltar que as vazões de injeção utilizadas naquele trabalho são menores do que as utilizadas na presente investigação. De acordo com Zhang e Zhu (2013), uma pluma com bolhas de diâmetro na faixa de 2-10 mm, na presença de escoamento cruzado constante, de fato, parece não experimentar mudanças visíveis de diâmetro à medida em que as bolhas se deslocam até a superfície. No presente estudo, observa-se que até mesmo a presença de ondas, não parece afetar a variação dos diâmetros das bolhas. Os resultados sugerem que o diâmetro das bolhas tende a diminuir com o aumento da velocidade do escoamento cruzado. Esse comportamento também foi reportado no trabalho de Zhang e Zhu (2013). 


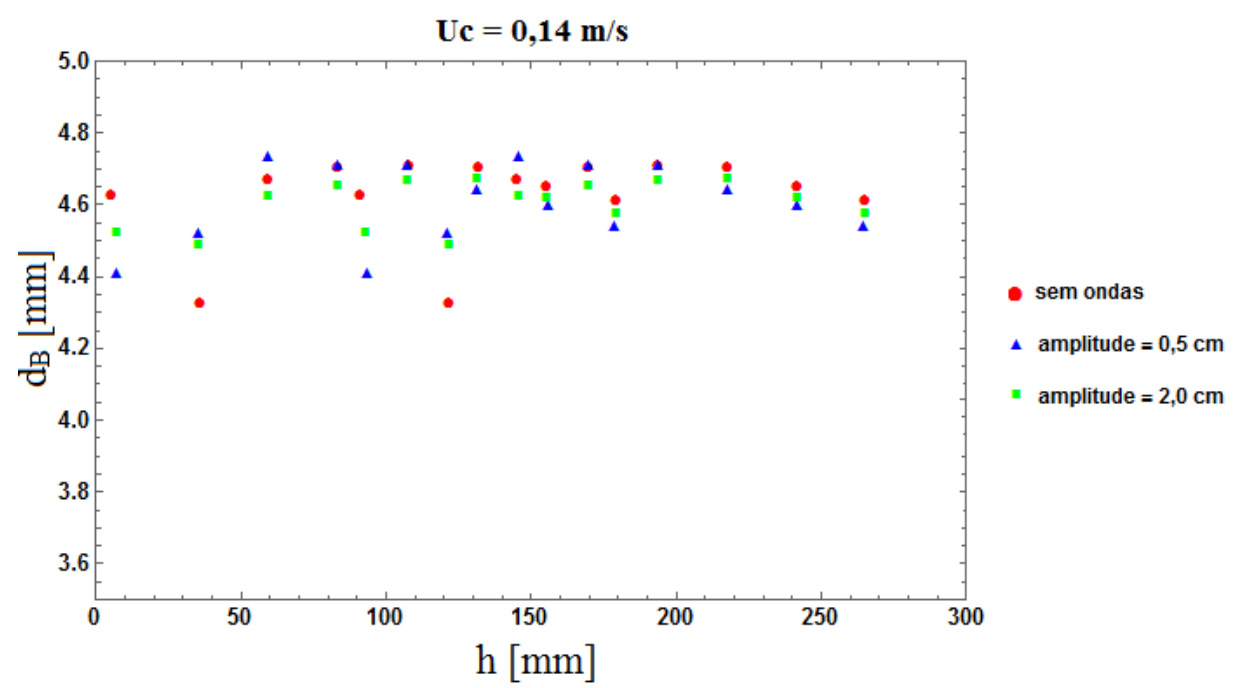

Figura 134 - Variação do diâmetro das bolhas $\left(d_{B}\right)$ com a altura $(h)$ para $U c$ $=0,14 \mathrm{~m} / \mathrm{s}$

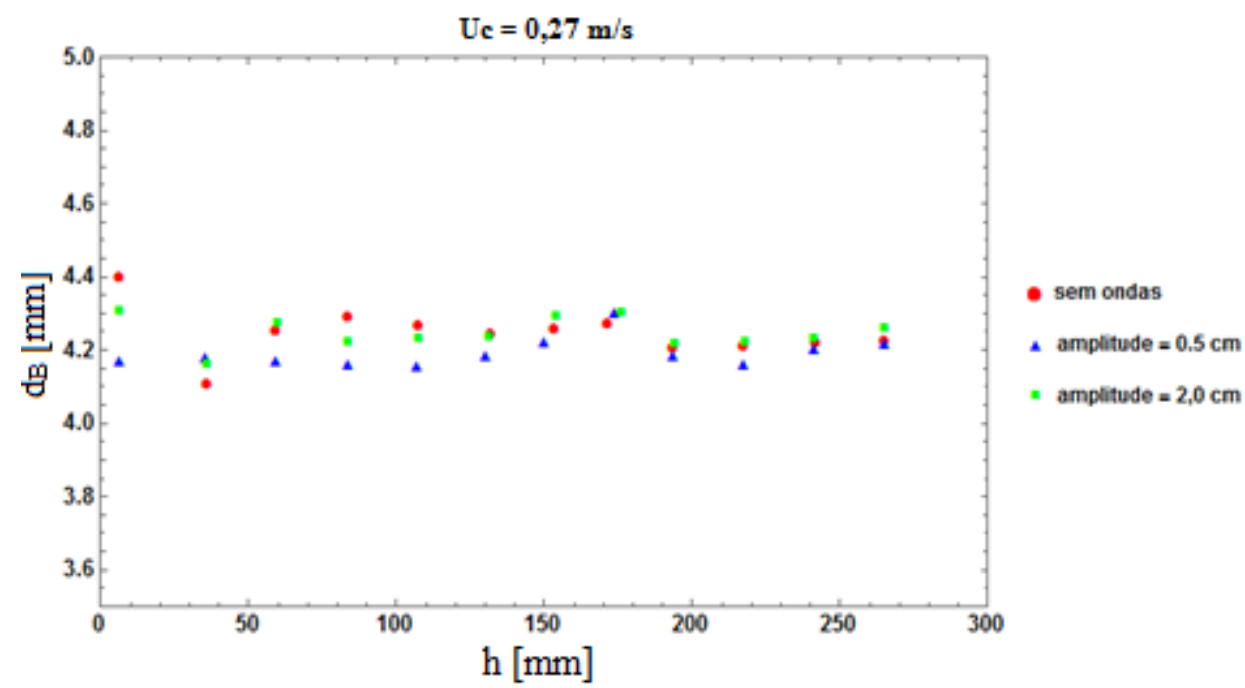

Figura 135 - Variação do diâmetro das bolhas $\left(d_{B}\right)$ com a altura $(h)$ para $U c$

$$
=0,27 \mathrm{~m} / \mathrm{s}
$$

A variação da velocidade das bolhas, $V_{B}$, ao longo da linha de centro da pluma para as duas variações de velocidade do escoamento cruzado, é apresentada na Figura 136 e na Figura 137. É possível observar um leve decaimento da velocidade das bolhas à medida em que as bolhas se aproximam da superfície da água. A tendência decrescente é similar a encontrada por Zhang e Zhu (2013) considerando a mesma faixa de velocidade das bolhas na presença de escoamento cruzado. A 
presença de ondas em diferentes amplitudes não aparenta mudar a velocidade média das bolhas ao longo da altura do nível d'água.

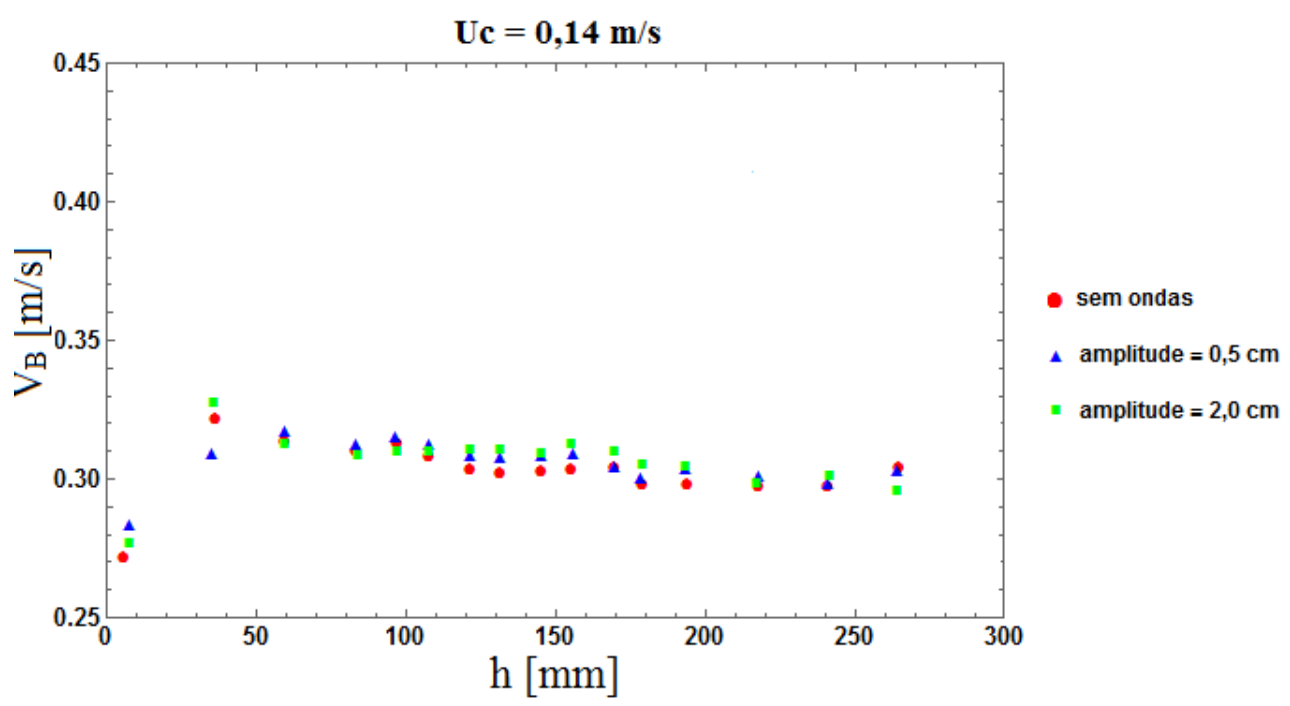

Figura 136 - Variação da velocidade das bolhas $\left(V_{B}\right)$ com a altura $(h)$ para

$$
U c=0,14 \mathrm{~m} / \mathrm{s}
$$

O aumento na velocidade de subida das bolhas no caso da velocidade de escoamento cruzado $U_{C}=0,27 \mathrm{~m} / \mathrm{s}$, comparado ao caso de $U_{C}=0,14 \mathrm{~m} / \mathrm{s}$, diverge da tendência dos experimentos de Wang e Socolofsky (2015), em que os autores perceberam uma redução da velocidade de subida das bolhas com o aumento da velocidade do escoamento cruzado. O motivo para essa discrepância ainda está sendo investigado. Pretende-se, no futuro, realizar uma análise detalhada da sensibilidade da velocidade de subida da bolha com a faixa de corte utilizada para os diâmetros das bolhas (Figura 122). 


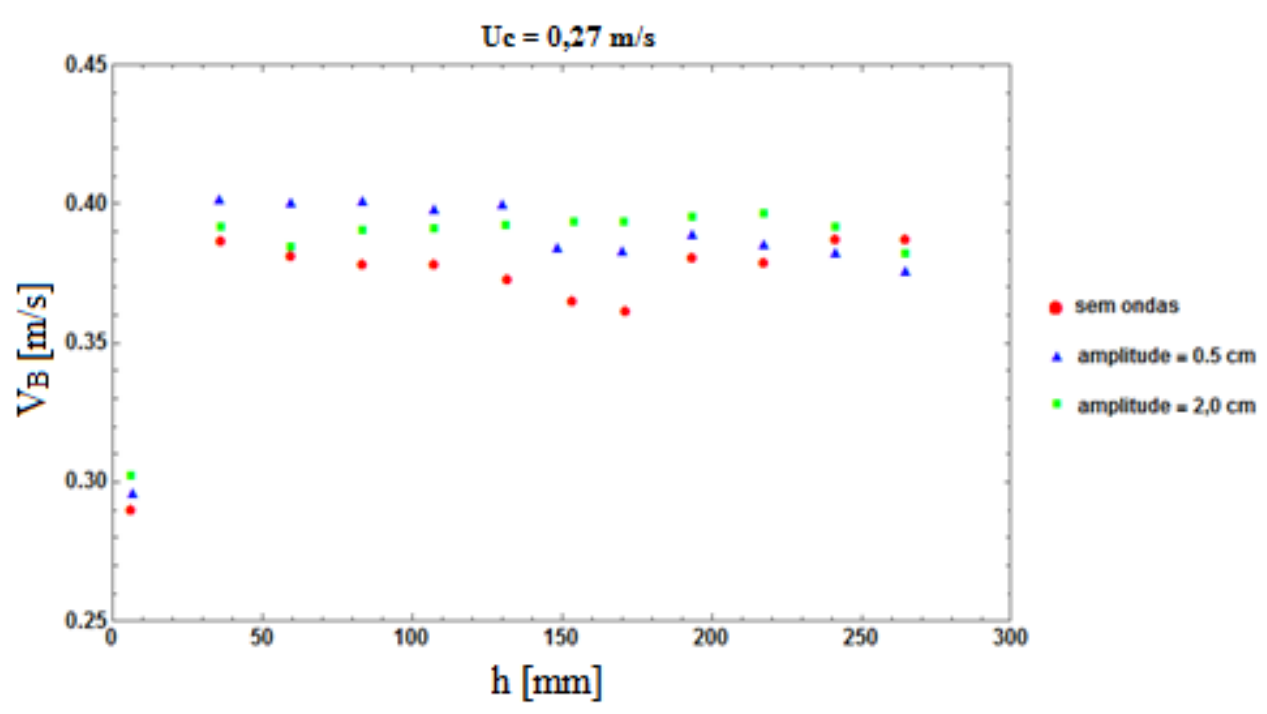

Figura 137 - Variação da velocidade das bolhas $\left(V_{B}\right)$ com a altura $(h)$ para

$$
U c=0,27 \mathrm{~m} / \mathrm{s}
$$

Com base nos dados obtidos, calculou-se a velocidade de escorregamento da bolha, $U_{S}$, definida na Equação (2-5). Para quantificar a velocidade da água induzida pela bolha, $U_{b w}$, utilizou-se os campos médios de velocidade do escoamento sem presença de bolhas no escoamento e os campos medidos quando as bolhas estavam presentes no escoamento. O campo médio com as bolhas foi subtraído do campo médio sem as bolhas. Os valores resultantes dessa subtração correspondem à velocidade induzida pelas bolhas no escoamento. Este método de estimativa de $U_{b w}$ difere do método utilizado por Zhang e Zhu (2013), em que utilizaram a injeção de corante no escoamento durante a passagem da pluma de bolhas e avaliaram a velocidade da água induzida pelas bolhas a partir de vídeos do movimento do corante.

Na Figura 138, os resultados experimentais são apresentados juntamente com correlações empíricas propostas por Clift et al. (1978), para bolhas isoladas em ambientes estagnados e por Neto et al. (2008), para plumas de bolhas em ambientes estagnados. Além disso, na figura mostra-se também os resultados experimentais do trabalho de Zhang e Zhu (2013). A partir da Figura 138, observa-se que os presentes resultados de $U_{S}$ se aproximam mais de uma bolha isolada em ambiente estagnado. Assim como no trabalho de Zhang e Zhu (2013), os resultados são menores do que aqueles da pluma de bolhas em ambiente estagnado. Esse 
comportamento pode estar relacionado ao efeito de esteira ser menor quando as bolhas são transportadas pelo escoamento cruzado.

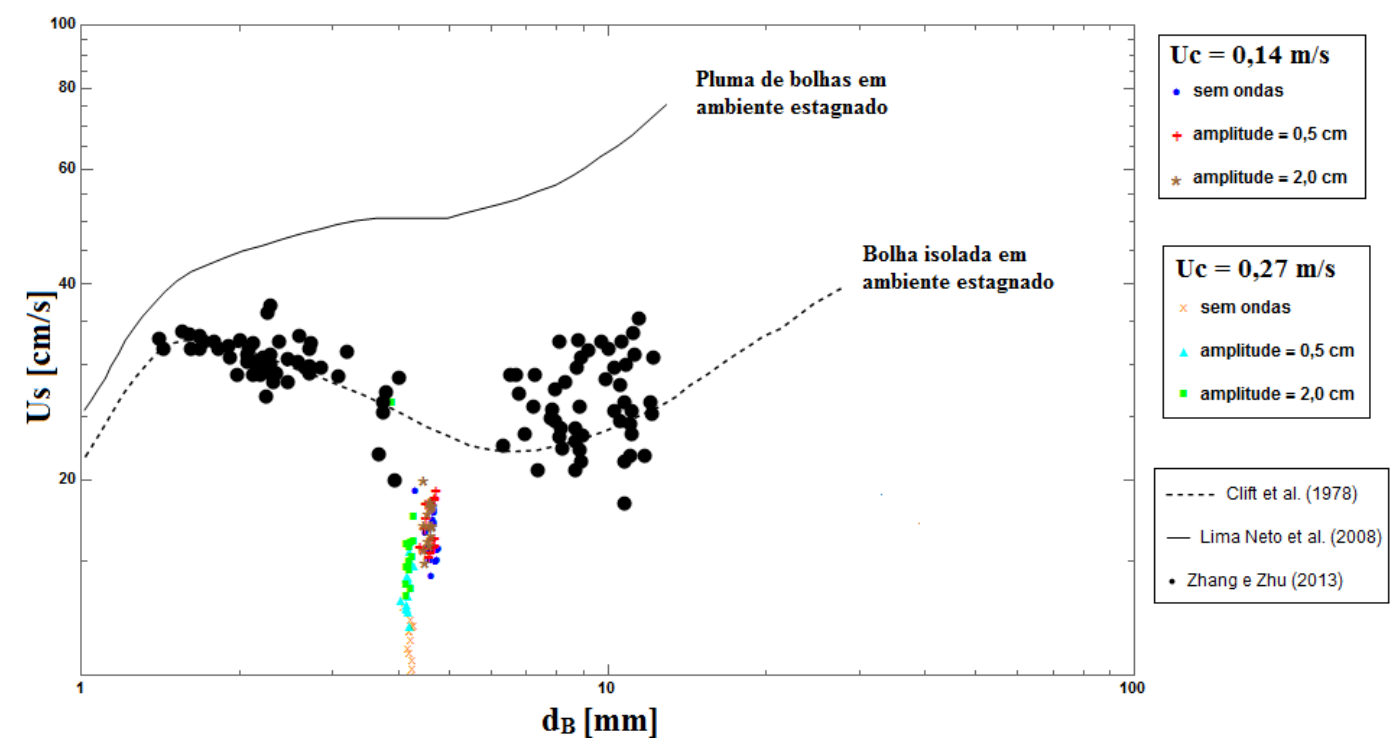

Figura 138 - Variação da velocidade de deslizamento $\left(U_{S}\right)$ com o diâmetro das bolhas $\left(d_{B}\right)$

A Figura 139 apresenta a variação do número de Weber, obtidos a partir da seguinte fórmula:

$$
W e=\frac{\rho V_{B}^{2} d_{B}}{\sigma}
$$

Onde $\rho$ é a massa específica da água e $\sigma$ é a tensão superficial da interface ar-água.

Como mostrado, os números de Weber obtidos nos experimentos estão diretamente na faixa de tendência dos experimentos de Zhang e Zhu (2013). Os autores consideram que as bolhas grandes compreendem a faixa de We $>4$ e bolhas muito pequenas apresentam $\mathrm{We}<4$. Os valores de $\mathrm{We} \approx 4$, segundo Zhang e Zhu (2013), são consistentes com valores críticos correspondentes a bolhas grandes ou pequenas. 


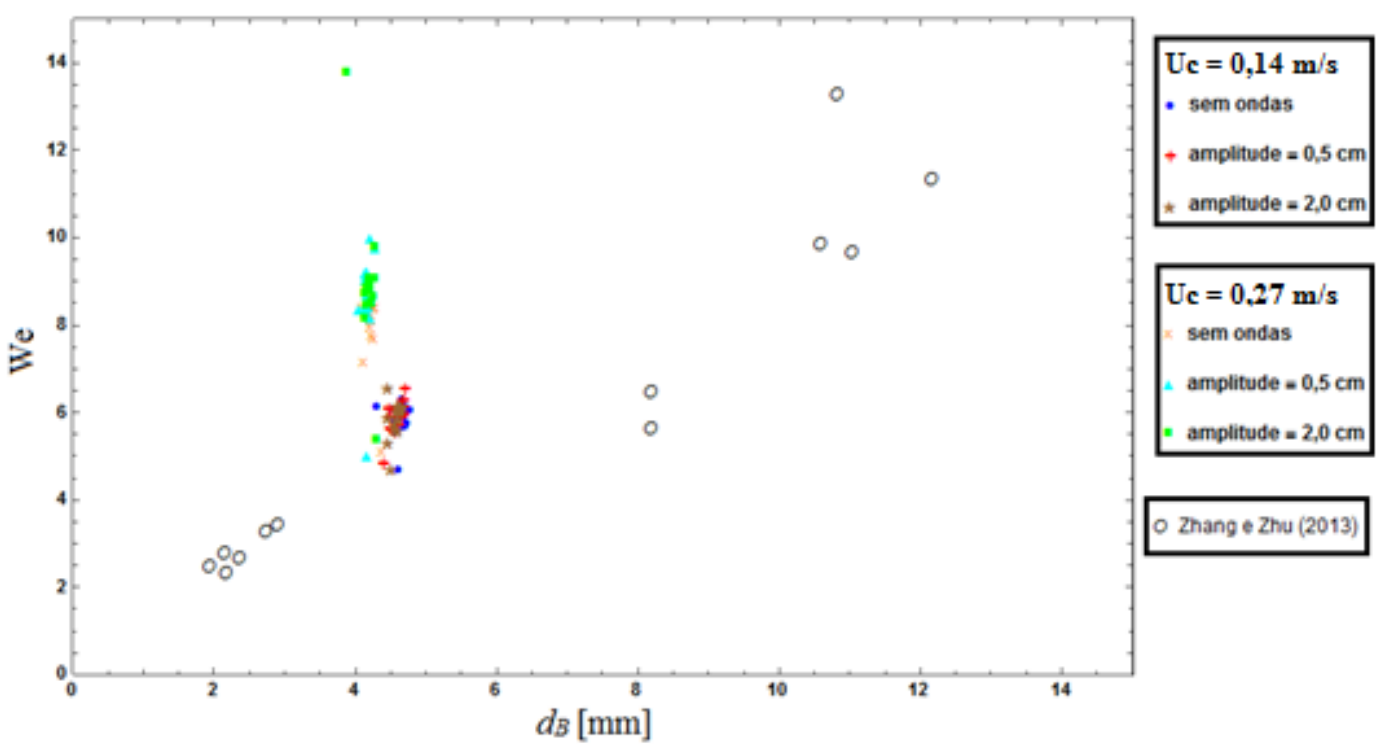

Figura 139 - Variação do número de Weber com o diâmetro das bolhas $\left(d_{B}\right)$

O coeficiente de arrasto das bolhas foi calculado a partir da seguinte equação:

$$
C_{D}=\frac{4 g d_{B}}{3 V_{B}^{2}}
$$

Onde $g$ é a aceleração da gravidade. Para o cálculo do número de Reynolds das bolhas, foi considerada a viscosidade cinemática da água, $v=10^{-6} \mathrm{~m}^{2} / \mathrm{s}$. $\mathrm{O}$ número de Reynolds é dado por:

$$
R e=\frac{V_{B} d_{B}}{v}
$$

A variação do coeficiente de arrasto, $C_{D}$, com o número de Reynolds da bolha, $R e$, está mostrado na Figura 140. Os valores de $C_{D}$ obtidos neste trabalho estão concentrados entre as duas curvas características dos experimentos de Clift et al. (1978) e Neto et al. (2008). Sendo que os experimentos com $U_{C}=0,14 \mathrm{~m} / \mathrm{s}$ se aproximam mais da curva de arrasto para uma única bolha subindo em ambiente estagnado (Clift et al. 1978), enquanto que os valores de arrasto para $U_{C}=0,27 \mathrm{~m} / \mathrm{s}$ tendem a se aproximar mais do arrasto característico de uma pluma de bolhas em ambiente estagnado. Ainda assim, a presença das ondas não afetou significantemente os valores do coeficiente de arrasto das bolhas. 


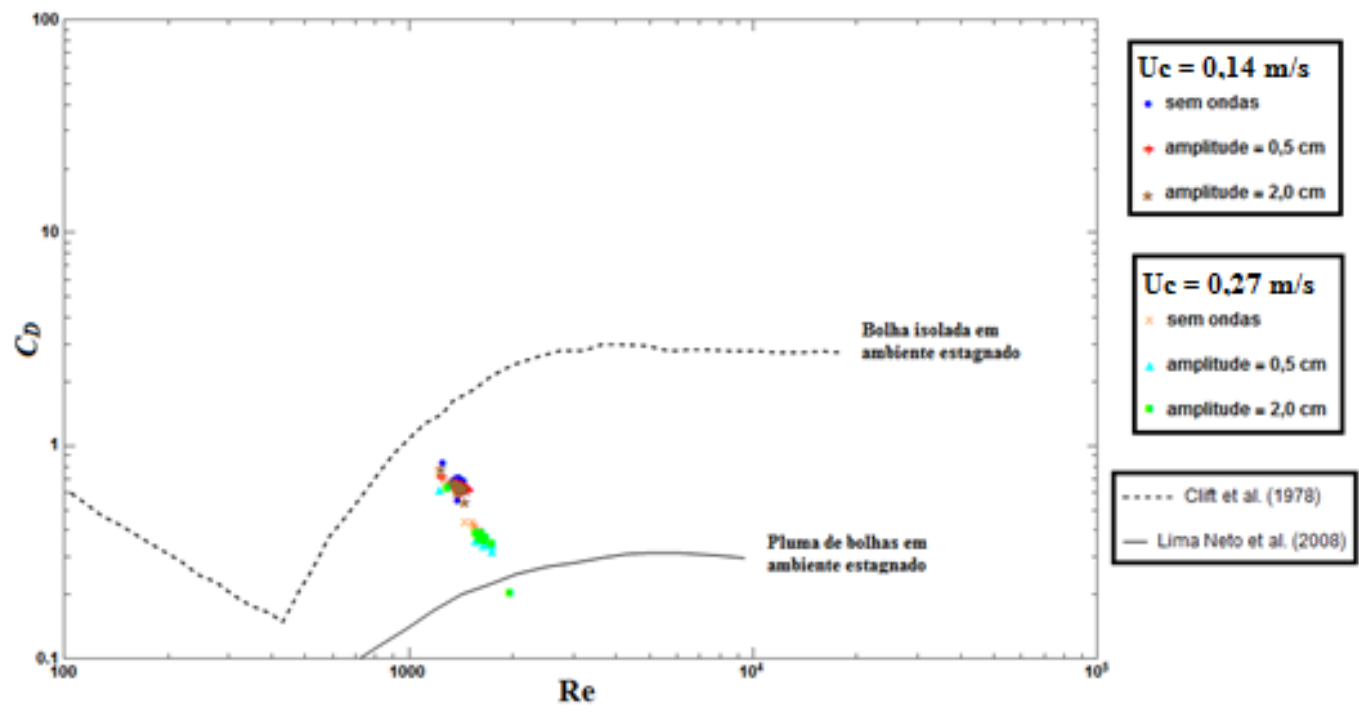

Figura 140 - Relação entre o coeficiente de arrasto $\left(C_{D}\right)$ e número de

Reynolds das bolhas 


\section{8 Conclusões e sugestões para trabalhos futuros}

Neste trabalho, as características do escoamento de uma pluma de bolhas foram estudadas em um canal de água sob diferentes condições de escoamento cruzado. A geração das ondas superficiais no escoamento cruzado permitiu a avaliação dos efeitos que o ambiente oscilatório induz na dispersão da pluma de bolhas e no escoamento próximo às bolhas.

As técnicas de Velocimetria por Imagem de Partícula e de detecção de sombra mostraram ser excelentes ferramentas para análise de escoamentos bifásicos. Com a combinação das duas técnicas, foi possível a implementação de rotinas de processamento no Matlab para distinção das duas fases presentes no escoamento. Assim, os campos vetoriais resultantes da técnica PIV puderam ser obtidos sem qualquer influência que poderia ser introduzida pela presença das bolhas nas imagens. Além disso, a rotina de processamento se mostrou apropriada para determinação do diâmetro e da velocidade das bolhas, embora o código automático tenha, algumas vezes, interpretado duas ou mais bolhas como sendo uma única bolha.

Através do levantamento dos perfis de velocidade ao longo do canal, foi possível observar a influência das ondas sobre o escoamento. Foram realizadas comparações entre resultados obtidos nos casos com a emissão da pluma de bolhas, em escoamento cruzado, sem a presença de ondas, com os resultados obtidos na presença de escoamento cruzado oscilatório. Observou-se que o escoamento médio foi pouco afetado pela presença de ondas. No entanto, a intensidade das flutuações foi consideravelmente alterada em boa parte da altura do canal. Os efeitos das ondas foram mais pronunciados nas regiões próximas à superfície. A análise conjunta dos resultados sugeriu que não há interação cruzada entre a pluma de bolhas e as ondas. Os resultados indicaram que o caso investigado corresponde a uma sobreposição do caso de plumas de bolhas em escoamento cruzado estacionário com o do caso de ondas de águas intermediárias sem plumas de bolhas. Esse resultado é interessante do ponto de vista de modelagem do problema, pois sugere ser possível acoplar 
alguns dos vários modelos de ondas existentes com alguns dos poucos modelos existentes para plumas de bolhas, em fluxo cruzado, para criar uma metodologia de previsão da dispersão de plumas de bolha em fluxo cruzado oscilatório.

As propriedades e características das bolhas também foram analisadas e, praticamente, não apresentaram uma relação ou tendência com à oscilação da superfície da água. Porém, a dispersão das bolhas foi afetada consideravelmente pela presença das ondas, evidenciando que a oscilação do escoamento induzido por ondas de superfície causou um maior espalhamento das bolhas. A variação do espalhamento foi mais perceptível próximo à superfície. Os resultados da análise do escoamento ajudaram a explicar o motivo da maior dispersão das bolhas na presença de ondas. Neste trabalho o aumento da dispersão foi atribuído à oscilação das bolhas nas frequências de oscilação do escoamento.

Em termos práticos, os resultados sugerem que em casos de vazamentos acidentais de gás, no fundo dos oceanos, a presença de ondas superficiais pode contribuir para o aumento da dispersão da pluma de gás. Além disso, os resultados sugerem que pode ocorrer maior dissolução do gás na água devido a um aumento do tempo de residência das bolhas no meio. No entanto, cabe ressaltar que os resultados deste trabalho foram obtidos utilizando parâmetros mais próximos de ondas em rios do que ondas oceânicas. Logo, é necessário a realização de estudos em outra faixa de parâmetros para que os resultados possam ser extrapolados para o caso de oceanos.

Sendo este o primeiro estudo realizado considerando a dispersão de uma pluma de bolhas em escoamento cruzado oscilatório, a comparação direta dos resultados obtidos com a literatura não foi possível. Como o presente trabalho teve um caráter mais exploratório, algumas ideias para o desenvolvimento trabalhos futuros foram vislumbradas. Dentre os possíveis desdobramentos do trabalho, destaca-se a realização de um estudo similar, mas com a injeção simultânea de água e de ar. Assim, os efeitos da onda na fase contínua podem ser visualizados a partir de técnicas de visualização como a Fluorescência Induzida por Laser. Outra sugestão é realização do estudo aplicando-se as condições de ondas de águas profundas, a fim de se verificar se o escoamento próximo à pluma de bolhas na presença dessas ondas varia em regiões mais profundas. Sugere-se ainda a realização de estudos com a variação de outros parâmetros do problema, tais como a vazão de injeção de gás, o diâmetro do bocal de injeção e a frequência das ondas. 
Simulações numéricas também são interessantes para comparação com os dados obtidos neste trabalho. 


\section{9 Referências bibliográficas}

ALHO, A. T. P.; FARIAS, M.H.; NETO, J.L.S. On the design of a circulating water channel for the Brazilian National Institute of Metrology - Inmetro. Taipei: Proc. 15th FLOMEKO, 2010.

BANDARA, U. C.; YAPA, P. D. Bubble sizes, breakup and coalescence in deep water gas/oil plumes. Journal Hydraulic Engineering, v. 137, n. 7, p. 729-738, 2011.

BIESEL, F. \& SUQUET, F. Les apparails generateurs de houle en laboratoire. La Houille Blanche, 6, 2, 4, and 5. Laboratory Wave Generating Apparatus English version Project report 39 St Anthony Falls Hydraulic Laboratory, Minnesota University Minneapolis, 1953.

BREWER, P.G., F.M. ORR, Jr., G. FRIEDERICH, K.A. KVENVOLDEN, D.L. Orange, J. McFarlane and W. Kirkwood. Deep Ocean Field Test of Methane Hydrate Formation from a Remotely Operated Vehicle. Geology, 25(5), pp. 407-415, 1997.

CASAS, P. M. Overview of ocean wave statistics. Bachelor's thesis, University of Catalunia, Barcelon, 3-12, 2009.

CEDERWALL, K.; DITMARS, J. D. Analysis of air bubble plume. Report KHR:KH-R-24. California Institute of Technology. p. 7. Pasadena, 1974.

CLIFT, R., GRACE, J.R., WEBER, M.E. Bubbles, Drops and Particles. Academic, New York, 1978.

CRAPPER, P.F. Forced plume characteristics. Tellus, n. 29, p. 470-475, 1977.

DASANAYAKA, L. K.; YAPA, P. D. Role of plume dynamics in a deep water oil and gas release model. Journal of Hydro-environment Research, v. 2, n. 4, p. 243-253, 2009.

DEAN, R. G. e DALRYMPLE, R. A. Water wave mechanics for engineers and scientists. Volume 2. World Scientific, 1991. 
DUARTE, D. G., FARIAS, M. H., OLIVEIRA, R. P, FREIRE, A. P. S. Entrainment coeficiente and Coanda bubble plume flows. Brasilía: $19^{\circ}$ International Congress of Mechanical Engineering, 2007.

EHRENHAUSER, F. S; AVIJ, P.; SHU, X.; DUGAS, V.; WOODSON, I.; LIYANA-ARACHCHI, T.; ZHANG, Z.; HUNG, F. R.; VALSARAJ, K. T. Bubble bursting as an aerosol generation mechanism during an oil spill in the deepsea environment: laboratory experimental demonstration of the transport pathway. Environ. Sci.: Processes Impacts, 65-73, 2014.

EDINBURGHDESIGNS. Piston Wavemakers. 2016. Disponível em: <http://www.edesign.co.uk/waves/some-wave-1/>

ET4U.ORG. Flow around a cylinder. 2016. Disponível em: <http://www.et4u.org/Toy_information/Cylinder_flow.html>

FARIAS, M. H., COSTA, F. O., RAMOS, M. V. Experimental analysis of a bubble plume in upward flowing near a vertical cylinder. Natal: $21^{\circ}$ International Congress of Mechanical Engineering, 2011.

FERNANDO, H. J. S. Handbook of Environmental Fluid Dynamics: Systems, Pollution, Modeling, and Measurements. Vol. 2. CRC Press, 2013.

FIGliola, R., S. e BEASley, D., E. Teoria e Projeto para Medições Mecânicas. $4^{\text {a }}$ Edição. LTC, 2007.

GARCIA, D. A. Avaliação do comportamento de plumas de bolhas de ar em escoamento cruzado. Trabalho de Conclusão de Curso, Escola de Ciências da Universidade do Grande Rio, Brasil, 2015.

GILBERT G., THOMPSON D.M. and BREWER A.J. Design curves for regular and random wave generators. Journal of Hydraulic Research, 9, No 2., pp 163196, 1971.

GUTMARK, E. J., IBRAHIM, I. M., MURUGAPPAN, S.; Dynamics of single and twin circular jets in cross flow. Experiments in Fluids, 653-663, 2011.

ILAK, M., SCHLATTER, P., BAGHERI, S., HENNINGSON, D. S.; Bifurcation and stability analysis of a jet in cross-flow: onset of global instability at a low velocity ratio. Journal of Fluid Mechanics, vol. 696, 94-121, 2012.

JAHANMIRI, M. Particle Image Velocimetry: Fundamentals and Its Applications. Chalmers University of Technology, Göteborg, Sweden, 2011. 
JUNIOR, J. R. B. O método dos sensores eletro-resistivos aplicado a plumas de bolhas. Rio de Janeiro, 1997. 121p. Dissertação (Mestrado). Universidade Federal do Rio de Janeiro.

KOBUS, H. E. Analysis of the flow induced by air-bubble systems. London: $11^{\circ}$ Coastal Engineering Conferences, 1968.

KOOLE, R. and SWAN, C. Dispersion of pollution in a wave environment. Coastal Engineering, Chapter 221, 3071-3085, 1994.

KRISHNAN, M. The interaction of jets with crossflow. Annual Review of Fluid Mechanics 45, 379-407, 2013.

LAM, K. M. and XIA, L. P. Experimental simulation of a vertical round jet issuing into an unsteady cross-flow. Journal of Hydraulic Engineering, vol. 127, no. 5, 369-379, 2001.

LEE, J. H. W. and CHU, V. H.; Turbulent Jets and Plumes - A Lagrangian Approach. WKAP, 2003.

LIN, J., HSIAO, S., HSU, T., CHANG, K. Buoyancy effect on turbulent round jet under regular waves. Journal of Waterway, Port, Coastal, and Ocean Engineering, vol. 139, no. 3, 190-208, 2013.

LINDKEN, R., MERZKIRCH, W. A novel PIV technique for measurements in multiphase flows and its application to two-phase bubbly flows. Experiments in Fluids 33, 814-825, 2002.

LIU, Z., ZHENG, Y., JIA, L., Zhang, Q. Study of bubble induced flow structure using PIV. Chemical Engineering Science, 3537-3552, 2005.

MANOA.HAWAII.EDU. A wave in deep water. 2016. Disponível em: $<$ https://manoa.hawaii.edu/exploringourfluidearth/physical/waves/wave-energyand-wave-changes-depth>

MASSARI, P. L.; DE PAULA, I. B.; FARIAS, M. H. Characterization of bubble plumes in unsteady cross flow. $16^{\text {th }}$ Brazilian Congress of Thermal Sciences and Engineering. Vitória, ES, Brazil, 2016.

MILANOVIC, I., ZAMAN, K. B. M. Q., BENCIC, T. J. Unsteady wake vortices in jets in cross-flow. The Visualization Society of Japan, 45-55, 2012. 
MORI, N. and CHANG, K. Experimental study of a horizontal jet in a wave environment. Journal of Engineering Mechanics, vol. 129, no. 10, 1149-1155, 2003.

MUNK, Walter H. Proceedings 1st International Conference on Coastal Engineering. Long Beach, California: ASCE: 1-4, 1950.

NETO, I. E. L.; ZHU, D. Z.; RAJARATNAM, N. Bubbly jets in stagnant water. International Journal of Multiphase Flow, n.12, v. 34, p. 1130-1141, 2008.

NETO, I. E. L. Turbulência induzida por jatos bifásicos do tipo gás-líquido em tanques de aeração. Revista Engenharia Sanitária e Ambiental, v. 15, n. 1, p. 75$82,2010$.

NEW, T. H., LIM, T. T., LUO, S. C. Elliptic jets in cross-flow. Journal of Fluid Mechanics, vol. 494, 119-140, 2003.

NOGUEIRA, S., SOUSA, R.G., PINTO, A.M.F.R., RIETHMULLER, M.L., CAMPOS, J.B.L.M. Simultaneous PIV and pulsed shadow technique in slug flow: a solution for optical problems. Experiments in Fluids 35, 598-609, 2003.

OISHI, Y., MURAI, Y. Horizontal turbulent channel flow interacted by a single large bubble. Experimental Thermal and Fluid Science 55, pp. 128-139, 2014.

PEPLINSKI, A., SCHLATTER, HENNINGSON, D. S. Investigations of stability and transition of a jet in crossflow using DNS. Fluid Mechanics and Its Applications 107, 2015.

RADHOUANE, A., BOURNOT, H., SAID, N. M., MHIRI, H., PALEC, G. L. Numerical and experimental study of a double jet inclination variation on its dynamic evolution within a crossflow. Heat Mass Transfer, 1597-1616, 2009.

RAFFEL, M., WILLERT, C., WERELEY, S., KOMPENHANS, J. Particle Image Velocimetry: A practical guide. Second edition. Springer, 2007.

RUZICKA, M. C. On bubbles rising in line. International Journal of Multiphase Flow, 1141-1181, 2000.

SEOL, D. G. and S. A. SOCOLOFSKY. Vector post-processing algorithm for phase discrimination of two-phase PIV. Exp. Fluids 45: 223-239, 2008.

SEPARADORESCOMPACTOS. Shadow Sizer System. 2016. Disponível em: <http://www.separadorescompactos.coppe.ufrj.br/valvulaciclonica/medicao.html> 
SRIDHER, P. C. Validating sub-sea gas pipeline leaks discharge model for Arabian sea conditions. Dehradun, 2012.

SZCZEPANSKI, R., B. EDMONDS, N. BROWN, and T. HAMILTON. Research Provides Clues to Hydrate Formation and Drilling-Hazard Solutions. The Oil and Gas Journal, 96(10), pp. 52-58, 1998.

THURMAN, H. V. and TRUJILLO, A. P. Essentials of Oceanography. Seventh edition. Prenhall, 1997.

VINCENTI I., GUJ G., CAMUSSI R., GIULIETTI E. PIV study for the analysis of planar jets in cross-flow at low Reynolds number. Atti $11^{\circ}$ Convegno Nazionale Aivela, 2003.

XU, Z., CHEN, Y., ZHANG, C., LI, C., WANG, Y., HU, F. Comparative Study of a vertical round jet in regular and random waves. Journal of Ocean Engineering, 200-210, 2014.

WANG, B. and SOCOLOFSKY, S. A. On the bubble rise velocity of a continually released bubble chain in still water and with crossflow. Physics of Fluids, vol. 27, 2015.

WEILAND, C.; VLACHOS, P. P. Round gas jets submerged in water. International Journal Multiphase Flow, v. 48, p. 46, 2013.

ZHANG, W. and ZHU, D. Z. Bubble characteristics of air-water bubbly jets in crossflow. International Journal of Multiphase Flow, 156-171, 2013.

ZOTIN, J. L. Z. Caracterização Experimental de um Escoamento sobre uma Superfície com Transição de Rugosidade através da Técnica de Velocimetria por Imagem de Partícula. Projeto Final de Curso, PEM/COPPE/UFRJ, Brasil, 2009. 